\title{
Integration of Photovoltaic Units into Electric Utility Grids: Experiment Information Requirements and Selected Issues
}

September 1980

Prepared for:

U.S. Department of Energy

Assistant Secretary for Resource Applications

Office of Electric Energy Systems

Under Contract No. AT03-79ET30351 


\section{DISCLAIMER}

This report was prepared as an account of work sponsored by an agency of the United States Government. Neither the United States Government nor any agency Thereof, nor any of their employees, makes any warranty, express or implied, or assumes any legal liability or responsibility for the accuracy, completeness, or usefulness of any information, apparatus, product, or process disclosed, or represents that its use would not infringe privately owned rights. Reference herein to any specific commercial product, process, or service by trade name, trademark, manufacturer, or otherwise does not necessarily constitute or imply its endorsement, recommendation, or favoring by the United States Government or any agency thereof. The views and opinions of authors expressed herein do not necessarily state or reflect those of the United States Government or any agency thereof. 


\section{DISCLAIMER}

Portions of this document may be illegible in electronic image products. Images are produced from the best available original document. 


\section{The following pages are an exact representation of what is in the original document folder.}


This report was prepared as an account of work sponsored by the United States Government. Neither the United States nor the United States Department of Energy, nor any of their employees, makes any warranty, express or implied, or assumes any legal liability or responsibility for the accuracy, completeness, or usefulness of any information, apparatus, product, or process disclosed, or represents that. its use would not infringe privately owned rights. Reference herein to any specific commercial product, process, or service by trade name, mark, manufacturer, or otherwise, does not necessarily constitute or imply its endorsement, recommendation, or favoring by the United States Government or any agency thereof. The views and opinions of authors expressed herein do not necessarily state or reflect those of the United States Government or any agency thereof.

Ava1lable from:

National Technical Information Service (NTIS)

U.S. Department of Commerce

5285 Port Royal Road

Springfield, Virginia 22161

Price: Printed Copy:

Microfiche:

$\$ 20.00$

$\$ 4.00$ 


\section{Integration of Photovoltaic Units into Electric Utility Grids: Experiment Information Requirements and Selected Issues}

September 1980

Prepared by:

The Aerospace Corporation

El Segundo, California 90245

Under Contract No. AT03-79ET30351

Prepared for:

This book was prepared as an account of work sponsored by an agency of tha United Stotes Government,
Neither the United States Government nor any warranty. express or imulied, or assumes any ly thereof. nor any of their employees, makes any completencess, or usefuiness of any information. appatus. pr resoonsibility for the accuracy. represents that its use would not initringe privately owmed rights Reference horess disclosed, or oommercial product, process, or service by trada name, trademark, mannufacturer, or oberwisecific

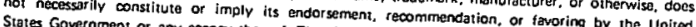

\section{U.S. Department of Energy}

Assistant Secretary for Resource Applications

Office of Electric Energy Systems

Washington, D.C. 20461 
THIS PAGE

\section{WAS INTENTIONALLY \\ LEFT BLANK}

$\equiv$

$\because$ 
ABSTRACT $\ldots \ldots \ldots \ldots \ldots \ldots \ldots \ldots \ldots \ldots \ldots \ldots \ldots \ldots \ldots$

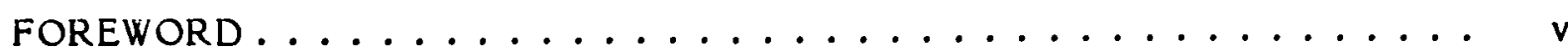

ACKNOWLEDGMENTS $\ldots \ldots \ldots \ldots \ldots \ldots \ldots \ldots \ldots \ldots$ vii

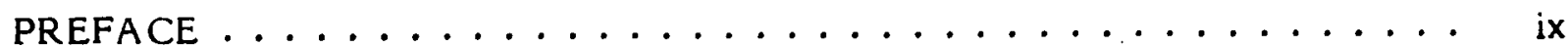

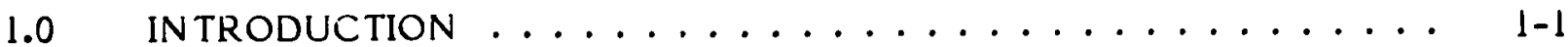

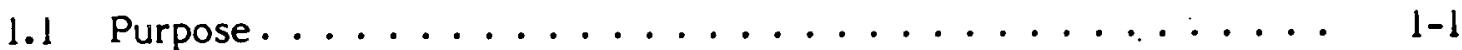

1.2 Scope of Task ...................... $1=5$

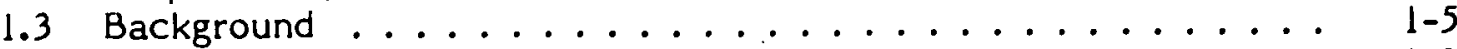

1.4 Guide to Report Content . . . . . . . . . . . . . . . . 1-9

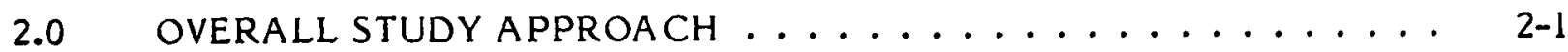

2.1 The Decision Process . . . . . . . . . . . . . . . . 2-1

2.2 Information Requirements Identification . . . . . . . . . 2-3

2.3 Information Content of the Experiment Inventory. . . . . . 2-3

2.4 Gap Analysis. . . . . . . . . . . . . . . . . 2-4

2.5 Findings and Recommendations Categories .......... 2-8

3.0 IDEN TIFICA TION OF CRITICAL UTILITY INFORMA TION

REQUIREMENTS ........................... 3-1

3.1 Utility Information Requirements Identification. . . . . . . . . 3-2

3.2 Utility Field Visits Message and Translation . . . . . . . . . . 3-7

3.3 Crucial Areas of Information . . . . . . . . . . . . . 3-11

4.0 ANALYSIS OF EXPERIMENT INFORMA TION CONTENT . . . . . . 4-1

4.1 Information Analysis Basis and Experiment Catalog . . . . . . 4-1

4.2 Experiment Information Evolution and Interpretation. . . . . . 4-3

5.0 ANALYSIS OF GAPS BETWEEN UTILITY/DOE-PV

INFORMA TION CRITERIA .................. 5 .

5.1 Comparisons of Apparent Philosophical Positions . . . . . . . . 5-1

5.2 Comparisons of Interpreted Results . . . . . . . . . . . . . 5-6

5.3 Review and Summary of Information Requirements/Content Gaps 5-10

6.0 OBSERVATIONS AND RECOMMENDATIONS .......... 6-1

6.1 Observations on Utility Viewpoints . . . . . . . . . . . 6 6-1

6.2 Experiment Program Recommendations ............ 6- 6-5

6.3 Crucial Areas of Information . . . . . . . . . . . . 6-8

APPENDIX A .................... A

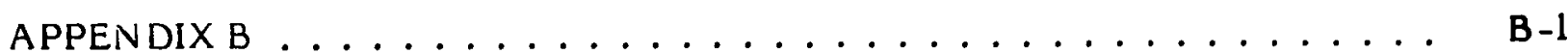




\section{FIGURES}

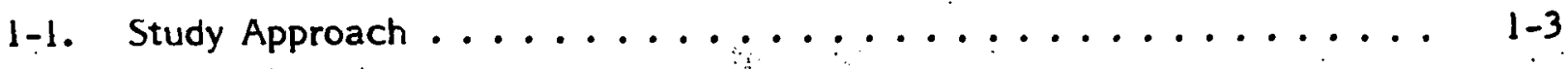

1-2. Hierarchy of "Energy Sufficiency" Supporting Objectives. . . . . . . . . 1-4

1-3. Merging of Conventional Generations and Alternate Technologies. . . . 1-8

2-1. Utility Decision Process .................... 2-2

2-2. The Demonstration Process Model .................. 2-6

2-3. Conceptual Information Document Tree ............... 2-7

3-1. Approach to Identify Utility Information Requirements. . . . . . . 3-3

3-2. Contemplated lnformation Categories ... . . . . . . . . . . 3-4

3-3. Contemplated Sub-Questions: Grid Integration ............ 3-5

4-1. DOE-PV Data Systems Requirements . . . . . . . . . . . . 4-2

4-2. Photovoltaic Concentrator Test and Evaluation Task Flow Diagram . . 4-7

4-3. DOE-PV Evolution Process Overview ................. 4-14

4-4. DOE-PV User Information Requirements Plan (Test and Applications) . . 4-15 
TABLES

3-1. Utility Field visits $\ldots \ldots \ldots \ldots \ldots \ldots \ldots$ 3-6 . . . . . . .

3-2. Key Messages from the Utility Field Visits . . . . . . . . . . . 3-8

3-3. Principal Near-Term Utility Concerns . . . . . . . . . . . 3-10

4-1. DOE PRDA $35 / 38$ Selected Experiments . . . . . . . . . . . . . 4-4

4-2. System Level Photovoltaic Projects . . . . . . . . . . . 4-5

4-3. Utility Experiments (EPRI Catalogued/Mionitored) . . . . . . . . . 4-6

4-4. DUE-PV Uniform Data Requirements Summary . . . . . . . . . . . . . 4-9

4-5. DOE-PV User Information Summary . . . . . . . . . . . . . 4-10

4-6. DOE-PV Prioritized Information Requirements for Utilities. . . . . . . 4 4-11

5-1. Utility/DOE-PV Philosophy Comparison . . . . . . . . . . 5-2

5-2. Utility/DOE-PV Information Requirement Priority Comparison ... . 5 5-7

5-3. Utility/DOE-PV Spatial Information Requirement Comparison . . . . 5 5-7

5-4. Utility/DOE-PV Temporal Information Requirement Comparison. . . . 5-8

5-5. Utility/DOE-PV Geographical Information Requirement Comparison .. 5-10 


\section{PAGES $\mathrm{i}$ to ii WERE INTENTIONALLY LEFT BLANK}


ABSTRACT

A number of investigations, including those conducted by The Aerospace Corporation and other contractors, have led to the recognition of technical, economic, and institutional issues relating to the interface between solar electric technologies and electric utility systems. These issues derive from three attributes of solar electric power concepts, including (1) the variability and unpredictability of the solar resources, (2) the dispersed nature of those resources which suggest the deployment of small dispersed power units, and (3) a high initial capital cost coupled with relatively low operating costs. It is imperative that these integration issues be pursued in parallel with the development of each technology, if the nation's electric utility systems are to effectively utilize these technologies in the near to intermediate term.

An important part of the DOE programs to develop new source technologies, in particular photovoltaic systems, is the experimental testing of complete or nearly complete power units. These experiments provide an opportunity to examine operational and integration issues which must be understood before widespread commercial deployment of these technologies can be achieved. Experiments may also be required to explicitly examine integration, operational, and control aspects of single and multiple new source technology power units within a utility system. An identification of utility information requirements, a review of planned experiments, and a preliminary determination of additional experimental needs and opportunities are presented in Part I of this report.

From the many other issues that are of concern in the integration of photovoltaic solar energy units into electric utility grids, several relative to on-site systems have been selected for further discussion and analysis:

- The impacts of on-site photovoltaic units on load duration curves and optimal generation mixes are considered.

- The impacts of on-site photovoltaic units on utility production costs, with and without dedicated storage and with and without sellback, are analyzed.

- Current utility rate structure experiments, rationales, policies, practices, and plans are reviewed. 


\section{THIS PAGE}

\section{WAS INTENTIONALLY \\ LEFT BLANK}




\section{FOREWORD}

The work described here was performed by The Aerospace Corporation under contract to the San Francisco Operations Office for the Office of Electric Energy Systems of the Department of Energy (Project Agreement 8, Modification No. 7 of Contract DE-AT03-79ET30351). This work covers a performance period from May 1979 through December 1979. The objective of this study was to identify and analyze selected issues of concern in the integration of photovoltaic systems into electric utility grids. The purpose of this report is to present in executive summary form investigations of three of these issues in self contained parts as indicated below:

Part I. Experiment Information Requirements

Part II. Generation Mix and Cost of Production Impacts

Part III. Rate Structures for On-Site Photovoltaic Units

A more detailed version of this report is also available. 
THIS PAGE

\section{WAS INTENTIONALLY LEFT BLANK}




\section{ACKNOWLEDGMENTS}

Part I, Experiment Information Requirements, of this report was written by Drs. Ted Davey and Richard Rountree and was based on analyses and interviews conducted by them and a utility consultant, Mr. James Beck. The material in Part II, Generation Mix and Cost of Production Impacts, was generated and prepared by two authors. Dr. Davey was responsible for the discussion on generation mix impact, and Dr. William Dickter was responsible for the discussion on fuel savings impact. The rate structure survey material, Part III, represents the work of Dr. Lawrence Schelhorse and Mr. Leon Bush and was written by Mr. Bush. Program management and documentation overview were provided by Drs. Mason Watson and Keith Cretcher.

The patient and extensive support in preparing the text and many of the tables and figures from Micki Lewis, Chriss Gamez, and Ginny Jackson is gratefully acknowledged. Appreciation is also extended to Mr. Fred Eggers for art and publications coordination. 
Blank

viii 


\section{PREF ACE}

A number of investigations, including those conducted by The Aerospace Corporation and other contractors, have led to the recognition of technical, economic, and institutional issues relating to the interface between solar electric technologies and electric utility systems. These issues derive from three attributes of solar electric power concepts, including (1) the variability and unpredictability of the solar resources, (2) the dispersed nature of those resources which suggests the feasible deployment of small dispersed power units, and (3) a high initial capital cost coupled with relatively low' operating costs. It is imperative that these integration issues be pursued in parallel with the development of each technology if the nation's electric utility systems are to effectively utilize these technologies in the near to intermediate term. The purpose of this report is to document investigations of three of these issues: utility information requirements, generation mix and production cost impacts, and rate structures in the context of photovoltaic units integrated into the utility system.

\section{Utility Information Requirements}

Although it is not clear whether on-site PV units will be owned or operated entirely or partly by utilities, it is certain that widespread near term deployment of PV units will require $a$ utility interconnection. This interconnection will require utilities to develop an understanding of PV units, their operation, and the effective integration of these units with the grid. To acquire this knowledge and experience, a number of experiments are to be conducted which should include utility participation. The specific utility information requirements to be met by these experiments must be examined to properly define the experimental program. The analysis of this issue is covered in Part 1 of this report.

\section{Generation Mix and Production Cost Impacts}

The introduction of significant numbers of PV units into the electric utility grid will affect utility generation costs through fuel savings, potential changes in the mix of 
future generation capacity to minimize production costs, changes in the operation of the system, and potential reductions in system capacity requirements allowing postpone. ments in installation or even cancellation of planned generating units.

Critical to determining the economic impact of PV units is the consideration of sellback of excess solar energy from on-site locations. On days of high insolation or low load, there could be a significant amount of such excess energy. Equally important to the analysis is whether there is dedicated on-site storage for accumulating excess energy during the day to meet the on-site nighttime demand. The benefits of PV storage or sellback, or a combination of these capabilities, will depend on the point of view taken: the utility, the customer, or the aggregate, and on the rate structure. A detailed analysis of these considerations is presented in Part II of this report.

\section{Kate Structures}

The electricity rate structures established for backup and sellback associated with PV units are of primary importance in determining both utility and customer economics. Such rate structures can either encourage or discourage the implementation of PV units. The practices, policies, rationales, experiments and plans of electric utilities, relative to PV or any solar parallel generation, are of definite interest and presently unresolved. The discussion of this issue is presented in Part III of this report. 
PART I. EXPERIMENT INFORMATION REQUIREMENTS $\cdots+$ e : :

\subsection{INTRODUCTION}

- The major contribution of this part of the study is the comparison of the informational contents of the major photovoltaic (PV) unit experiments with the informational requirements imposed by electric utility companies who are facing PV decision opportunities. The outcomes of the comparison are reported in the form of recommendations for modifications and additions to existing experiments, for the formation of an information transmittal format for communication with utility companies, and for augmentation of the national PV experiment program.

The conclusions drawn in this report are preliminary, and greater clarity of the issues will develop as the utility companies themselves devote more attention to the natures and weights of the impacts associated with PV implementation.

The overall purpose of the study task is to support the utility implementation decision process through identifying and defining utility information requirements and through characterizing the information potentially available in the national experiment program as it is presently conceived by the Photuviltaic Division of DDE (DOE-PV). The realization of the purpose is approached through the accomplishment of the following four specific task objectives:

1. Identify the information which will be required by electric utilities in making decisions regarding the integration of on-site photovoltaic systems.

2. Determine the extent to which the pertinent information will actually be obtained in the course of photovoltaic experiments and system demonstrations.

3. Identify gaps or discrepancies between the information required and the information to be actually obtained.

4. Recommend alterations of and/or additions to the national program of experiments and demonstrations. 
It is clear that the goal of accelerated commercialization of PV supports the top level national purpose of energy sufficiency through both conservation and production contributions. The conservation contribution arises from a fuel use replacement effect and results in a view of PV, especially in on-site applications, as a load modification. The production contribution arises from the view of PV as an additional energy generator. To support the utility decision process, information is needed and a primary source of such information is the DOE-PV experiment program.

It is important to realize that while the commercialization goal is definitely supported by the development of PV technology, an ongoing activity for several years, it is also necessary that the stage be set for system implementation by thoroughly satisfying the needs of the electric utility companies within whose supply networks such systems will be built. 
The first step in identifying the utility. information requirements was the creation of an Aerospace in-house hierarchy of utility concerns. The hierarchy was created through a process of identifying issues which, if resolved, would support resolution of an issue at the next higher level. In this sort of hierarchal analysis there is a gradual shift from broad and wide ranging concepts near the top of the hierarchy, through more sharply defined activities in the middle, to detailed requirements at the bottom. From the experiment information requirements point of vien', the analysis process terminates when the branches in the hierarchy end in the definition of actual variables to be sensed, recorded, and processed in an experiment. This report provides relevant information through middle level requirements.

The preliminary Aerospace analysis was taken into the field and exposed to several groups of utility personnel. A background briefing w'as presented at each utility company visited, followed by extensive round tables on the issues as appreciated by that particular utility. The utility companies visited then agreed to continue on their own with in-house analyses of the issues using the Aerospace-derived requirements as a structure, and to communicate the results to Aerospace when available. Finally, the Aerospace study team interpreted the discussions from a composite utility viewpoint.

Next, the availability and suitability of the utility-required information within the context of the presently defined DOE-PV experiment program were investigated. The task activity involved assessing the scope of the information content expected from the presently planned experiments and translating this information into a form convenient for comparison with the utility requirements.

The gap analysis, which is the term used to refer to the process in which gaps or discrepancies in the informational content of experiments from the utility point of view are identified, consists of a comparison between the information which is needed and the information which will be available and suitable as a result of the experiment process. 


\subsection{IDENTIFICATION OF CRITICAL UTILITY INFORMATION REQUIREMENTS}

The identification of critical utility information requirements was initiated by Aerospace with an in-house analysis based on prior PV experience and previous utility interactions. This information base was expanded with a literature search, and by conducting a preliminary utility field visit with Southern California Edison Company (SCE) personnel. The expanded set of information requirements was categorized according to five major PV question areas facing utility decision-makers. The five question areas span the utility/PV issues of:

- Grid Integration

- Economic Impact

- PV Techirulogy

- Social/Institutional

- $\quad$ Equipment Supply

Seven utility field visits were made including the early coordination meeting with SCE. Aerospace structured the visits as information brainstorming sessions posing Aerospace as an effective communication channel to DOE from the utilities.

The preliminary set of utility information requirements identified to date are based on the messages obtained from the technical interchanges accomplished during each field visit, on the utility consultant's recommendations, and on the Aerospace experience and literature search.

Several basic messages regarding PV implementation in utility grids received by Aerospace during the utility field visits are summarized below. The comments represent a consensus of utility opinion, although some variations of emphasis naturally occurred. An interesting sidelight is that the utilities appeared enthusiastically interested in participating, since they felt the activities served to better prepare them for forthcoming similar investigations of other new energy source evaluations.

Rankings of the concerns of the utilities indicate that grid integration issues are of paramount importance in utility considerations, followed closely by economics 
and technical performance. However a time phased perspective of these issues, as indicated in Section 4.0, indicates a degree of reversal. Experiments addressing technical performance need to be accomplished first in order to answer some of the critical grid integration questions. Furthermore, economic verification will depend on hard cost data, which will come out of actual experience.

An important result of the study is the identification of a number of specific areas in which utilities have indicated a crucial need for PV experiment information:

- Sufety of Personnel

Identification of hazard areas and activities

Techniques for system disconnection, interlocks, etc.

Training levels required for safety in maintenance

Structural and support loading measurements, environment

- System Protection

PV impacts on power quality, network stability

Power conditioner performance effects

Tests of control equipment

Identification of network control and switching operation impacts

Synchronization experience

- Load Management

Hardware performance characteristics

Load management logic and implementation

Identification of appropriate loads

Load management accommodation of PV impacts

- Economics

System and installation cost data for extrapolation

Maintenance and other operating cost information

Elasticity of PV demand with sellback rates

Preferential rate structures

Hidden costs due to grid integration

Local perturbations (environments, costs, etc.)

Implementation impacts on utility financial well-being

- Customer Attitudes

Maintenance logs documenting service calls and resolutions

Tolerance to resident system

Aesthetic considerations 
- System Lifetime/Reliability

Long-term data

Failure modes and intervals

Performance trend analyses, deterioriation

Warranties

- Capacity Credit

Loss of load measurements

- Legal/Jurisdictional

Liability for system damage and bodily injury

Ownership

Insurability

Service access

Rate base

- Maiket

Rates of penetration

Rate structure tolerance

Incentive efficacy

- Preferred Systems

Qualification procedures for suppliers, installers, servicers Degree of public reliance on local utility recommendations Optimum configurations (flat, concentrator, storage, etc.) Availability

- Demand Profile Data

Periodic sampling for utility analyses

- Grid Connection

Methods and designs for connection

Required network modifications

Equipment problems

- Training

Methods and materials

Minimum levels acceptable

- Maintenance

Technical system performance as function of maintenance levels Maintenance requirements on systems

Recurring fault areas 


\subsection{ANALYSIS OF EXPERIMENT IN FORMATION CONTENT}

An analysis of the information flow within the DOE-PV experiment program was performed to determine the extent to which pertinent information is expected to be obtained from current and planned photovoltaic experiments and demonstrations. Plans for the DOE-PV experiments, for example, the Intermediate Load Center experiments conducted under PRDA 35/38, have placed a high degree of emphasis on the development of information requirements. The study summarized here included detailed examinations of requirements and plans which are reported in the main study report volume. The most significant observations from this effort pertain to the perceived position of the utilities among data users.

. It is pertinent that the utility community is perceived as one of a group of many users. This perception does not fully exploit the greater spatial and temporal extent of the utilities as common participants in many individual projects during each program phase and through several phases of the program from initial experimentation through commercialization. Further assessment of experimental information flow and formatting may increase the effective use of the unique position enjoyed by the utilities by which they can obtain the maximum transfer of data from project to project. Data transfer between parallel or similar projects is important during each development phase and also between projects that are sequentially related across the several development phases, e.g., Initial System Evolution Experiments through Commercial Readiness Demonstrations. 


\subsection{ANALYSIS OF GAPS BETWEEN UTILITY/DOE-PV IN FORMATION CRITERIA}

A summary of the apparently different philosophical positions held by the utilities and DOE-PV provides the first stage of the gap analysis. The gaps identified in this section serve as the source of specific recommendations regarding the experiment program.

Anticipation for the Commercial Readiness of PV. The utilities view commercial readiness as being in the distant future, if at all, and must retain their current commitments for expanding generation mixes over 10 years in the future. They share an experienced uncertainty regarding actual lifetime of any new technology. Conversely, DOE-PV anticipates readiness for the residential and ILC applications by the mid-1980s, based on its studies and developments to date. DOE-PV will rely on reliability being established along the way and on accelerated aging tests.

Means for Progressing to Potential Commercial Readiness. The utilities want a sequential evolutionary process with proven feasibility carried along at each step. The utility community would prefer to rely on a few well conceived experiments with appropriate funding for each. The basic concept of the DOE-PV approach is similar in that an evolutionary process is intended, but a difference exists in the implementation by DOE-PV. This difference involves parallel activities and sequential equipment development in order to accomplish the mid-1980 readiness, without anticipation of failure.

Degree of Realism to be Incorporated in the Experiments. Utilities are concerned about customer reactions, safety in servicing, unexpected load changes, and other factors. They feel that meaningfully high levels of power must be involved to ascertain the true influence on their grid networks; higher levels would require higher funding for the experiment involved. Contrasting the higher levels of power sought by utilities, the existing plan calls for lower levels at multiple experiment sites as the pattern for using available funds.

Impacts Associated with Grid Connection. The utilities are uncertain about the impact of PV on the operation of their grids, on grid security, in terms of protecting controllability and stability, and on the safety of people involved in installing, operating, and maintaining the equipment. A key factor in their consideration is adequate training for those involved in such activities. Again, DOE-PV indicates interest in most of these issues, although it feels grid backup is forthcoming with proper utility arrangements. Grid impact is expected to be determined by data evaluation corresponding to the series of system experiments, but very little appears in DOE-PV literature regarding training requirements. 
Degree of Awareness that Exists Concerning the Planned DOE-PV Program. The utilities have expressed concern about the apparent lack of planning, logic, coordination, and priorities in the program. However, the Multi-Year Program Plan (MYPP) addresses such issues, and the forthcoming User Requirements report addresses data requirements for the critical system experiments.: Expediting draft coordination and document release would alleviate a . substantial amount of this concern.

Attitude of Underlying Caution Among the Utilities. Such caution seems to be due to a feeling of a lack of realism in an accelerating program being conducted independent of their involvement. However, the program does place some emphasis on actual user environment, and DOE-PV interacts with utilities by using utility representatives (e.g., individuals, EPRI) as advisors, as eventual users of the experiments data, and as PRDA associates.

General Need for Utility-Specific Information Requirements to be Adequately Addressed. Utilities are highly concerned about their service areas and local regions, and would like information extrapolated for use in their local analysis activities. Such a requirement would have to be built into the program early. In contrast, DOE-PV essentially views the utilities as a group and as one of many user groups interested in the experiment data, which would therefore be privy to the general data bank to be provided by DOE-PV to all user groups.

Ownership and Control of PV Units. The scope of this utility concern comprises responsibility for such activities as operation and maintenance, associated basic training, warranties, and personnel safety. Very little has appeared in the DOE-PV literature to date on this issue, but implied responsibility would exist with the public in the residential/Intermediate Load Center (ILC) applications, and with the utilities in the central stations. An early resolution of this issue is essential for the smooth integration of PV into utility scenarios.

Central Station vs Distributed Applications. The utilities would prefer a resolution via early well conceived experiments comparing each approach. DOE-PV has adopted the residential/ILC applications as being highly probable for early commercial readiness, with central station perhaps following in the future. Several utilities point out that large, centralized plants have historically always won in the economics tradeoff.

Sellback of Excess Energy Generation. The impact and role of the various candidate approaches, relative to potential capacity credit, is part of the resolution to be accomplished. DOE-PV presently relies on study results, preferring sellback over the apparently more expensive storage options, and will gather data on the subject during planned experiments. 
Degree of Experiment Flexibility. Utilities indicate an inclination toward incorporating modularity in a few early and on-going established experiments, thereby allowing adoption of advanced technology breakthroughs as they occur. The PV program is planned to incorporate such breakthroughs in some of the multiple experiments to be subsequently initiated.

Availability of Complete PV Experiment Program Documentation for the Utilities. This includes test and evaluation plans, progress reports, and individual and composite experiment final results, including such data as preferred systems and qualified suppliers. Present DOE-PV intentions are to provide the utility data according to their user priorities, to provide the general PV data bank, and to issue appropriate specifications and standards.

Utility Involvement and Active Participation. The utilities indicated a desire to particlpate, but they appeared to be more sensitive to their own service areas or local regions, and to well conceived experiments designed to meet their own needs and interests. Currently, DOE-PV relies on utilities as advisors, eventual users of experiment data, and as PRDA associates.

Increase in Interest Concerning Utility Demand Control Options. The interest in options such as load management and storage is increasing due to the effects of photovoltaic energy on the utility load profiles and on the consequent daily planning for generation. The current DOE-PV program does not appear to address these issues together, so experiments providing information on the viable combinations of these factors need to be defined.

Completeness of Information Categories Created by Aerospace. The utility field visit results indicate that they were essentially complete, but that the priorities assigned to each should be time phased. Comparison to the DOE-PV data requirements indicates that the six requirements categories match those of the PV Tost and $\Lambda$ pplications (T\& $\Lambda$ ) program activities, but time phasing pertains to a different categorization of the same information.

A review of the comparisons made indicates that there are a few significant gaps in philosophy. Some issues recur for more than one of the comparison interpretation viewpoints, but there is a much smaller overall gap existing than is generally recognized by the utilities. For example, both communities are highly concerned about real-world problems, evolving into commercial readiness, and developing a well structured program plan to carry out the evolution. Many of the gaps are matters of degree of different preferences rather than basic polarities, and can be remedied with minor modifications and additions to the DOE-PV program. 
Basic and recurring gaps were determined to be associated with the following:

- Longer test periods are needed to establish reliability and commercial readiness.

- Utility communication and participation activities need to be initiated and emphasized.

- Greater concentration of program resources on a few experiments is needed.

- Greater emphasis is needed on resolving system ownership and jurisdictional concerns.

- Mutual awareness of problems and progress is needed by utilities and DOE. -

- Approaches are needed for interpreting results of distant experiments to local applications.

- Greater emphasis is needed on quantifying grid integration impacts on utility operation.

- Central station application needs greater attention.

- Load management effects in the presence of solar generation need study. 


\subsection{OBSERVATIONS AND RECOMMENDATIONS OBSERVATIONS}

Several observations were made during the course of the study which are not actually results or conclusions of the analysis effort. Instead, they represent attitudes and experiences which are judged to be significant either because of their ubiquity among the utility companies or because of their potentially pivotal effect on the course of alternative energy generation developments.

It is emphasized that these observations are the study team's interpretations of its experiences and of utility-held attitudes. Therefore, the observations do not necessarily represent positions held either by the Aerospace team or by every utility visited, nor do they constitute specific recommendations for DOE action. They are reported for their information value.

- Furthermore, despite the apparently wide gap implied by some of the observations given below, the gap analysis conducted for this study yields two supplemental observations:

- Informational and approach gaps between identified utility requirements and planned experiments are not as wide as implied by some of these perceptions.

- Recommendations can be made to minimize gaps that do exist, and these are offered for consideration in the final section.

Utility Attitudes Toward Government Activities: The utility companies visited varied somewhat in the expressions of their attitudes toward the roles government agencies, particularly DOE, are taking in the PV development activities. However, there were some common themes heard more or less loudly at nearly all the utility companies.

There is a general feeling that government is too eager to get to the marketplace with the alternative energy systems and that insufficient time and experience are being devoted to the demonstration of commercial readiness. The vision is of huge government expenditures to create what may be an artificial market, which 
will collapse into the tremendous vacuum left by government's withdrawal of support after victory has been declared. A related concern is that the market will be seriously damaged by disenchantment with devices which have not been thoughtfully and carefully tested over long periods of time. Several groups illustrated their concern in this area with examples from the solar heating and cooling experience.

Other feelings in this category expressed by the utilities included:

- Political considerations are being allowed to contaminate technical decisions regarding $\mathrm{PV}$ experiment planning, with the result that information content is seriously degraded for all the experiments.

- The inconstant and possibly ephemeral nature of government incentives programs renders long term planning for PV an exercise in guesswork.

- The transience of DOE personnel creates severe disruptions in government funded programs.

- There is a tendency to see DOE as a monolithic entity, without clear distinction between the organizations and purposes of the Photovoltaic Division and the Office of Electric Energy Systems.

Utility Perceptions of PV Imminency: There is a general consensus that photovoltaic energy conversion is an exotic technology and that any meaningful penetration of the energy supply by $\mathrm{PV}$ is in the distant future, even in utility planning units of time. The earliest estimate for a central station installation was 1990, and this was viewed as a very small experimental plant.

Status of Utility Awareness of PV Impacts: Due partly to the nonimminence of PV implementation and partly to the typical work pressure on utility technical staff personnel, the depth of detailed analysis regarding PV impacts already performed by utilities was in general not sufficient to allow real-time discussion of the detailed information requirements in the meetings. It was not possible to penetrate to a detailed level, that is, to the actual data requirements. However, all of the utilities expressed a willingness to use the hierarchy charts as a structure within which to 
perform additional review and analysis on their own. It was also not possible to get a clear statement of information requirement priorities (i.e., "What really needs to be known first?") beyond the first hierarchical level.

The Aerospace study team came away from some of the meetings with a qualitative impression that many utility companies could be much better informed regarding DOE programs, in particular the PV Multi-Year Program Plan and the activities of the PV Data System Task Team being organized within the PV Program by Jet Propulsion Laboratory. On the other hand, the companies feel they are not adequately included in the PV Program, and that they are not being consulted extensively enough regarding the requirements they have and the constraints on their operational choices.

Utility Positions on PV Experiment Programs: The utility companies generally agreed that many of their information requirements could be satisfied by experiments involving other utilities, and uniformly expressed a preference for a program which sponsors a few very well conceived and implemented experiments rather than a plethora of limited ones patterned after what several termed a "scattergun" approach. In general, they are desirous of participating in experiment design and in monitoring the course of experiments in other utilities. With respect to experiments in which they. are the host utility, there was a desire for funding flexibility to allow the introduction of the latest technology equipment.

With respect to PV lifetime qualification testing, a very high priority requirement with all the companies, there was considerable doubt surrounding the value of accelerated life testing. The attitude was that accelerated testing serves as an indicator, but no hard generation planning decisions can be based on it. The minimum actual life test duration for credibility with the utilities was given as five years, and the utilities stressed that the testing had to be performed under local environmental conditions.

Utility Positions on Selected Technical Issues: Utility perceptions on three specific technical issues are included here due to the widespread interest in them. The issues are: 
- The degree to which capacity credit, if any, can be earned by PV The appropriate position to take regarding excess energy sellback

- The central station versus on-site applications question

With respect to capacity credit, very few of the generation planning people involved in the meetings felt that capacity credit would be earned by PV. In general, they recognized that this position contradicts analysis results based on loss-of-load probability considerations, and gave as justification the presence of evening demand peaks, weather outages, and the practical limits of energy storige.

The companies generally expressed uncertainty with regard to the best approach to determining sellback policies and rates. It is recognized that sellback energy can have serious effects on generation operations, and that it may be economically justifiable, though possibly precluded by public utility commission actions, to charge the customer with on-site photovoltaic generation a higher rate for backup energy than his nonsolar neighbor.

Several of the utilities perceive that a major decision has been made favoring on-site applications over central stations. They argue that the utility industry exhibits a long history of economy-of-scale success and that it is too early to make any irreversible decisions.

Utility Reception of the Aerospace Information Requirements Mission: The utility companies were uniformly cooperative in establishing the visits, and exhibited considerable energy in supporting the Aerospace mission. Personnel from many areas of each company were committed to the meetings for their duration, usually 4-5 hours, and there was a strong interest in expressing their positions, utilizing the study team's role as a communication channel with DOE.

It was also noticed that the discussions and the requirements hierarchies left with the companies served an unforeseen purpose as a stimulus to their own thinking and as a structure within which to pursue in-house analysis of their. information requirements. 
With respect to the information requirements identified, the following sets of recommendations are advanced to promote the satisfaction of the crucial utility information requirements. Some recommendations relate to activities already planned for accomplishment by DOE-PV, and in such cases the intent here is to reinforce those steps. Some of the others are directed at the strategies to be implemented by the Office of Electric Energy Systems (DOE-EES).

\section{RECOMMEN DATIONS}

The recommendations based on study findings are of three distinct types. The first adheres strictly to the purpose of the study and suggests modifications or additions to the photovoltaic experiments in the current catalog. The second type of recommendation addresses the foru und furction of information transmittal to the utility company for its decision-making activities. Finally, the third type of recommendation addresses some of the broader issues which surfaced in the Aerospace contacts with the utility companies, and which can be described as policy recommendations.

\section{Experiment Modifications and Additions}

Power Levels (DOE-EES): Select at least one experiment for which the photovoltaic power produced exceeds demand in an isolatible branch of the energy distribution system to allow measurements to be accumulated in a sellback regime.

Grid Interaction (DOE-EES): Develop and incorporate procedures and supporting equipment for rapid location, isolation, and removal and repair of failed PV units, and document associated findings.

Technical Performance (DOE-PV/EES): (1) Ensure that data are collected to yield key sensitivities such as the dependence of PV structure costs on environmental differences, or network performance as a function of $\mathrm{PV} / \mathrm{grid}$ dynamic parameters; (2) acquire data to identify both operational and non-operational characteristics of the inverters: i.e.; power quality, VAR requirements, and quiescent role as a load.

Load Management (DOE-EES): Include an experiment to investigate realistic load managem ent options coupled with PV energy generation.

Duration (DOE-PV): Identify an early experiment to demonstrate a minimum PV five year lifetime. Utility acceptance of commercial readiness cannot be assumed until at least that point is reached. 
Installation, Operation, Maintenance (DOE-PV): (1) Provide descriptive material documenting installation procedure experience, including mistakes and blind alleys; (2) design and incorporate service forms for use in logging customer telephone calls - nature of service request and resolution; (3) determine training requirements and procedures that are necessary for - operation in the various spatial scenarios, and provide corresponding documentation including training materials and films.

Customer Interactions (DOE-EES): (1) Establish test educational programs, such as short courses for utility planning personnel to aid in monitoring PV experiments and readying for subsequent penetration; (2) supplement one or two experiments with the sampling of attitudes, reactions, and various market forces.

\section{Information Transmittal}

User Requirements: Each experiment should incorporate and satisfy the user requirements identified in the DOE-PV Data System Task Team activity.

Data Planning: Ensure that data will be available to the utilities from each experiment stage, from component development through the Commercial Readiness Demonstration Programs, and assess how Test and Applications information will be used in Commercial Readiness Demonstration Program activities.

Reduced Raw Data: Since all data forthcoming from the DOE-PV data bank will apparently be already reduced, it is crucial to identify the parameters of interest (e.g., sensitivities) or make raw data available to utilities.

Utility Functions: Consider categorizing end-use, experiment information along utility functional lines such as generation, operations; service, billing, transmission, and distribution to facilitate use within the utility.

Before and After PV: Ensure availability of pre-project data, to obtain before and af ter assessments.

\section{DOE-PV/EES Policies}

Utility Involvement: Expand the participation level of and general consideration accorded to utility company personnel in the national photovoltaics program. Ways to accomplish this include (1) formation of a DOE-PV/EES/Utility Information Working Group; and (2) elevating utility status from one of many user groups to a separate participating interest group. 
Working Group Charter: Adopt a Utility Information Working Group charter to: (1) include creation of a Multi-Year Program Plan for Information (MYPPI) which parallels the present version of the DOE-PV program MYPP, includes the goals and strategies anticipated by DOE, and thereby links the temporal phases of PV development together; (2) incorporate information requirements and findings coordinated with the various utility experiments that are being cataloged and monitored by EPRI; (3) expand the PV Data System Task Team activities in the T\&A area using the team as a subcommittee.

MYPP Release: Coordinate MYPP upgradings with the working group, thereby facilitating utility awareness of the national photovoltaics program. Create an MYPP tutorial document for easy assimilation by utilities, and institute a mechanism for utility feedback.

PV Data System Task Team Activities: Renew emphasis on and provide funding for the team activities to ensure the incorporation of identified user requirements into data parameters and functional requirements throughout the PV experiment program.

Program Emphasis: Increase emphasis on central station applications and establish a focussed central station responsibility. Define commercial readiness to include utility decision process with respect to PV lifetime and reliability. 
PART II. GENERATION MIX AND COST OF PRODUCTION IMPACTS

\subsection{IN TRODUCTION}

Due to the cyclic and occasionally intermittent character of on-site photovoltaic generation, most applications involving significant penetration of the on-site load will require the availability of backup energy from the utility company through some form of grid connection. The existence of a connection with the grid opens the possibility of reverse energy flow, termed sellback, during periods in which the photovoltaic generation exceeds the demand of the local load. Both these energy flow's, backup and sellback, create perturbations in the utility demand profile and have corresponding impacts on the optimum generation $\mathrm{mix}$, the capacity factors of the various conventional generating units, and the resulting costs of energy production.

It is the objective of the task summarized in this section to quantify these impacts, and to analyze their sensitivity to changes in such variables as solar penetration of the on-site load, photovoltaic array size, insolation levels, conventional plant generating mix, and others.

A fundamental property of photovoltaic systems is that, although the fuel is free, the conversion equipment is expensive relative to customary utility operation. Thus the adoption of on-site photovoltaic units may require a shift in the payback periods required by owners as a criterion for making capital expenditures. Also a factor concerning fuel price as an analysis parameter is its differential rate of price escalation. This is a quantity of great uncertainty in analyses of future scenarios. Given the situation with respect to foreign control of a significant portion of domestic fossil fuel availability, it is appropriate to perform analyses using escalation rates greater than experienced in the past, and certainly greater than the "standard" expectations of only a few percent per year.

The effective and appropriate use of energy storage remains as an issue, even with a sellback path for excess energy generation. The point is that the sellback-only configuration requires the utility to accept the excess energy whenever it is available, not necessarily when it is needed. The result can be a degradation in generation efficiency and possibly the requirement for increased use of peaking units. Storage may provide special load management options not otherwise available. 
Financial assumptions pertaining to the ownership of on-site units will have considerable effect on calculations of the cost of energy production. Utility companies have been reluctant to have a large number of small customer-owned systems connected to their grids and may themselves eventually own and operate on-site units. On the other hand utility attitudes appear to be changing and financing may be less expensive for individual owners than for a utility so that individually owned, controlled, and maintained units may become the norm.

There are several utility impact scenarios which can be defined for analysis. In the fixed utility scenario the conventional generating units are assumed to be prescribed and PV units are introduced. Calculations are then performed to examine the impacts. In an optimal utility scenario an optimum mix of conventional units is developed from a menu of possibilities to meet a given demand profile. PV units are then introduced and a new optimum $\mathrm{mix}$ is calculated using the same menu of conventional possibilities: The impact of PV penetration is inferred by comparing those two optimum configurations. In a transition utility scenario a prescribed mix of conventional units is assumed and new conventional and PV units are added consistent with a postulated growth in demand. The mix may not be optimal at any point in time because. some of the units were selected at prior times when conditions were different.

\subsection{IMPACTS ON OPTIMAL GENERATING MIX}

In the analysis of the optimal utility scenario, the methodology adopted is a static incremental cost optimization formulation. In this methodology the demand is incorporated through standard load duration curves, and the optimization of the generating $\mathrm{mix}$ is calculated by superimposing the incremental cost of production curves for the various conventional generating units in the mix.

To discover the future-based cost of production characteristics of actual generating units, a menu of conventional power plants was compiled for projected 1990 costs expressed in 1980 dollars.

The corresponding cost of production curves were graphed and, with the lone exception of combined cycle generation, the crossover points of the various generating units are nearly coincident (Figure 2-1). The indication is that an optimal mix would 


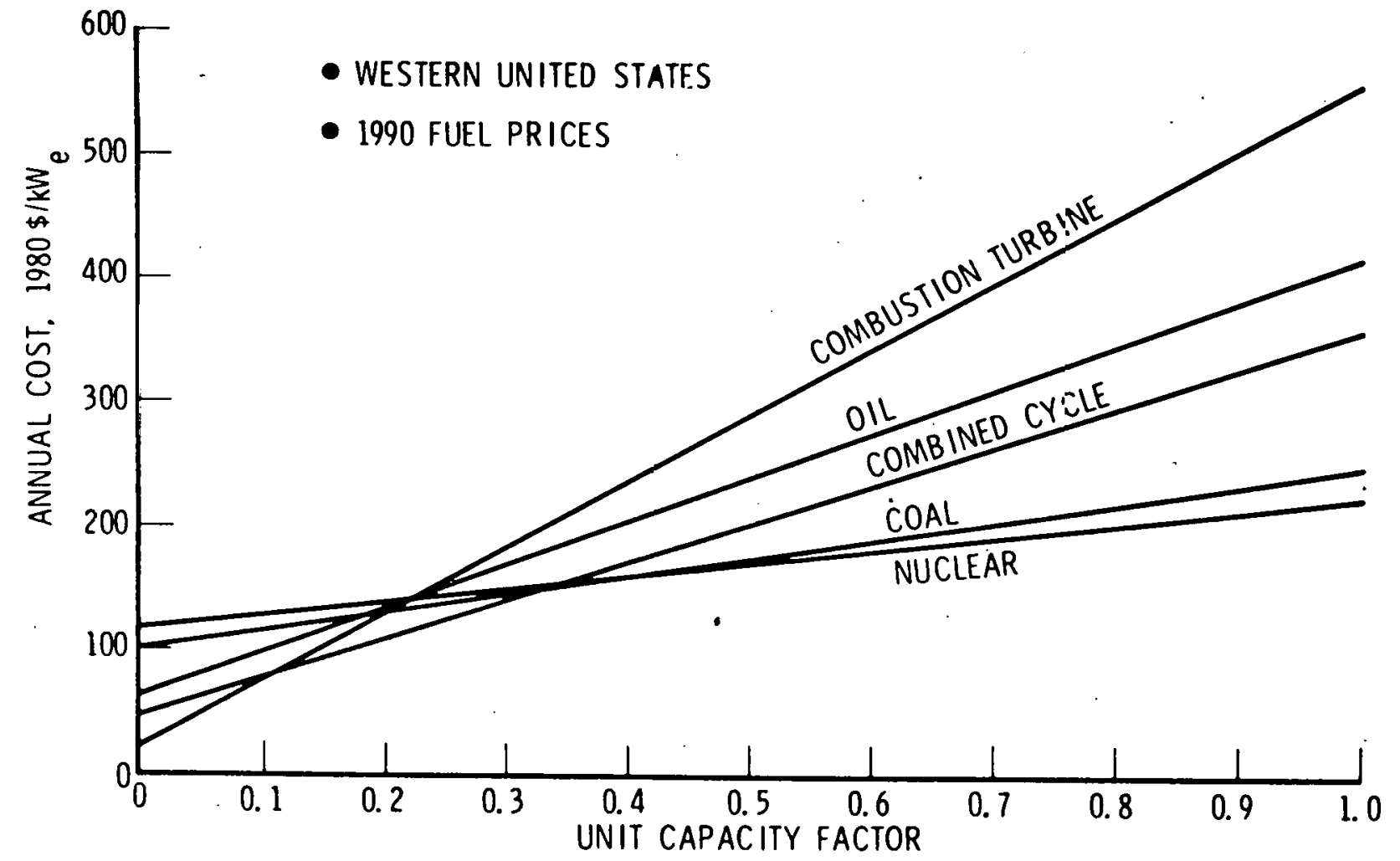

Figure 2-1. Annual Cost of Conventional Generation 
consist almost entirely of combustion turbines and whichever baseload plants, coal and/or nuclear, are available. Also available from this analysis was the observation that, even with combined cycle plants in the mix, the highest crossover point is at only 0.32 capacity factor. In addition, oil thermal plants are precluded in an optimal mix with these data.

Using the load duration curve model for utility demand, the effects of photovoltaic penetration of the utility demand were introduced. The basic utility demand profile used is the projected Southern California Edison demand for 1990. The insolation data is based on Inyokern, California measurements taken in 1963. The change in the annual load duration curve for several PV penetration scenarios is shown in Figure 2-2. 2

For the utility studied, the Aprll and December hourly load profiles exhibit an evening peak which is unmodified by the photovoltaic energy. However, for this utility the peak demand season occurs in summer due to cooling loads and this daytime peak is reduced by the photovoltaic source. The results support an argument for some capacity credit, but beyond a certain threshold of solar penetration the capacity requirement is determined by the secondary evening peak. It appears very likely that the amount of capacity credit to be accorded solar will be strongly utility dependent and this issue is still very much in controversy.

The incremental cost of production optimization and the calculation of the optimal capacity mix selected from the three types of conventional plants indicates that there are clear increases in combustion turbine utilization, and decreases in baseload coal utilization, as functions of increasing photovoltaic penetration, and that essentially all of the energy produced by photovoltaics displaces coal use in the optimal analysis scenario.

Interim observations and tentative conclusions based on the work include:

\section{Incremental Cost Optimization Analysis}

- As oil prices rise, oil plants, including combined cycle, become inappropriate in an economically optimum system mix. 


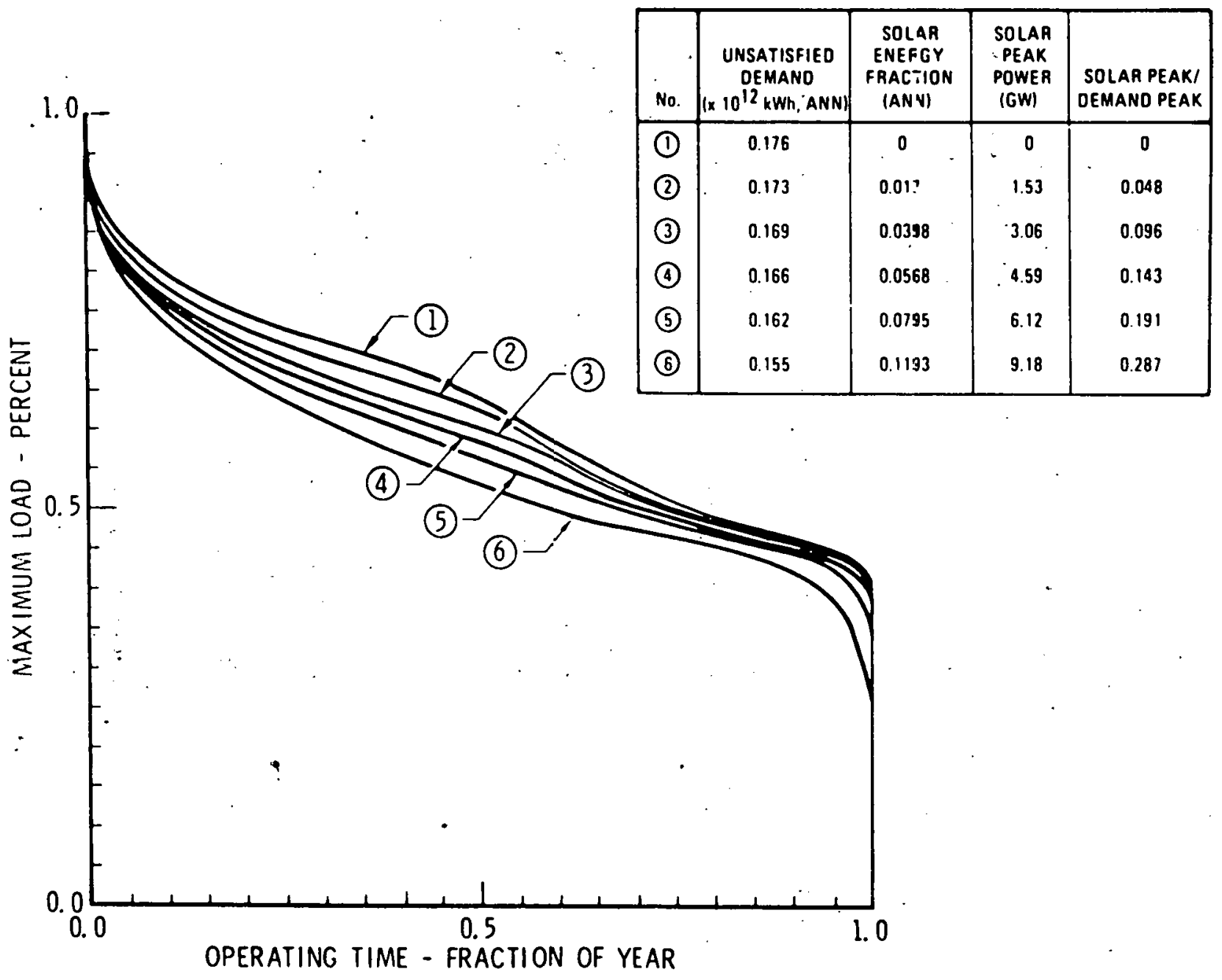

Figure 2-2. Effect of Solar Penetration on Load Duration Curve 
- The particular methodology used does not allow for study of the sensitivities of costs of production to oil price since the economic optimum precludes oil from the mix altogether.

\section{PV Penetration Analysis}

- Without storage or sellback large penetrations can impact baseload. capacity and also reduce system peaks.

- Without storage but with perfect sellback there is a small impact on the optimum mix of conventional plants with a slight increase in cycling units.

\subsection{IMPACTS ON PRODUCTION COST AND FUEL CONSUMPTION FOR A FIXED UTILITY}

The purpose of this analysis is to investigate the impact of on-site photovoltaic units on an electric utility having a fixed conventional generation mix. The two figures of merit used in the study are fuel costs and fuel consumption, especially the reduction in oil usage. It is recognized that other utility costs such as investment in capacity, transmission, or distribution equipment, and operating costs such as maintenance, metering, or dispatching may also be impacted. However, the reduction in fuel costs and fuel consumption is believed to represent the most significant parameters characterizing the impact of on-site PV units.

The impact of on-site PV units was also examined in terms of a simplified utility rate structure. As noted above, one measure of PV impact is the resulting fuel cost reduction realized by the utility. The results of the fuel cost reduction analyses are integrated into a simplified rate model to determine an appropriate rate to be paid by the PV unit owner for backup electricity, and a rate to be paid by the utility to the homeowner for PV generated energy fed back into the utility grid.

A reference residential PV unit for use in the analysis was taken from a previous Aerospace study of optimum residential photovoltaic electric units. A limited number of parametric changes, such as varied array size and storage capacity, were examined from the perspective of the utility. The definition of the reference residence includes the house physical characteristics and demand profiles. Diversity among the 
PV residences was represented in the analysis by varying individual house loads. The performance of the PV unit with respect to the site meteorology was simulated using the Aerospace developed computer program PVHOUSE, which provided the input to the utility system economic analyses.

The postulated utility is described using such characteristics as the location, types and sizes of plants and cost parameters. $A$ single case which w'as analysed postulating an Arizona utility, w'as modelled after the broadly representative synthetic utility Scenario D developed by the Electric Power Research Institute (EPRI)(Ref. II-1). The sizes and types of power units included in the generating mix are noted in Table 3-1. This mix implies a fuel cost at the peak which is more than five times the baseload fuel cost as shown in Figure 3-1. Total utility system production cost impacts were assessed with a computer code which yields annual fuel costs, given the utility/load profiles, with and without on-site photovoltaic unit operation. Figures 3-2-through 3-5 illustrate the changes in the hourly load profiles for a typical case in which 100,000 PV residential units were postulated both with and without an energy storage capability at each house. Figures 3-6 and 3-7 indicate the resulting oil savings (other fuel savings are not shown) considering the several combinations in which energy storage is and is not included and also where a sellback provision is or is not (excess energy is then "dumped") provided. Figure 3-8 displays the impact on oil savings of various energy storage capacities:

A highly simplified residential rate model u'as postulated to examine the impact of varying PV penetrations on backup and sellback rates. This model assumes that the residential PV units are not credited with displacing conventional capacity or distribution system capital costs. It is also assumed that the capital costs attributed to the conventional capacity required to back up the PV units is allocated to the PV ouner through a backup energy rate that is higher than the rate charged non PV owners but no distribution system capital costs are subtracted when calculating the rate to be paid by the utility for the excess energy (the sellback energy) sold to the utility, i.e., there is no "wheeling" charge. Figure 3-9 illustrates the backup and sellback rates expressed as a fraction of the rates applicable to a non PV residence. 
Table 3-1. Fuel Cost and Efficiency Assumptions

\begin{tabular}{|l|c|c|c|c|}
\hline Type of Fuel & Size, MW & $\begin{array}{c}\text { Fuel Cost } \\
(\$ / \text { Million Btu }\end{array}$ & $\begin{array}{c}\text { Heat Rate } \\
(\text { Btu } / \mathrm{kWh})\end{array}$ & $\begin{array}{c}\text { Fuel Cost } \\
(\mathrm{Mill} / \mathrm{kWh})\end{array}$ \\
\hline Nuclear & 1200 & .885 & $1.044 \times 10^{4}$ & $9.2 \vdots$ \\
Oil & 800 & 3.62 & $9.155 \times 10^{3}$ & 33.1 \\
& 400 & 3.62 & $9.447 \times 10^{3}$ & 34.2 \\
& 200 & 3.62 & $9.979 \times 10^{3}$ & 36.1 \\
& 600 & 1.31 & $8.989 \times 10^{3}$ & 11.8 \\
Coal & 400 & 1.31 & $9.045 \times 10^{3}$ & 11.9 \\
& 200 & 1.31 & $9.576 \times 10^{3}$ & 12.5 \\
\hline & 50 & 3.99 & $1.400 \times 10^{4}$ & 55.9 \\
\hline
\end{tabular}

$*$

1985 Cost in terms of 1980 dollars 


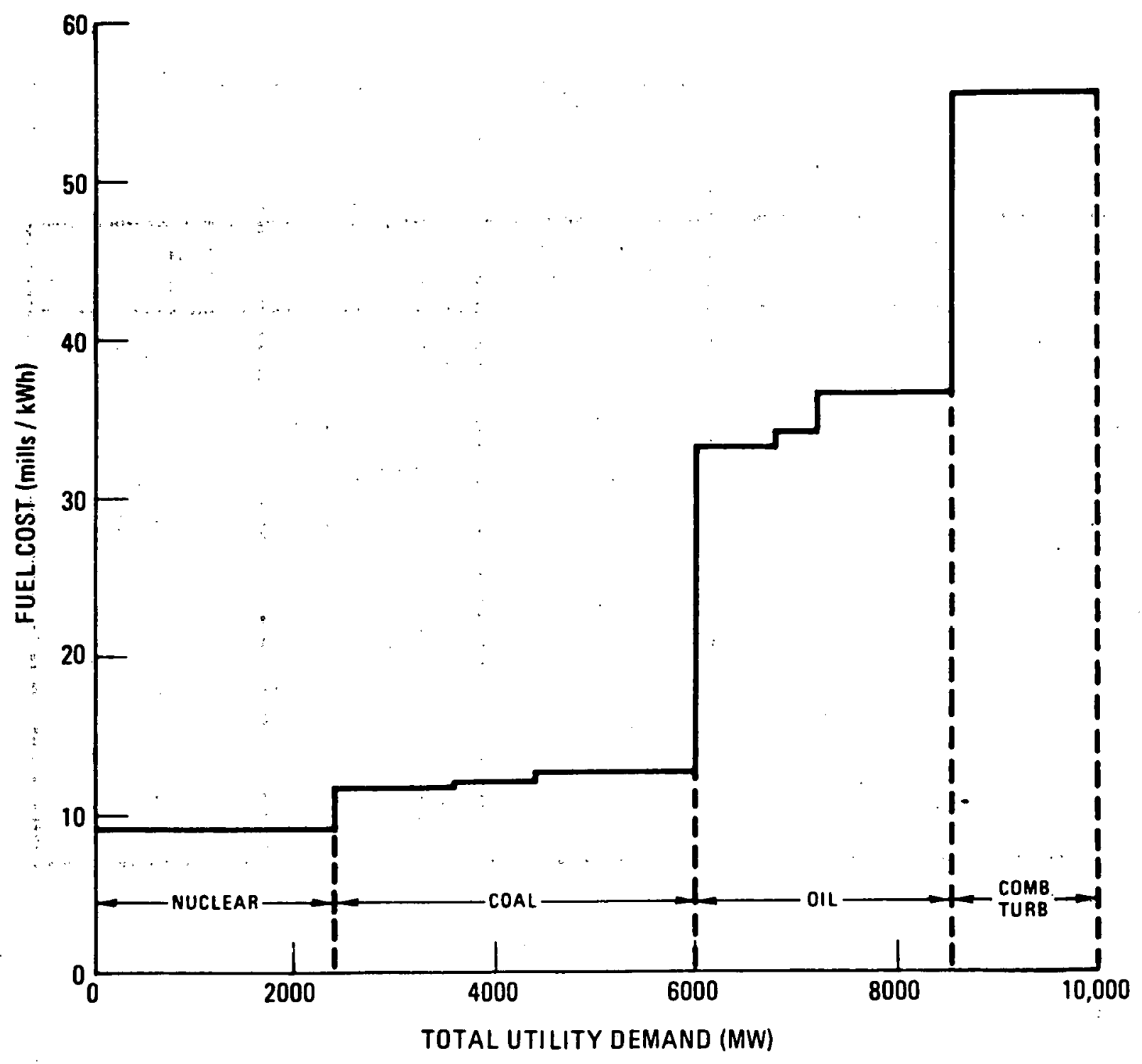

Figure 3-1. Utility Incremental Cost Curve 
- 100.000 UNITS $\bullet 80 \mathrm{~m}^{2}$ ARRAY AREA - NO STDRAGE

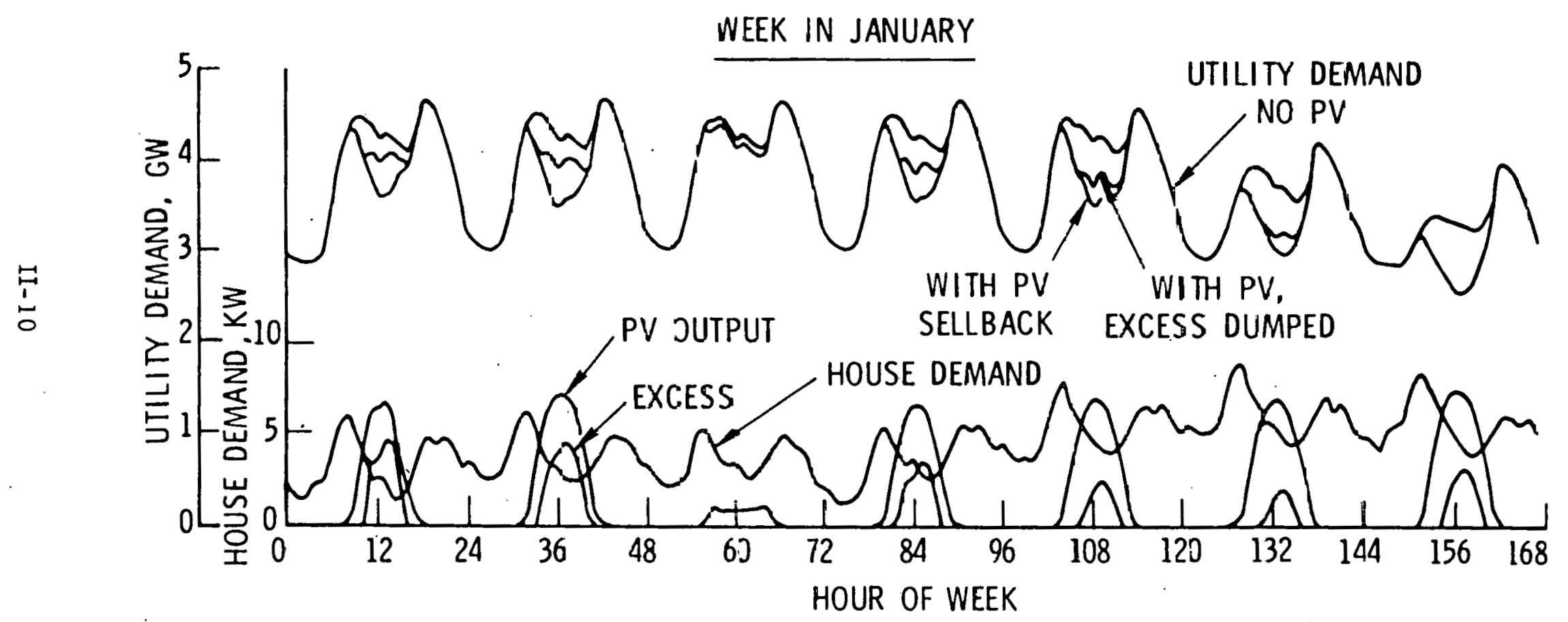

Figure 3-2. Demand and PV Output Profiles 


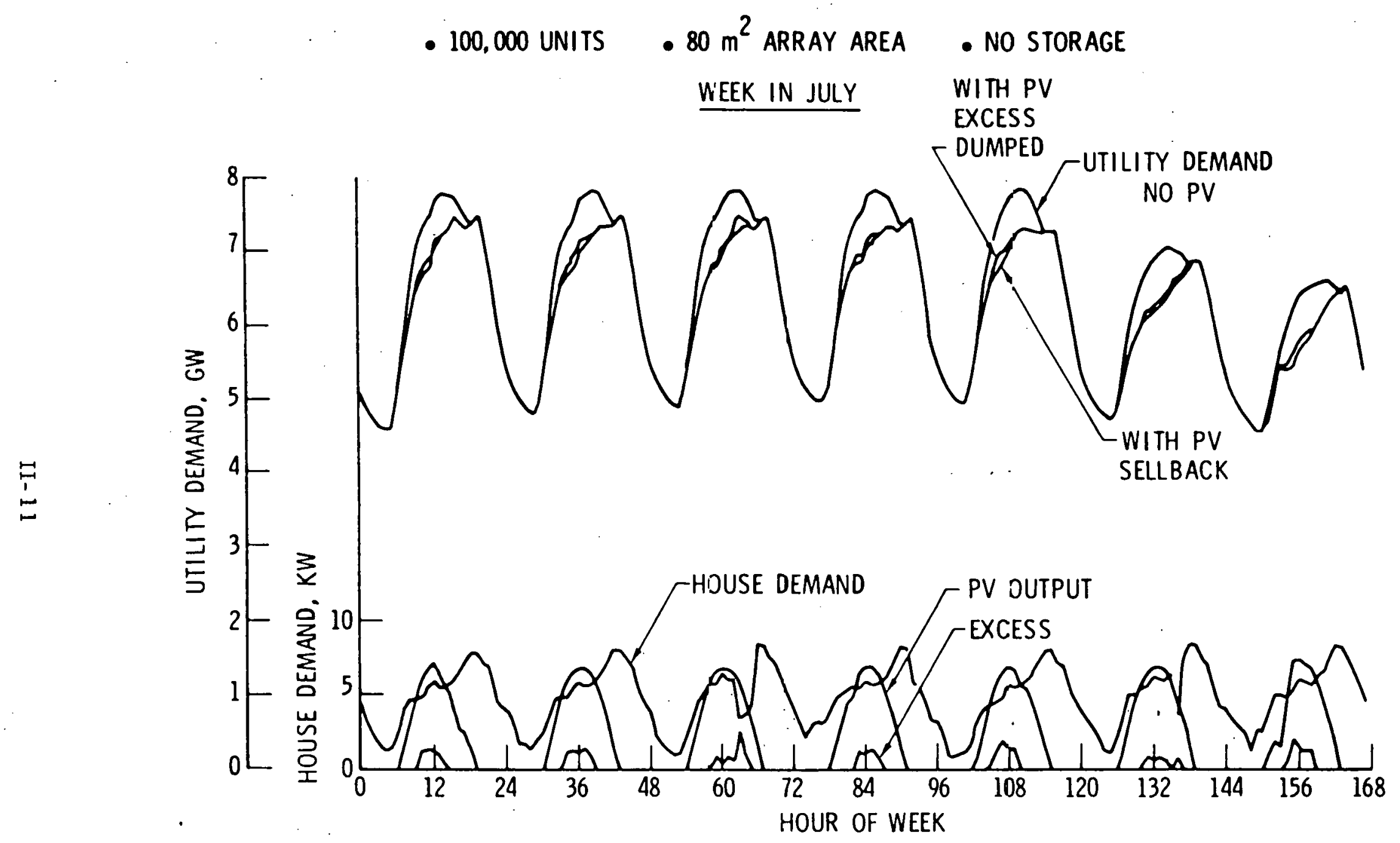

Figure 3-3. Demand and PV Output Profiles 
- 100,000 UNITS $\quad 80 \mathrm{~m}^{2}$ ARRAY AREA $\quad 32.6 \mathrm{kWh}$ STORAGE

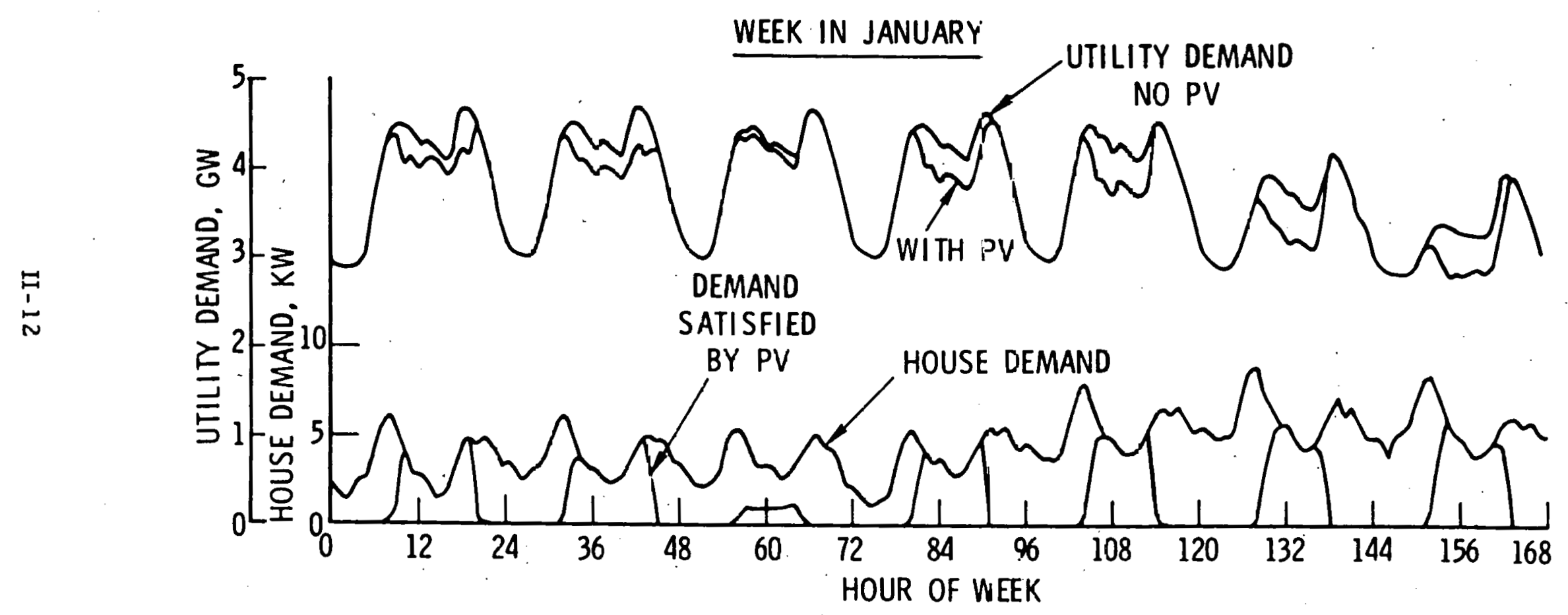

Figure 3-4. Demand and PV Jutput Profiles 
- 100,000 UNITS $\quad$ - $80 \mathrm{~m}^{2}$ ARRAY AREA $\quad 32.6 \mathrm{kWh}$ STORAGE WEEK IN JULY

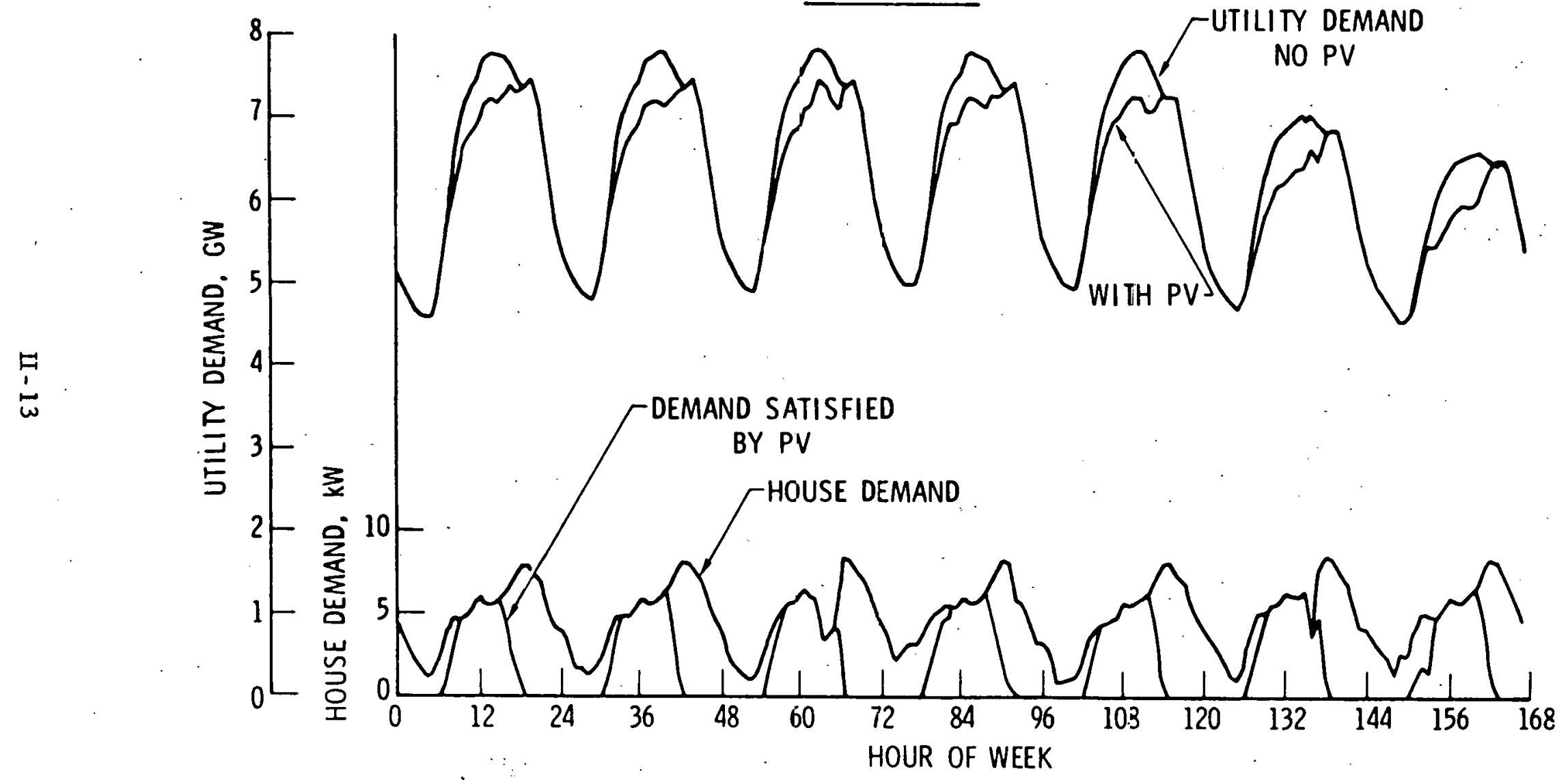

Figure 3-5. Demand and PV Output Profiles 


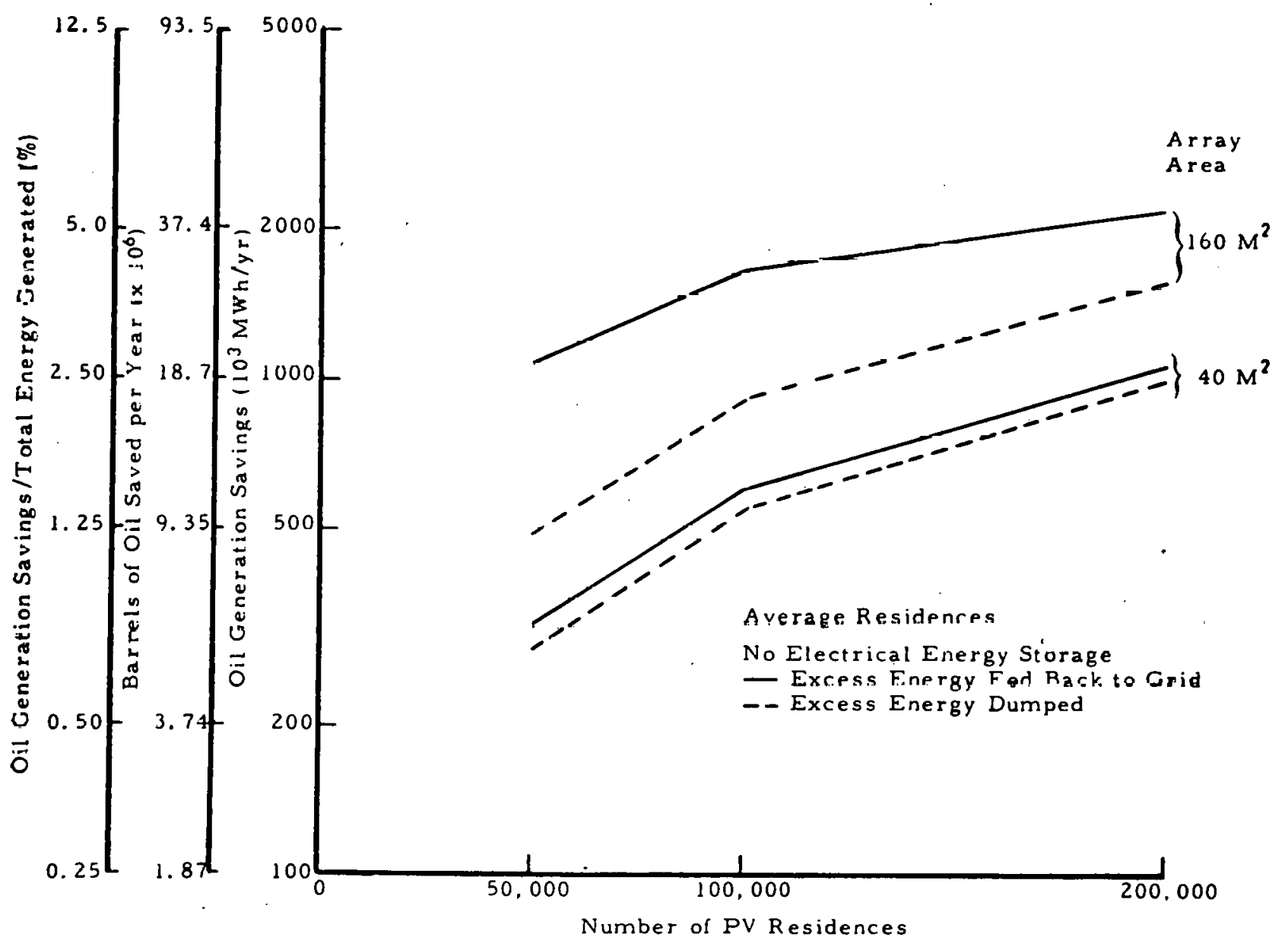

Figure 3-6. Oil Savings vs Number of PV Residences - No Storage 


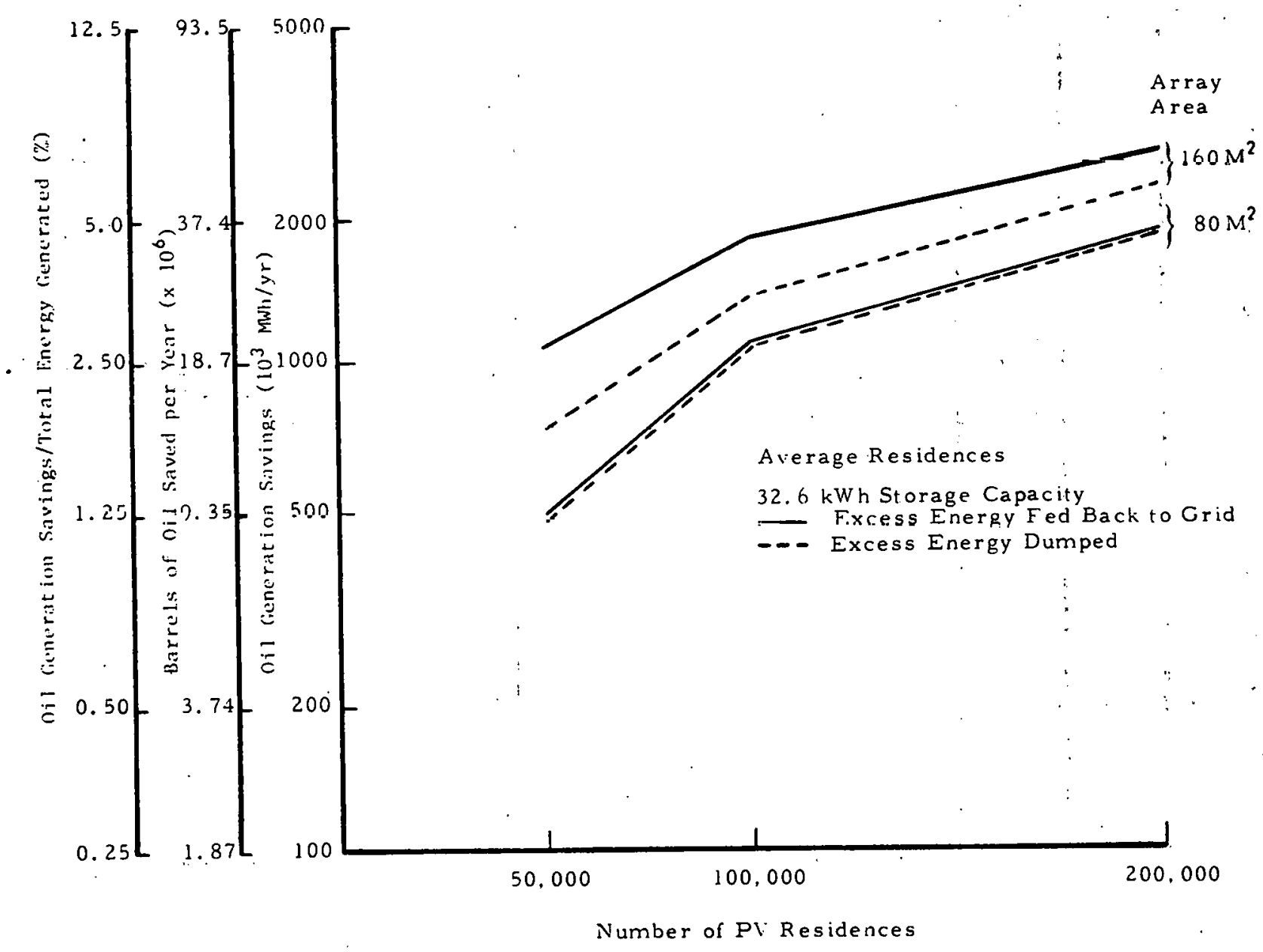

Figure 3-7. Oil Savings vs Number of PV Residences - On-Site Storage 

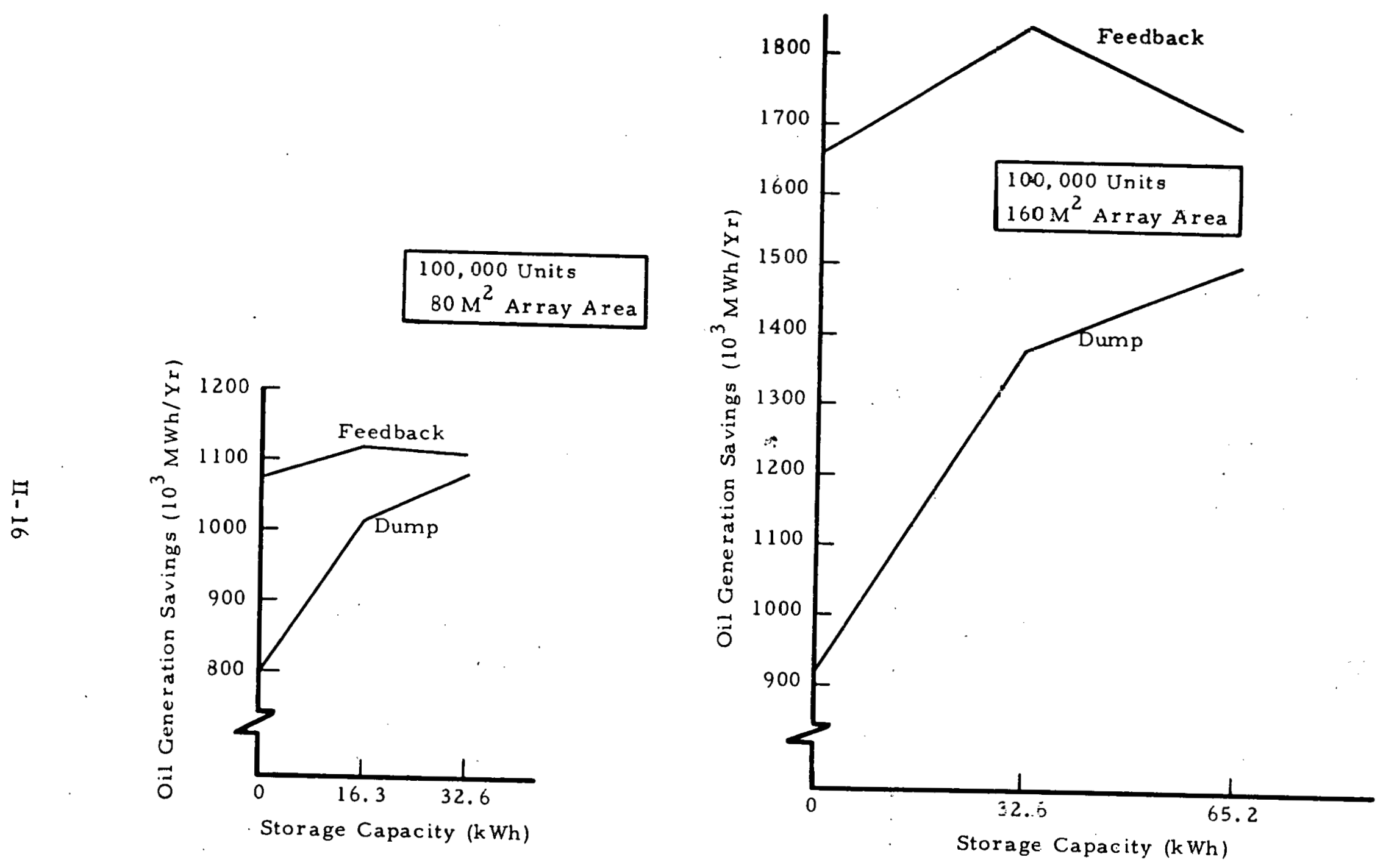

Figure 3-8. Impact of Storage and Feedback on Oil Generation Savings 

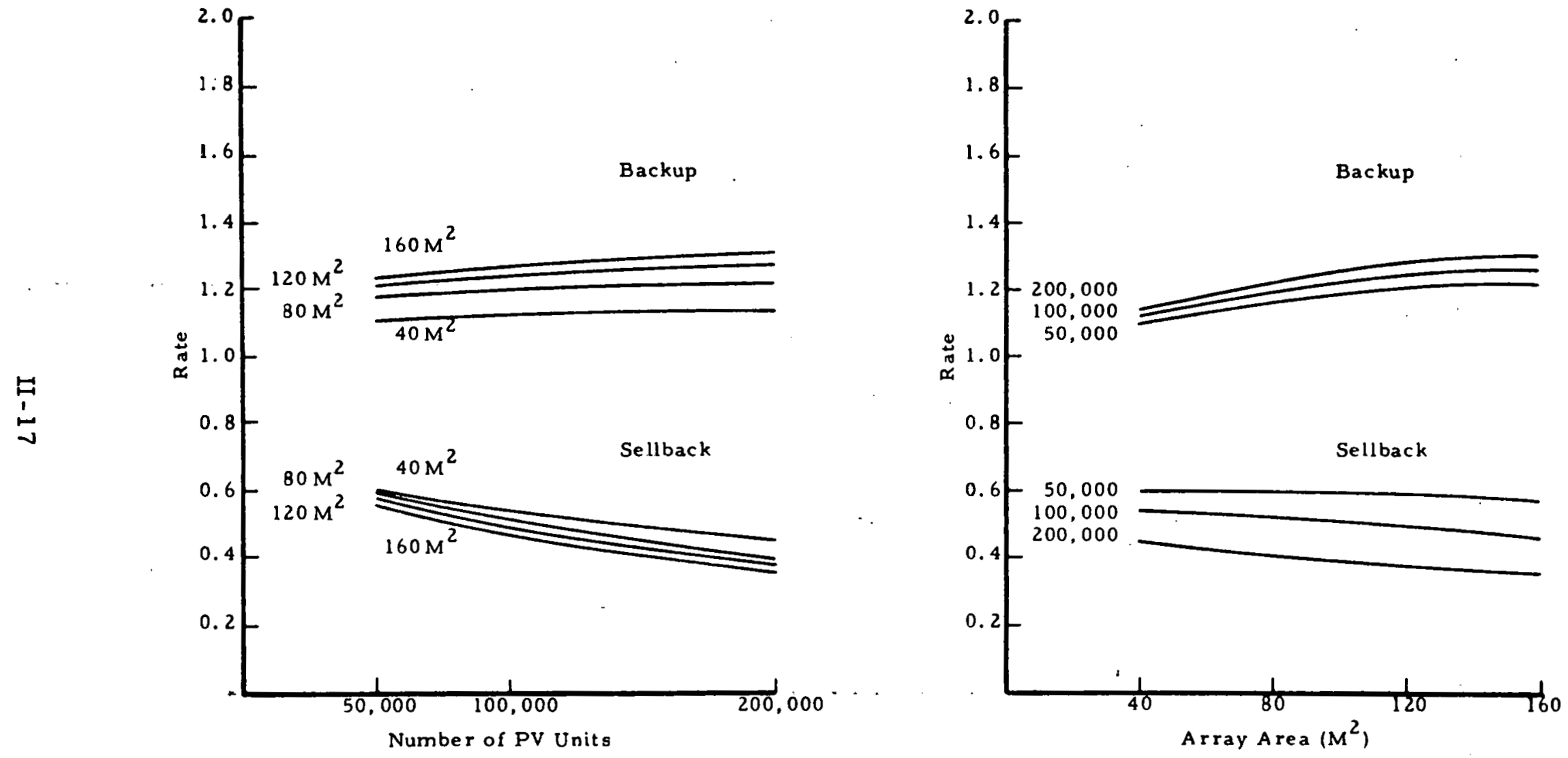

Figure 3-9. Backup and Sellback Rates vs PV Penetration - No Storage 
The conclusions from this brief study, which are summarized below', must be view'ed with an appropriate degree of caution. That is, the conclusions apply specifically to the boundary conditions, assumptions, and parameter values chosen and may vary for other locations, utilities, economic parameters and so on.

\section{Oil Conservation}

On-site photovoltaic units achieve oil conservation due to the gross energy displacement effect even though much of the generating capacity w'as coal or nuclear (Figures 3-6 and 3-7).

\section{Storage and Sellback}

Oil savings are impacted by both storage and sellback. In terms of oil conservation, more barrels of oil are saved when excess PV gencrated energy is feu back to the grid (Figures 3-6 and 3-7). This impact is enhanced when on-site storage is added (compare Figures 3-7 vs 3-6); however, beyond a critical value of storage capacity, the amount of oil conserved when energy is fed back decreases and approaches as a limit the amount conserved w'hen excess PV energy is dumped (Figure 3-8). Similar trends are noted in terms of fuel cost savings. From the utility point of view, the net influence is a function of the storage efficiency, the prevailing prices for sellback and backup energy, and the alteration in the demand profile due to the particular storage logic employed. Storage and sellhark tend to be countcractive in that the benefit due to their combination is less than the sum of their individual benefits.

\section{Modelled Sellback and Backup Rates}

The utility sellback rate decreases w'ith inereasing PV saturation, and also with array areas for the larger sizes, because the incremental excess energy displaces incrementally less valuable conventional fuel. The backup rate increases with increasing solar penetration, both array area and saturation, because the capacity factor of the conventional generators is thereby reduced resulting in less efficient utilization of the fixed capacity. The effect of energy storage is to further increase the backup energy rate and the sellback rate. The sellback rate decreases for very large array areas as the storage capacity increases. 


\section{Coupled Analysis Needed}

The site owner and the utility company will of ten have opposing economic motives. Previous studies have concentrated on only one of the parties, with consequent loss of economic representation for the other. System acquisition decisions must involve coupled analyses in which the preferences and constraints of both groups are considered. 


\section{PART II. REFERENCE}

II-1. Synthetic Electric Utility Systems for Evaluating Advanced Technologies, EPRI EM-285, Electric Pon'er Research Institute, Palo Alto, California, February 1977. 


\section{PART III. RATE STRUCTURES FOR ON-SITE PHOTOVOLTAIC UNITS}

\subsection{INTRODUCTION}

The objective of this brief task was to assess current activities concerning rate structure studies, practices, rationales, and experiments as they affect the use of on-site photovoltaic power units.

\subsection{FACTORS AFFECTING RATE STRUCTURE}

Ownership: The rates which a utility will charge a customer, or pay a customer for electricity generated at the customer's residence is dependent upon ownership. If the utility owns the photovoltaic unit, the cost of power production will probably be treated as a supply of usable energy to the entire service area just as if it were produced at a central generating facility. If the customer owns the solar facility; however, the rate structure must consider the impact on utility capacity, requirements, capacity utilization, system operations, the time-of-day value of sellback energy, special interconnection and metering costs, and changes which occur as a result of increasing penetration of photovoltaics in the overall system. The utility rate base would not include the photovoltaic power production investment although the investment in distribution (excluding any interconnection equipment), transmission, capacity and general plant required to provide backup power would continue to be included in the rate base.

Solar System Characteristics: Since the utility generally bases its rate structure on energy use, capacity requirements, and operational efficiency ${ }^{*}$, the solar unit characteristics and output as well as the nature of the customer demand are both important to the determination of an appropriate rate structure. The nature of the insolation on an hour-by-hour basis relative to the load is important, as well as the amount of storage present in the photovoltaic unit.

* Most residential rates are highly simplified and do not explicitly identify these considerations. Operational efficiency refers to the use of a power factor related charge. 
Utility Characteristics: The summer versus winter peaking characteristics of a utility could have a profound effect on the rate structures which are appropriate for photovoltaic systems. Another characteristic is the demand profile and weather sensitivity experienced by the utility and the aggregate size of the photovoltaic demand relative to the total load. Unit energy cost increases may occur from a need to use units that consume higher cost fuels per unit of energy output more frequently, to maintain larger spinning reserves, and to provide for special metering, status monitoring, maintenance, safety, or power quality provisions.

\subsection{SURVEY SUMMARY}

The analysis began with a survey of recent literature on rate structure development, especially those studies which address solar units. These included $\forall$ number of time-of-day studies initiated by EPRI; documentation of special rates developed by utilities in anticipation of solar unit employment; ERDA and DOE-funded studies; and studies, policies, and regulations of various state and federal agencies. Several of the studies are summarized below (from Refs. III-1 to 8).

\section{Study Source}

Electric Pow'er Research Institute (EPRI)

Johns Hopkins University

Feldman/Anderson

Office of Technical Assessments, DOE (OTA)

\section{$\underline{\text { Relevant Contents }}$}

Time of use studies and experiments. Rates using marginal costs.

Review of field experiments for electrical rate design.

Assessment of ongoing activities in the interface between utility industry and solar energy for buildings.

Recommendations related to pricing.

Recommended Federal Policies for promoting and regulating on-site solar energy. 
Solar Energy Research Institute (SERI)

ICF, Inc.
Review of utility rate structures. ' Effect of rates on solar unit economics. Examples of proposed solar and wind rates.

Impacts of alternate rate design for solar space and water heating. Impacts of solar on utility costs and prices. Regulatory guidelines relevant to solar power.

After the initial literature review, 'telephone interviews were held with four researchers active in the field of utility rates, four utilities, the California Public Utilities Commission (PUC), and EPRI. These intervieu's confirmed that there were few completed studies which were applicable directly to the problem of rate making for photovoltaic systems, but revealed that some were now under way.

\subsection{EXISTING SOLAR RATE STRUCTURES}

Solar Backup Power Rates: Sixteen utilities in tw'elve states have developed electric rates which are explicitly available to residential customers who own solar space and/or water heating units and who use electricity as a backup to these units. The rates include traditional declining block rates, energy charges varying with time of day, demand-energy rates, and controlled service tariffs. In most instances these rates are identical in structure and in level to those offered to all-electric customers. In a number of cases these rates have been incorporated to overcome exclusionary clauses. For example, some total electric schedules specify that electricity must be the primary or sole source of heating; a special rate or rider would be necessary for solar owners to be eligible for this tariff.

Parallel Generation Rates for Solar: Many states are now studying special rates with sellback provisions for on-site photovoltaic units and wind machines. States with such filings already adopted include California, Vichigan, Montana, and New York. Some provide for an energy credit equal to the average cost of fuel per $\mathrm{kWh}$, but impose a "demand" charge, either as a minimum or fixed value per kilowatt of capacity. One other rate schedule does not have a demand charge and provides energy credits which 
are different for on-peak and off-peak usage. Another has no demand charge, and an energy credit equivalent to the energy charge except that the net energy cost cannot be negative. This rate implies a subsidy for the solar unit and does not appear to reflect the relative costs of service.

\subsection{THE FUTURE OF SOLAR RATES}

Most of the existing rate tariffs offered for solar are experimental in nature, and few residential customers have applied for these rates. Utilities and regulatory agencies are moving to have the rates in place before substantial penetration of solar occurs. As the market penetration of solar with sellback potential increases, the experimental rates will be converted to more permanent rates. Since these rates can be strongly affected by federal and state regulatory policies, it is important to examine these policies in detail in order to anticipate the new trends in rate making.

A comparison of the current solar rates with the.rule making proposed by the Federal Energy Regulatory Commission (FERC) in response to the Public Utility Regulatory Policies Act (PURPA) (Ref. III-9) results in some significant discrepancies, since most of the current rates do not reflect the avoided costs to the utilities in their buy-back prices. The following represent areas recommended for further study: (1) continue to monitor public utility commissions and utilities as they respona to the FE RC rule making, (2) continue impact studies to determine the aggregate effect of solar photovoltaic units on utilities in order to develop a quantitative understanding of costs avoided and additional costs incurred as a result of on-site power units with sellback which may be used as a basis for future rate making, (3) explore the effects of these new rate structures and the interconnection costs on market penetration of solar photovoltaic systems as a function of different regions and utility load types. 
III-1. Electric Utility Rate Design Study, 1978 Plan of Study, Electric Power Research Institute, Palo Alto, California, December 1977.

III-2. Field Experiments for Electric Rate Redesign Decisions: Review and Assessment, Final Report, The Johns Hopkins University Center for Metropolitan Planning and Research, Baltimore, Maryland, February 1979.

III-3. 'Public Utility and Solar Energy Interface: An Assessment of Policy Options, Final Report, Energy Research and Development Administration, Division of Sular Energy, December 1976.

III-4. Application of Solar Technology to Today's Energy Needs, Volume I, Office of Technology Assessment, Washing ton, DC., June 1978

III-5. Regulated Utilities and Solar Energy, Solar Energy Research Institute, Golden, Colorado, SERI/TR-62-225, June 1979.

III-6. Case Studies on Impacts of Rate Design on Dispersed Solar Energy Systems, Task IIIB: Demand and Rates Analysis, ICF Incorporated, Washington, DC., December 1979.

III-7. Case Studies on Impacts of Rate Design on Dispersed Solar Energy Systems, Task I: Literature Review and Survey of Utilities, ICF Incorporated, Washington, DC., March 1979.

III-8. Technical, Institutional and Economic Analysis of Alternative Electric Rate Designs and Related Regulatory Issues in Support of DOE Utility Conservation Programs and Policy, Volume I: Domestic Rate Survey, ICF Incorporated, Washington, DC., August 1978.

III-9. Public Law 95-617, 95th Congress, Public Utility Regulatory Policies Act of 1978, November 1978. 
CONTENTS

ABSTRACT $\ldots \ldots \ldots \ldots \ldots \ldots \ldots$

FOREWORD............................. v

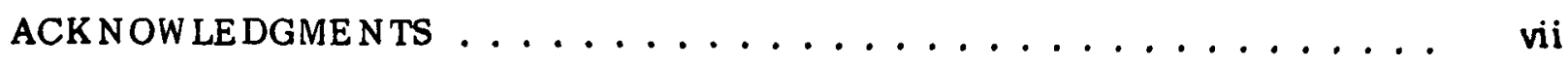

PREFACE .......................... ix

PART I.

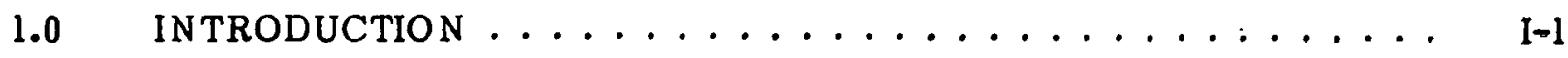

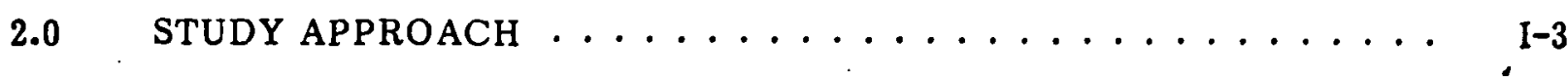

3.0 IDENTIFICATION OF CRITICAL UTILITY INFORMATION REQUIREMENTS ........................ I I

4.0 AN ALYSIS OF EXPERIMENT IN FORM ATION CONTENT . . . . . I-7

5.0 AN ALYSIS OF GAPS BETWEEN UTILITY/DOE-PV INFORMATION CRITERIA ......................... I 1.8

6.0 OBSERVATIONS AND RECOMMENDATIONS. ............ 1 . 12 PART II.

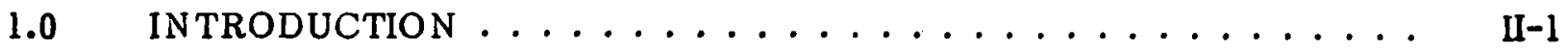

2.0 IMPACTS ON OPTIM AL GENERATING MIX ............ II-2

3.0 IMPACTS ON PRODUCTION COST AND FUEL CONSUIMPTION FOR A FIXED UTILITY. ..................... II-6

REFERENCE ............................. II-20

PART III.

$1.0 \quad$ INTRODUCTION $\ldots \ldots \ldots \ldots \ldots \ldots$ III-I

2.0 FACTORS AFFECTING RATE STRUCTURE ............ III-I

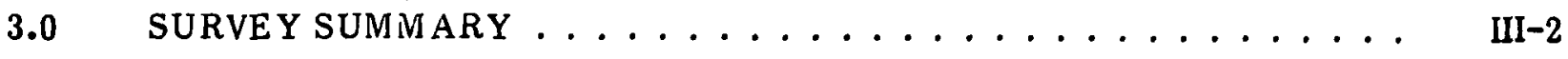

4.0 EXISTING SOLAR RATE STRUCTURES $\ldots \ldots \ldots$ III-3

5.0 THE FUTURE OF SOLAR RATES........................ III-4 REFERENCES .............................. III 
FIGURES

2-1. Annual Cost of Conventional Generation ............ Il-3

2-2. . Effect of Solar Penetration on Load Duration Curve . . . . . . . . II-5

3-1. Utility Incremental Cost Curve . . . . . . . . . . . . II-9

3-2. Demand and PV Output Profiles (January - No Storage) . . . . . . I I-10

3-3. Demand and PV Output Profiles (July - No Storage) . . . . . . . . . II-11

3-4. Demand and PV Output Profiles (January - $32.6 \mathrm{kWh}$ Storage). . . . . . II-12

3-5. Demand and PV Output Profiles (July $-32.6 \mathrm{kWh}$ Storage). . . . . . . II-13

3-6. Oil Savings vs Number of PV Residences - No Storage. . . . . . . . II-14

3-7. Oil Savings vs Number of PV Residences - On-Site Storage . . . . . . 11-15

3-8. Impact of Storage and Feedback on Oil Generation Savings . . . . . . II-16

3-9. Backup and Sellback Rates vs PV Penetration - No Storage . . . . . . II-17

TABLE

3-1. Fuel Cost and Efficiency Assumptions . . . . . . . . . . II-8 


\section{ABSTRACT}

A number of investigations, including those conducted by The Aerospace Corporation and other contractors, have led to the recognition of technical, economic, and institutional issues relating to the interface between solar electric technologies and electric utility systems. These issues derive from three attributes of solar electric power concepts, including (1) the variability and unpreoictability of the solar resources, (2) the dispersed nature of those resources which suggest the deployment of small dispersed power units, and (3) a high initial capital cost coupled with relatively low operating costs. It is imperative that these integration issues be pursued in parallel with the development of each technology, if the nation's electric utility systems are to effectively utilize these technologies in the near to intermediate term.

An important part of the DOE programs to develop new source technologies, in particular photovoltaic systems, is the experimental testing of complete or nearly complete power units. These experiments provide an opportunity to examine operational and integration issues which must be understood before widespread commercial deployment of these technologies can be achieved. Experiments may also be required to explicitly examine integration, operational, and control aspects of. single and multiple new source technology power units within a utility system. An identification of utility information requirements, a review of planned experiments, and a preliminary determination of additional experimental needs and opportunities are presented in Part I of this report.

From the many other issues that are of concern in the integration of photovoltaic solar energy units into electric utility grids, several relative to on-site systems have been selected for further discussion and analysis:

- The impacts of on-site photovoltaic units on load duration curves and optimal generation mixes are considered.

- The impacts of on-site photovoltaic units on utility production costs, with and without dedicated storage and with and without sellback, are analyzed.

- Current utility rate structure experiments, rationales, policies, practices, and plans are reviewed. 


\section{FOREWORD}

The work described here was performed by The Aerospace Corporation under contract to the Office of Electric Energy Systems of the Department of Energy (Project Agreement 8, Modification No. 7 of Contract DE-AT03-79ET30351). This work covers a performance period from May 1979 through December 1979. The objective of this study was to identify and analyze selected issues of concern in the integration of photovoltaic systems into electric utility grids. The purpose of this report is to document investigations of three of these issues in self contained parts as indicated below:

Part I. Experiment Information Requirements

Part II. Generation Mix and Cost of Production Impacts

Part III. Rate Structures for On-Site Photovoltaic Units

An Executive Summary for this report is also available. 
THIS PAGE

\section{WAS INTENTIONALLY \\ LEFT BLANK}




\section{ACKNOWLEDGMENTS}

Part I, Experiment Information Requirements, of this report was written by Drs. Ted: Davey and Richard Rountree and was based on analyses and interviews conducted by them and a utility consultant, Mr. James Beck. The material in Part II, Generation Mix and Cost of Production Impacts, was generated and prepared by two authors. Dr. Davey was responsible for the discussion on generation mix impact, and Dr. William Dickter was responsible for the discussion on fuel savings impact. The rate structure survey material, Part III, represents the work of Dr. Lawrence Schelhorse and Mr. Leon Bush and was written by Mr. Bush. Program management and documentation overview were provided by Drs. Mason Watson and Keith Cretcher.

The patient and extensive support in preparing the text and many of the tables and figures from Micki Lewis, Chriss Gamez, and Ginny Jackson is gratefully acknowledged. Appreciation is also extended to Mr. Fred Eggers for art and publications coordination. 
THIS PAGE

\section{WAS INTENTIONALLY LEFT BLANK}




\section{PREFACE}

\section{BACKGROUND}

A number of investigations, including those conducted by The Aerospace Corporation and other contractors, have led to the recognition of technical, economic, and institutional issues relating to the interface between solar electric technologies and electric utility systems. These issues derive from three attributes of solar electric power concepts including (1) the variability and unpredictability of the solar resources, (2) the dispersed nature of those resources which suggest the deployment of small dispersed power units, and (3) a high initial capital cost coupled with relatively low operating costs. It is imperative that these integration issues be pursued in parallel with the development of each technology if the nation's electric utility systems are to effectively utilize these technologies in the near to intermediate term.

A number of relevant issues are identified in the following discussion according to the general categories of concern involved.

\section{ISSUES IN PV IN TEGRA TION IN TO UTILITY GRIDS}

\section{Generation Mix and Production Cost Impacts}

The introduction of significant numbers of PV units into the electric utility grid will affect utility generation costs through fuel savings, potential changes in the mix of future generation capacity to minimize production costs, changes in the operation of the system, and potential reductions in system capacity requirements allowing postponements in installation or even cancellation of new generating units. The diurnal variation of the insolation inputs is particularly important in determining fuel costs since the incremental costs of production also vary diurnally. The capacity mix problem relates to the type of fuel displaced with particular concern overoil burning units. Changes in system capacity requirements may occur as a result of demand displacement during the time of system peak. Even though this displacement is a function of insolation level, which can be very low on some days, overall system reliability may still be maintained with a lower system capacity requirement. This particular aspect requires very careful evaluation. 
In determining prociuction cost impacts the effects of spinning reserve criteria, intended to provide rapid response to unit outages, is potentially important. Therefore the impact of the variable and unpredictable photovoltaic unit power output is of concern. Also of concern will be the implications in the increased cycling of units, especially baseload units, that would be implied by a large penetration of PV units.

Critical to determining the economic impact of PV units is the consideration of sellback of excess solar energy from on-site locations. On days of high insolation or low load, e.g., an Indian summer weekend, there could be a significant amount of such excess energy. Equally important to the analysis is whether there is dedicated on-site storage for accumulating excess energy during the day to meet the on-site "nighttime demand. The benefits of PV storage or sellback, or a combination of these capabilities, will depend on the point of view: the utility, the customer, or the aggregate (see section on PV Configuration below), and on the rate structure (see section on Rate Structure below).

The results of any generation impact analysis will be dependent on the geographic location due to variation in the weather and insolation effects and will also depend on utility characteristics (generating mix, load profiles, etc.).

\section{Reliability and Control}

Because the reduction in cemand experienced by the utility due to on-site grid connected photovoltaic units will be highly variable and generally unpredictable, there can be significant effects on system generation reliability. There may be some capacity displacement associated with the aggregated photovoltaic units. The magnitude of this displacement will depend on the overall insolation characteristics, demand correlations, and utility reliability indices. Reliability and control can also be concerns at the distribution system level because of the potential for rapidly changing demands, power surges or overloads when excess energy is fed back into the grid, and power oscillations between individual on-site units. These factors will tend to limit desirable PV penetration at the aistribution end of the system. 
Significant penetration by on-site PV units into a utility grio will require many thousands of individual units. It is unclear at this time whether utilities will be allowed to control the units in any fashion, whether utilities will want to control them, or whether they will be able to exercise reasonable control. The number and variety of such units present formidable control problems. Control issues will impact system security in a manner not now understood.

\section{Rate Structures}

The electricity rate structures established for backup and sellback associateo with PV units are of primary importance in determining both utility and customer economics. Such rate structures can either encourge or discourage the implementation of.PV units. The practices, policies, rationales, experiments and plans of electric utilities relative to $\mathrm{PV}$, or any solar parallel generation are of definite interest and presently unresolved.

\section{Policies}

If there is to be an acceleration of the penetration of PV units into the utility grids to achieve widespread implementation, appropriate strategies must be developed that account for varying roles and interests of customers, utilities and PV unit manufacturers, sales organizations, and maintenance services.

\section{Environment}

Environmental issues may exist relative to PV units but significant ones remain to be identified that will not be resolved in the course of improving performance, cost, safety, reliability, durability, and public acceptance.

\section{Utility Requirements for Photovoltaic Experiments}

Although it is not clear whether on-site FV units will be owned or operated entirely or partly by utilities, it is certain that widespread near term deployment of PV 
- units will require a utility interconnection. This interconnection will require utilities to develop an understanding of PV units, their operation, and the effective integration of these units with the grid. To acquire this knowledge and experience a number of experiments are to be conducted which should include utility participation. The specific utility information requirements to be met by these experiments must be examined to properly define the experimental program. This subject is covered in detail in Part 1 of this report.

.

Photovoltaic Configuration and Operations

On-site PV configurations and sizing analyses are often carried out from the point of view of the customer without taking into account the ramifications relative to the electric utility grid. If electric rates are going to be based on the cost to serve, then analyses of cost impacts on both sides of the customer/utility interface and the aggregate is required to determine correspondingly optimum configurations. Specific issues include the proper PV array size, incorporation of energy storage with the PV unit, the details of the interconnection equipment, and alternative operating modes.

\section{On-Site PV Unit Ownership}

There are a number of issues associated with the ownership of the PV units. For example, the primary responsibility for maintenance, installation and safety rnild lie with either the homeowner or the utility. Even if the primary responsibility is assigned to the homeowner the utility will retain some responsibility due to the backup/sellback interconnection to the grid. Education and training requirements for neither scenario are adequately understood.

\section{SELECTED ISSUES}

Although the various issues discussed above do not constitute an exhaustive list by any means, it is obvious that there are a great many issues requiring further arialysis. In this report several issues have been selected for assessment or review. The selection was based partially on the apparent apriori importance of the issues and 
partially on the existence of related work or capabilities at The Aerospace Corporation in PV and other new resource technologies. The number of issues was limited by the scope of the contract.

The selected issues are identified below with references to the Sections in which they are discussed.

- The requirements that utilities have for information to support their integration planning are analyzed in Part I.

- The impacts of on-site photovoltaic systems on utility generation mixes, production costs and fuel savings both with and without dedicated storage, and with and without sellback, are analyzed in Part II. This section also examines some implications for resicential rates.

- Current utility rate structure studies, practices, and plans are reviewed in Part III. 
Blank

xiv 


\section{PART I. EXPERIMENT INFORMATION REQUIREMENTS}

\subsection{INTRODUCIION}

The major contribution of the study being reported is the comparison of the informational contents of the major Photovoltaic Units (PVU) experiments with the informational requirements imposed by electric utility companies who are facing PVU aecision opportunities. The outcomes of the comparison are reported in the form of recommendations for existing experiment modifications and additions, for the formation of an information transmittal format for communication with utility companies, and for augmentation of the national PV experiment program.

The conclusions drawn in this report are preliminary, and greater clarity of the issues will develop as the utility companies themselves devote more attention to the natures and weights of the impacts associated with PVU implementation. This report is intended to be the initial formulation of a structure or context within which the questions of utility participation in PVU implementation can be studied. Such a structure should be useful to the utility companies as well as to the development program sponsors.

The study incorporates the results of an in-house deliberation by The Aerospace Corporation based on prior utility-related activities, review of the technical literature, the viewpoint and recommendations of a utility consultant, and in-depth conversations in conference with utility personnel at seven utility companies. The study is being sponsored by the Office of Electric Energy Systems of the Department of Energy (DCE-EES), and represents one of the tasks in the first phase of a project in which many questions regarding the utility viewpoints are to be examined.

\section{1 . PURPOSE}

The overall purpose of the study task is to support the utility implementation decision process through identifying and defining utility information requirements and through characterizing the information potentially available in the national experiment program as it is presently conceived by the Photovoltaic Division of DOE (DOE-PV). 
The realization of the purpose is approached through the accomplishment of the following four specific task objectives, which are illustrated in Figure 1-1:

1. Icientify the information which will be required by electric utilities in making declslons regarding the acquisition and/or grid connection of on-site photovoltaic systems.

2. Determine the extent to which the pertinent information will actually be obtained in the course of photovoltaic experiments and system demonstrations, either currently in progress or designed for future implementation.

3. Identify gaps or discrepancies between the information required and the information to be actually obtained.

4. Recommend alterations of and/or additions to the national program of experiments and demonstrations.

Achievement of these objectives supports the top level national purpose of energy sufficiency as indicated in the hierarchy of national energy program objectives in Figure 1-2, as conceived for this study. There are two fundamental barriers to achieving energy sufficiency: foreign control of petroleum resources, and environmental penalties. The presence of both of these barriers is associated with current practice in energy generation. Many alternative technologies, including PVU, have been suggested as means of overcoming these barriers. Crucial energy generation decisions are therefore faced by the nation's energy supply industry.

From the hierarchy in Figure $1-2$ it is clear that the goal of accelerated commercialization of PVU supports the top level purpose of energy sufficiency through both the conservation and the production paths. The conservation contribution arises from a fuel use displacement effect and results in a view of PVU, especially in on-site applications, as a load modification. The production contribution arises from the view of PVU as an additional energy generator which is dispatchable, especially if used in conjunction with storage. It is true that PVU generate energy, supporting the production view. On the other hand, the availability of the energy is not controllable, causing it to appear more as a negative demand, supporting the conservation view. The uncertainties associated with this duality pose unique problems. for the utility 


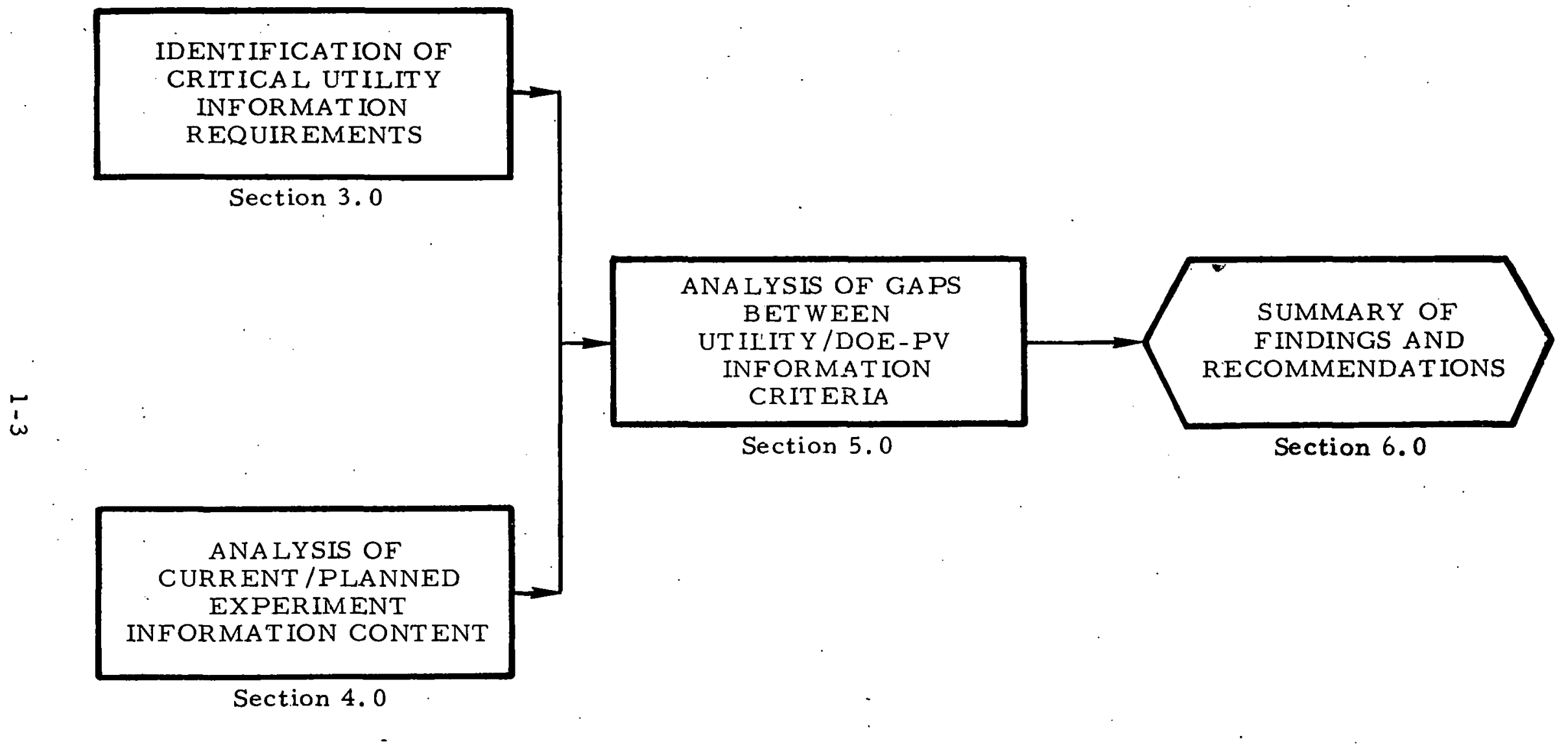

- Figure 1-1. Study Approach 


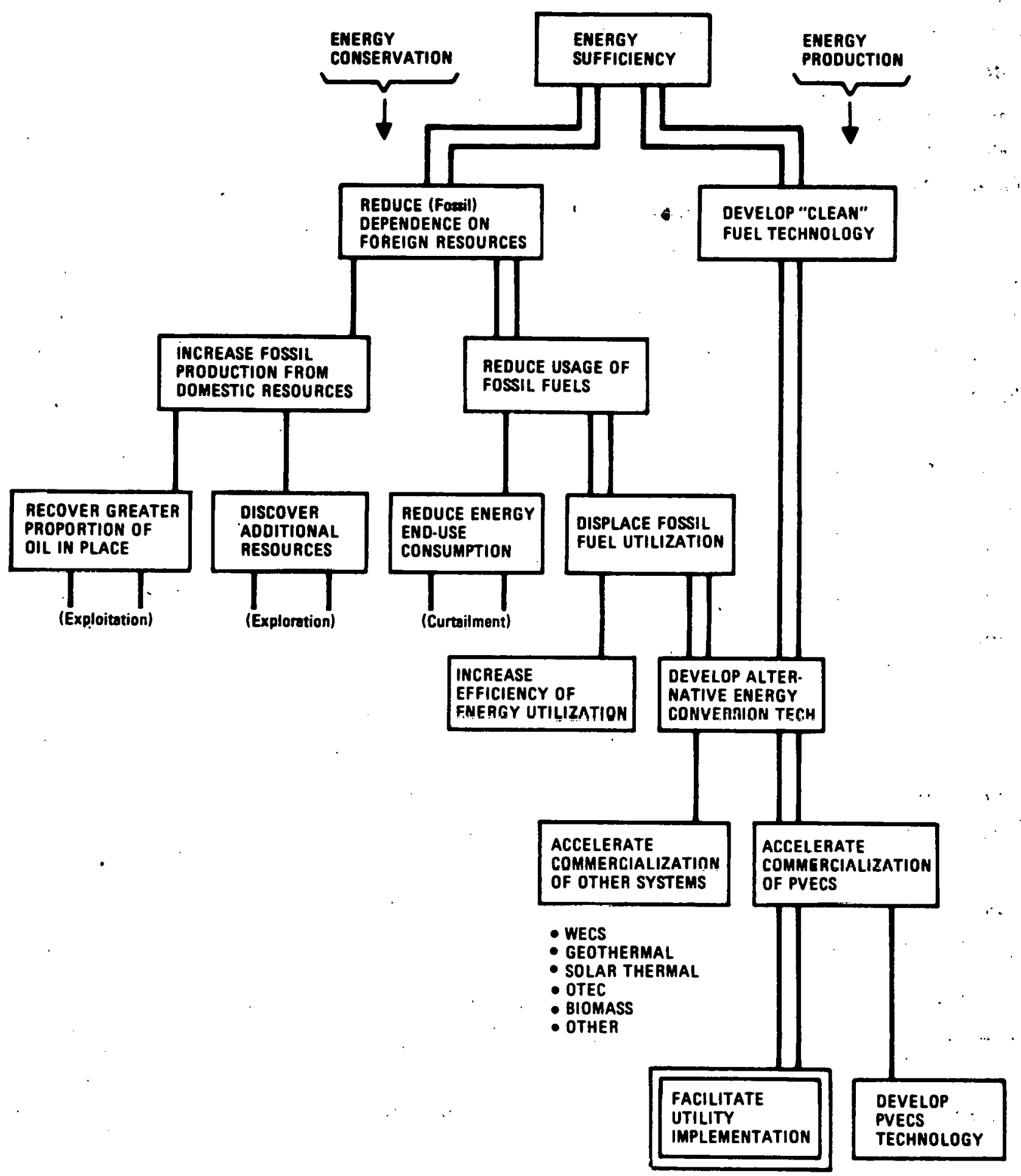

Figure 1-2. Hierarchy of "Energy Sufficiency" Supporting Objectives 
companies, affecting a variety of their internal planning and decision-making processes. To achieve certainty ano appropriateness in utility decisions, supporting information is needed, and a primary source of such information is the DOE-PV experiment program. The function of this information is to reduce the uncertainty associated with energy planning decisions, a subject more fully discusseo in Section 2.0 , Overall. Study Approach.

It is important to realize that while the commercialization goal is definitely supported by the development of PVU technology, an ongoing activity for several years, it is also necessary that the stage be set for system implementation by thoroughly satisfying the needs'of the electric utility companies within whose supply networks such systems will be built.

\subsection{SCOPE OF TASK}

In this study consideration was given to all those issues which utility companies must confront in planning and decision-making with respect to an alternative energy technology such as PVU. The ultimate goal was to analyze each information requirement issue completely by arriving at specific experimental data requirements. This has been accomplished for some of the issue areas, and not yet for others. This report is confined to the application of the four analysis activities outlined in Section 1.1 to the issues and requirements considered by the utility companies to be most crucial. Ultimately all the issues raised by utilities should be reduced to a set of detailed intormation requirements.

\subsection{BACKGROUND}

A major uncertainty being faced by modern society is the adequate supply of electrical energy to future demand. The conventionally fueled sources of electrical energy (i.e., oil, gas, and nuclear) are increasingly restricted by economic, technical, political, and social considerations. At the same time there is a strong feeling that our well-being as a people is critically dependent upon a continually increasing expenditure of energy for production, transportation, environment control, and the other concommitants of modern civilization.

Many new energy technologies have been proposed as potential solutions to the developing discrepancy between available supply and demand. Some of these 
technologies amount to innovative processes which increase the efficiencies of conventional fuel approaches. Others represent the exploitation of new fuels, such as solar, winc, geothermal, ocean thermal, etc.

The potential availability of these new technologies, especially those involving new fuels, creates an atmosphere in which new options exist and new choices must be made by the electric utility companies. It may be shortsighted to consider PVU and the other alternative technologies only within the context of existing practices (rate structures, ownership, supply networks, etc.). It may be that a whole new pattern is emerging and that actual new systems will be created, not just systems that are new because they contain some new elements.

The specific technology of photovoltaic conversion, the subject technology of this study, exhibits several characteristics requiring new approaches to utility generation planning. One of these characteristics is the uncontrollable, and occasionally unpredictable, availability of the fuel. Another is a shift to capital intensive, low operating cost economics. The significant penetration of energy demano by photovoltaics will require adjustments in the decision processes currently employed by utility companies. As previously noted, it is the overall intention of this study to provide insight into those considerations, presumed important by utilities, which affect the outcome of their decision processes.

The National Photovoltaic Program was initiated in recognition of the potential of photovoltaics to provide a portion of the nation's electric energy requirements and of the need for government action to accelerate progress in that direction. The primary goal of the program is to develop reliable low cost photovoltaic systems and to stimulate the creation of a viable commercial industry capable of marketing, producing, and distributing these systems in large-market domestic applications. The program was begun in 1971, and currently has budgeted activities planned through 1988. At present, photovoltaic arrays cost $\$ 10,000-11,000 / \mathrm{kW}$ pk $(1980 \$)$ and therefore economic use of photovoltaic systems is limited to remote, low power applications. 
In order to achieve the required improvements in system cost, market penetration, and industry capabilities to yield competitive systems in other applications, a program strategy has been developed by DOE which consists of two main elements:

1. Research and technology development activities to aid industry in reducing the cost of photovoltaic systems through improvements in production technology and design that can provide low cost photovoltaic arrays.

2. Field test and commercialization of photovoltaic systems in various applications and locations to (a) provide information on system performance and cost, (b) expand the market for photovoltaic systems through purchase of systems for field test and through stimulation of user interest in commercial applications of such systems, and (c) resolve institutional, legal, environmental, or financial issues that can impede the acceptance of photovoltaic systems. It is expected that expansion of the market for photovoltaic systems will also reduce the cost of such systems because of the incentive provided to manufacturers to automate cell and array production processes.

The National Photovoltaic Program activities are implemented for DOE by Jet Propulsion Laboratory (JPL), which is responsible for Technology Development, Systems Engineering, Tests and Applications and Commercialization; and by the Solar Energy Research Institute (SERI) which is responsible for the Advanced Kesearch and Development activities required to achieve very low collector costs.

Figure 1-3 portrays the evolutionary process in which increasing economic and social costs of conventional generation approaches on the one hand, and the development of alternative energy technologies such as the DOE-PV program on the other, are merging to create a decision opportunity. This decision opportunity must be made in the face of certain utility concerns as shown in the figure, and the utility-perceived needs associated with acidressing the opportunity are information and representation. The information needed by utilities is of a nature which would 


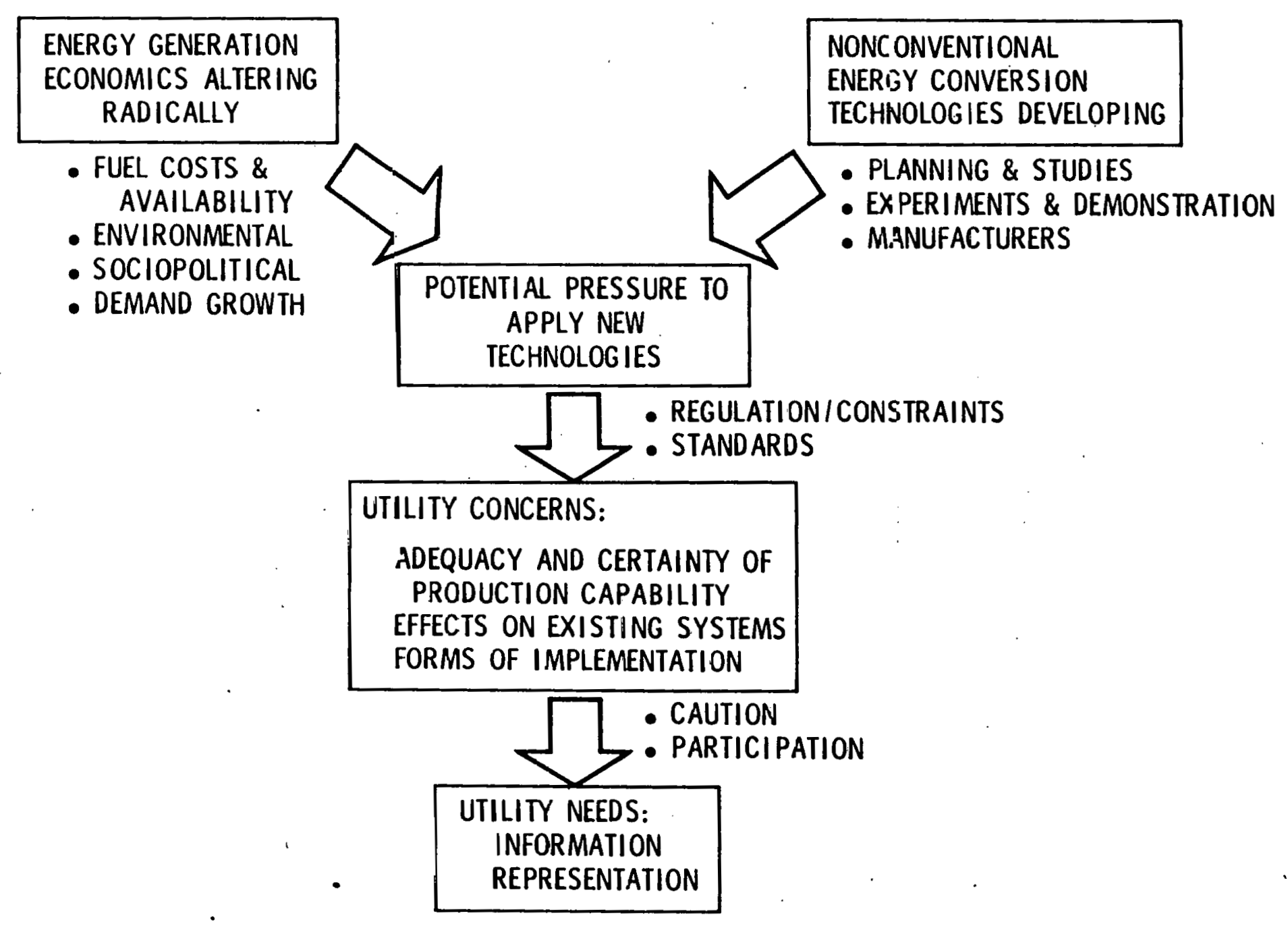

Figure 1-3. Merging of Conventional Generations and Alternate Technologies 
facilitate a decrease in the decision-making uncertainty, and representation of utility positions will allow PV program policy to more fully reflect utility requirements so that the needed information will be available.

\subsection{GUIDE TO REPORT CONTENT}

Part 1 consists of five technical sections describing the study activities. The intent of each of these sections is as follows:

- Section 2.0, Overall Study Approach -- provides an overview of the approach taken to accomplish the four task objectives aimed at supporting a utility decision-making process.

- Section 3.0, Identification of Critical Utility Information Requirements -" describes the activities taken to accomplish the first task objective and the resulting identified requirements.

- Section 4.0, Analysis of Experiment Information Content -- presents the basis for accomplishing the second task objective and resulting interpretations of existing information content.

- Section 5.0, Analysis of Gaps, between Utility/DOE-PV Information Criteria -- describes the accomplishment of the third task objective by comparing and assessing the findings of Sections 3.0 and 4.0.

- Section 6.0, Observations and Recommendations -- presents observations made in the course of the study, summarizes the areas of informational needs judged to be held critical by the utilities, and translates these into recommended courses of action from three viewpoints. 
Blank

$1-10$ 


\subsection{OVERALL STUDY APPROACH}

The primary intent of this section is to indicate the approaches selected to attain the four task objectives (see Figure $1-1$, Section 1.0) and to outline the actual courses of the work performed. However, before describing these activities, the task purposes are discussed from a simplified utility decision-making viewpoint in order to place the individual tasks in a proper perspective. The information requirement identification process used in the study is then discussed and shown to evolve out of consideration of the decisions to be faced by utility companies over the next few cecades. This process corresponds to the first task objective. The process of determining how well the identified information can be made available and suitable is the subject of the remaining three task objectives.

The following subsections provide overviews of the conceptual decision-making structure and of the approaches taken to accomplish each of the four task objectives. The subsequent major sections ( 3.0 through 6.0 ) elaborate on these approaches.

\subsection{THE DECISION FROCESS}

In confronting decisions involving uncertainty, the decision- maker typically seeks to reduce the uncertainty through the processes of reflection, modeling, and information acquisition. Figure 2-1 shows the experiment information requirements as a key element of the utility decision process. However, to acquire useful information the decision maker must identify those requirements. It is this goal, and the assurance that the requirements can be met, which form the purpose of the present study.

Figure 2-1 illustrates the information requirement support path among the several that are required for decision-making. The utility value system at the left refers to the internally held set of policies, procedures, and preferences which motivate the company's basic approach to service. This set determines what the company would like to do. The constraints system at the right refers to the set of laws, regulations, and practices imposed by authorities external to the utility company. This set determines what the company is allowed to do. Finally, the information requirements refer to the set of what the utility needs to know in order to make decisions which optimize its value 


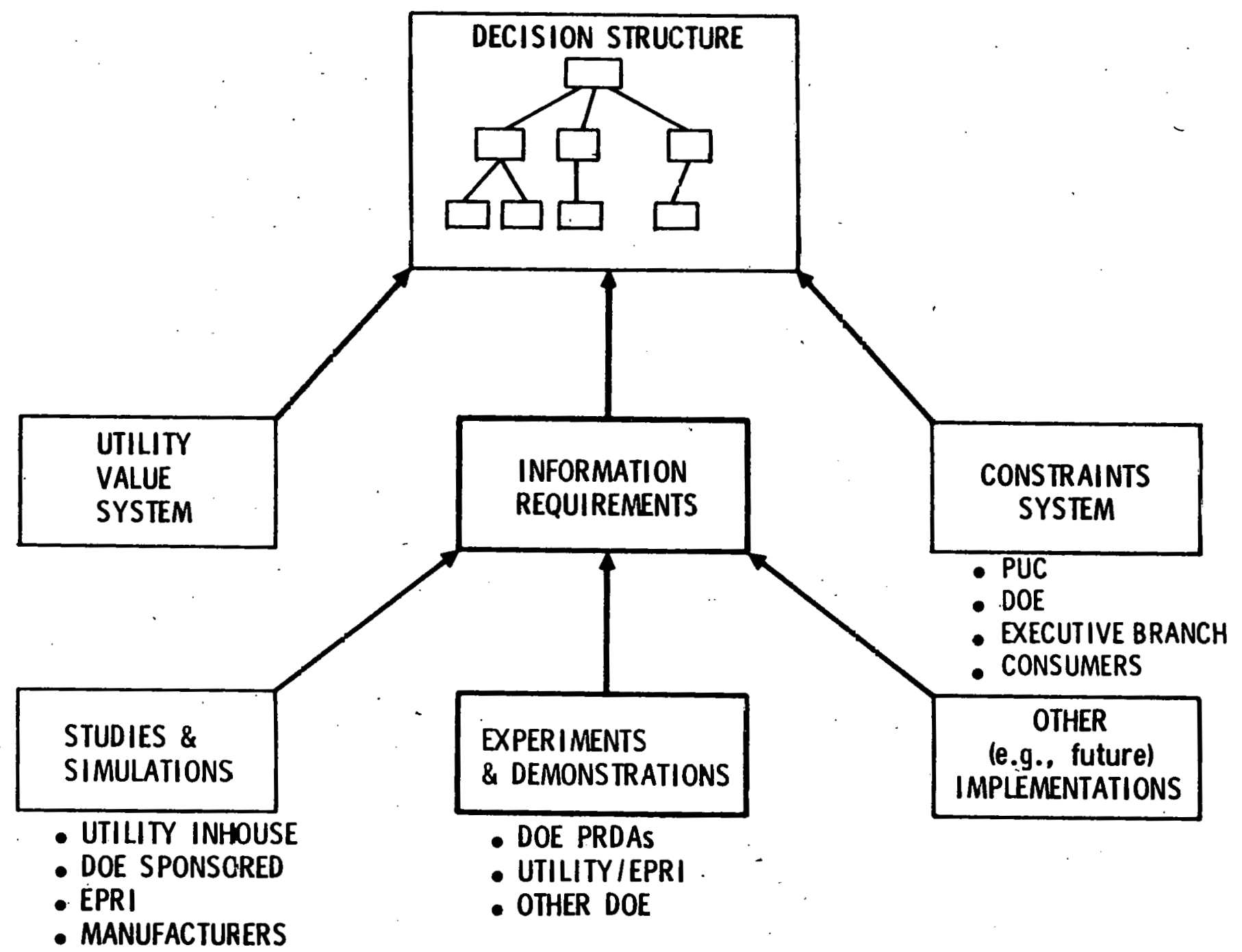

Figure 2-1. Utility Decision Process 
within the constraints. The experiments will provide the real world versions of the total information set which is shown in the figure to also include study and simulation results. Whatever the specific source, emphasis should be given to both accuracy in identifying the information and suitability in formatting it for presentation to the decision-maker.

\subsection{INFORMATION REQUIREMEN TS IDEN TIFICATION}

This first task objective promotes the identification of those issues and uncertainties held to be crucial by a utility company in determining the outcome of its decision-making deliberations. A phased approach to the discovery process was taken.

The first step was the creation of an Aerospace in-house hierarchy of utility concerns. The hierarchy was created through a process of identifying issues which, if resolved, would support resolution of an issue at the next higher level. In this sort of hierarchal analysis there is a gradual shift from broad and wide-ranging concepts near. the top of the hierarchy through more sharply defined activities in the middle to detailed requirements at the bottom. From the experiment information requirements point of view, the analysis process terminates when the branches in the hierarchy end in the definition of actual variables to be sensed, recorded, and processed in an experiment. This report provides information through middle level requirements.

The preliminary Aerospace analysis was taken into the field and exposed to several groups of utility personnel. A background briefing was presented at each utility company visited, followed by extensive round tables on the issues as appreciated by that particular utility. These utility companies then agreed to continue independently with in-house analyses of the issues using the Aerospace-derived requirements as a structure, and to communicate the results to Aerospace when available.

Finally, the Aerospace study team interpreted the discussions from a composite utility viewpoint.

\subsection{INFORMATION CONTENT OF THE EXPERIMENT INVENTORY}

The second task objective represents the first step towards determining the availability and suitability of the utility-required information within the context of the 
presently defined DOE-PV experiment program (see Section 4.0). The task activity involved assessing the scope of the information content expected from the presently planned experiments, and translating this information into a form convenient for comparison with the utility requirements.

For the utility-oriented purposes of this report, the term experiment is generally used in a broad sense to refer to any activity in which component or system operations are being monitored for data to support further development activity. Thus, an experiment may be a laboratory component test, a system demonstration project, or even a commercial plant which is instrumented for data acquisition beyono the normal requirements of plant operation. However, existing DOE-PV program terminology is used where appropriate, e.g., Commercial Readiness Demonstration Project (CRDP).

The catalog of pertinent experiments includes a variety of sponsoring agencies, utility interface types, storage approaches, and applications. A substantial group of the experiments comprise the successful Program Research and Development Analysis 35/38 Phase 1 projects. Also considered, because of their indication of utility company interest, are some of the unsuccessful PRDAs, whose status is being catalogued ana monitored by EPRI. The entire list is indicated in Section 4.0.

\subsection{GAP ANALYSIS}

The third task ubjective comprises gap analysis, which is the term used to refer to the process in which gaps or discrepancies in the informational content of experiments from the utility point of view are identified. The analysis consists of a comparison between the information which is needed and the information which will bc available and suitable as a result of the experiment process.

In addition to the point-by-point comparisons between individual information requirements and experiment outputs, there are other broad approaches to the categorization of experiments which yield insight into the completeness of the program. In one of these categorizations, experiments are classed along a temporal scale of experiment evolution. In another approach, experiments can be classed spatially or topologically in terms of their interface point within the generation, transmission, cistribution, and end-use network. Other points of comparison are the geographical 
separation between the locations of experiments and utilities, and the completeness of documentation. Utility interest is naturally higher when experiments are conducted locally and some information requirements can be met only by local experimentation. Also, a continuous flow of experiment reporting, from the planning stages to the final program results, supports the decision making process.

The temporal characterization of experiment evolution can be illustrated by the Demonstration Process Model shown in Figure 2-2. The progression in information extraction is from isolated experimental data for components (Step 1), through measurements on individual subsystems (Step 2), through subsystem integration (Step 3), and finally to full-scale demonstration of the connected system (Step 4). With the evolution in time are associated gradual increases in the reality of the experimental environment and decreases in unique or special handling activities. There is movement toward off-the-shelf component use, less specialized instrumentation, decreased special training levels for operation and maintenance personnel, and reduced levels of system surveillance. Steps 3 and 4 in the process represent reasonably long-term demonstrations that would be limited in scope (perhaps 10 years) and full-scale (perhaps 20 years), respectively. Such durations associated with the types of activities shown in the Demonstration Process Mociel would establish PVU feasibility in stages, including the critical PVU lifetime span. Each of these steps should be conducted by a minimum number (e.g., 1-3) of separate demonstrations that are well conceived and accordingly well funded by DOE.

The spatial categorization of experiments relies on the topological location of the photovoltaic unit grid connection point within the energy distribution network. This point may be at the site, in a distribution string, within the transmission subsystem, or at the generation source. Each connection point type has unique characteristics which cannot be completely evaluated, with experiments at other connection types.

Well documented transmittal of experiment information is deemed important to the utilities. A conceptual version of the required information document tree is shown in Figure 2-3, which shows a commonality of structure to that of the Demonstration Process Model. A common contextual relationship is also shown to link lower level experiment information to the highest level demonstration. Documentation to be 


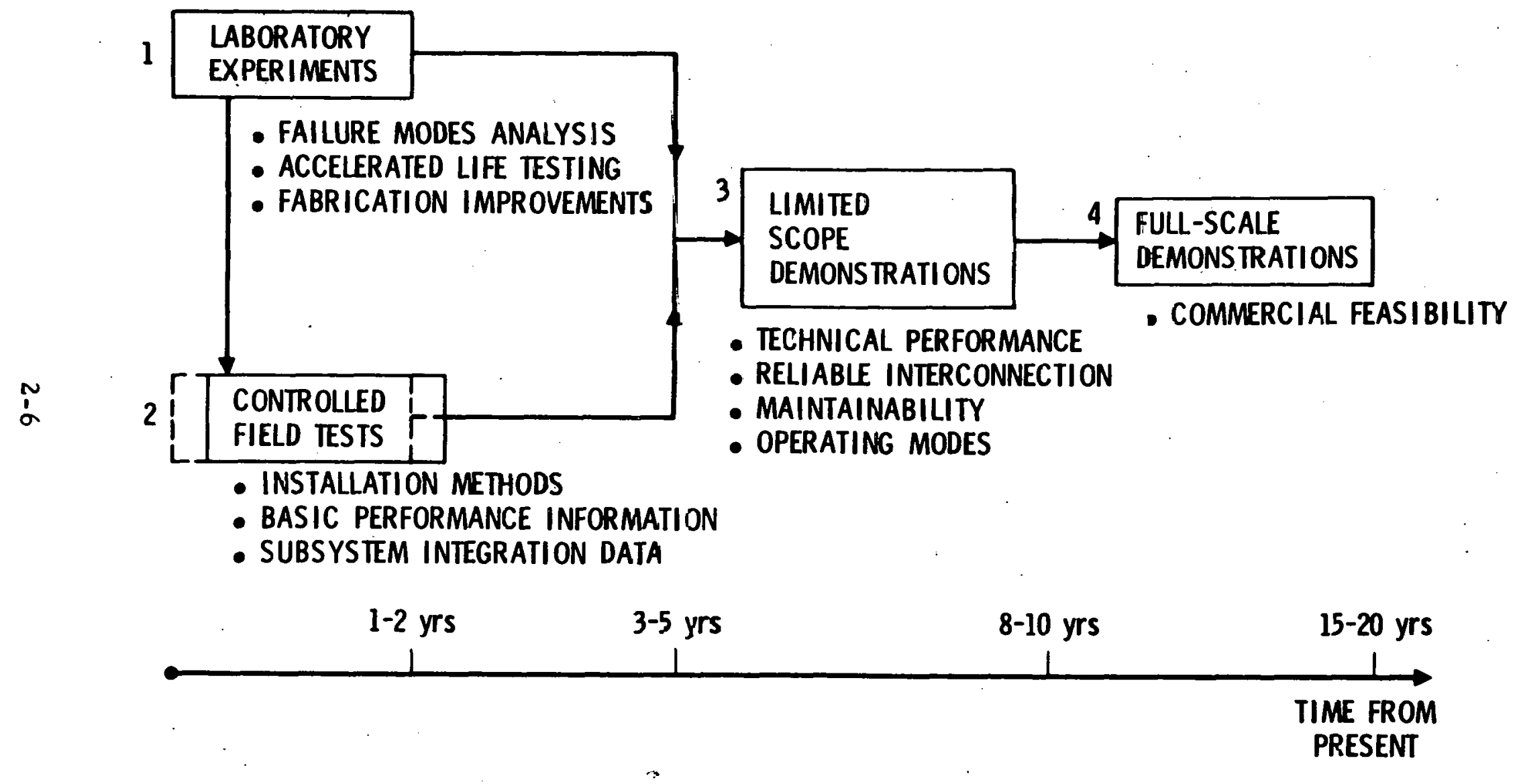

Figure 2-2. The Demonstration Process Model 


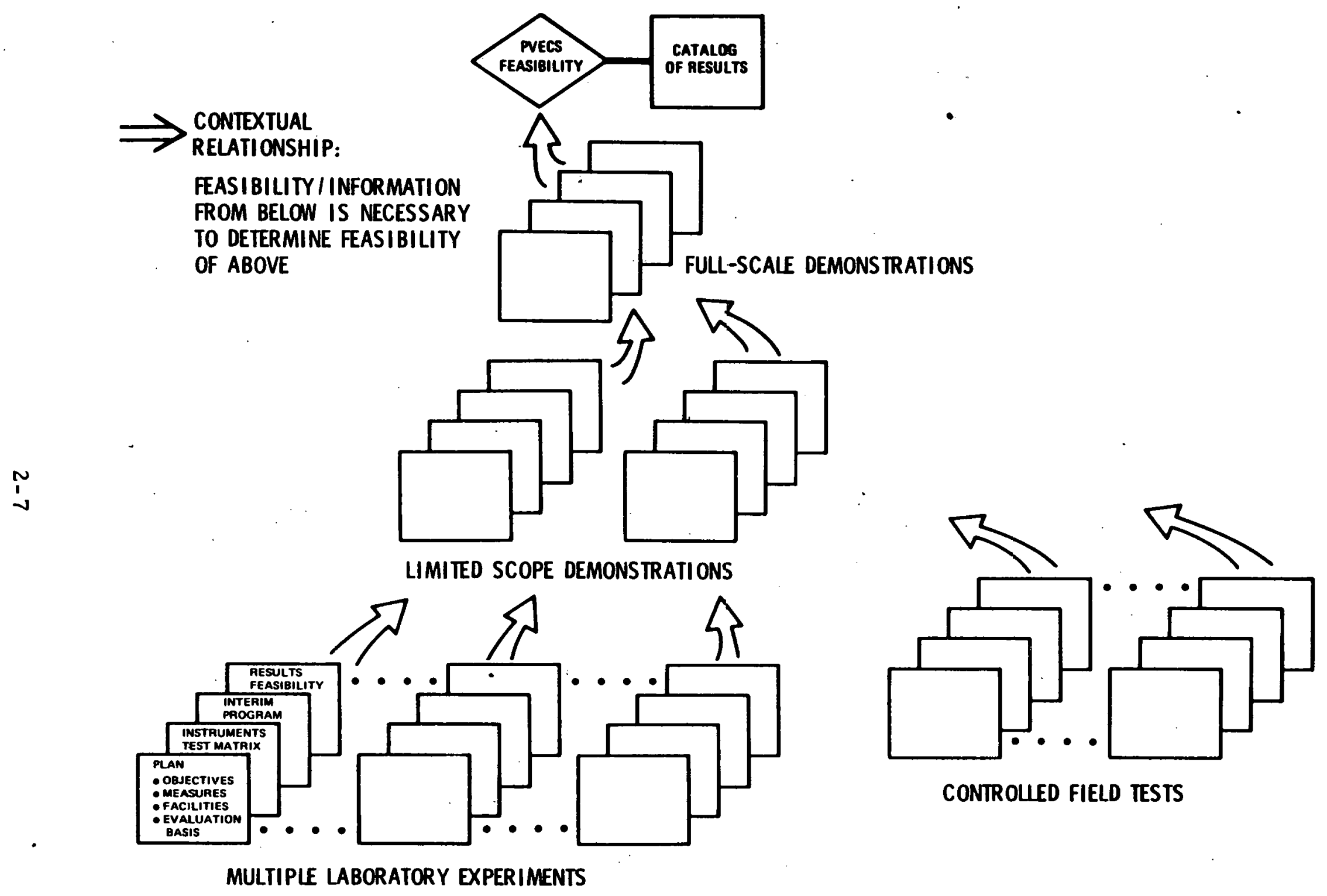

Figure 2-3. Conceptual Information Document Tree 
provided at each level includes plans, instrumentation and test matrices, interim progress reports, and final reports that provide adequate completion and/or feasibility of that particular experiment.

\subsection{FINDINGS AND RECOMMENDATIONS CATEGORIES}

The fourth task objective involves recommendations based on study findings of the information requirement iaentification process. The recommendations advanced as results of the investigation are of three distinct types. The first adheres strictly to the purpose of the study and suggests modifications or additions to the photovoltaic experiments in the current catalog. The second type of recommendation addresses the form and function of information transmittal to the utility company for its decision-making activities. Finally, the third type of recommendation addresses some of the broader issues which surfaced in the Aerospace contacts with the utility companies, and which can be described as policy recommendations. 


\subsection{IDENTIFICATION OF CRITICAL UTILITY INFÖORMATION REQUIRENIENTS}

This section describes the activities and accomplishments to date associated with the first task objective: to identify the information required by electric utilities for them to make decisions regarding acquisition/grid-connection of photovoltaic systems (PVU). The emphasis was on information requirements for PVU experiments, and the activities involved the combination of Aerospace experience and analysis, coordination with a utility consultant, and direct communication with appropriate utility personnel from the solar belt to translate the requirements into a form suitable for comparison with current/planned PVU experiments. A basic intent was to provide a structural context for a variety of utility needs, including:

- Utility practices, e.g., generation capacity planning, rate structures, operational policies.

- Utility positions regarding their representation ano participation in PVU experiments.

- Utility interests from viewpoints of spatial (topological) and temporal (experiment evolution) considerations.

- Immediacy of experiment impact açcording to geographic separation.

- Characterization of experiment information regarding type; nature, format, means, and time phasing of transmittal to utilities.

Description of the activities and accomplishments is presented in three steps. First an overview of the approach taken to accomplish this objective is given in flowchart form, and the intent of each block in the flowchart is discussed to provide a basis for the subsequent analyses and categorizations. Next, an assessment is made to interpret the utility messages and philosophies obtained auring the utility discovery visits. Finally, the interpretations are summarized in critical groups for comparison with the current and planned experiments. 


\subsection{UTILITY INFORMATION REQUIREMENTS IDEN TIFICATION}

The flow of activities adopted to identify the critical utility information requirements is shown in Figure 3-1. Solid lines and boxes pertain to those activities conducted to date, and slashed lines correspond to work in progress that will be reported in subsequent documentation.

Activity was initiated by Aerospace with an in-house analysis based on their prior PVU experience and previous utility interactions. The prior information base was expanded with a literature search, and by conducting a preliminary utility field visit with Southern California Edison Company (SCE) personnel. The expanded set of information requirements was categorized according to five major (and one supplemental) PVU questions facing utility decision-makers, as shown in Figure 3-2. The five questions span the utility/PVU issue areas of:
- Grid integration
- Economic impact
- PVU technology
- Social/institutional
- Equipment supply

Each of these questions was further refined in terms of subquestions pertinent to the utilities. An example of one such subdivision is shown in Figure 3-3, and the entire set is part of Appendix $B$, which is discussed further under utility field visits.

The seven utility field visits accomplished to date are indicated in Table 3-1, which includes the early coordination meeting with SCE. Aerospace structured the visits as information brainstorming sessions posing Aerospace as an effective communication channel to DOE from the utilities. Figures 3-2 and 3-3 are part of the briefing package contained in Appendices $A$ and $B$, which were presented to the utilities in two parts: an overview subset (Appendix A) given the day of the visit, and detailed requirements categories (Appendix B) left for the utilities to carefully examine and improve. The sets in Appendices $A$ and $B$ are the actual hand-lettered versions which were intentionally informal to encourage the utility personnel to incorporate their own 


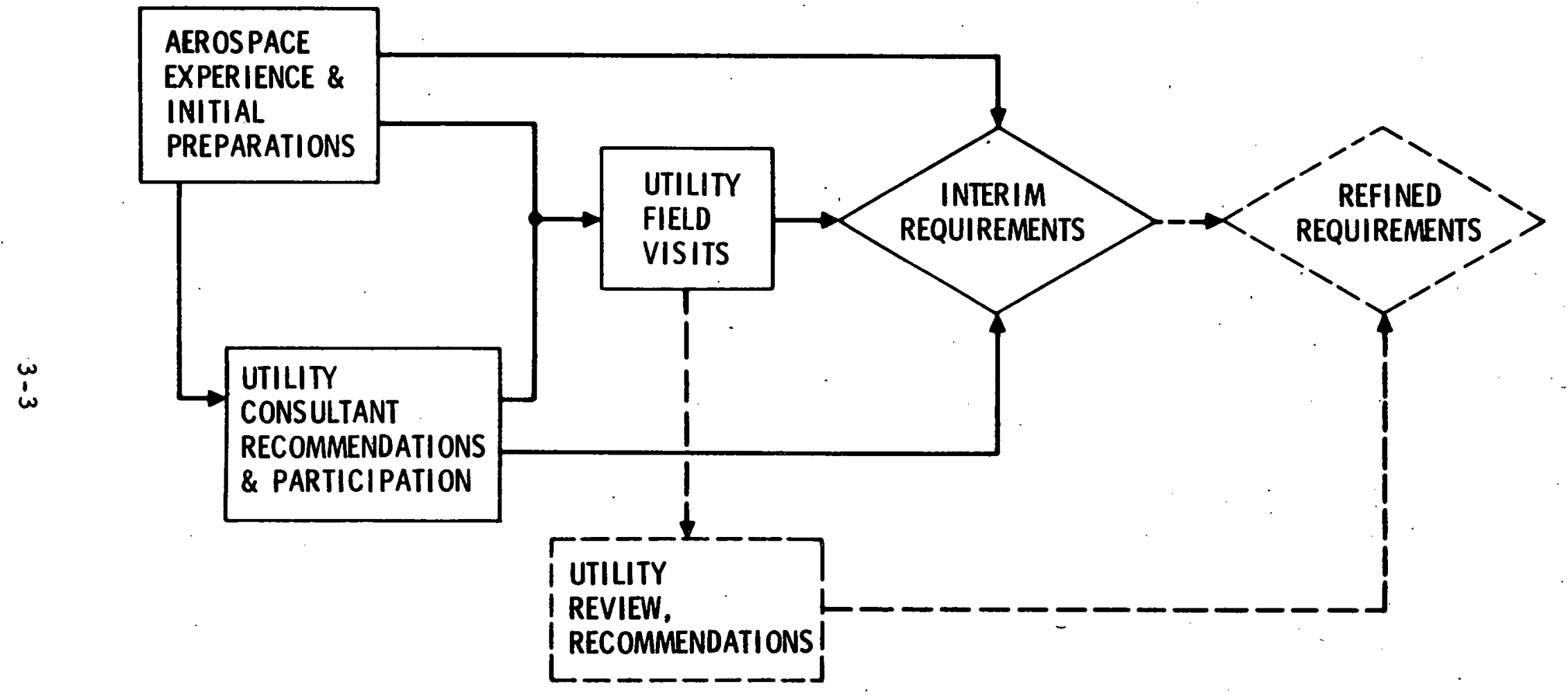

Figure 3-1. Approach to Identify Utility Information Requirements 


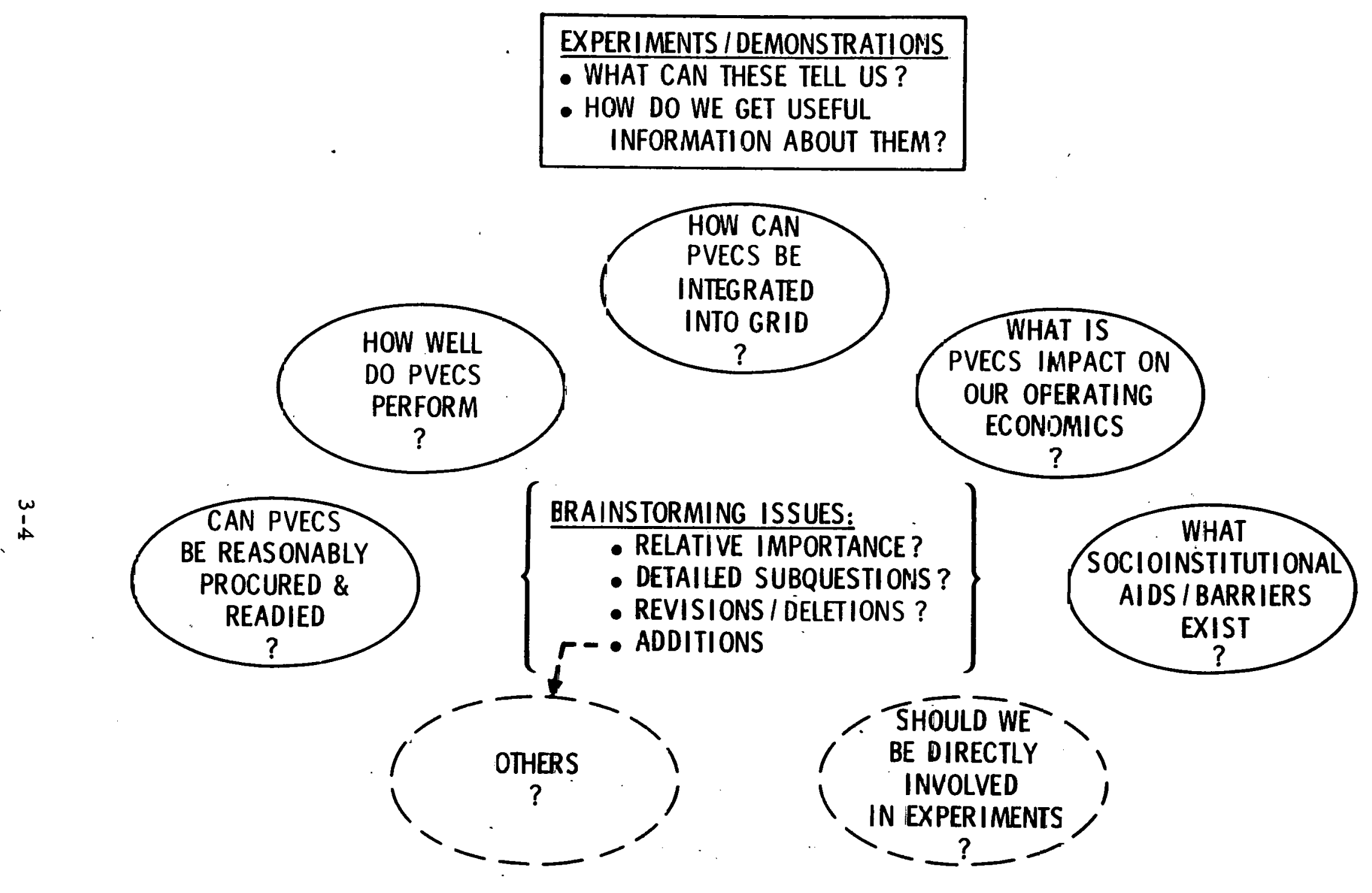

Figure 3-2. Eontemplated Informatian Categories 


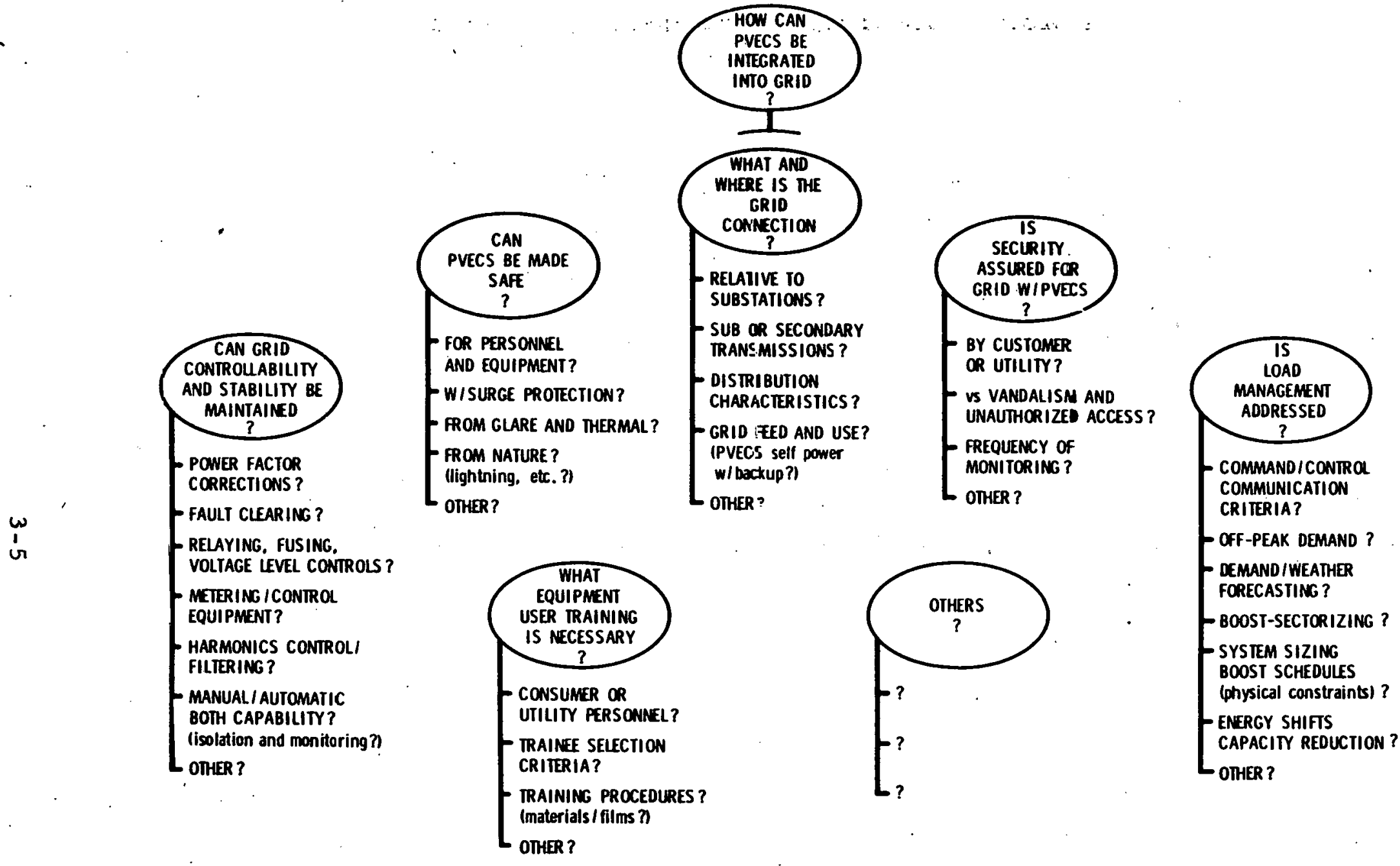

Figure 3-3. Contemplated Sub-Questions: Grid Integration 
Table 3-1. Utility Field Visits

\begin{tabular}{|l|r|}
\hline \multicolumn{1}{|c|}{ Accomplished to Date } \\
\hline $\begin{array}{l}\text { Southern California Edison } \\
\text { (SCE) }\end{array}$ & $8-10-79$ \\
- Los Angeles Department \\
of Water and Power (LADWP) \\
- Arizona Public Service \\
$\begin{array}{l}\text { (APS) } \\
\text { Public Service of New }\end{array}$ & $10-31-79$ \\
$\begin{array}{l}\text { Mexico (PSNM) } \\
\text { Florida Power and Light } \\
\text { (FPL) }\end{array}$ & $11-01-79$ \\
- Alabama Power Company \\
$\begin{array}{l}\text { (ATC) } \\
\text { Tennessee Valley } \\
\text { Authority (TVA) }\end{array}$ & $11-07-79$ \\
\hline
\end{tabular}


viewpoints or to at least make improvements. All utilities visited agreed to review the vugraph package of Appendix $B$ and make corresponding recommendations regarding their viewpoints on PVU experiment requirements. Those returns will be incorporated in future reports.

The preliminary requirements identified to date are given in the ensuing subsections of this chapter. They are based on the messages obtained from the technical interchanges accomplished during each field visit, on the utility consultant's recommenciations, and on the Aerospace experience and literature search. A refined set of information requirements will be subsequently developea after all utility returns have been received and analyzed by Aerospace.

\subsection{UTILITY FIELD VISITS MESSAGE AND IRANSLATION}

Some basic messages regarding PVU implementation in utility grids were received by Aerospace during the utility field visits and these are summarized next. Subsequently these messages are interpreted and combined with prior Aerospace ano utility consultant findings to yield a hierarchy of near-term information requirements.

A composite interpretation of the utility fielo visits to date is presented in Table 3-2. The table is intended to represent a consensus of utility opinion, although some variations of emphasis naturally occurred. This report will be circulated to the participating utilities for their review comments which will be incorforated in the subsequent reports. An interesting sidelight is that the utilities appeared enthusiastically interested in participating, since they felt the activities served to better prepare them for for thcoming similar investigations of other new energy source evaluations. Miany utility-generated information requirements woulc be common to any such investigations. The interpretations in Table 3-2 also serve as a basic comparison between utility and DOE-PV philosophies summarized in Section 5.0.

Table 3-3 represents the results of translating the utility messages and the Appendix $B$ requirement breakdown into a set of prioritized principal utility concerns that should be adidressed in the near term. The prioritization for near-term consideration represents a far more difficult task than merely listing the major and 
Table 3-2. Key Messages from the Utility Field Visits

\section{TECHNICAL ISSUES}

- Generation Scheduling: The introduction of significant photovoltaic energy portends modifications of the utility load profiles and corresponding impacts on their short-term (24 hour) generation scheduling. Utilities are uncertain about how to perform scheduling to accommodate this additional source of uncertainty.

- Loao Mianagement: The additional source of uncertainty in generation scheciuling representeo by photovoltaic is stimulating interest in demand control options such as storage and load management.

- Sellback: Sellback of excess energy contains unresolved issues. The utility value of the various options needs to be addressed.

- System Ownership: The issue of who owns and who controls PVU is not receiving proper attention. This encompasses a wide scope of concerns, incluoing operation and maintenance, associated basic training, warranties, and operator and repairman safety.

- Grid Security: Uncertainty exists concerning what will happen to grid control and stability upon integration of PVU.

- Personnel Safety: There is strong concern for the safety of personnel, both utility service people and site owners or.tenants.

\section{EXPERIMENT DESIGN ISSUES}

- Experiment Flexibility: A degree of flexibility must be built into the PVU experiments. This implies modularity of both components and complete subsystems to incorporate new technology breakthroughs that occur after experiment initiation.

- Real World Issues: Real world issues must be addressed. These include the day-by-day problems of customer complaints and service resolution, and those of environmental changes and customer load shifts. Sufficiently high power levels must be considerea at each experiment evolutionary stage to examine utility impacts.

\section{UTILITY ISSUES}

- PVU Impact in Remote Future: A PVU era will arrive in the distant future, if at all, and has no impact on currently planned utility expansion commitments (requiring at least 20 years lead time). 
Table 3-2. Key Messages from the Utility Field Visits (Cont.)

.

- Utility Participation: The utilities are willing to participate in an active capacity in meaningful, well conceived, key PVU experiments, especially if they are geographically local. They have a need and desire for the information, and they believe they have something to offer in the process. For experiments conducted in distant geographic locations, they are willing to assign monitors and 'consultants when meaningful.

- Utility Information Neecis: Utility incustry information needs are not being satisfactorily addressed in the existing demonstration program, and they should be factored into the program immediately. DOE should plan for providing data directly usable by the utilities rather than presenting general data subject to special intcrpretations by various users.

\section{DOE PROGRAM ISSUES}

- Caution Regarding DOE: An underlying caution exists among the non-federal utilities regarcing DOE. This seems to be due to a utility impression of the lack of realism in an accelerating PVU program that is being conducted with insufficient input from the utility community. Also a factor is the perception of transcience of DOE personnel.

- PVU Program Planning: A need exists for a well structured top down PVU program. Utilities generally feel there are insufficient logic, planning, coordination, and prioritization for the existing PVU demonstration program. This is viewed by them as a weakness that should be addressed immediately.

- PVU Program Communication: Appropriate documentation of all elements of the PVU program must be made available to utilities. This includes plans containing objectives and measures, interim progress reports and findings, and a catalog of program results translated into a utility basis.

- Commercialization Demonstration Overcompressed: Potential commercialization should be approached by way of an evolution of a few well conceived experiments with either success or failure of commercial PVU being an acceptable outcome. Basic component and subsystem data should be gathered and evaluated before a full-scale demonstration is undertaken. PVU lifetime/reliability must be established prior to commercialization and accelerated lifetime tests can provide only a partial answer.

- Central Distributed System Emphasis: The central vis-a-vis distributed PVU issue is unresolved to the utilities satisfaction. Therefore, that choice should not yet be made, and the answer should also be achieved in conjunction with a minimum number of well conceived and realistic experiments. Experiments designed to study central station issues should be implemented. 


\section{Table 3-3. Principal Near-Term Utility Concerns}

\begin{tabular}{|c|c|c|c|}
\hline Rank & Major Is gue & Sub-Is gues in Priority & Specific Concerns (Measurable/Calculable) \\
\hline 1 & $\begin{array}{l}\text { Integration } \\
\text { Into } \\
\text { Grid }\end{array}$ & $\begin{array}{l}\text { - Central vs. Distributed } \\
\text { - Interconnecting Equipment } \\
\text { - Safety/Training for Operation/Repair } \\
\text { - Security/Reliability of Operation } \\
\text { - Load Management Capabilitiey } \\
\text { - Control \& Stablc Operating Capabilities } \\
\text { - Demand Level vs. Capacity }\end{array}$ & $\begin{array}{l}\text { - Harmonics, Filter Requirements } \\
\text { - Optinum Voltage/Curycht Slzes } \\
\text { - Fault Clearing Methods } \\
\text { - Repair Requirements } \\
\text { - Training for O\&M } \\
\text { - PVU/Storage Sizing \& Scheduling } \\
\text { - Relaying. Fusing, Voltage Control } \\
\text { Coordination } \\
\text { - Metering and Control Requirements } \\
\text { - Transmission \& Distyibution Syatom } \\
\text { Configurations or Changes }\end{array}$ \\
\hline 2 & $\begin{array}{l}\text { Impact on } \\
\text { Operations } \\
\quad \text { and } \\
\text { Economics }\end{array}$ & $\begin{array}{l}\text { - Capital and Operating Costs } \\
\text { Economic Impacts } \\
\text { Ownership/Control } \\
\text { O\&M. Manpower and Costs } \\
\text { Special Economic Considerations }\end{array}$ & $\begin{array}{l}\text { - Equipment Costs } \\
\text { - Spare Parts Needs } \\
\text { - Production Costs } \\
\text { - Capacity Deferrals/Credits } \\
\text { - Utility/Customer Aggregate Economics } \\
\text { (Energy Balance) } \\
\text { - Tax Credits and Incentives } \\
\text { - Rate Changes Before and After PVU }\end{array}$ \\
\hline 3 & $\begin{array}{c}\text { PVU } \\
\text { Performance }\end{array}$ & $\begin{array}{l}\text { - Output Power \& Energy Capabilities } \\
\text { Operating Modes/ Duty Cycle } \\
\text { - Lifetime and Reliability } \\
\text { - Onverter Performance } \\
\text { - Other Design Congiderations }\end{array}$ & $\begin{array}{l}\text { - Optimum Size vs. Grid Demand/Energy } \\
\text { - Optimum PVU Size (Based on Equipment.) } \\
\text { - Central Station vo. Distributed Operating } \\
\text { Modes } \\
\text { - Normal/Startup } \\
\text { - Etuergincy/Ghutdown } \\
\text { - Steady State/Transient } \\
\text { - Demand Profiles With and Without PVU } \\
\text { - PVU Equipment Limilarions/Conetraints } \\
\text { - Inverter AC Quality } \\
\text { - Inverter as a Load } \\
\text { - Failures, Rates/Modes } \\
\text { - Service Calls and Resolutions } \\
\text { - Degradation Rates/Mechanisms }\end{array}$ \\
\hline 4 & Other & $\begin{array}{l}\text { - Environmental/Legal Constraints } \\
\text { - Sellback Power } \\
\text { - PVU Industry Status } \\
\text { - Preferred Systems } \\
\text { - Legal/Jurisdiction } \\
\text { - Achieved Rate of Penetration } \\
\text { - Institutional Relationships } \\
\text { - }\end{array}$ & $\begin{array}{l}\text { - Site Requirements } \\
\text { - Physical Impacts/Siting Limitations } \\
\text { - Legal Point of Transfer of Ownership/ } \\
\text { Respongibility } \\
\text { - Judgements Regarding Mandatory Power } \\
\text { Supply and Acceptance } \\
\text { - Metering of Two-way Energy Flow } \\
\text { - Standards. Codes, Permits } \\
\text { - Specifications. Production Capabilities, } \\
\text { Equipment Selection, Acceptance } \\
\text { Procedures } \\
\text { - Acceptable Suppliers } \\
\text { - Interfaces With Federal and Local } \\
\text { Governments } \\
\text { - Labor Union/Skills Interfaces/Constraints }\end{array}$ \\
\hline
\end{tabular}


minor issues (potential problems) given in Appendix B. Therefore, the table provides one attempt to address the issues of most importance to the utilities in the immediate future.

The rankings in Table 3-3 indicate that grid integration issues are of paramount importance in utility considerations, followed closely by economics and technical performance. However a temporal or time-phased perspective of these issues, as indicated in Section 4.0, inoicates a degree of reversal. Experiments addressing technical performance need to be accomplished first in orcier to answer some of the critical grid integration questions. Furthermore, economic verification will depend on hard cost data, which will come out of actual experience. Highllghts selected from the other major information requirement categories in Appendix B are grouped into the final category of Table 3-3 which would be expected to be accomplished later in the "near-term" grouping. Each of the ranked major issues is fur ther defined in Table 3-3 in terms of priority sub-issues and specific concerns that are rieasurable or calculable.

\subsection{CRUCIAL AREAS OF INFORMATION}

This section summarizes specific areas in which utilities have incicated a crucial need for PVU experiment information.

- Safety of Personnel

Identification of hazard areas and activities Techniques for system disconnection, interlocks, etc. Training levels required for safety in maintenance Structural and support loading measurement, environment

- System Protection

PVU impacts on power quality, network stability Power concitioner performance effects

Tests of control equipment Identification of network control and switching operation impacts Synchronization experience

- Load Management

Hardware performance characteristics

Load management logic and implementation

Identification of appropriate loads

Load management accommodation of PV impacts 
- Economics

System ano installation cost data for extrapolation Maintenance and other operating cost information

Elasticity of PV demand with sellback rates

Preferential rate structures

Hidden costs due to grid integration

Local perturbations (environments, costs, etc.)

Implementation impacts on utility financial well-being

- Customer Attitudes

Maintain logs documenting service calls and resolutions

Tolerance to resident system

Aesthetic considerations

1

- System Lifetime/Reliability

Long-term data

Failure modes and intervals

Performance treno analyses - deterioriation

Warranties

- Capacity Credit

Loss of load measurements

- Legal/Jurisdictional

Liability for system damage and bodily injury

Ownership

Insurability

Service access

Rate base

- Market

Rates of penetration

Rate structure tolerance

Incentive efficacy

- Preferred Systems

Qualification procedures for suppliers, installers, servicers Degree of public reliance on local utility recommendations Optimum configurations (flat, concentrator, storage, etc.) Availability

- Demanó Profile Data

Periodic sampling for utility analyses 
- Grid Connection

Methods and designs for connection

Required network modifications

Equipment problems

- Training

Methods and materials

Minimum levels acceptable

- Miaintenance

Technical system performance as function of maintenance levels Miaintenance requirements on systems

Recurring fault areas

In supplement to these crucial information requirements areas, the specific utility concerns delineated in Table 3-3 should also be addressed by the experiment program. 
Blank

$$
3-14
$$




\subsection{ANALYSIS OF EXPERINIENT INFORMATION CONTENT}

An analysis of the information flow within the DOE-PV experiment program is necessary to accomplish the second task objective: to determine the extent to which pertinent information will actually be obtained from current and planned photovoltaic experiments and demonstrations. The task activities involved assessing the scope of the experiment information contents and developing these into a suitable form for comparison with the utility needs considered in Section 3.0. The DOE-PV experiments have placed a reasonably high degree of emphasis on information requirements, but at present there is only a partial implementation of the corresponding information flow. Therefore, this section presents an interpretation of the current status from an overall program viewpoint without addressing the specific details of each experiment.

The accomplishment of the information flow analysis is presented in three steps. First, an overview is prèsented of the basis on which existing information contents were determined and the catalog of experiments involved is displayed. Second, the information flow evolution is discussed and separated into a hierarchy for utilities, as currently assigned by DOE. Finally, the categories of information content are reviewed in summary form, leading to the comparison with utility needs in Section 5.0.

\subsection{INFORMATION ANALYSIS BASIS AND EXPERIMENT CATALOG}

Analysis of the overall DOE-PV information flow was accomplished by cooroination with DOE and the PV Data Systems Task Team, which is addressing the overall experiment catalog for the DOE-PV Test and Applications (T\&A) area. Discussions follow regarding the basis of that coordination, and the characterizations of the various experiments and demonstrations involved.

Nuch of the data contained in this section were derived as a result of Aerospace's role as a field organization supporting the PV Data System Task Team headed by JPL. That role is described in Figure 4-1, which indicates the overall DOE-PV approach for T\&A activities, and involves generating user requirements that will be incorporated in both data requirements and data system functional requirements corresponding to a data system plan. To date, only the user require- 


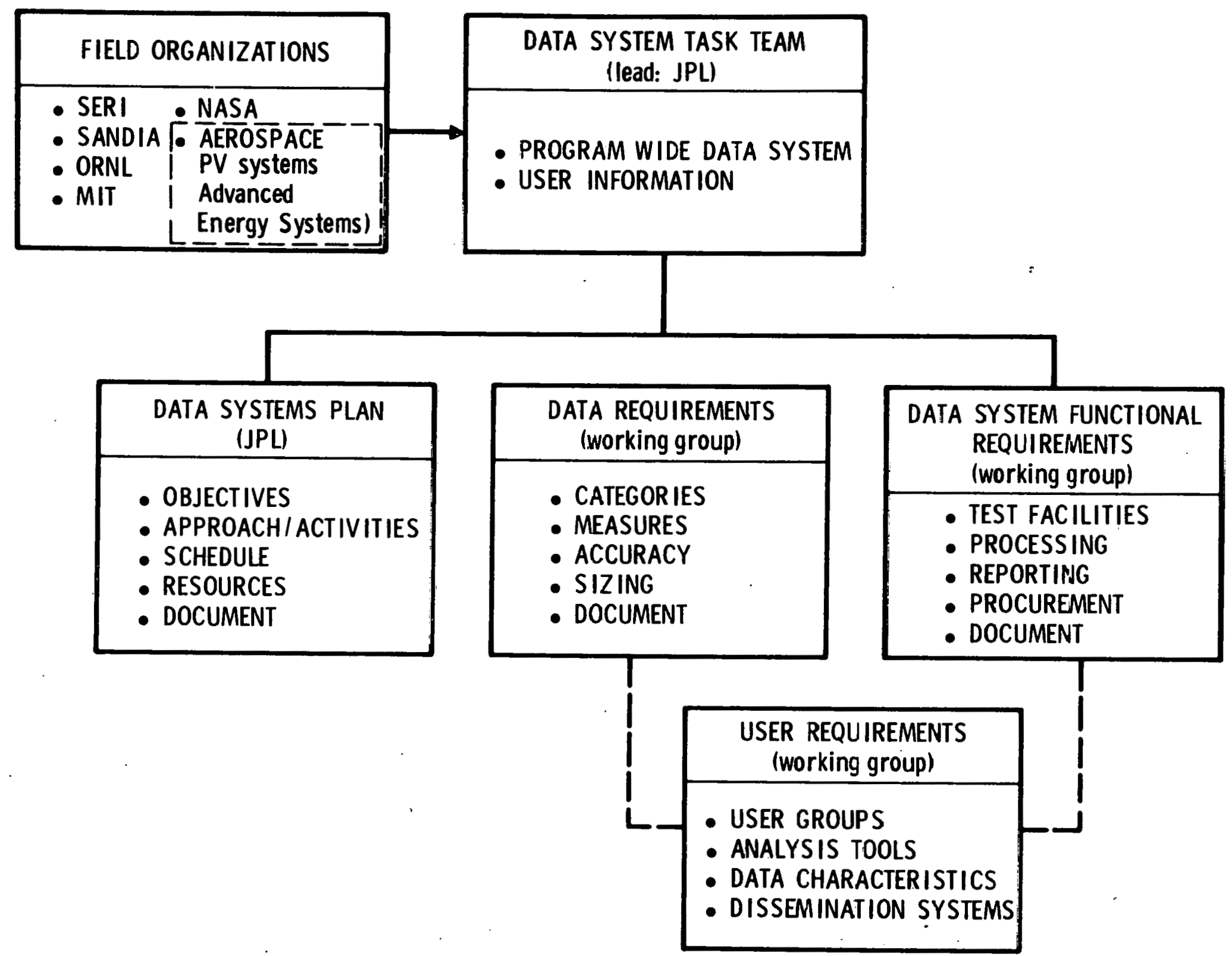

Figure 4-1. [IOE-PV Data Systems Requirements 
ments working group has made its results available, and Aerospace was responsible for the central station contributions. This work is an extension of activities involving PVU mission analysis ano Program Research and Development Analysis (PRDA) review and evaluation, which provided a data base of DOE-PV/EES multi-year program plans and selected PRDA's documentation; all of which contributed to the information contents discussed.

Tables 4-1 through 4-3 identify the experiments considered to date. Generalized characterizations are presented for the experiments to provide insight into their magnitude and scope, and more details are readily available in the Aerospace data bank. Table 4-1 summarizes the five concentrator and four flat panel experiments that were selected as finalists for PRDA 35 and PRDA 38 Phase 3 by DOE. Table 4-2 provides similar summary data for some individual system level projects pertaining to Intermediate Load Centers (ILCs).

\subsection{EXPERIMENT INFORMATION EVOLUTION AND INTERPRETATION}

- Data requirements have been assigned a reasonably high priority by DOE since early in the DOE-PV program, and currently are being investigated to assign priorities for a wide variety of users of the 'T\&A system data. Available descriptive literature was reviewed regarding test and evaluation requirements for pertinent component technology development, Initial System Evaluation Experiments (ISEEs), and System Keaciness Experiments (SREs); examples of this review follow. Material aefining data requirements for Commercial Readiness Demonstration Projects (CRDPs) was not available for review.

DOE has built provisions for data requirements into the various statements of work for PV component technology development and PRDA Phase 1 activities. Figure 4-2 is a flow diagram example excerpted from Sandia's PV concentrator test and evaluation plan, which was also incorporated in the PRDA-35 Phase 1 contract initiation meeting document of June 1, 1978. The figure indicates a planned merger of data handling and analysis for materials and components testing as well as full scale collector tests. DOE has attempted through such provisions to accomplish a uniform set of data requirements and data collection techniques applicable through the Phase I activities. 
Table 4-1. DOE PRDA 35/38 Selected Experimerts

\begin{tabular}{|c|c|c|c|c|c|}
\hline & $\begin{array}{l}\text { EXPERIMENT } \\
\text { (application) }\end{array}$ & LOCATIION, OWNER & $\begin{array}{l}\text { GRID } \\
\text { INTERACTION } \\
\end{array}$ & $\begin{array}{l}\text { TIME } \\
\text { FRAME } \\
\end{array}$ & $\begin{array}{l}\text { KW } \\
\text { LEVEL }\end{array}$ \\
\hline & - CONCENTRATORS: & & & & \\
\hline & HOSPITAL & KAUAI, HAWAII & PARALLEL & $1980 / 81$ & 85 \\
\hline & AIRPORT TERMINAL & PHOENIX, ARIZCINA. & $\begin{array}{l}\text { PARALLEL, UTI_ITY ONLY, } \\
\text { PV ONLY }\end{array}$ & & 280 \\
\hline & OFFICE BUILDING & ALBUQUERQUE, AEW MEXICO & PARALLEL & . & 47 \\
\hline & $\begin{array}{l}\text { AIRPORT UTILITY } \\
\text { PLANT }\end{array}$ & FORT WORTH, TE:XAS & $\begin{array}{l}\text { PARALLEL } \\
\text { SELLBACK PRDHIBITED }\end{array}$ & 1 & 28 \\
\hline & SEAWORLD & ORLANDO, FLORIDA & $\begin{array}{l}\text { PARALLEL, } \\
\text { SELLBACK UNL IKELYY }\end{array}$ & $1980 / 81$ & 110 \\
\hline & - Flat PANEL: & & & & \\
\hline & SHOPPING CENTER & LOVINETON, NEW MEXICO & PARALLEL & $1980 / 81$ & 150 \\
\hline & POWER SUPPLY & EL PASO, TEXAS & PARALLEL & & 18 \\
\hline & SCIENCE BUILDING & OKLAHOMA CITY. OKLAHOMA & PARALLEL PLUS SELLBACK & & 150 \\
\hline & HIGH SCHOOL & BEVERLY, MASS & PARALLEL PLUS SBLBACK & $1980 / 81$. & 146 \\
\hline
\end{tabular}


Table 4-2. System Level, Photovoltaic Projects

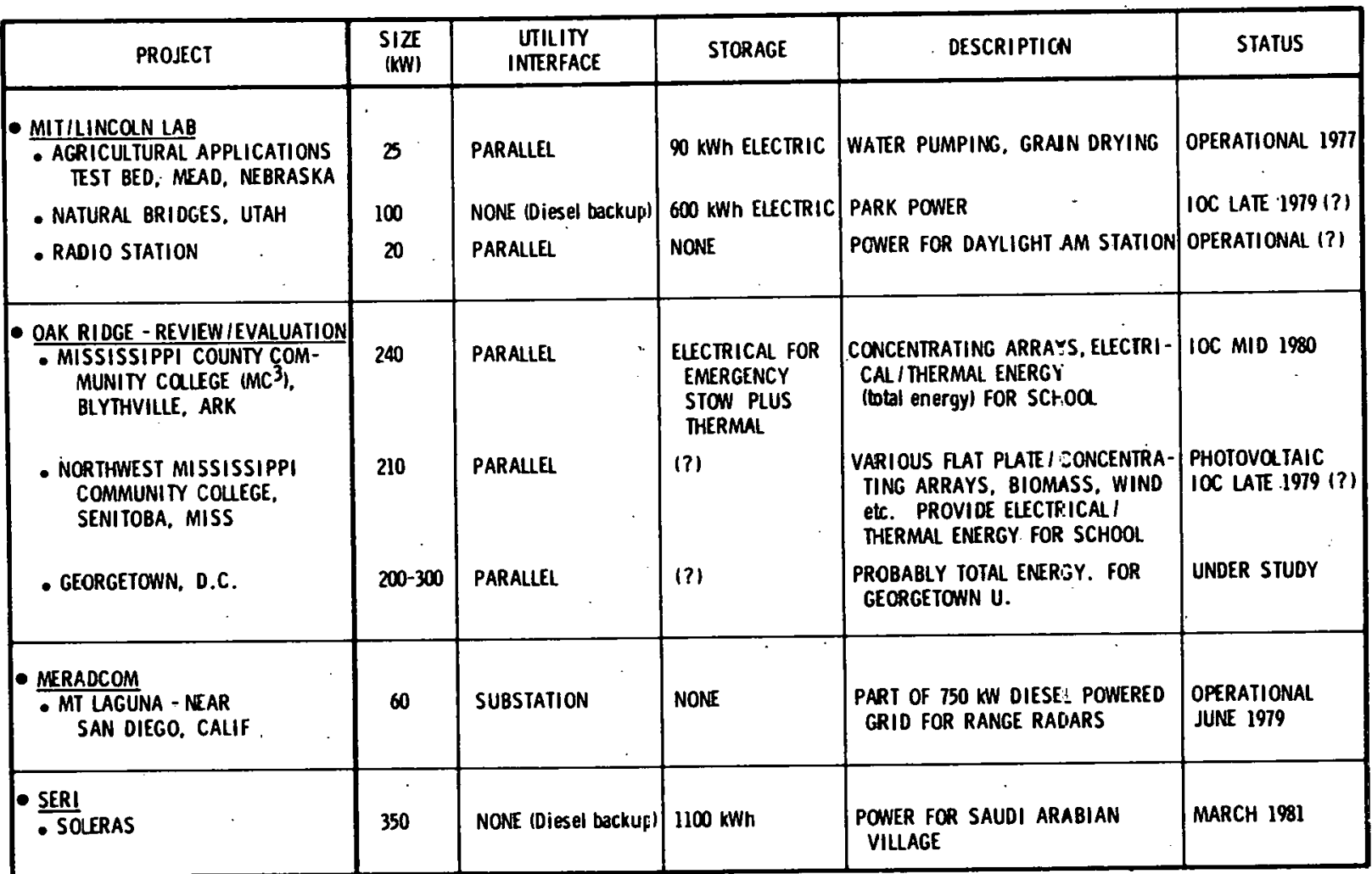




\begin{tabular}{|c|c|c|c|c|c|}
\hline EXPERIMENT & $\underline{\text { UTILITY }}$ & $\begin{array}{c}\text { GRID } \\
\text { INIERACTION } \\
\end{array}$ & $\begin{array}{l}\text { kW } \\
\text { LEVEL }\end{array}$ & STORAGE & STATUS $110 C$ \\
\hline $\begin{array}{l}\text { SOLAR I } \\
\text { HOUSE }\end{array}$ & DELMARVA, PP\&L & $?$ & ? & $\begin{array}{l}\text { SALT } \\
\text { BINS }\end{array}$ & OPERATIIONAL / 73 \\
\hline PV CONCENTRATOR & COL.\& SO. DHIC & $\begin{array}{l}\text { PARALLEL \& } \\
\text { FEEDBACK }\end{array}$ & 158 & $\begin{array}{l}\text { W/WO } \\
\text { ON SIIE }\end{array}$ & DESIISN PHASE / 80 \\
\hline $\begin{array}{l}\text { PV CONCENTRATOR } \\
\text { APPLICATIONS }\end{array}$ & DUKE POWER & CONNECTION & 90 & $?$ & DESIGN PHASE $/ 78$ \\
\hline $\begin{array}{l}\text { DEMONSTRATION OF } \\
\text { PV ENERGY }\end{array}$ & FLORIDA P\&E & CONNECTION & $?$ & NONE & COMPLETE \\
\hline $\begin{array}{l}\text { CATHODIC } \\
\text { PROTECTION }\end{array}$ & FLORIDA POWER & $?$ & LOW & BATIERY & $\begin{array}{l}\text { OPERATIONAL } \\
\text { SINCE / } 76\end{array}$ \\
\hline PV METERING & MET. EDISON & PARALLEL & 185 & $?$ & DESIIGN PHASES / 80 \\
\hline $\begin{array}{l}\text { COMMERCIAL } \\
\text { DEMO. PLANT }\end{array}$ & GËORGIA POWER & $?$ & 20 & $?$ & $\begin{array}{l}\text { INSTALLATION } \\
\text { DUE / BO }\end{array}$ \\
\hline $\begin{array}{l}\text { PV CONCENTRATOR } \\
\text { APPLICATIONS }\end{array}$ & PG\&E & DIRECT & $20-50$ & $\begin{array}{l}\text { MINOR } \\
\text { BATIERY }\end{array}$ & DESIGN PHASE / (?) \\
\hline $\begin{array}{l}\text { PV FLAT } \\
\text { PANEL }\end{array}$ & PNM & $?$ & $?$ & $?$ & DESIGN PHASE /(?) \\
\hline PV POWER SYSTEM & SANTA CLARA & $\begin{array}{l}\text { PARALLEL } \\
\text { W/O FEEDBACK }\end{array}$ & 30 & NONE & DESIGN PHASE 180 \\
\hline $\begin{array}{l}\text { RELIABILITY } \\
\text { DEMONSTRATION }\end{array}$ & SCE & $?$ & 2.5 & $?$ & $\begin{array}{l}\text { PERFORMANCE } \\
\text { BEING MONITORED }\end{array}$ \\
\hline $\begin{array}{l}\text { DEMONSTRATION } \\
\text { PLANT }\end{array}$ & TACOMA PUBLIC & $?$ & $?$ & $?$ & $\begin{array}{l}\text { FEASIBILITY } \\
\text { BEING STUDIED/(?) }\end{array}$ \\
\hline PV CONCENTRATOR & TAMPA ELECTRIC & PARALLEL & 30 & NONE & DESIGN PHASE / 80 \\
\hline PV ARRAY EVAL & TVA & $?$ & $?$ & $?$ & $\begin{array}{l}\text { PRELIM. EVALUATIOR } \\
\text { INITIATED }\end{array}$ \\
\hline
\end{tabular}




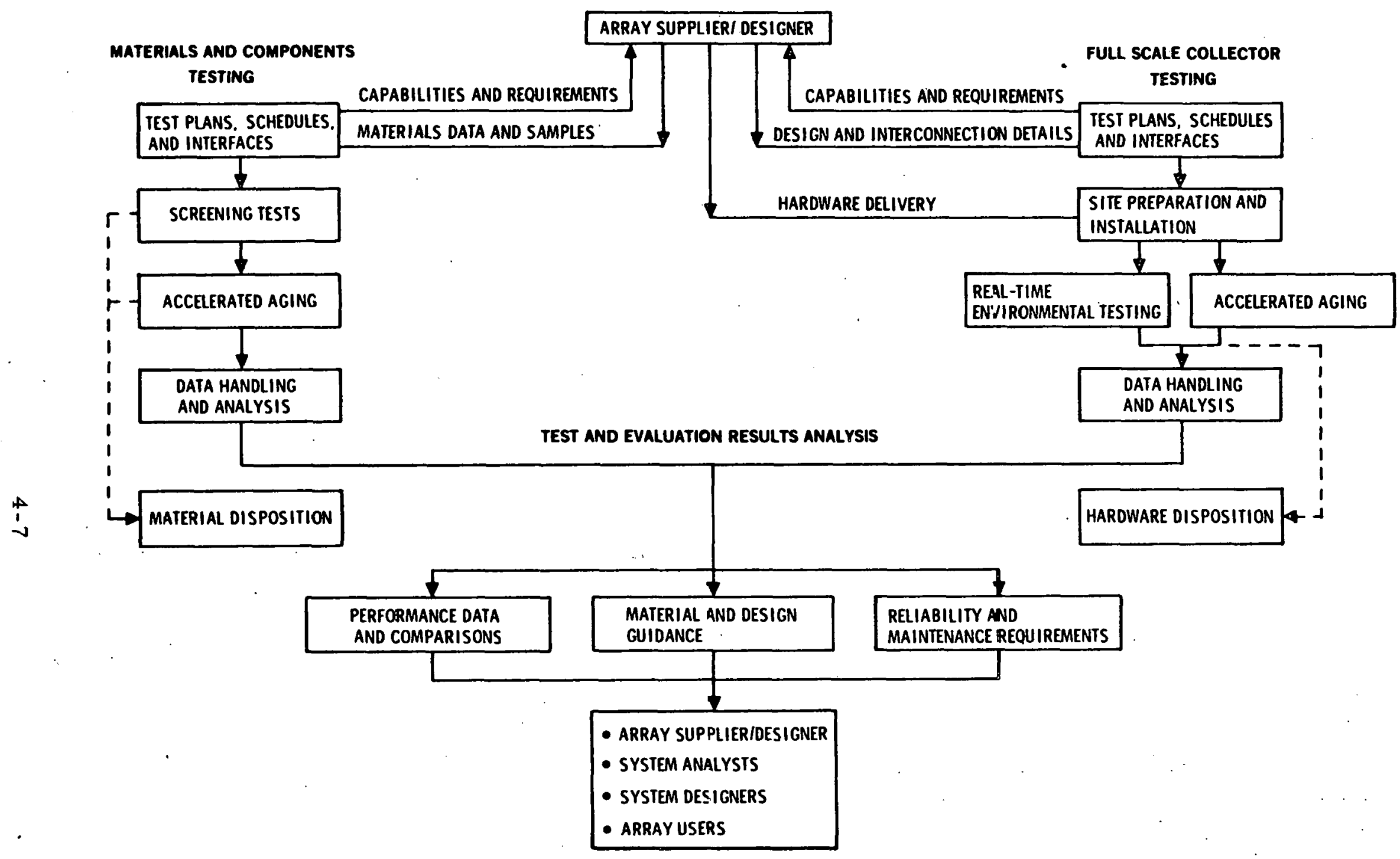

Figure 4-2. Photovoltaic Concentrator Test and Evaluation Task Flow Diagram 
Such uniform data requirements were further defined in that contract initiation meeting document of 1 June 1978 in terms of "soft" and transducer data, and this categorization has been carried on into Phase 3 considerations. A summary of the key data items in each category is shown in Table 4-4 to provide an interpretation regarding the nature of each. Each item was further assigned descriptions of scope, purpose, data content, and estimates of recording frequency. The data set represented by Table, 4-4. was considered a minimum set offered to the various contractors, thereby allowing for expansion by the particular applications involved should any unique features so dictate. Phase 3 contractors will provide a complete set of test and evaluation criteria for their individual applications.

Data systems requirements are currently being defined for the overall DOE-PV Test and Application Program by the PV Data System Task Team, as shown in Figure 4-1. Primary work to date has been to define the user requirements. An extensive analysis of such requirements has been conducted by the Task Team User Requirement Working Groups for applications pertaining to the residential, ILC, central stations, and remote/international sectors. Niodeling needs were considered a supplemental sector. Table 4-5 provides a summary of the major information categories deemed pertinent to each sector. The major categories are seen to be comprehensive and include a set of utility considerations which are further refined in summary form. The requirements document prepared by the Task Team has further cefined each of the miajor information categories into detailed data items. Greater attention was given to utility considerations by the ILC and central station sectors.

It is pertinent that the data requirement prioritizing by the User Requirements Working Group treats the utility community as only one of a group of many users. Table 4-6 is an extraction of the utility-specific considerations from the overall prioritized information requirements, and represents only a small subset of the total users involved. The information categories down the lefthand side, and the main plus first level subheadings across the top are complete sets; it is the parenthetical subheadings that represent the small utility subset. Explicit priority ratings, are 
Table 4-4. DOE-PV Uniform Data Requirements Summary SOFT DATA

Site Description

- Purchased Equipment Costs

- Capital/Construction Costs

- Construction Schedule

- Scheduled/Unscheduled Cleaning, Maintenance, Calibration, Repair

- System Downtime

- Equipment Failures

- Pre-Operational Testing and Checkout
- Environmental Considerations

- Utility Interface

- Safety Considerations

- System Schematic

- Inverter Output Harmonic Content

- Battery State of Charge

- System Description Parameters

TRANSDUCER DATA

- Array Field/Subfield Voltages, Currents, Energy

- Power Conditioning Voltage, Current, Power

- Meteorological: Radiation, Winds, Pressure, Humidity, Temperature

- Array Thermal Properties of Temperatures, Flow Rates
- Battery Storage Voltages, Current, Power

- Thermal System Temperatures

- Electrical Load Power Source, Load Voltage/Current/ Power

- Other: Mode Switching, Master Switching, Date/Time 
Table 4-5. DOE-PV User Information Summary

\begin{tabular}{|c|c|c|c|c|c|}
\hline \multirow{2}{*}{$\begin{array}{c}\text { Major Information } \\
\text { Category }\end{array}$} & \multicolumn{5}{|c|}{ Designated Application } \\
\hline & Residential & $\begin{array}{l}\text { Intermediate } \\
\text { Load Center }\end{array}$ & $\begin{array}{l}\text { Central } \\
\text { Station }\end{array}$ & $\begin{array}{c}\text { Remote } \\
\text { International }\end{array}$ & Modeling \\
\hline $\begin{array}{l}\text { - Meteorological } \\
\text { - Operational Performance } \\
\text { (System, Subsystem) } \\
\text { - System Description } \\
\text { - Load Profiles } \\
\text { - Reliability } \\
\text { - Operation \& Maintenance } \\
\text { - Training Role } \\
\text { - Cost Items } \\
\text { - Institutional Barriers } \\
\text { - Environmental Impact } \\
\text { - Market/User Acceptance } \\
\text { - Utility Considerations } \\
\text { - Coordination Arrangements } \\
\text { - Nearby Utility Description } \\
\text { - Daily Operational Problems } \\
\text { - PV Level vs Grid Capacity } \\
\text { - Responsible PVU } \\
\text { - Rate Structure } \\
\text { - Demand Changes } \\
\text { - Energy Need Monitoring } \\
\text { - Capacity Credit } \\
\text { - Grid Interaction, Location }\end{array}$ & $\begin{array}{c}\mathbf{x} \\
\mathbf{x} \\
\mathbf{x} \\
\mathbf{x} \\
\mathbf{x} \\
\mathbf{x} \\
\mathbf{x} \\
\mathbf{x} \\
\mathbf{x} \\
\mathbf{x} \\
\mathbf{x} \\
\mathbf{x} \\
\mathbf{x}\end{array}$ & $\begin{array}{l}\mathbf{x} \\
\mathbf{x} \\
\mathbf{x} \\
\mathbf{x} \\
\mathbf{x} \\
\mathbf{x} \\
\mathbf{x} \\
\mathbf{x} \\
\mathbf{x} \\
\mathbf{x}\end{array}$ & $\begin{array}{l}\mathbf{x} \\
\mathbf{x} \\
\mathbf{x} \\
\mathbf{x} \\
\mathbf{x} \\
\mathbf{x} \\
\mathbf{x} \\
\mathbf{x} \\
\mathbf{x} \\
\mathbf{x} \\
\mathbf{x}\end{array}$ & $\begin{array}{l}\mathbf{x} \\
\mathbf{x} \\
\mathbf{x} \\
\mathbf{x} \\
\mathbf{x} \\
\mathbf{x}\end{array}$ & $\begin{array}{l}\mathbf{x} \\
\cdot \\
\mathbf{x} \\
\mathbf{x}\end{array}$ \\
\hline
\end{tabular}


Table 4-6. DOE-PV Prioritized Information Requirements for Utilities

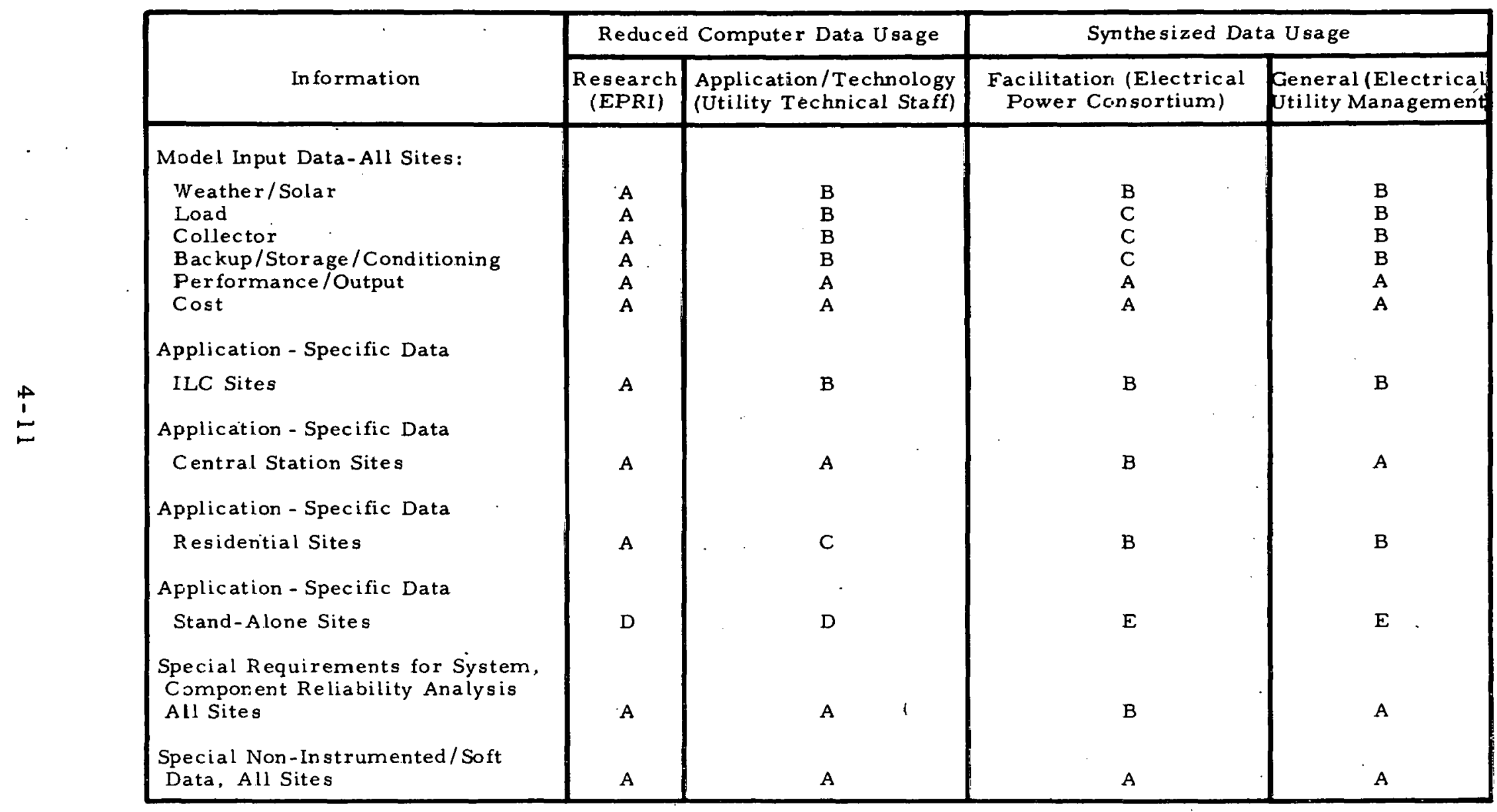

Priority Ratings: $A=$ Most Needed .... B .... C ... D ....E $=$ Least Needed 
designated on the table, and further ratings are implied by the left to right sequence across the top (i.e., left is higher priority). Utilities are included in each of the four prioritized usage categories although only indirectly through EPRI in the area of research data (which would come first on a temporal basis). The sequence of information categories down the lefthand side does not represent any particular priority rating as shown, but the Task Force did assign priorities based on the overall user group. Such ratings implied higher priorities'for cost data, residential applications, reliability, and soft data in that order. Lowest ratings went to stand-alone applications and load data.

Tables 4-5 and 4-6 also serve to provide an interpretation of DOE-PV information requirements in a spatial context. The tables clearly indicate that the program addresses each of the spatial sectors according to the type of system; i.e., residential, Intermediate Load Center (ILC), central station, and remote. A key spatial consideration contained in the tables is the first priority that has been assigned to the residential and ILC applications by DOE-PV, exhibiting a primary emphasis on end-use rather than generation applications. This priority is based on the assessment of studies to date of break-even prices, anticipated market penetrations, and high probability of early commercial energy impact in those areas. Furthermore, DOE-PV indicates that its technology development to date has yielded baseline components suitable for the. residential and ILC applications.

The temporal or time phasing context reflects considerable parallel overlap between the flow of information from one stage to another in the research, development, and demonstration processes for PVU components and systems. Initially, DOE-PV laid out a theoretical sequentially phased program which involved establishing ' technical feasibility and readiness of components, system feasibility via Initial System Evaluation Experiments (ISEEs), combining the findings of these two steps to determine system readiness in the System Readiness Experiments (SREs), and subsequently advancing to demonstrations of commercial readiness in the Commercial Readiness Demonstration Programs (CRDPs). Currently, DOE-PV has translated that theoretical approach into one of parallel activities and sequential equipment 
development/utilization, as shown in Figure 4-3. The figure indicates that commercial reaciness of residential/ILC applications is expected by $1986-89$, with a delay to 1990 for central stations. Off-the-shelf hardware will satisfy the early (1980) stages.

An overall document tree was not available from DOE-PV which would describe intended information flow to information users from the component test stages through the commercial demonstrations. However, Figure 4-4 represents the JPL Task Force. approach that will lead to the equivalent of such a tree within the major T\&A area which comprises the ISEEs and SREs. The figure emphasizes the user needs and issues, and the upgrading of requirements and priorities through activity feedback. 


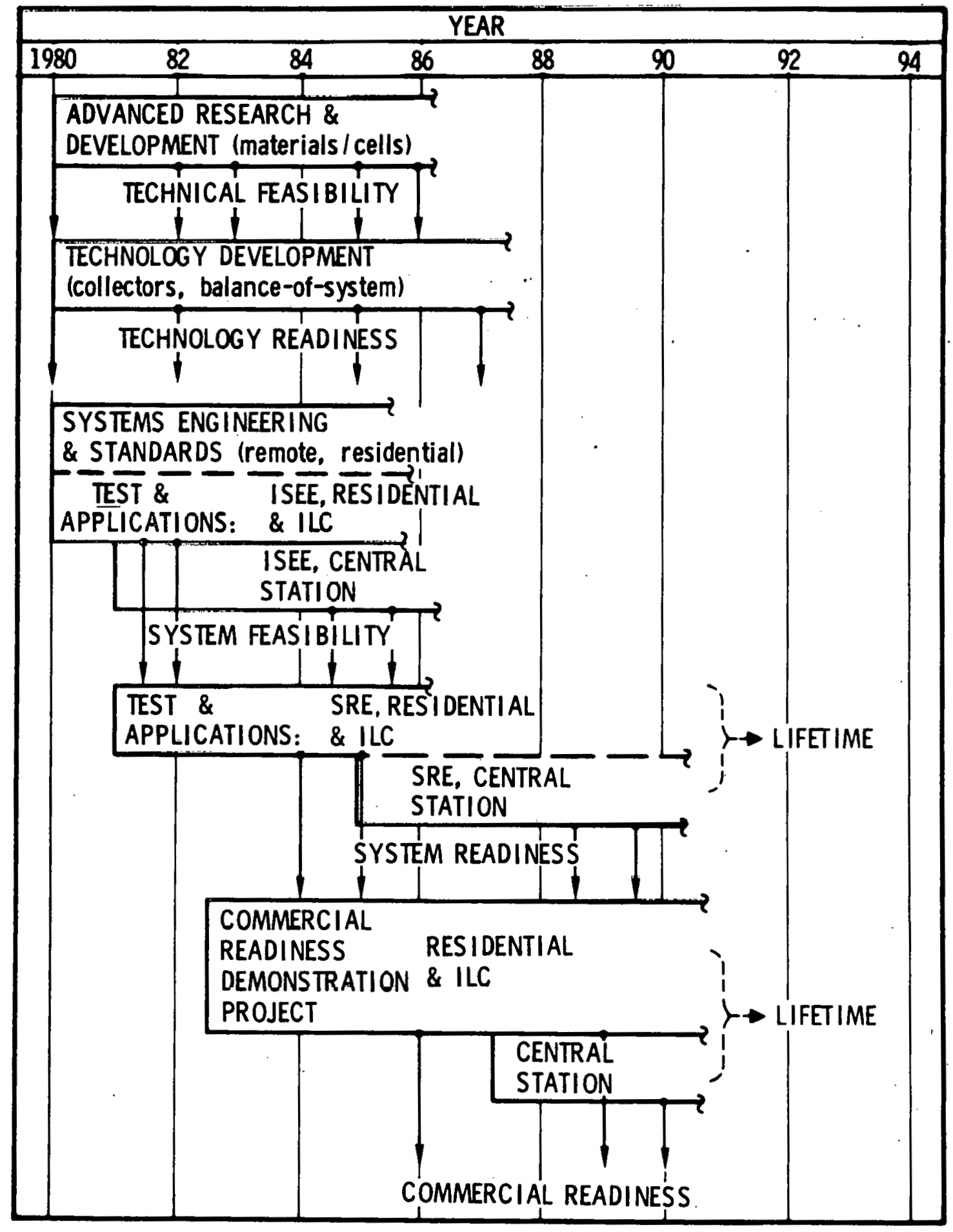

Figure 4-3. DOE-PV Evolution Process Overview 


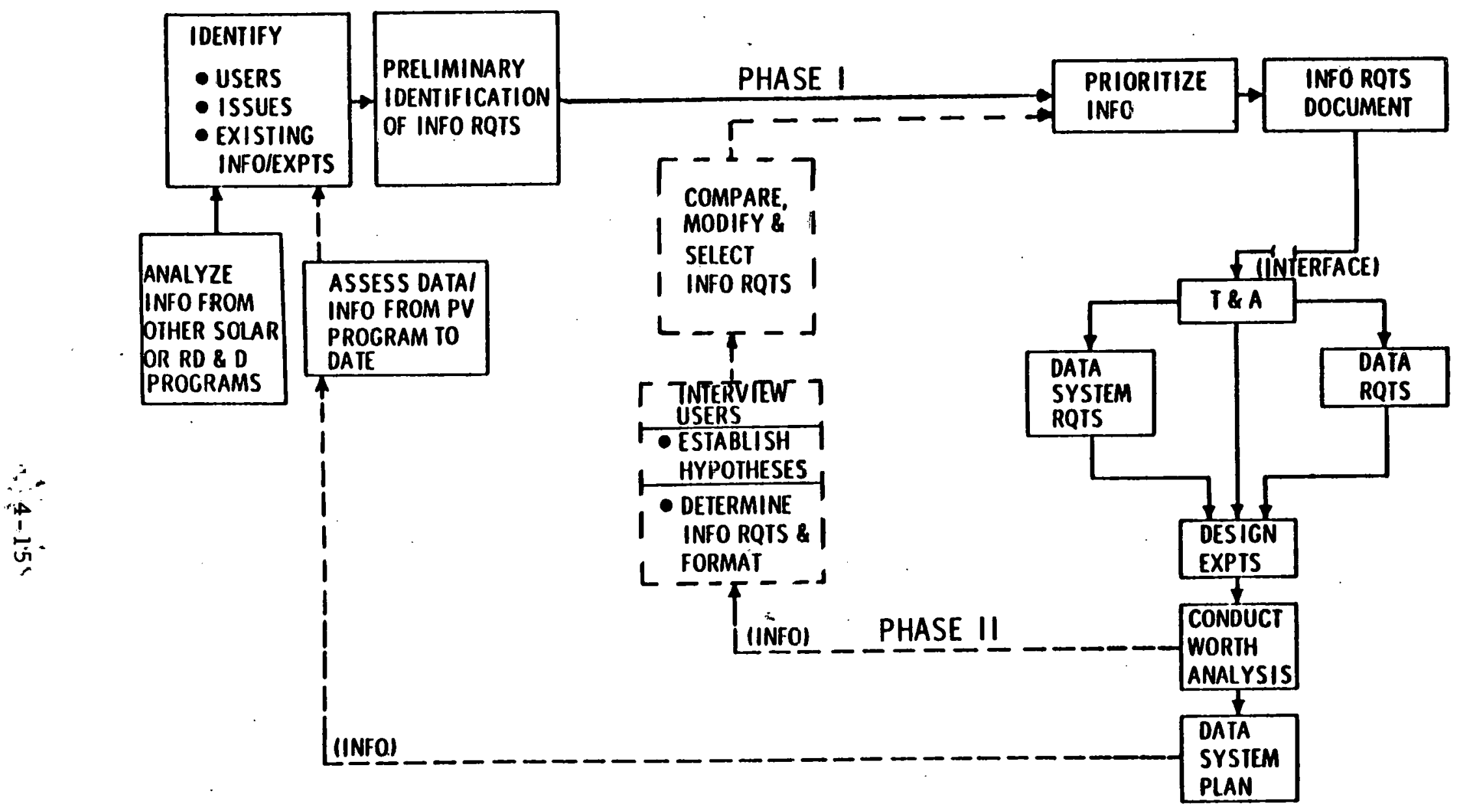

Figure 4-4. DOE-PV User Information Requirements Plan (Test and Applications) 
- Blant

$4-16$ 


\subsection{ANALYSIS OF GAPS BETWEEN UTILITY/DOE-PV INFORMATION CRITERIA}

A comparison is made in this section between the utility information requirements results developed in Section 3.0 and the information contents of the experiments program discussed in Section 4.0. Such a comparison serves to.accomplish the third task objective: to identify gaps or discrepancies between the information required and the information actually to be obtained. The gaps identified in this section serve as the source of the specific recommendations made in Section 6.0.

The gap analysis is presented in three distinct steps. In Section 5.1, a comparison is drawn between the philosophical positions regarding the proper approaches to PV integration that are held by DOE-PV and by the utility community. In Section 5.2, a series of distinctions are between the Aerospace interpretations of the utility-oriented information requirement and the information content associated with the DOE-PV experiment program is exhibited. These distinctions are arawn along several dimensions. One distinction is in the apparent priority or sense of urgency communicated regarding the various information categories. Also, distinctions can be appreciated by placing the experiments along the dimensions of spatial connection points within the utility network, and also among the phases of the temporal demonstration process. In Section 5.3, the predominant gaps are revealed by analysis of the differences in the two community viewpoints.

\subsection{COMPARISONS OF APPARENT PHILOSOPHICAL POSITIONS}

A summary of the apparent philosophical positions held by the utilities and DOE-PV is presented in Table 5-1. The table presents the Aerospace interpretation of each community's position pertaining to each of the key utility messages presented in Table 3-2. Discussions of these positions follow.

1. Anticipation for the Commercial Readiness of PVU: The utilities view commercial readiness as being in the distant future, if at all, and must retain their current commitments for expanding generation mixes over 10 years in the future. They share an experienced uncertainty regarding actual lifetime of any new technology. 
Table 5-1. Utility/DOE-PV Philosophy Comparison

\begin{tabular}{|c|c|c|}
\hline \multirow{2}{*}{ Is sue } & \multicolumn{2}{|c|}{ Apparent Viewpoints/Concerns } \\
\hline & Utility & DOE-PV \\
\hline $\begin{array}{l}\text { 1. PVU Future and } \\
\text { Lifetime/Reliability }\end{array}$ & $\begin{array}{l}\text { In Distant Future; Consideration } \\
\text { of Generation Planning } \\
(>10 \text { Years Lead) }\end{array}$ & $\begin{array}{l}\text { Residential/ILC by Mid- } \\
1930 s: \text { Reliability "As } \\
\text { You Go"; Accelerated } \\
\text { Aging Tests }\end{array}$ \\
\hline $\begin{array}{l}\text { 2. Acceleration to } \\
\text { Commercial Status }\end{array}$ & $\begin{array}{l}\text { Sequential Evolutionary Process: } \\
\text { Success or Failure via Few Well- } \\
\text { Conceived Experiments }\end{array}$ & $\begin{array}{l}\text { Parallel Evolution; } \\
\text { Success Oriented; } \\
\text { Widespread Distribution }\end{array}$ \\
\hline 3. Real-World Issues & $\begin{array}{l}\text { Customer Service and Load } \\
\text { Changes: High Meaningful Levels } \\
\text {. }\end{array}$ & $\begin{array}{l}\text { Same Except, Multiple } \\
\text { Low Levels; Funding } \\
\text { Constraints }\end{array}$ \\
\hline $\begin{array}{l}\text { 4. Grid Impact; Safety and } \\
\text { Security }\end{array}$ & $\begin{array}{l}\text { Grid Control and Stability; } \\
\text { Training Required }\end{array}$ & $\begin{array}{l}\text { Grid Backup During ISEEs } \\
\text { and SREs; Data Evaluation }\end{array}$ \\
\hline $\begin{array}{l}\text { 5. Top-Down PVU } \\
\text { Program Plan }\end{array}$ & $\begin{array}{l}\text { No apparent Logic, Plan, Coor- } \\
\text { dination, Priorities }\end{array}$ & $\begin{array}{l}\text { Multi-Year Plan; Data } \\
\text { Requirements Task Force }\end{array}$ \\
\hline 6. Utility Caution & $\begin{array}{l}\text { Lack of Program Realism; } \\
\text { Independent of Utilities } \\
.\end{array}$ & $\begin{array}{l}\text { Actual User Environ- } \\
\text { ment; Utility as Advisors, } \\
\text { Data Users, and PRDA } \\
\text { Associates }\end{array}$ \\
\hline $\begin{array}{l}\text { 7. Information Needs in } \\
\text { PVU Program }\end{array}$ & $\begin{array}{l}\text { Data Translated for Regional } \\
\text { Utility Use; Build in Early }\end{array}$ & $\begin{array}{l}\text { Utility as One of Many } \\
\text { Users of Data Bank }\end{array}$ \\
\hline 8. Ownership and Control & $\begin{array}{l}\text { Responsibility for O\&M. Training, } \\
\text { Warranties. Sa fety }\end{array}$ & $\begin{array}{l}\text { Residential/ILC by } \\
\text { Public; Central Station } \\
\text { By Utilities }\end{array}$ \\
\hline $\begin{array}{l}\text { 9. Central vs Distributed } \\
\text { PVU }\end{array}$ & $\begin{array}{l}\text { Unresolved; Needs Experiment } \\
\text { Verification }\end{array}$ & $\begin{array}{l}\text { Residential/ILC First; } \\
\text { Perhaps Central Station }\end{array}$ \\
\hline 10. Sellback vs Storage & $\begin{array}{l}\text { Unresolved; Consider With } \\
\text { Capacily Ciedil }\end{array}$ & $\begin{array}{l}\text { Studies; Sellback } \\
\text { Prefe rred; Subsequent } \\
\text { Data }\end{array}$ \\
\hline 11. Experiment Flexibility & $\begin{array}{l}\text { Modularity to Accommodate } \\
\text { Technology Breakthroughs in } \\
\text { On-Going Experiments }\end{array}$ & $\begin{array}{l}\text { Subsequent ISEEs and } \\
\text { SREs }\end{array}$ \\
\hline $\begin{array}{l}\text { 12. Complete Document } \\
\text { Availability }\end{array}$ & $\begin{array}{l}\text { Includes Plans, Interim and Final } \\
\text { Results; Preferred Suppliers }\end{array}$ & $\begin{array}{l}\text { Utility User Priorities; } \\
\text { Specifications and } \\
\text { Standards }\end{array}$ \\
\hline 13. Utility Participation & $\begin{array}{l}\text { Active Capacity; Higher Interest } \\
\text { in Local Well-Conceived Experi- } \\
\text { ments }\end{array}$ & $\begin{array}{l}\text { Utilities as Advisors } \\
\text { and User; Also PRDA } \\
\text { Associates }\end{array}$ \\
\hline $\begin{array}{l}\text { 14. Utility Demand } \\
\text { Control Options }\end{array}$ & $\begin{array}{l}\text { Increased Interest; Effects of } \\
\text { PVU on Utility Load Profile } \\
\text { and Daily Generation Planning }\end{array}$ & $\begin{array}{l}\text { Not Addressing Combined } \\
\text { Effects }\end{array}$ \\
\hline 15. Information Categories & Time Phasing of Six Categories & $\begin{array}{l}\text { Time Phasing of Dif- } \\
\text { ferent Categories (Same } \\
\text { Information) }\end{array}$ \\
\hline
\end{tabular}


Conversely, DOE-PV anticipates readiness for the residential and ILC applications by the mid-1980s, based on the stuoies and developments to date. DOE-PV will rely on reliability being established along the way and on accelerated aging tests. Utility planners are reluctant to allow any moaification in their planning forecasts for what they consider to be an unproven technology. This is one key philosophical difference with strong polarity.

2. Means for Progressing to Potential Commercial Readiness. The utilities want a sequential evolutionary process with proven feasibility carried along at each step, with abandonment or reevaluation of the PVU concept should any one step fail. The utility community would prefer to rely on a few well conceived experiments with appropriate funding for each. The basic concept of the DOE-PV approach is similar in that an evolutionary process is intended, but a difference exists in the implementation by DOE-PV which involves parallel activities and sequential equipment development in order to accomplish the mid- 1980 readiness, without anticipation of failure. Another difference relates to the planned widely separated distribution of experiments with correspondingly lower funding for each. Polarity is nearly as strong on this issue.

3. Degree of Realism to be Incorporated in the Experiments. Utilities are concerned about customer reactions, safety in servicing, unexpected load changes and others. They feel that meaningfully high levels of power must be involved to ascertain the true influence on their grid networks; higher levels would require higher funcing for the experiment involved. Contrasting the higher levels of power sought by utilities, the existing plan calls for lower levels at multiple experiment sites as the pattern for using available funds.

4. Impacts Associated with Grid Connection. The utilities are uncertain about the impact of PVU on the operation of their grids in either a backup mode (for ressidential/ILC applications) or primary mode (for central stations). Their concern extends to grid security in terms of protecting its controllability and stability, and to safety of people involved in installing, operating, and maintaining the equipment. A key factor in their consideration is adequate training for those involved in such activities. Again, DOE-PV indicates interest in most of these issues, although it feels grid 
backup is forthcoming with proper utility arrangements. Grio impact is expected to be determined by data evaluation corresponding to the series of ISEEs and SREs, but very little regarding training requirements appears in the literature .

5. Degree of Awareness that Exists Concerning the Planned DOE-PV Program. The utilities have expressed concern about the apparent lack of planning, logic, coordination, and priorities in the program. However, the Miulti-Year Program Plan (MYPP) addresses such issues, and the forthcoming User Requirements report addresses data requirements for the critical ISEEs and SREs. Expediting draft coordination and document release would alleviate a substantial amount of this concern.

6. Attitude of Underlying Caution among the Utilities. Such caution seems to be due to a feeling of a lack of realism in an accelerating program being conducteo independent of their involvement. However, the program does place some emphasis on actual user environment, and DOE-PV interacts with utilities by using utility representatives (e.g., individuals, EPRI) as advisors, as eventual users of the experiments data, and as PRDA associates. The gap here is not wide.

7. General Need for Utility-Specific Information Requirements to be Adequately Addressed. Utilities are highly concerned about their service area and local regions, and would like information extrapolated for use in their local analysis activities. Such a requirement would have to be built into the program early. In contrast, DOE-PV essentially views the utilities as a group and as one of many user groups interested in the experiment data, which would therefore be privy to the general data bank to be provided by DOE-PV to all user groups.

8. Ownership and Control of PVU. The scope of this utility. concern comprises responsibility for such activities as operation and maintenance (O\&M), associated basic training, warranties, and personnel safety. Very little has appeareo in the DOE-PV literature to date on this issue, but implied responsibility would exist with the public in the residential/ILC applications, and with the utilities in the central stations. An early resolution of this issue is essential for the smooth integration of PVU into utility scenarios. 
9. Central Station vs Distributed Applications. The utilities would prefer a resolution via early. well conceived experiments comparing each approach. DOE-Py has adopted the residential/ILC applications as being highly probable for early commercial readiness, with central station perhaps following in the future. Several utilities point out that large, centralized plants have historically always won in the economics tradeotf.

10. Sellback of Excess Energy Generation. The impact and role of the various candidate approaches, relative to potential capacity credit, are part of the resolution to be accomplished. DOE-PV presently relies on study results, preferring sellback over the apparently irore expensive storage options, and wlll gather data on the subject during planned experiments. This does not appear to be a major gap.

11. Degree of Experiment Flexibility. Utilities indicate an inclination toward incorporating modularity in a few early and on-going establisheo experiments, thereby allowing adoption of advanced technology breakthroughs as they occur. The PVU program is planned to incorporate such breakthroughs in some of the multiple experiments to be subsequently initiated.

12. Availability of Complete PVU Experiment Program Documentation for the Utilities. This includes test and evaluation plans, progress reports, and individual and composite experiment final results, including such data as preferred systems and qualified suppliers. Present DOE-PV intentions are to provide the utility data according to user priorities, to provide the general PVU data bank, and to issue appropriate specifications and standards.

13. Utility Involvement and Active Participation. The utilities indicated a desire to participate, but they appeared to be more sensitive to their own service areas or local regions, and to well conceived experiments designed to meet their own needs and interests. Currently, DOE-PV relies on utilities as advisors, eventual users of experiment data, and as PRDA associates.

14. Increase in Interest Concerning Utility Demand Control Options. The interest in options such as load management and storage is increasing due to the effects of photovoltaic energy on the utility load profiles and on the consequent daily planning 
for generation. The current DOE-PV program does not appear to address these issues together, so experiments providing information on the viable combinations of these factors need to be defined.

15. Completeness of Information Categories Created by Aerospace. The utility field visit results indicate that they were essentially complete, but that the priorities assigned to each should be time phased. Comparison to the DOE-PV data requirements indicates that the six requirements categories match those of the PVU Test and Applications program activities, but time phasing pertains to a oifferent categorization of the same information.

\subsection{CONIPARISONS OF INTERPRETED RESULTS}

In this section, comparisons are drawn between the utility information requirements interpretations and PVU program information contents in terms of information priorities, spatial connection, and temporal process considerations.

The priorities comparison is shown in Table 5-2. Utilities assign high priority to information related to general grid integration problems and to data pertaining to overall operation and economic impact. The present DOE-PV priorities are extracted from a matrix of applications versus data usage categories. The table shows that the top rankings for these two dimensions pertain to cost modeling and residential applications, and to use of research data by EPRI and application/technology data by the utility staffs. The definition of these priority rankings will be upgraded by subsequent responses based on the Aerospace utility field visits, and by the activity feedback of the DOE-PV data requirements activity. The present versions shown in the table indicate that some, but not substantial, gaps exist in the rankings.

The spatial information comparison is illustrated in Table 5-3. This table compares information rankings for the application type or grid connection point of PVU. Such a comparison highlights the gap between utility central station preference and the DOE-PV residential/ILC priority.

Comparisons between information requirements and contents from the temporal experiment program evolution viewpoint can be accomplished using the Demonstration 
Table 5-2. Utility/DOE-PV Information Requirement Priority Comparison

\begin{tabular}{|c|c|c|}
\hline \multirow{2}{*}{ Utility } & \multicolumn{2}{|r|}{$D O E-P V$} \\
\hline & Application & Utility Usage \\
\hline $\begin{array}{l}\text { 1) Grid Integration } \\
\text { 2) Operation/Economic Impact }\end{array}$ & $\begin{array}{l}\text { 1) Cost (Modeling) } \\
\text { 2) Residential }\end{array}$ & $\begin{array}{l}\text { 1) Research by EPRI } \\
\text { 2) Application/Technology } \\
\text { Data by Utility Staff }\end{array}$ \\
\hline 3) PVECS Performance & 3) Reliability & $\begin{array}{l}\text { 3) Facilitation by Electrical } \\
\text { Power Consortiums }\end{array}$ \\
\hline $\begin{array}{l}\text { 4) Socioinstitutional, Procurement/ } \\
\text { Readiness, Utility Participation }\end{array}$ & 4) Soft Data & $\begin{array}{l}\text { 4) General by Utility } \\
\text { Management }\end{array}$ \\
\hline
\end{tabular}

Table 5-3. Utility/DOE-PV Spatial Information Requirement Comparison

\begin{tabular}{|l|l|}
\hline \multicolumn{1}{|c|}{ Utility } & \multicolumn{1}{|c|}{ DOE-PV } \\
\hline Type of PVECS Ranking & - Type of PVECS Ranking \\
1) Central Station & 1) Residential \\
2) ILC & 2) ILC \\
3) Residential & 4) Remote \\
4) Remote & $\begin{array}{l}\text { Preference to User } \\
\text { Preference to Generation }\end{array}$ \\
$\begin{array}{l}\text { End of Connection } \\
\text { Point Spectrum }\end{array}$ & End of Spectrum \\
\hline
\end{tabular}


Process Model of Figure 2-2 and the DOE-PV evolutionary process of Figure 4-3. Table 5-4 provides the highlights of such a comparison. Both communities desire an evolutionary process. The utility version (the Demonstration Process Miodel) calls for a sequential step-by-step procedure that delays passage to the next step unless success is achieved. Proven lifetime capability is essential and complete commercial reaciness would not be achieved until 15 to 20 years in the future. The accelerated DOE-PV version accentuates parallel evolution leading to a possible early commercial readiness by 1986. The Demonstration Process Model (Step 2) includes the need for a few well instrumented and controlled system integration experiments exposed to real-world environments. Such a step is not apparent in the DOE-PV version which indicates a junip from laboratory level to multiple ISEEs. The residential application appears to come closest to the utility perceived Demonstration Process Niodel Step 2, but the final residential plan is not yet available. Therefore, the Demonstration Process Model Step 2 appears to represent one critical temporal evolution gap between the utilities and the DOE-PV approach.

Table 5-4. Utility/DOE-PV Temporal Information Requirement Comparison

\begin{tabular}{|c|c|}
\hline Utility & DOE-PV \\
\hline $\begin{array}{l}\text { - Sequential Evolution } \\
\text { Leading to Success/Failure } \\
\text { - Need for Few Well } \\
\text { Instrumented/Controlled } \\
\text { Experiments in Realworld } \\
\text { Environments }\end{array}$ & $\begin{array}{l}\text { - Parallel Evolution } \\
\text { Leading to Success } \\
\text { - Jump From Laboratory } \\
\text { to Multiple ISEEs }\end{array}$ \\
\hline $\begin{array}{l}\text { - Need Long-Term System } \\
\text { Lifetime Data }\end{array}$ & $\begin{array}{l}\text { - Accelerated Aging Data; } \\
\text { Lifetime Data Available } \\
\text { in Future }\end{array}$ \\
\hline
\end{tabular}


Temporal information comparisons overlap with those of the spatial viewpoints regarding the preference for central generation (utility) versus user (DOE-PV) considerations. Utilities would generally prefer to see the generation aspects adciressed early or at least in parallel, while the DOE-PV approach places central station applications downstream in the experiment program.

Consideration of geographic separation addresses the utilities need for information related to their specific regions, while the current PVU plan calls only for provision to any local utility participating in the experiment, the composite utility industry, and any special requests made by a particular utility. The geographic consideration also highlights the previously montioned gap between the utility preference for a few well conceived experiments at strategic locations versus the PVU plan for geographically widespread multiple experiments with reduced scope. Miost utilities tended to define their strategic locations as identical with their own service areas.

Documental comparisons of information requirements ano contents are given in Table 5-5. The comparisons are essentially between the conceptual document tree of Figure 2-3 and the feedback updating process for T\&A activities in Figure 4-4. The document tree represents a well structured bottom-up information flow matching the temporal evolution of the Demonstration Process Model; i.e., the use of data from each demonstration step would be assigned so that such data would play a role in determining the progression of feasibility from laboratory level experiments to full-scale demonstrations. The closest approach DOE-PV has taken to such a tree corresponds to its component development and T\&A activities which compare to Demonstration Process Model Steps 1 and 3, laboratory experiments, and limited scope demonstrations, respectively. Data links between these two steps, and the CRDP data requirements, are not identified in the available literature. An overall program information requirement master plan has also not been identified in the available literature. In addition, the utility need again arises under the documental requirements for continuity of test and evaluation plans, progress reports, and final results, particularly catalogued results translated into regional terms and definitions. The contrasting DOE-PV provisions will be ifor selected data to utility users, the data base for all users, and specifications and standards. The document tree therefore represents at least a partial gap. 
Table 5-5. Utility/DOE-PV Geographical Information

Requirement Comparison

\begin{tabular}{|c|c|}
\hline Utility & DOE-PV \\
\hline $\begin{array}{l}\text { Locale of PVU Ranking } \\
\text { 1) Local Service Area } \\
\text { 2) Adjacent Area/State } \\
\text { 3) Continental U. S. } \\
\text { 4) International } \\
\text { - Geographic and Specific Utility } \\
\text { Differences Must be Translated } \\
\text { - Need for Few Well-Conceived } \\
\text { Experiments at Strategic Sites }\end{array}$ & $\begin{array}{l}\text { - Locale of PVU Ranking } \\
\text { 1) Widespread Continental U.S. } \\
\text { 2) Sun Belt } \\
\text { 3) International } \\
\text { - Provide to Composite Utility } \\
\text { Industry, Experiment Participants, } \\
\text { and to Special Requests } \\
\text { - Many Reduced Scópe Experiments }\end{array}$ \\
\hline
\end{tabular}

\subsection{REVIEW AND SUMMARY OF INFORMATION REQUIREMENTS/CONTENT GAPS}

A review of the comparisons made in this section indicates that there are a few significant gaps in philosophy. Some issues recur for more than one of the comparison interpretation viewpoints, but there is a much smaller overall gap existing than is generally recognized by the utilities. For example, both communities are highly concerned about real-world problems, evolving into commercial readiness, and developing a well structured program plan to carry out the evolution. Many of the gaps are matters of degree of different preferences rather than basic polarities, and can be remedied with minor modifications and additions to the DOE-PV program. The following paragraphs summarize the basic and recurring gaps and discuss possible gap resolutions, which in turn yield the recommendations made in Section 6.0.

Basic and recurring gaps were determined to be associated with the following:

- Longer test periods needed to establish reliability and commercial readiness.

- Utility communication and participation activities need to be initiated and emphasized. 
- Neeo greater concentration of program resources on a few experiments.

- Greater emphasis is needed on resolving system ownership and jurisdictional concerns.

- Mutual awareness of problems and progress is needed by utilities and DOE.

- Approaches are neecied for interpreting results of distant experiments to local applications.

- Greater emphasis is needed on quantifying grid integration impacts on utillty operativin.

- Central station application needs greater attention.

- Load management effects in the presence of solar generation need study.

One apparent resolution to closing or minimizing these gaps would be to increase DOE-PV encouragement of utility active participation and more efficiently utilize their long-term expertise in the supply and servicing of public electrical power. A joint DOE-PV Utility Working Group to address information requirements for the PVU experiment program is one gap-reducing move, and elevating the utility cata user role to a primary status would be another. An active working group role can be created by either formation of a new group or by specific modification of the current Data System lask Team. In such a role utilities can point out realistic information needs and shortcomings in the planned experiment program and provide guidance and recommendations regarding modifications and additions. Specific gaps they can help close are:

- Defining Demonstration Process Model Step 2 experiments in terms of . objectives, scope, measures, and general information requirements.

- Establishing training and public awareness programs to supplement the experiments. 
- Identifying the tradeoffs of responsibilities for ownership and control.

- Helping to create an information flow master plan that would yield regionally valuable experiment data.

- Aiding in establishing program compromises regarding system types and experiment distribution and scope.

- Implementing Central Station Experiments. 


\subsection{OBSERVATIONS AND RECOMMENDATIONS}

The translation of crucial issues and information gaps into recomimendations for revised courses of action constitutes the fourth task objective: to recommend alterations of and additions to the national program of experiments and demonstrations. The recommendations made here are directed toward the general information content of the DOE-PV program and to general areas within the program. This generality is consistent with the currently diffuse status of data requirement definitions for the on-going PVU experiments.

The material is presented in twu major categories. First, a summary is presented of several observations made regarding utility company points of view. Second, recommendations are made to satisfy the informational needs as well as utility concerns in general.

\subsection{OBSERVATIONS ON UTILITY VIEWPOINTS}

The content of this section is a summary of several observations made during the course of the study. These observations are not actually results or conclusions of the analysis effort, but represent attitudes and experiences which are judged to be significant either because of their ubiquity among the utility companies or because of their potentially pivotal effect on the course of alternative energy generation developments.

It is emphasized that these observations are the study team's interpretations of their experiences and of utility-held attitudes. Therefore, they do not necessarily represent positions held by the Aerospace team or by every utility visited, nor do they constitute specific recommendations for DOE action. They are reported for their information value.

Furthermore, despite the apparently wide gap implieo by some of these observations, the gap analysis in Section 5.0 yields two supplemental observations:

- Informational and approach gaps between identified utility requirements and planned experiments are not as wide as implied by some of these perceptions. 
- Recommendations can be made to minimize gaps that do exist, and these are offered for consideration in Section 6.2.

\subsubsection{Utility Attitudes Toward Government Activities}

The utility companies visited varied somewhat in the expressions of their attitudes toward the roles government agencies, particularly DOF, are taking in the PVU development activities. However, there were some common themes heard more or less loudy at nearly all the utility companies.

There is a general feeling that government is too eager to get to the marketplace with the alternative energy systems and that insufficient time and experience are being devoted to the demonstration of commercial readiness. The vision is of huge government expenditures tu create what may be an artificial market, which will collapse into the tremendous vacuum left by government's withdrawal of support after victory has been declareo. A related concern is that the market will be seriously damaged by disenchantment with devices which have not been thoughtfully ano carefully tested over long periods of time. Several groups illustrated their concern in this area with examples from the solar heating and cooling experience.

Other feelings in this category expressed by the utilities included:

- Political considerations are being allowed lu contaminạte terhnical decisions regarding $\mathrm{PVU}$ experiment planning, with the result that information content is seriously degraded for all the experiments.

- The inconstant and possibly ephemeral nature of government incentives programs renders long term planning for PVU an exercise in guesswork.

- The transience of DOE personnel creates severe disruptions in government funded programs.

- There is a tendency to see DOE as a monolithic entity, without clear distinction between the organizations and purposes of the Photovoltaic Division and the Electric Energy Systems Division. 


\subsubsection{Utility Perceptions of PVU Imminency}

There is a general consensus that photovoltaic energy conversion is an exotic technology and that any meaningful penetration of the energy supply by PVU is in the distant future, even in utility planning units of time. The earliest utility estimate for a central station installation is 1990 , and this is viewed as a very small experimental plant.

\subsubsection{Status of Utility Awareness of PVU Impacts}

Due partly to the non-imminence of PVU implementation and partly to the typical work pressure on utility technical staff personnel, the depth of detailed analysis regarciing PVU impacts already performed by utilities was in general not sufficient to allow real-time discussion of the detailed information requirements in the meetings. Perusal of Appendix B, in which the requirements hierarchies prepared by Aerospace appear, reveals a considerable mass of detail, and it was not possible to penetrate to the next, more detailed level, that is, to the actual data requirements. However, all of the utilities expressed a willingness to use the hierarchy charts as a structure within which to perform additional review and analysis on their own. It was also not possible to get a clear statement of information requirement priorities (i.e., "What really needs to be known first?") beyond the first hierarchal level.

The Aerospace stuoy team came away from some of the meetings with a qualitative impression that many utility companies could be much better informed regarding DOE programs, in particular the PV Multi-Year Program Plan ano the activities of the PV Data System Task Team being organized within the PV Program by Jet Propulsion Laboratory. On the other hand, the companies feel they are not adequately included in the PV Program, and that they are not being consulted extensively enough regarding the requirements they have and the constraints on their operational choices.

\subsubsection{Utility Positions on PVU Experiment Programs}

The utility companies generally agreed that many of their information requirements could be satisfied by experiments involving other utilities, and unitormly expressed a preference for a program which sponsors a few very well conceived and 
implemented experiments rather than a plethora of limited ones patterned after what several termed a "scattergun" approach. In general, they are desirous of participating in experiment design and in monitoring the course of experiments in other utilities. With respect to experiments in which they are to be the host utility, there was a desire for funding flexibility to allow the introduction of the latest technology equipment.

Regarding PVU lifetime qualification testing, a very high priority requirement with all the companies, there was consicierable doubt surrounding the value of accelerateo life testing. The attitude was that accelerated testing serves as an indicator, but no hard generation planning decisions could be based on it. The minimum actual life test duration for credibility with the utilities was given as five years, and the utilities stressed that the testing had to be performed under local environmental conditions.

\subsubsection{Utility Positions on Selected Technical Issues}

Utility perceptions on three specific technical issues are included here due to the wioespread interest in them. The issues are:

- The degree to which capacity credit, if any, can be earned by PVU

- The appropriate position to take regarding excess energy sellback

- The central station versus on-site applications question

With respect to capacity credit, very few of the generation planning people involved in the meetings felt that capacily credit would be earned by PVII. In general, they recognized that this position contradicts analysis results based on loss-of-load probability considerations, and gave as justification the presence of evening demand peaks, weather outages, and the practical limits of energy storage.

The companies generally expressed uncertainty with regard to the best approach to determining sellback policies and rates. It is recognized that sellback energy can have serious effects on generation operations, and that it may be economically justifiable, though possibly precluded by public utility commission actions, . to charge the customer with on-site photovoltaic generation a higher rate for backup energy than his nonsolar neighbor. 
Several of the utilities perceive that a major decision has been made favoring on-site applications over central stations. They argue that the utility incustry exhibits a long history of economy-of-scale success and that it is too early to make any irreversible decisions.

\subsubsection{Utility Reception of the Aerospace Information Requirements Miission}

The utility companies were uniformly cooperative in establishing the visits, and exhibited considerable energy in supporting the Aerospace mission. Personnel from many areas of each company were committed to the meetings for their duration, usually 4-5 hours, and there was a strong interest in expressing their positions, utilizing the study team's role as a communication channel with DOE.

It was also noticed that the discussions and the requirements hierarchies left with the companies served an unforeseen purpose as a stimulus to their own thinking and as a structure within which to pursue in-house analysis of their information requirements.

\subsection{EXPERIMENT PROGRAM RECOMMENDATIONS}

The following three sets of recommendations are advanced to promote the satisfaction of the crucial utility information requirements. Some recommendations relate to activities already planned for accomplishment by DOE-P.V, and in such cases the intent here is to reinforce those steps. Some of the others are directed at the strategies to be implemented by DOE-EES.

\subsubsection{Experiment Modifications and Adaitions}

One general and several specific courses of action are recommended for the current or planned PVU experiments. The general recommenoation is that one or two of the Initial System Evaluation Experiment (ISEE) level experiments now planned be expanded in scope, or new ISEEs be established as necessary to ensure that the crucial areas of Section 6.2 and those of Table 3-3 are included in a well controlled application. The specific recommendations pertain to the following categories and are directed to DOE-PV, DOE-EES, or both, as shown: 
Power Levels (DOE-EES): Size at least one experiment for which the photovoltaic power produced exceeds demand in an isolatable branch of the energy distribution system to allow measurements to be accumulated in $a$ sellback regime.

Grid Interaction (DOE-EES): Develop and incorporate procedures and supporting equipment for rapid location, isolation, and removal and repair of failed PV units, and document associated findings.

Technical Performance (DOE-PV/EES): (1) Ensure that data are collected to yield key sensitivities such as the dependence of PV structure costs on environmental differences, or network performance as a function of $\mathrm{PV} / \mathrm{grid}$ dynamic parameters; (2) acquire data to identify both operational and non-operational characteristics of the inverters, i.e., power quality, VAR requirements, and quiescent role as a load.

Load Management (DOE-EES): Include an experiment to investigate realistic load management options coupled with PV energy generation.

Duration (DOE-PV): Identify an early experiment to demonstrate a minimum PV five year lifetime. Utility acceptance of commercial readiness cannot be assumed until at least that point is reached.

Installation, Operation, Maintenance (DOE-PV): (1) Provide descriptive material documenting installation procedure experience, including mistakes and blind alleys; (2) design and incorporate service forms for use in logging customer telephone calls - nature of service request and resolution; (3) determine training requirements and procedures that are necessary for operation in the various spatial scenarios, and provide corresponding documentation including training materials and films.

Customer Interactions (DOE-EES): (1) Establish test educational programs such as short courses for utility planning personnel to aid in monitoring PV experiments and readying for subsequent penetration; (2) supplement one or two experiments with the sampling of attitudes, reactions, and various market forces. 


\subsubsection{Information Transmittal}

The following recommendations are made regarding format and transmittal of PVU experiment documentation within the experiment program itself and also to the utility community. These recommendations apply to both D.OE-PV and DOE-EES, but they are particularly directed at the DOE-EES strategy to develop data for utility planning and to transfer system information to utilities regarding new source technologies.

User Requirements: Each experiment should incorporate and satisfy the user requirements identified in the DOE-PV Data System Task Team activity.

Data Planning: Ensure that data will be available to the utilities from each experiment stage, from component development through the Commercial Readiness Demonstration Programs, and assess how Test and Applications information will be used in Commercial Readiness Demonstration Program activities.

Reduced Raw Data: Since all data forthcoming from the DOE-PV data bank will apparently be already reduced, it is crucial to identify the parameters of interest (e.g., sensitivities) or make raw data available to utilities.

Utility Functions: Consider categorizing end-use, experiment information along utility functional lines such as generation, operations, service, billing, transmission, and distribution to facilitate use within the utility.

Before and After PV: Ensure availability of pre-project data, to obtain before and after assessments.

\subsubsection{DOE-PV/EES Policies}

The following recommendations are made for joint DOE-PV/EES consideration, and involve some of the broader issues identified throughout the report. The intent is to offer avenues which would lead to a narrowing of some of the gaps that apparently exist between the DOE-PV and utility communities. 
Utility Involvement: Expand the participation level of and general consideration accorded to utility company personnel in the national photovoltaics program. Ways to accomplish this include (1) formation of a DOE-PV/EES/Utility Information. Working Group; and (2) elevating utility status from one of many user groups to a separate participating interest group.

Working Group Charter: Adopt a Utility Information Working Group charter to: (1) include creation of a Multi-Year Program Plan for Information (MYPPI) which parallels the present version of the DOE-PV program MYPP, includes the goals and strategies anticipated by DOE, and thereby links the temporal phases of PV development together; (2) incorporate information requirements and findings coordinated with the various utility experiments that are being cataloged and monitored by ERRI; and (3) expand the PV Data System Task Team aclivities in the $1 \& \mathrm{~A}$ area using the team as a subcommittee.

MYPP Release: Coordinate MYPP upgradings with the working group, thereby facilitating utility awareness of the national photovoltaics program. Create an MYPP tutorial document for easy assimilation by utilities, and institute a mechanism for utility feedback.

PV Data System Task Team Activities: Renew emphasis on and provide funding for the team activities to ensure the incorporation of identified uscr requirements into data parameters and functional requirements throughout the PVU experiment program.

Program Emphasis: Increase emphasis on central station applications and establish a focussed central station responsibility. Define commercial readiness to include utility decision process with respect to PVU lifetime and reliability.

\subsection{CRUCIAL AREAS OF INFORMATION}

This section summarizes specific areas in which utilities have indicated a crucial need for PVU experiment information. 
- Safety of Personnel

Identification of hazard areas and activities

Techniques for system disconnection, interlocks, etc. '

Training levels required for safety in maintenance

Structural and support loading measurement, environment

- System Protection

PVU impacts on power quality, network stability

Power conditioner performance effects

Tests of control equipment

Identification of network control and switching operation impacts

Synchronization experience

- Load Management

Hardware performance characteristics

- Load management logic and implementation

Identification of appropriate loads

Load management accommodation of PV impacts

- Economics

System and installation cost data for extrapolation

Maintenance and other operating cost information

Elasticity of PV demand with sellback rates

Preferential rate structures

Hidden costs due to grid integration

Local perturbations (environments, costs, etc.)

Implementation impacts on utility financial well-being

- Customer Attitudes

Miaintain logs documenting service calls and resolutions

Tolerance to resident system

Aesthetic considerations

- System Lifetime/Reliability

Long-term data

Failure mocies and intervals

Performance trend analyses - deterioriation

Warranties

- Capacity Credit

Loss of load measurements 
- Legal/Jurisdictional

Liability for system damage and bodily injury

- Ownership

Insurability

Service access

Rate base

- Market

Rates of penetration

Rate structure tolerance

Incentive efficacy

- Preferred Systems

Qualification procedures for suppliers, installers, servicers

Degree' of public reliance on local utility rccommendalions

Optimum configurations (flat, concentrator, storage, eti.)

Availability

- Demana Profile Data

Periodic sampling for utility analyses

- Grid Connection

Methods and designs for connection

Requireo network modifications

Equipment problems

- Trailing

Methocis and materials

Minimum levels acceptable

- Maintenance

Technical system performance as function of maintenance levels Maintenance requirements on systems

Recurring fault areas. 


\section{VISIT PACKAGE FOR UTILITY INFORMATIONAL REQUIREMENTS DISCOVERY}

The following figures are the set of vugraphs actually presented by Aerospace to each of the utilities visited. The set was presented hand-lettered as shown to deemphasize finality and to encourage the utilities to incorporate their own viewpoints and improvements. 
UTILITH/DOE INTERFACE: AEROSPACE ROLE Rewazionseres:

$\stackrel{s}{\sim}$

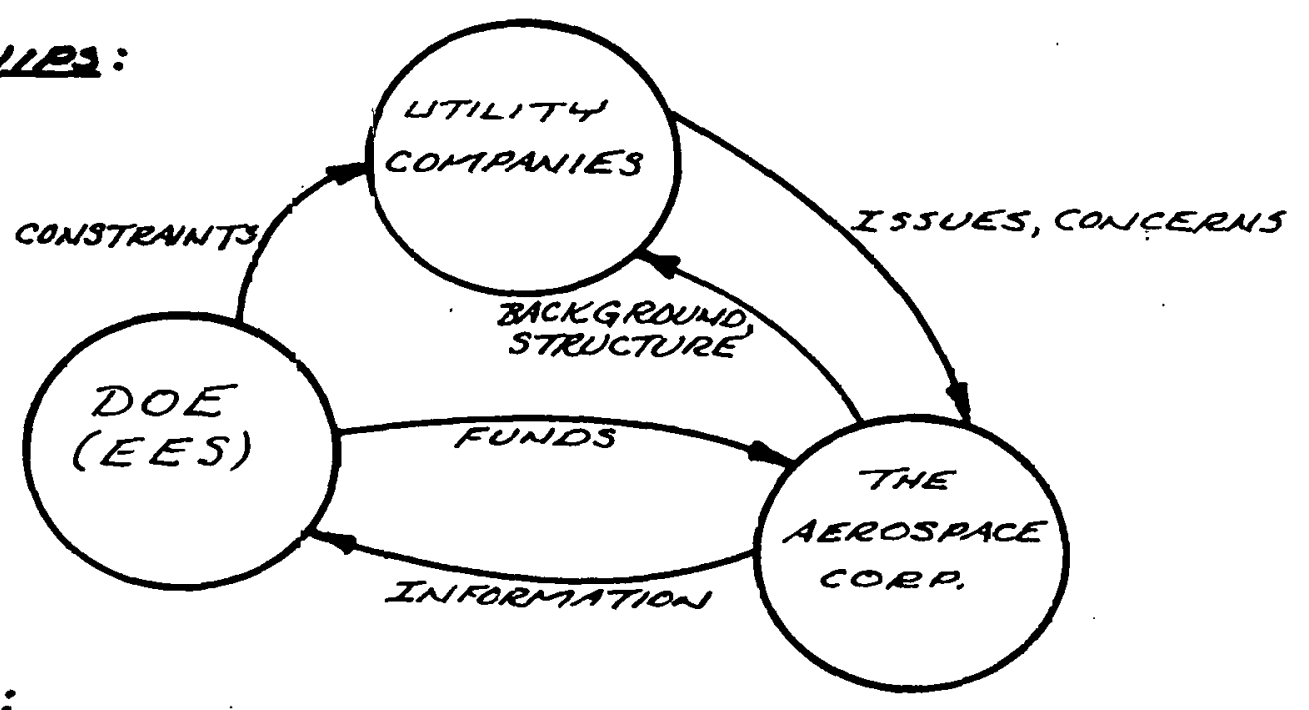

Aleosence:

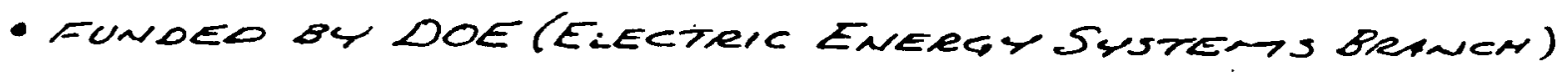

- iofutify conceens helo by utilities

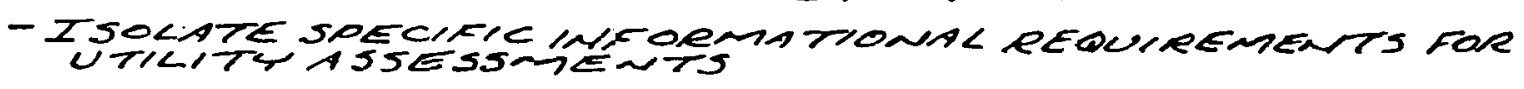

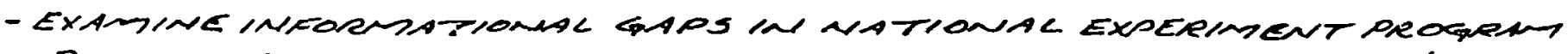

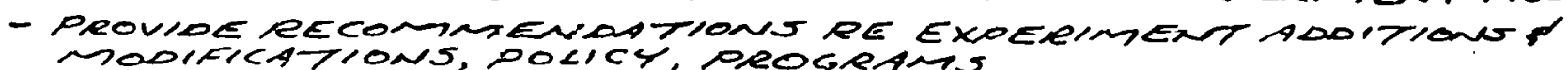

- SERV as an EFFECTNE REPRESEnTATION OF uTIRTH InTERESTS 
UTILITH REQUIREMENTS FOR PHOTOVOLTAIC EXPERIMENTS

REMETIVES:

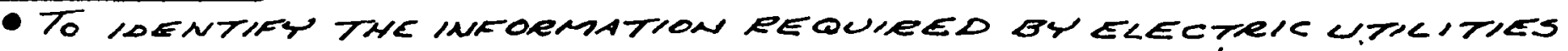
FOP THEN TO MAKE DECISTONS RE ACOUISITION/GRID-COUNECTION

of pHOTOVOLTAIC SUSTEMS

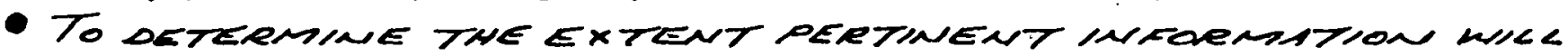

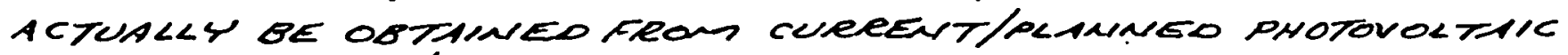

- EXPERMIENTS/DEMONOTRATIONS

- To eVALUATE/ANALYZE gAPS dR DISCEEPANCIES BETUEEN THE

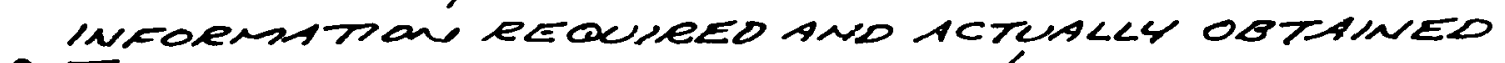

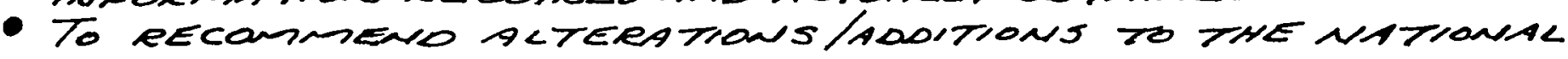
$\stackrel{p}{\omega}$ PROGRAM OF EXPERIALNTS/DEMON STRATIONS TO FILL GAPS

Appronsh:

INFOEMATION IDENTIFICATION

PERTINENT EXPERINENT 


\section{UTILITIES F NEW ENERGIES}

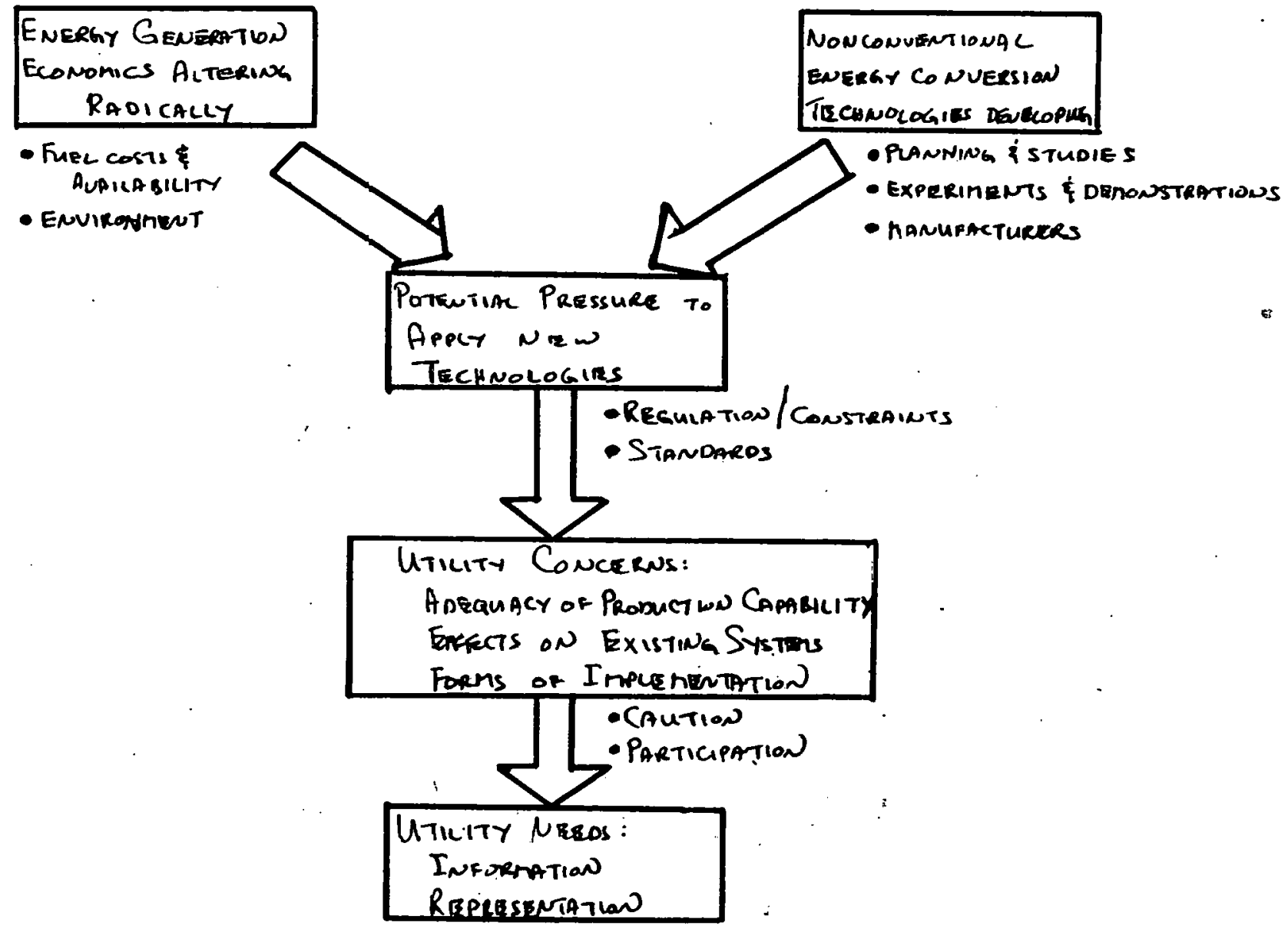




\section{APPENDIX B}

\section{DETAILED INFORMATIONAL SUBQUESTIONS}

The following figures serve as documentation of the set of vugraphs left by Aerospace at each utility visit for their careful examination and improvement, and of Aerospace's own interpretation of experiment information requirements for purposes of this report. 


\section{CONTEMPLATED SUB-QUESTIDNS: GRID INTEGRATION}

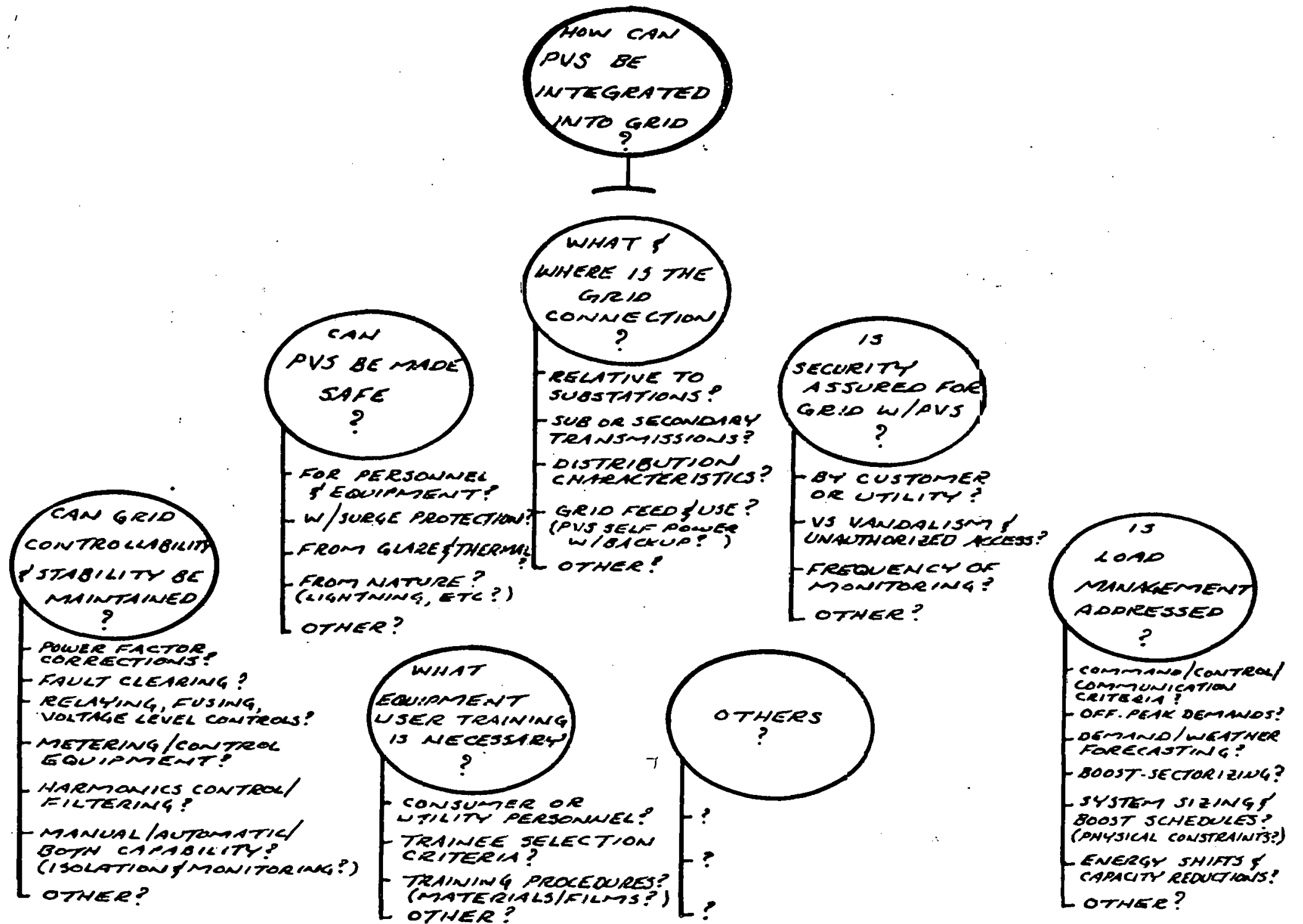


CONTEMPLATED SUB-QUESTIONS: OPERATING ECONONICS

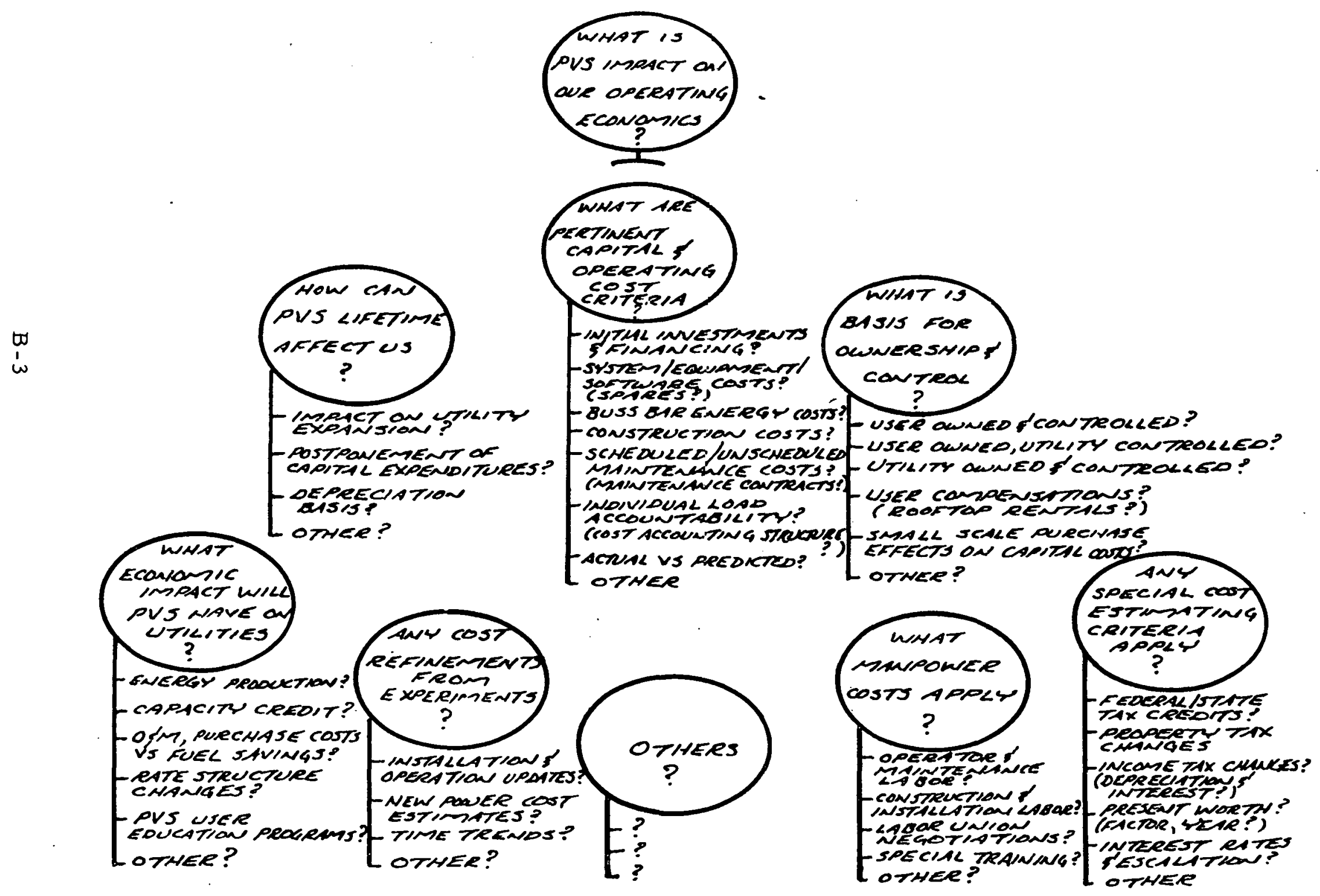




\section{CONTEMPLATEO SUB-QUESTIONS : PERROENANCE}

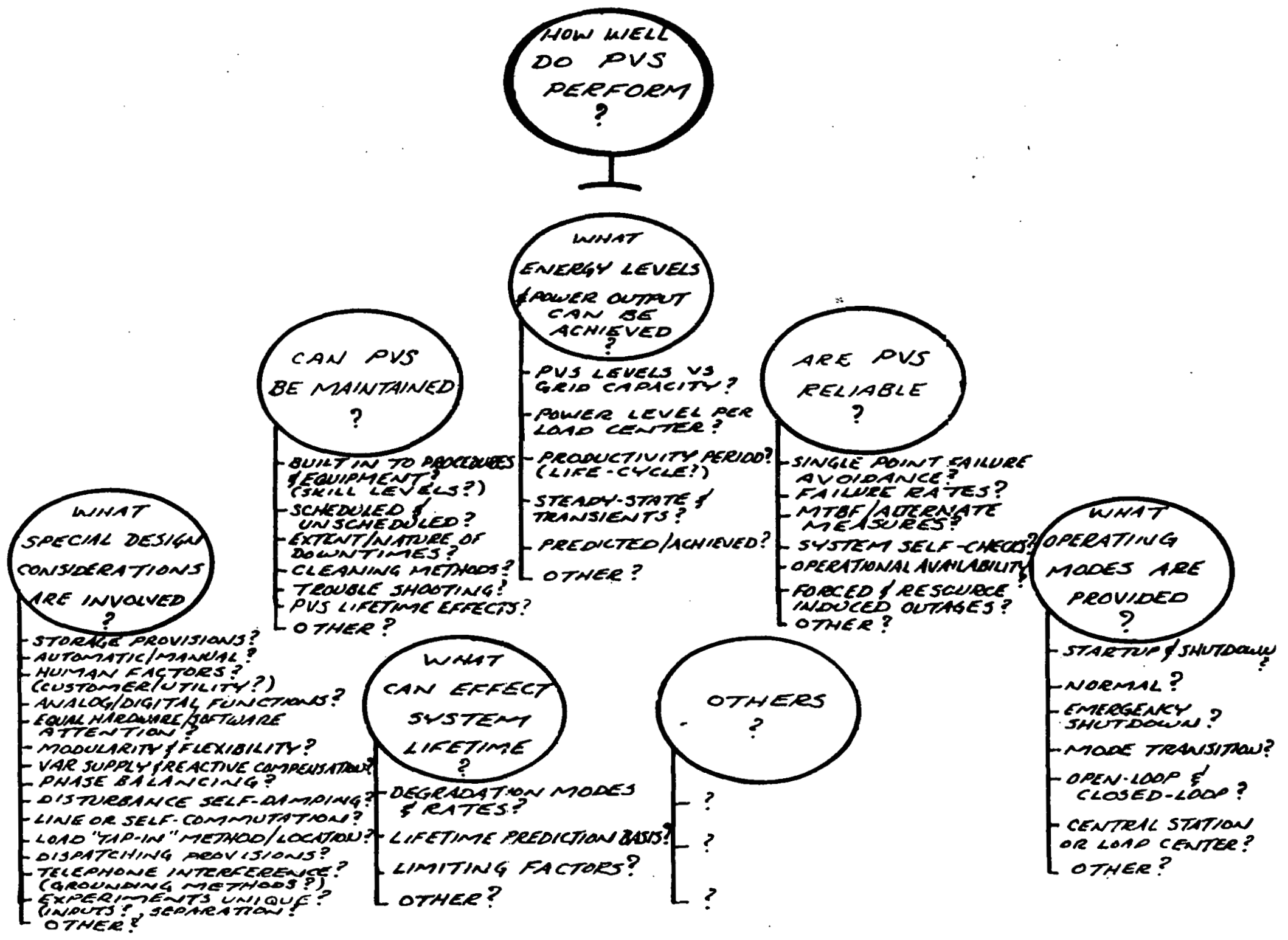




\section{CONTEMPLATED SUB-QUESTIONS: SOCIOINSTITUTIONAL}
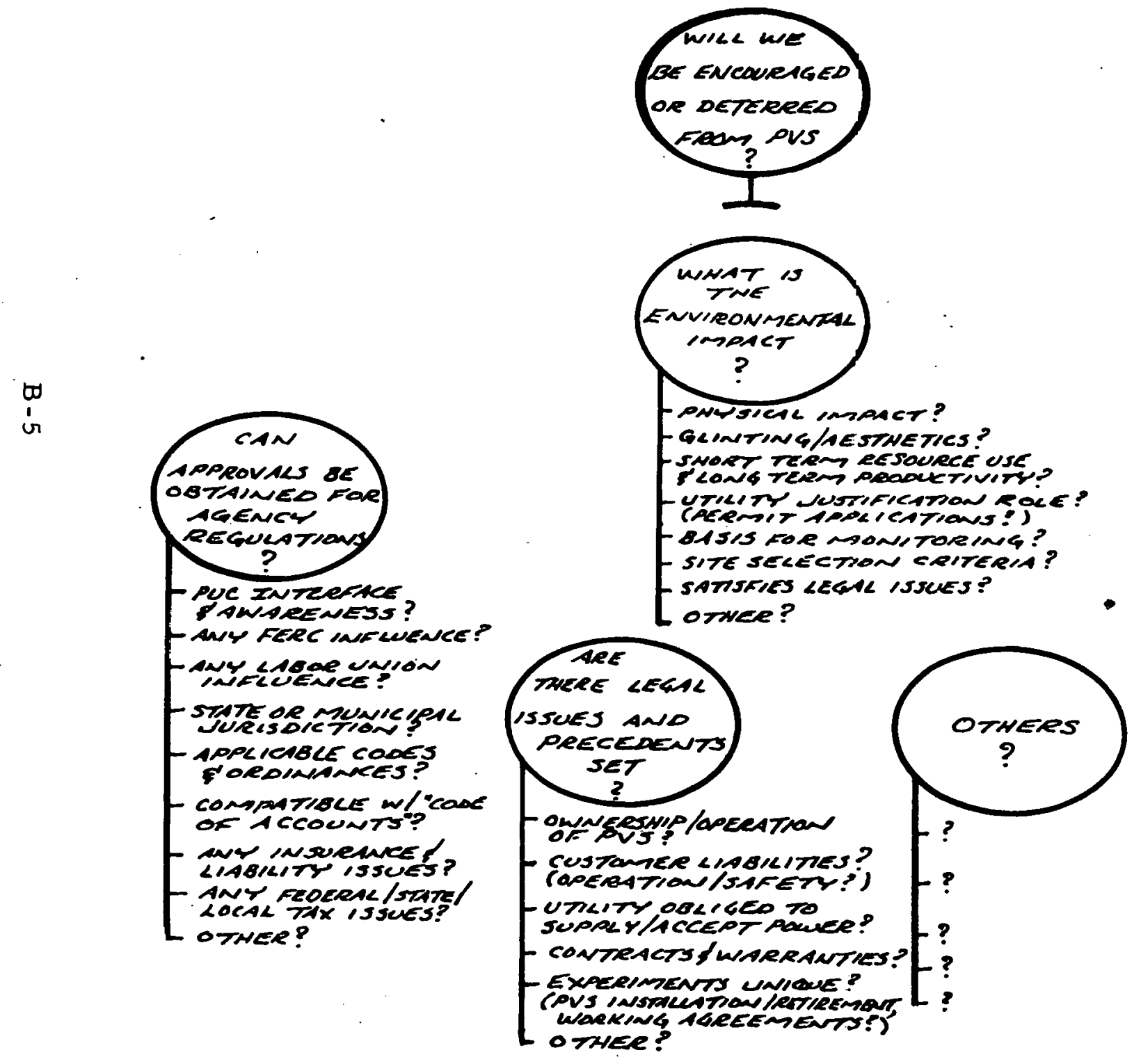


\section{CONTEMPLATED SUB-OUESTIONS: PROCUREMENT/READINESS}

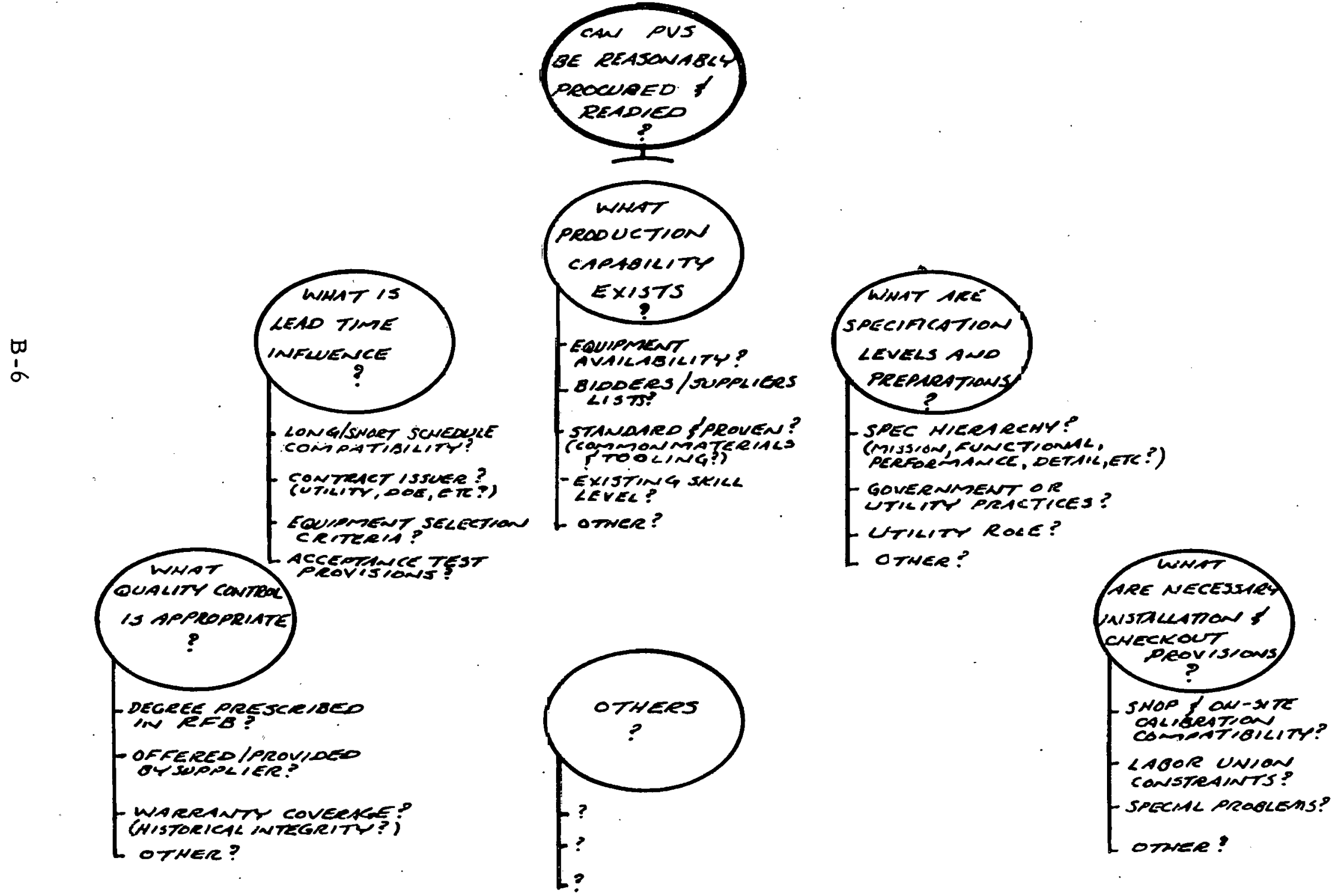




\section{CONTEMPLATED SUB-QUESTIONS: UTILITY INVOLVEMENT}
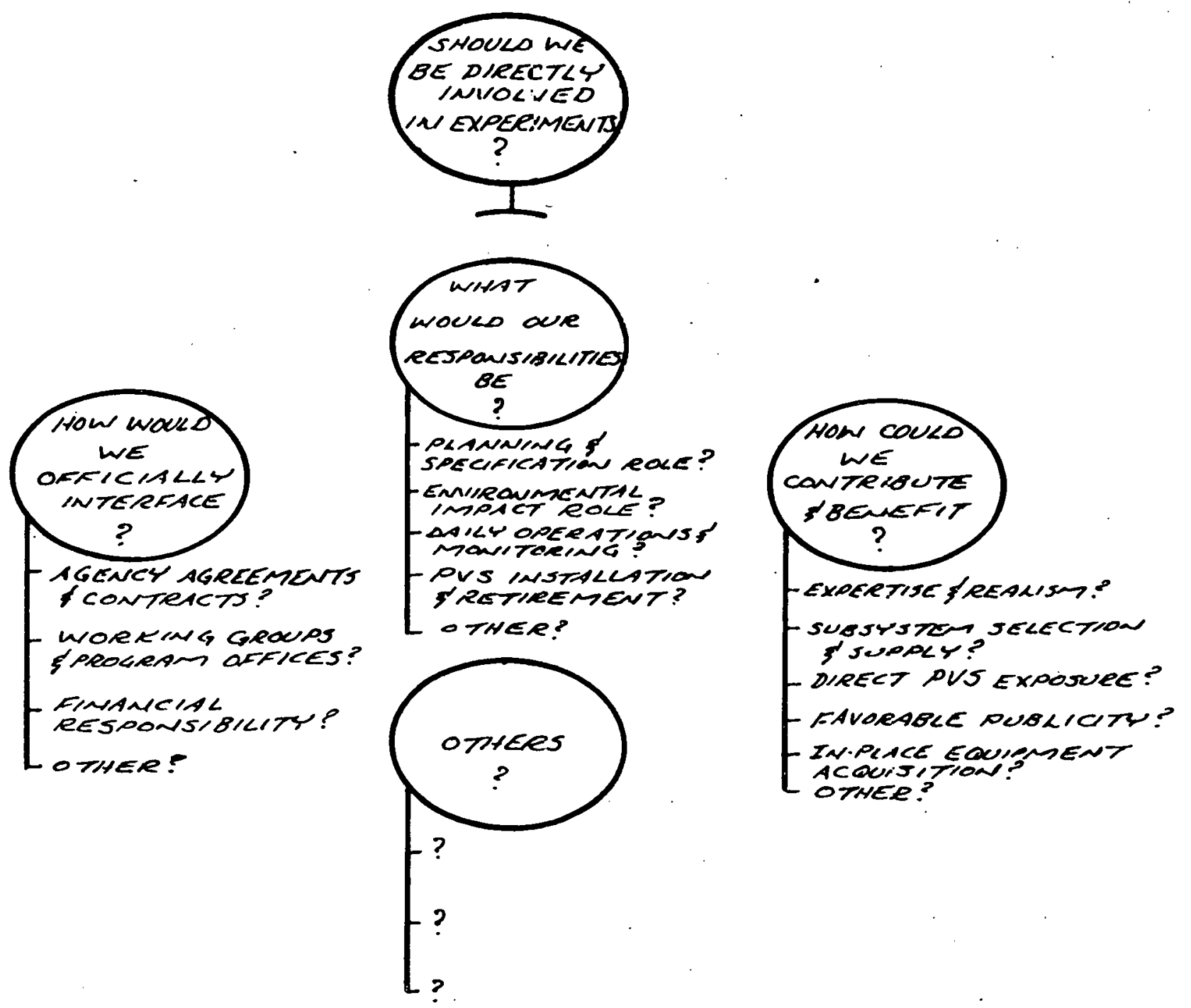

Acours'tion? 
CONTEMPLATED QUESTION: FORMATION ACQUISITION

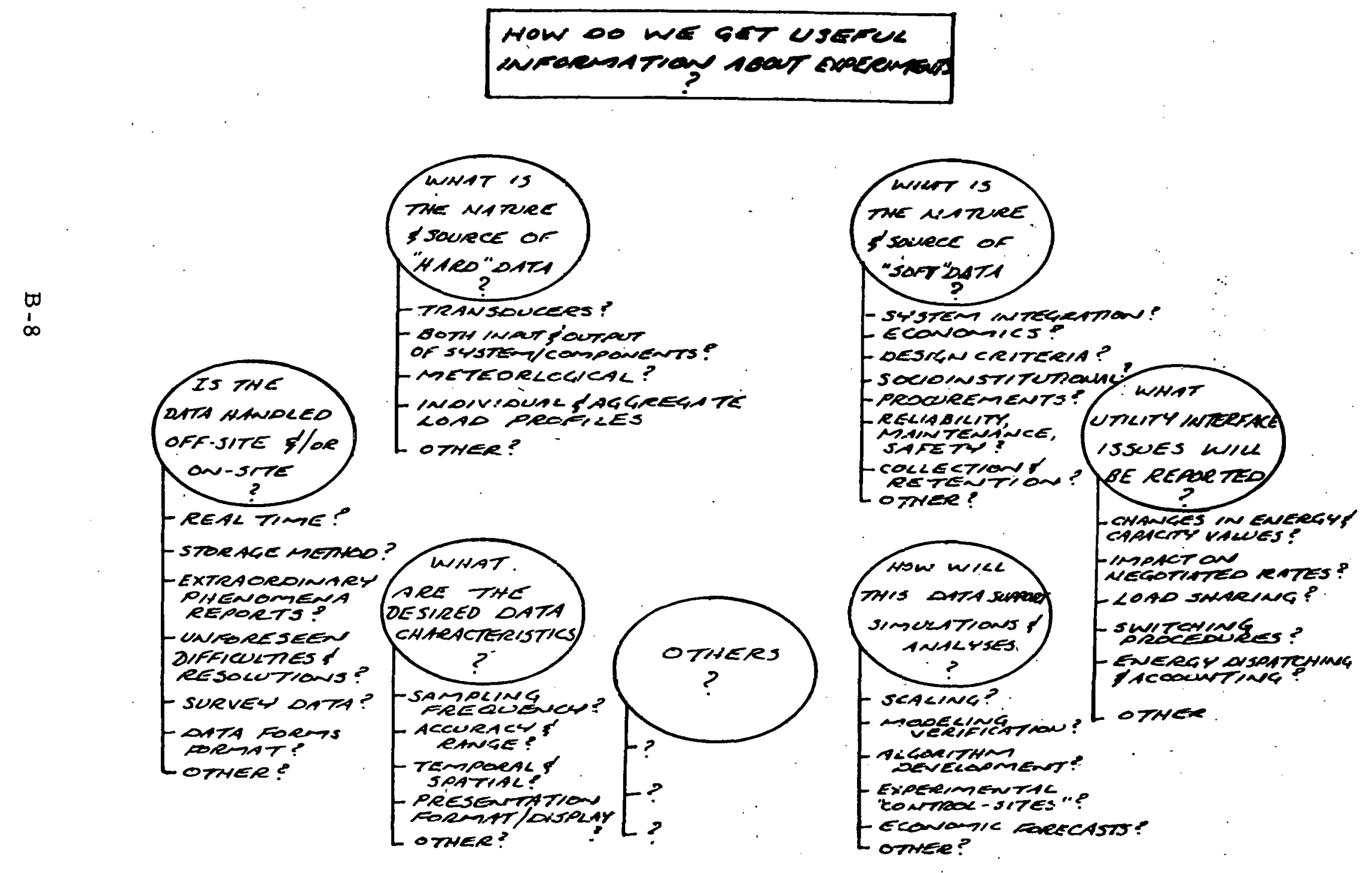


PART II. CONTEN TS

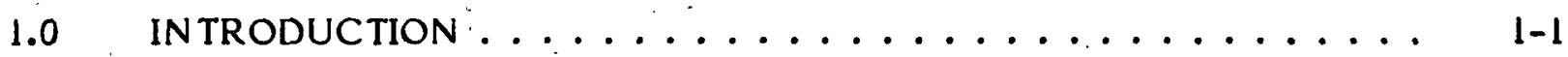

2.0 IMPACTS ON OPTIMAL GENERATION MIX .......... 2 .

2.1 Introduction and Approach ................ 2-1

2.2 Incremental Cost of Production Optimization Analysis . . . . . 2-1

2.3 Load Duration Curve Analysis . . . . . . . . . . . . . 2-6 2-6

2.4 Photovoltaic Penetration Analysis . . . . . . . . . . . . 2-6

2.5 Assessment .................... 2-12

3.0 IMPACTS ON PRODUCTION COST AND FUEL CONSUMPTION FOR A FIXED UTILITY ............................ $3-1$

3.1 Introduction and Approach ............. 3-1

3.2 On-Site Photovoltaic Units . . . . . . . . . . . . 3 3-4

3.3 PV Performance Model ................. 3-8

3.4 Utility Model . . . . . . . . . . . . . . . . . 3-10

3.5 Utility Impact Results . . . . . . . . . . . . . . . . . 3-15

3.6 Conclusions and Recommendations. . . . . . . . . . . . 3-47

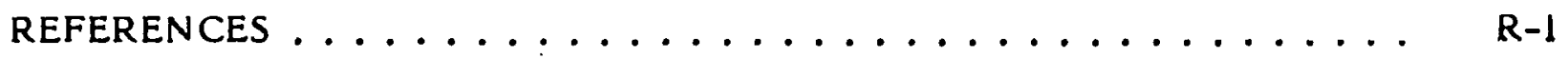

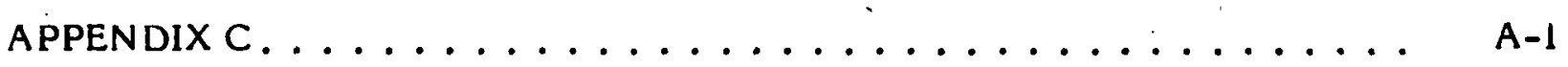




\section{FIGURES}

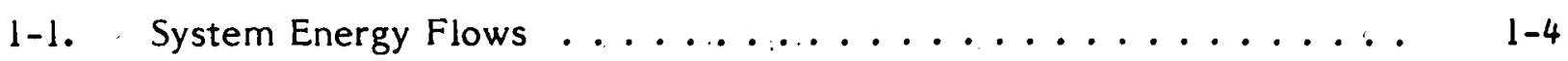

2-1. Utility System Economics Model (USEM) ................ 2-2

2-2. Menu of 1990 Conventional Power Plants - 1980 Real Dollars,

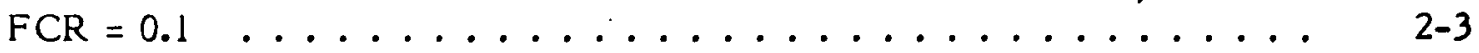

2-3. Annual Cost of Conventional Generation .............. 2-4

2-4. Menu of Conventional Power Plants - 1968 Real Dollars, FCR $=0.1$. 2-5

2-5. Geographic Diversity of Load Duration Curves - FPC Form 12 Data . . 2-7

2-6. Seasonal Diversity of Load Duration Curves - FPC Form 12 Data . . 2-8

2-7. December Demand Profiles (Photovoltaic Penetration 10\%). . . . . 2-9

2-8. December Demand Profiles (Photovoltaic Penetration 30\%). . . . . 2-9

2-9. April Demand Profiles (Photovoltaic Penetration 10\%) ....... 2-10

2-10. April Demand Profiles (Photovoltaic Penetration 30\%) ....... 2-10

2-11. August Demand Profiles (Photovoltaic Penetration 10\%) ....... 2-11

2-12. August Demand Profiles (Photovoltaic Penetration 30\%) ....... 2-11

2-13. Effect of Solar Penetration on Load Duration Curve . . . . . . . . 2-13

2-14. Optimal Conventional Mix vs PV Penetration............. 2-14

2-15. Energies Produced by Optimal Mix vs PV Penetratinn . . . . . . 2-15

2-16. Conventional Generation Costs $\left(x 10^{9} \$\right) \ldots \ldots$ 2-16

3-1. Plan for Investigating Impact of PV Units on Electrical Utilities . . . 3-3

3-2. House Energy Demand .................... 3-6

3-3. Utility Total Energy Demand by Month . . . . . . . . . . . . 3-11

3-4. Utility Incremental Cost Curve ................. 3-14

3-5. Demand and PV Output Profiles (Week in January - No Storage) . . . 3-16

3-6. Demand and PV Output Profiles (Week in January - $32.6 \mathrm{kWh}$

Storage $\ldots \ldots \ldots \ldots \ldots \ldots \ldots$ 
FIGURES (Cont.)

3-7. Demand and PV Output Profiles (Week in July - No Storage). . . . . 3-20

3-8. Demand and PV Output Profiles (Week in July - 32.6 kWh Storage) . . . 3-22

3-9. Load Duration Curve - $80 \mathrm{M}^{2}$ Array Area, Excess Energy Dumped . . . 3-23

3-10. Load Duration Curve - $80 M^{2}$ Array Area, Excess Energy Fedback . . 3 3-24

3-11. Load Duration Curve - $160 \mathrm{M}^{2}$ Array Area, Excess Energy Dumped. . . 3-25

3-12. Load Duration Curve - $160 \mathrm{M}^{2}$ Array Area, Excess Energy Fedback. . . 3-26

3-13. Oil Savings vs Number of PV Residences - No Storage and Excess

Energy Dumped .......................... 3-28

3-14. Oil Savings vs Number of PV Residences - No Storage . . . . . . . 3-29

3-15. Oil Savings vs Number of PV Residences - On-Site Storage and

3-16. Oil Savings vs Number of PV Residences - On-Site Storage . . . . . 3-31

3-17. Impact of Storage and Feedback on Oil Generation Savings . . . . . 3-32

3-1 8. Fuel Cost Differential - No Storage and Excess Energy Dumped . . . 3-34

3-19. Fuel Cost Differential - No Storage ............... 3-34

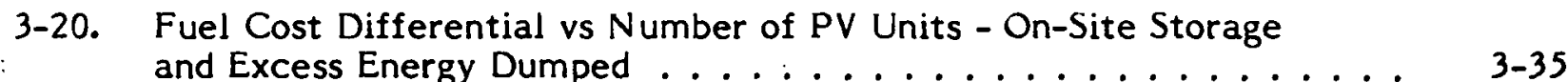

3-21. Fuel Cost Differential vs Number of PV Units - On-Site Storage . . . . 3-35

3-22. Impact of Storage and Feedback on Fuel Cost Differential . . . . . 3-36

3-23. Backup and Sellback Rates vs PV Penetration - No Storage . . . . . . 3-40

3-24. Effect of PV Penetration on Backup and Sellback Rates - With

3-25. Backup and Sellback Ratios - With and Without Storage . . . . . . 3-44

3-26. Backup and Sellback Rates as a Function of Penetration . . . . . . . . 3-45 


\section{TABLES}

1-1. Utility Impact Scenarios .................. 1-3

2-1. Analysis Parameters ...................... 2-1

3-1. Definition of Load Diversity ............... 3-5

3-2. PV Unit Characteristics ................ 3-7

3-3. Comparison of Utilities - Mix of Generating Units . . . . . . . 3-10

3-4. Mix of Plants for Utility Model . . . . . . . . . . . . 3-12 .

3-5. Fuel Cost and Efficiency Assumptions . . . . . . . . . . 3-13

3-6. Fractional Energy Values Due to PV Unit Operation . . . . . . . . 3-17

3-7. PV Penetration (Percent Conventional Capacity) as a Function of Array Area and Number of PV Units ........... 3-17

3-8. Comparison of Fuel Cost Differential for Average and Dispersed Sources (Array Area $=80 \mathrm{M}^{2}$ and No Storage) . . . . . . 3-46 


\section{PART II. GENERATION MIX AND COST OF PRODUCTION IMPACTS}

\subsection{INTRODUCTION}

As a result of the cyclic and occasionally intermittent character of on-site photovoltaic generation, most applications involving significant penetration of the on-site load will require the availability of backup energy from the utility company through some form of grid connection. The existence of a connection with the grid opens the possibility of reverse energy flow, termed sellback, during periods in which the photovoltaic generation exceeds the demand of the local load. Both these energy flows, backup and sellback, create perturbations in the utility demand profile and have corresponding impacts on the optimum generation mix, the capacity factors of the various conventional generating units, and the resulting costs of energy production.

It is the objective of the task discussed in this section to quantify these impacts and to analyze their sensitivity to changes in such variables as solar penetration of the on-site load, photovoltaic array size, insolation levels, and conventional plant generating mix.

In the analysis, photovoltaic penetration is viewed as a two-dimensional parameter in which the overall penetration of utility demand is roughly the product of on-site load penetration and the fraction of on-site loacis equipped with photovoltaics. For some photovoltaic configurations the generation impact will be a function of the choice of on-site load penetration and fraction of loads equipped, even though their product (utility load penetration) remains constant.

A fundamental property of photovoltaic systems is that, although the fuel is free, the conversion equipment is expensive relative to customary utility operation. Thus the adoption of on-site photovoltaic units may require a shift in the payback periods required by owners as a criterion for making capital expenditures. Also a factor concerning fuel price as an analysis parameter is its differential rate of price escalation. This is a quantity of great uncertainty in analyses of future scenarios. Given the situation with respect to foreign control of a significant portion of domestic fossil fuel availability, it is appropriate to perform analyses using 
escalation rates greater than experienced in the past, and certainly greater than the "standard" expectations of only a few percent per year.

The effective and appropriate use of energy storage remains an issue, even with a sellback path for excess energy generation. The sellback-only configuration requires the utility to accept the excess energy whenever it is available, not necessarily when it is needed. The result can be a degradation in generation efficiency and possibly the requirement for increased use of peaking units. Storage may provide special load management options not otherwise available.

Financial assumptions pertaining to the ownership of on-site units will have considerable effect on calculations of the cost of energy production. Utility. companies have been reluctant to have a large number of small customer-owned systems connected to their grids and may themselves eventually own and operate on-site units. On the other hand utility attitudes appear to be changing and financing. is less expensive for individual owners than for a utility, so that individually owned, controlled, and maintained units may become the norm.

Several utility impact scenarios can be defined for analysis, as indicated in Table 1-1. A major reason for categorizing these scenarios is that the analysis procedures appropriate for each are likely to exhibit essential differences. In the fixed utility scenario (Section 3.0), the conventional generating units are dssumed to be prescribed and PV units are introduced. Calculartons are then performed to permit examination of the impacts.

In an optimal-utility scenario (Section 2.0), an optimum mix of converitional units is developed trom a menu of possibilities to meet a given demand profile. PV units are then introduced, and a new optimum mix is calculated using the same menu of conventional possibilities. The impact of PV penetration is inferred by comparing those two optimum configurations. In a transition-utility scenario, a prescribed mix : of conventional units is assumed and new conventional and PV units are added consistent with a postulated growth in demand. The mix may not be optimal at any point in time, because some of the units were selected at prior times when conditions were different. 
Table 1-1. Utility Impact Scenarios

\begin{tabular}{|c|c|}
\hline Utility Type & Representative Impacts \\
\hline Fixed & $\begin{array}{l}\text { Short-Term Impacts } \\
\text { Utilization Adjustment of Installed Uriis } \\
\text { Immediate Cost of Production Effects } \\
\text { No Demand Growth } \\
\text { No Price Escalation }\end{array}$ \\
\hline Transition & $\begin{array}{l}\text { Micterm Impacts } \\
\text { Phasing of Generation Capacity } \\
\text { Interim Cost of Production Effects } \\
\text { Unit Purchase Postponement } \\
\text { Unit Replacement Decisions. }\end{array}$ \\
\hline Optimal & $\begin{array}{l}\text { Long-Term Impacts } \\
\text { Optimization of Installed Capacities } \\
\text { Ultimate Cost of Production Effects } \\
\text { Demand Projections } \\
\text { Price Escalation }\end{array}$ \\
\hline
\end{tabular}

To clarify the PV configurations being considered, a graphic model of energy flows is given in Figure 1-1. The solid lines represent flows consiojered in the analysis. The dashed lines represent flows that are possible in a real implementation, but are not adciressed in the analysis. (The function of the dedicated generator would be viewed as an optimizing supply for dedicated storage rather than as a means for satisfying on-site load, since the utility grid is already available as an on-site load backup.). Explicitly exhibitec are the backup ano sellback paths forming the major subjects of this generation impact study. The backup flow comprises the supply of energy to the on-site loa by the grid, altered by energy input from the photovoltaic array and possibly from storage. Backup is characterized in the study as a modified or "delta" demand. Sellback can also be included in delta demand, with the recognition that demand may sometimes be negative in that case.

The analysis reported in Section 2.0 treats the optimizeci mix case. The subject of Section 3.0 is the impact on a fixed utility, the short-term case. 


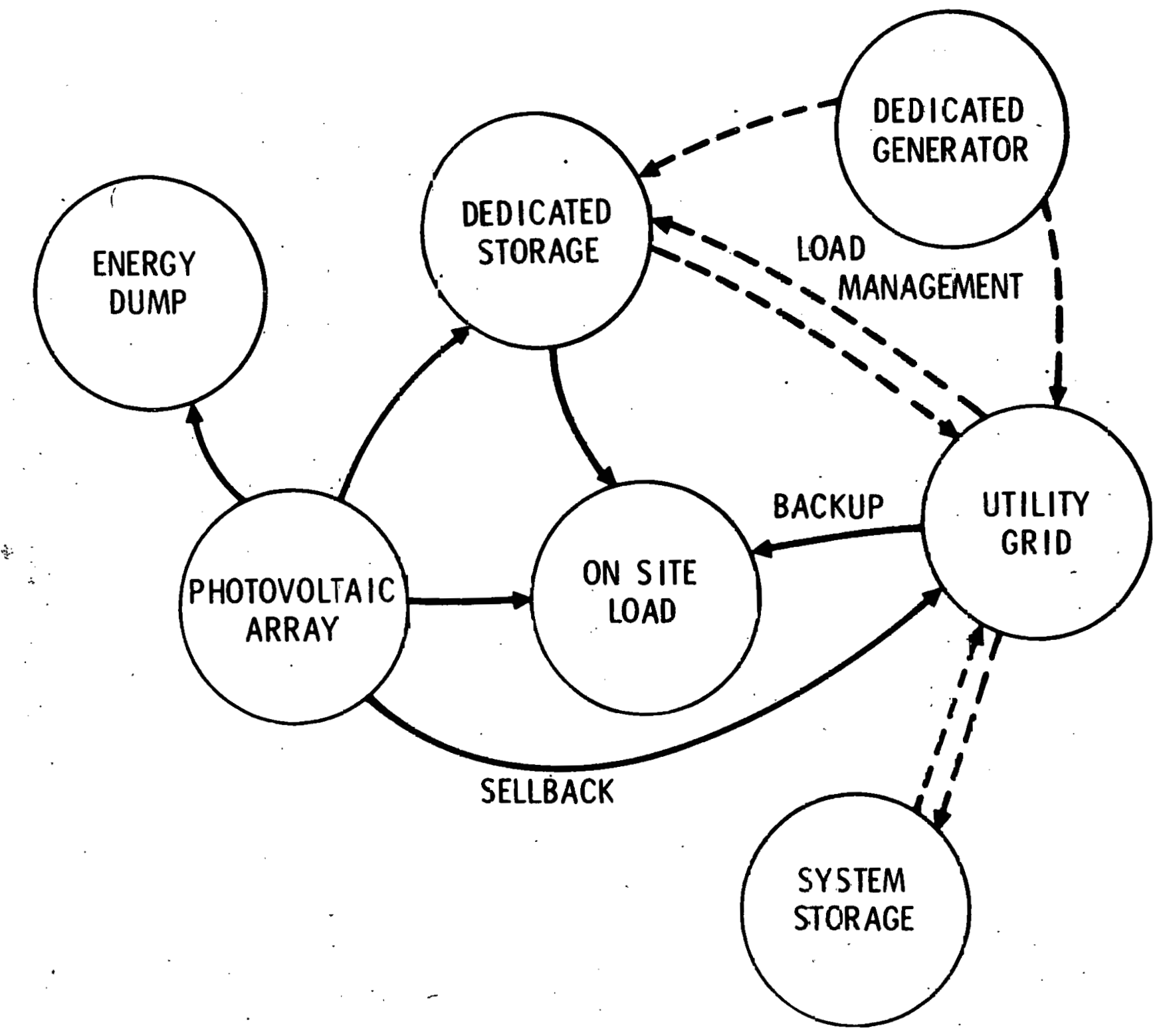

Figure 1-1. System Energy Flows 


\subsection{IMIPACTS ON OPTIMAL GENERATING MIX}

\subsection{INTRODUCTION AND APPROACH}

The methodology adopted for this analysis is a static incremental cost optimization.formulation. In this methodology, the demand is incorporated through standard load duration curves, and the optimization of the generating mix is calculated by superposing the incremental cost of production curves for the various conventional generating units in the mix. This calculation is performed in the Aerospace computer code USEM, summarized in Figure 2-1. The example shown in the figure is for three conventional generation types. In this analysis approach startup and shutciown costs are ignored, and LOLP.considerations are excluded. The incremental cost curves are drawn showing gooc textbook separation between the crossover points.

\subsection{INCREMENTAL COST OF PRODUCTION OPTIMIZATION ANALYSIS}

To oiscover the future-based cost of production characteristics of actual generating units, the menu of conventional power plants in Figure 2-2 was compiled for projected 1990 custs expressed in 1980 dollars.

A graph of the corresponding cost of production curves is shown in Figure 2-3. With the sole exception of combined cycle generation, the crossover points of the various generating units are nearly coincident. The indication is that an optimal mix would consist almost entirely of combustion turbines and whichever baseload plants, coal, nuclear, or both, are available. It can also be observeo from Figure 2-3 that, even with combined cycle plants in the mix, the highest crossover point is at only 0.32 capacity factor. Oil thermal plants are precluded in an optimal mix with these data. These results represent such a marked departure from the manner in which the curves historically have been drawn that further investigation appeared to be warranted. To accomplish this, a menu of plants using 1968 cost of production data was created and the result is given in Figure 2-4, in which the curves clearly follow the historical expectation. The conclusion is that, because of time-based cost factors, the crossover points of the incremental cost lines have been migrating to successively lower capacity factor values. 
INPUTS

- ECONOMIC PARAMETERS: ESCALATION RATES, FINANCIAL STRUCTURE, TAXES, INSURANCE

- SYSTEM MIX IOPIIONALI: CAPACITY FOR EACH PLANT CLASS IN MIX, HEAT RATES,

AVERAGE AVAILABILITY FOR EACH CLASS, PLANT COSTS

- PV PLANT SPECIFICATION: CAPACITY, ARRAY AREA, CAPITAL AND O\&M COSTS

- SYSTEM DEMANC.AND PV POWER PROFILE OUTPUTS

- BASELOAD, CYCLIING, PEAKING CAPACITY, ENERGY

- ENERGY AND COST DISPLACED BY PHOTOVOLTAIC PLANTS FOR EACH FUEL IN THE MIX

- COST OF SERVICE TO RESIDUAL DEMAND BY THE CONVENTIONAL SYSTEM

- cost/BEnEFit ratio, net value, bBeC METHOD
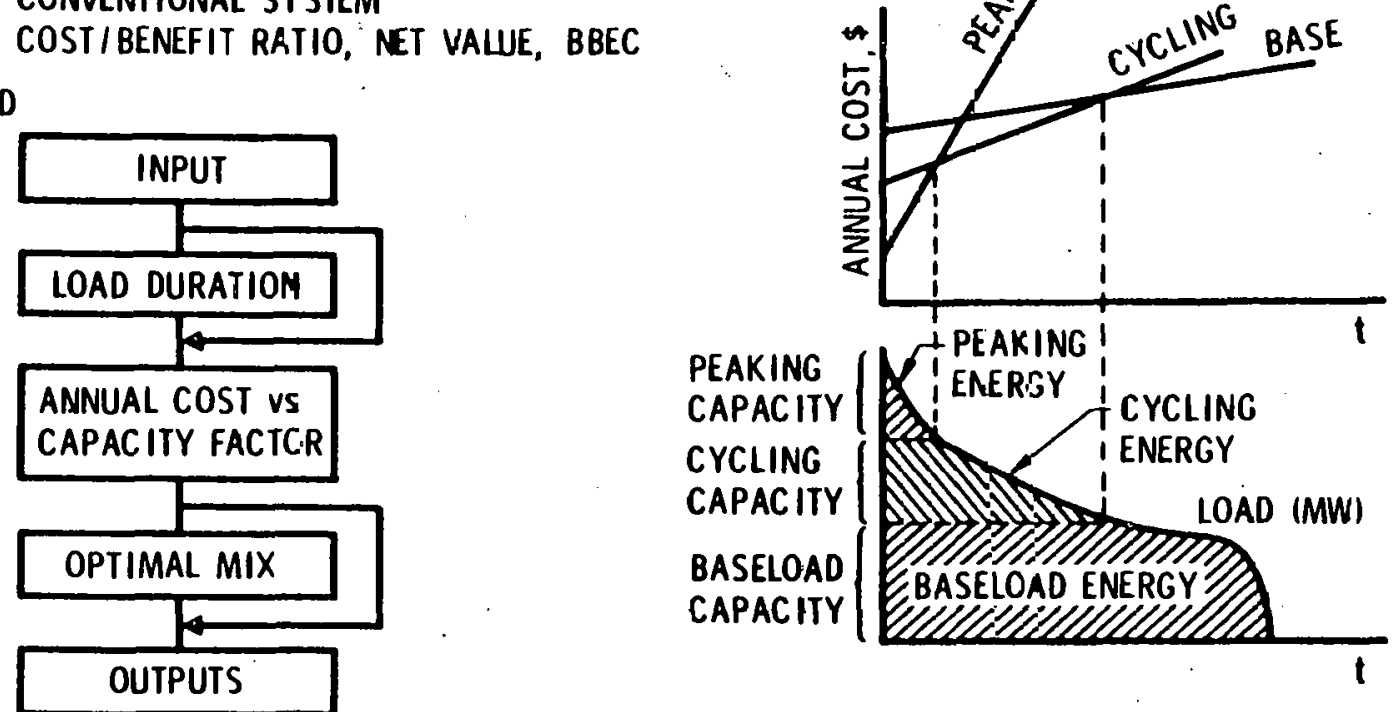

Figure 2-1. Utility System Economics Model (USEM) 


\begin{tabular}{|c|c|c|c|c|c|c|c|c|}
\hline TYPE & \multicolumn{2}{|c|}{$\begin{array}{l}\text { INV COST, } \$ / \mathrm{KW} \\
1976^{*} \\
1980\end{array}$} & $\begin{array}{l}\text { OPEF } \\
\text { FIXED, } \\
1976^{*}\end{array}$ & $\begin{array}{r}\text { ATIONS } \\
\$ / K W / y r \\
1980\end{array}$ & $\begin{array}{l}\text { AND MAIN } \\
\begin{array}{c}\text { VARIABLE } \\
1976^{\circ}\end{array}\end{array}$ & $\begin{array}{c}\text { ENANCE } \\
\text { mills/kWh } \\
1980\end{array}$ & \multicolumn{2}{|c|}{$\begin{array}{l}1990 \text { FUEL COSTS, } \$ / \mathrm{mBtu} \\
1976^{*} \\
1980\end{array}$} \\
\hline $\begin{array}{l}\text { NUCLEAR } \\
(\text { HR }=10.400)\end{array}$ & 778 & 1140 & 2.68 & 3.91 & 0.68 & 0.99 & 0.71 & 1.04 \\
\hline $\begin{array}{l}\mathrm{COAL} \\
(H R=10,102)\end{array}$ & 675 & 985 & 2.44 & 3.56 & 1.45 & 2. 12 & 0.98 & 1.43 \\
\hline $\begin{array}{l}\text { OIL } \\
(H R=9700)\end{array}$ & 415 & 605 & 1.75 & 2.55 & 0.28 & 0.41 & 2.84 & 4. 14 \\
\hline $\begin{array}{l}\text { COMBUSTION TURBINE } \\
(H R=14,000)\end{array}$ & 160 & 235 & 0.47 & 0.69 & 1.94 & 2.83 & 2.84 & 4. 14 \\
\hline $\begin{array}{l}\text { ADV COMB CYCLE } \\
(H R=7500)\end{array}$ & 275 & 400 & 1.20 & 1.75 & 0.85 & 1.24 & 2.84 & 4. 14 \\
\hline $\begin{array}{l}\text { COMB INED CYCLE } \\
(H R=8100)\end{array}$ & 325 & 475 & 1.05 & 1.47 & 1.20 & 1.75 & 2.84 & 4. 14 \\
\hline
\end{tabular}

$\tilde{N}_{\omega}^{\tilde{\omega}}$

\begin{tabular}{|l|c|l|}
\hline & $C_{F}$ & \multicolumn{1}{|c|}{$C_{U}$} \\
\cline { 2 - 3 } NUCLEAR & $\$ 118 / \mathrm{kW}$ & $\$ 103 / \mathrm{kW}-\mathrm{yr}$ \\
COAL & 102 & 145 \\
OIL & 63 & 355 \\
COMBUSTION TURBINE & 24 & 532 \\
ADV COMB CYCLE & 42 & 283 \\
COMBINED CYCLE & 49 & 309 \\
\hline
\end{tabular}

*EPRI Technical Assessment Guide, June 1977

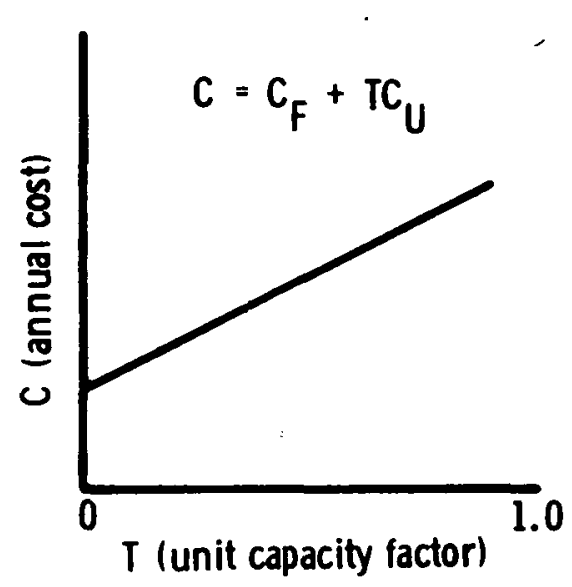

Figure 2-2. Menu of 1990 Conventional Power Plants - 1980 Real Dollars, FCR $=0.1$ 


\section{- 1988 FUEL PRICES}

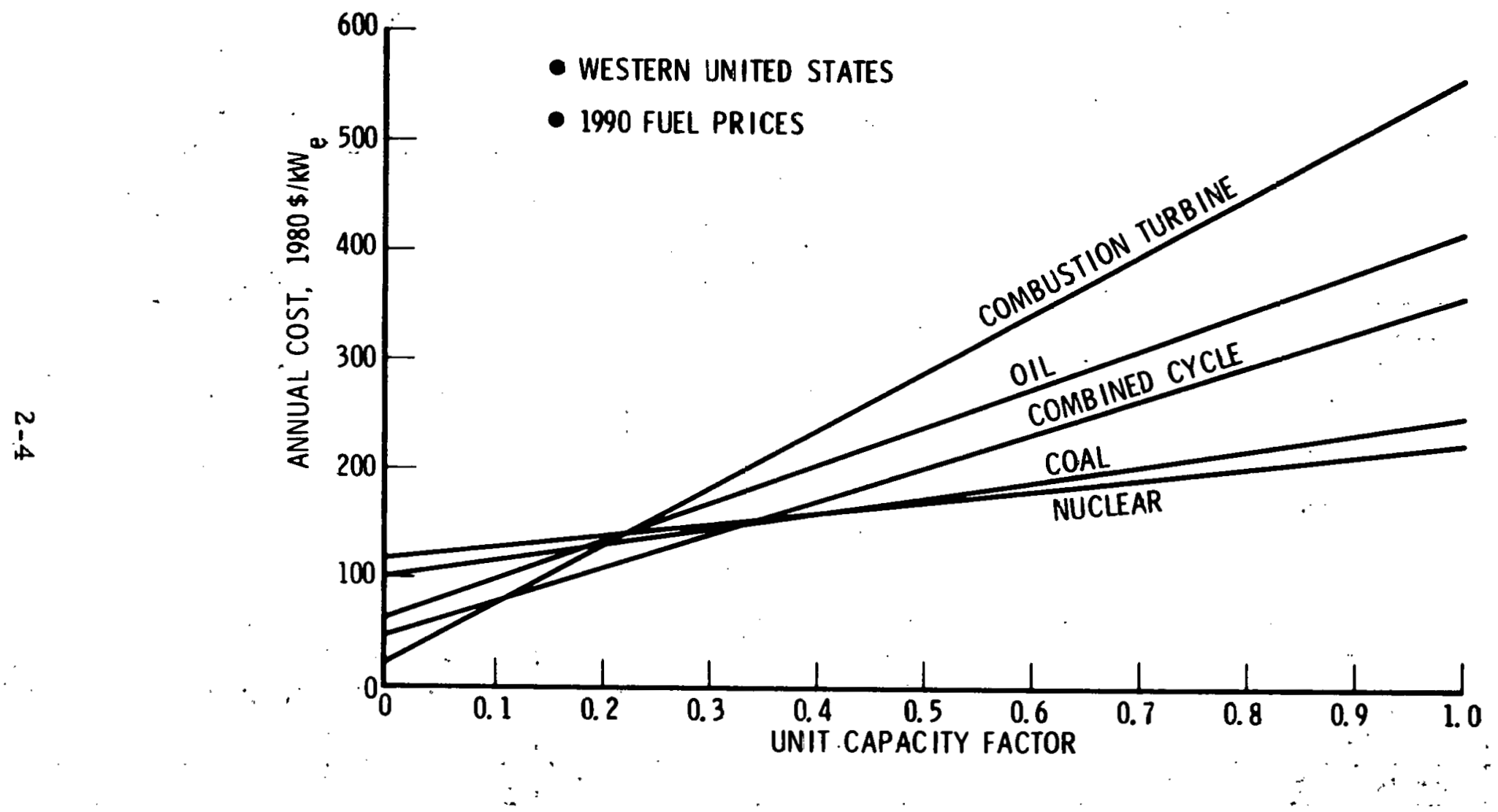

Figure 2-3. Annual Cost of Conventional Generatior. 


\begin{tabular}{|l|c|c|c|c|}
\hline \multicolumn{1}{|c|}{ TYPE } & INVESTMENT COST, \$/KW & FUEL COSTS; \$/mBtU & HEAT RATE, BtU/kWh & VARIABLF COST, \$/mWh \\
\hline NUCLEAR & 240 & $\ddots$ & - & 2.0 \\
FOSSIL & 165 & 0.29 & 11,000 & 3.2. \\
COMBUSTION TURBINE & 85 & 0.60 & 15,000 & 9.0 \\
\hline
\end{tabular}

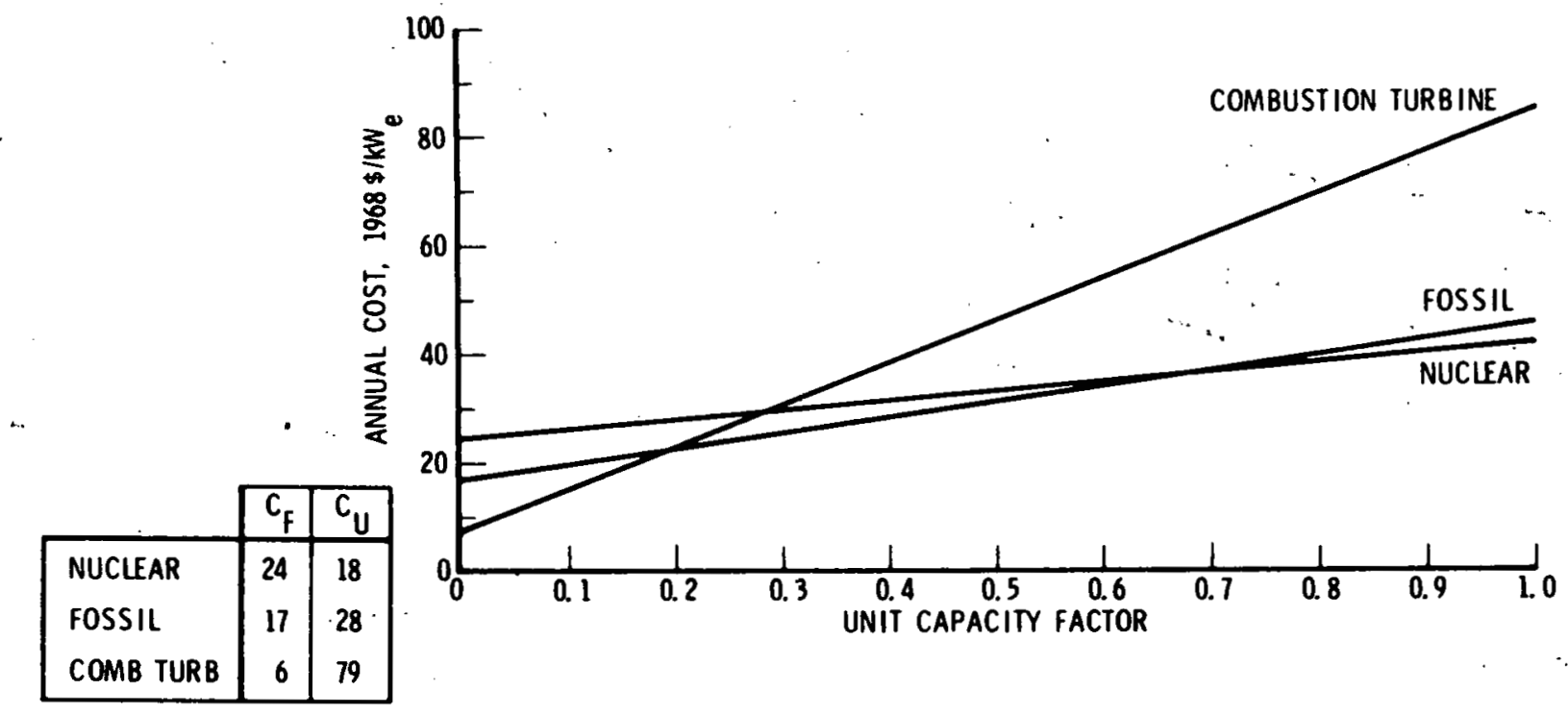

Figure 2-4. Menu of Conventional Power Plants - 1968 Real Dollars, FCR = 0.1 


\subsection{LOAD DURATION CURVE ANALYSIS}

The load duration curves in Figure 2-5 are included to enhance understanding of the load duration characteristics. Each set of curves represents one of four ditferent utility companies, ano each of the three curves in a given set represents a one-week period during a particular season of the year. Each curve is separately normalized to unity peak demand over its seven day interval. There is a striking similarity among the normalized load duration curves across the seasons within a specific utility and also across the different utilities.

To incicate the effects of the normalization operation, the curves in Figure $\mathbf{z}-6$ were constructed to give a side-by-side comparison of normalized and not normalized load duration curves for a single utility. Superimposed on the "not normalized" set is the effective annual curve that would result from considering a year-long interval instead of week-long intervals. Figure 2-6 indicates that caution must be exercisec, in using annual curves, especially if the analysis being performed includes a maintenance downtime model relying on demand lulls.

\subsection{PHOTOVOLTAIC PENETRATION ANALYSIS}

The foregoing discussion has been offered as background so that the effects of photovoltaic penetration of the utility demand could be introduced. The effects on a week long utility demand profile of two different penetration levels for three different seasons are shown in Figures 2-7 through 2-12. The penetration levels of 10 and 30 percent refer to the percentage of peak demand represented by peak solar generation. The basic utility demand profile used is projected Southern California Edison demand for 1990. The insolation data are based on Inyokern, California measurements taken in 1963.

Note that April and December exhibit an evening peaking phenomenon that is unmodified by the photovoltaic energy. However, for this utility the peak demand season occurs in summer because of cooling loads, and this daytime peak is reduced by the photovoltaic source. The fourth day of the August profile is interesting for its apparent cloud cover. The curves support an argument for some capacity credit, but beyond a certain threshold of solar penetration the capacity requirement is 

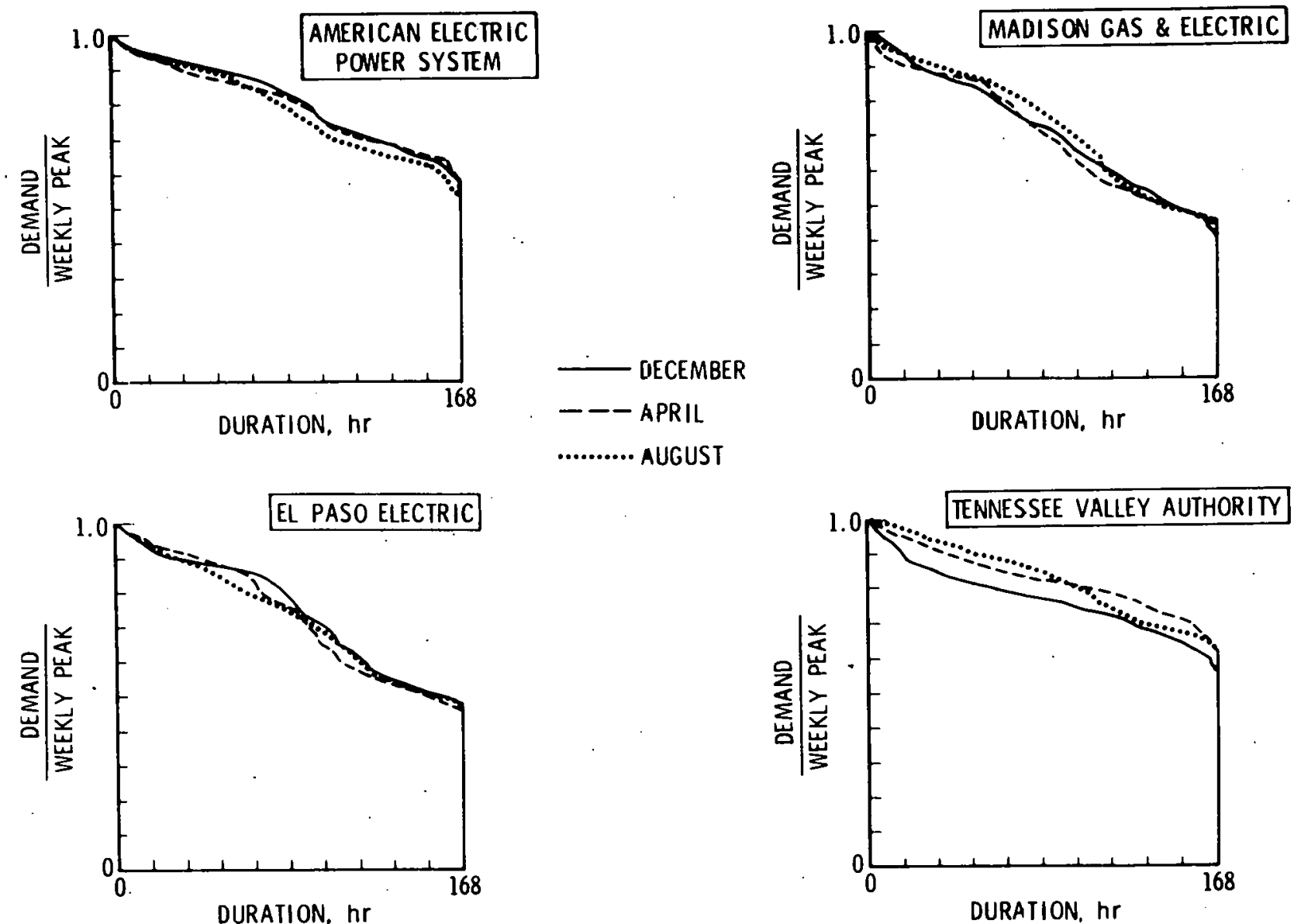

Figure 2-5. Geographic Diversity of Load Duration Curves F PC Form 12 Data 

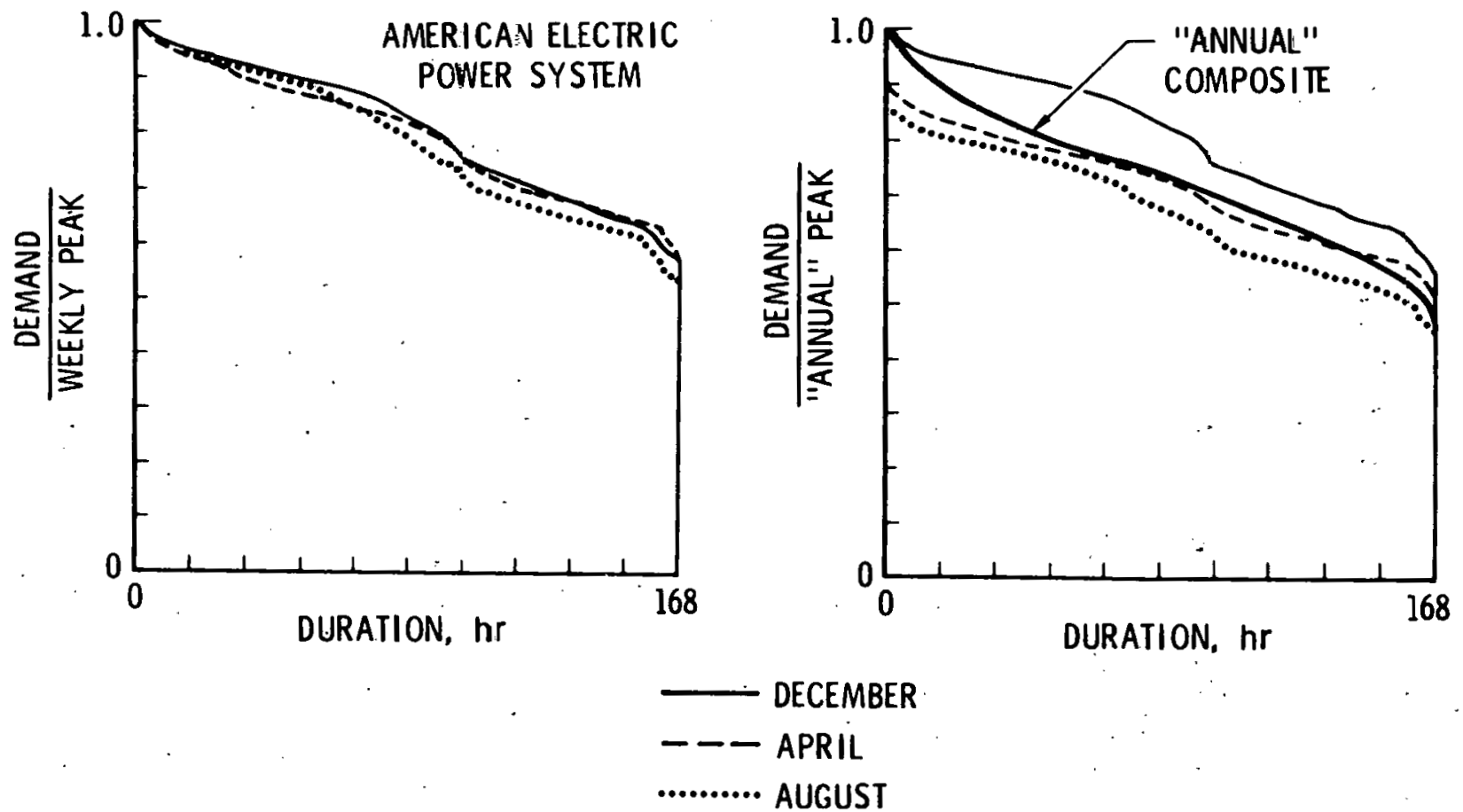

Figure 2-6. Seasoral Diversity of Load Duration Curves FPC Form 12 Data 

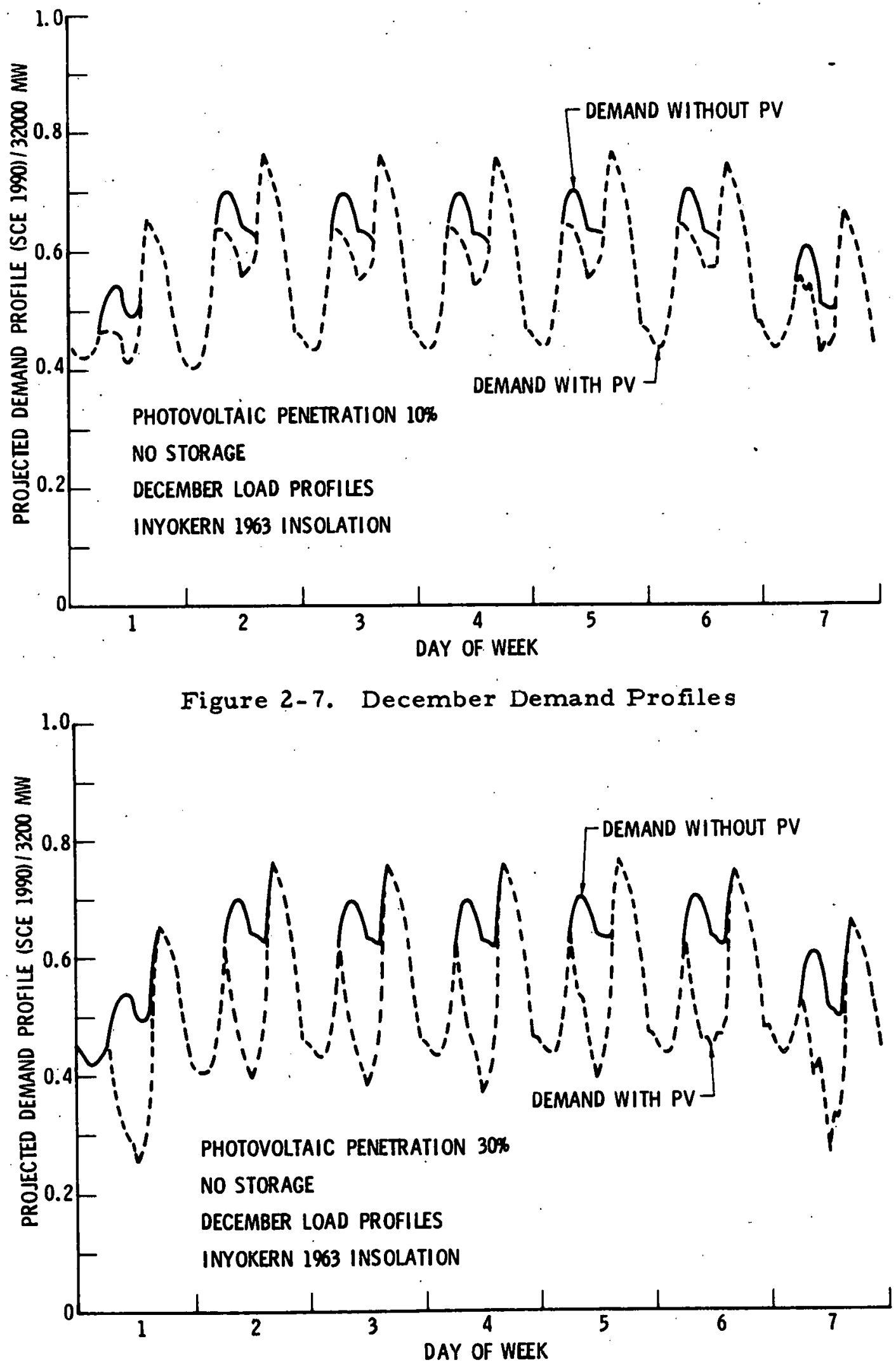

Figure 2-8. December Demand Profiles 


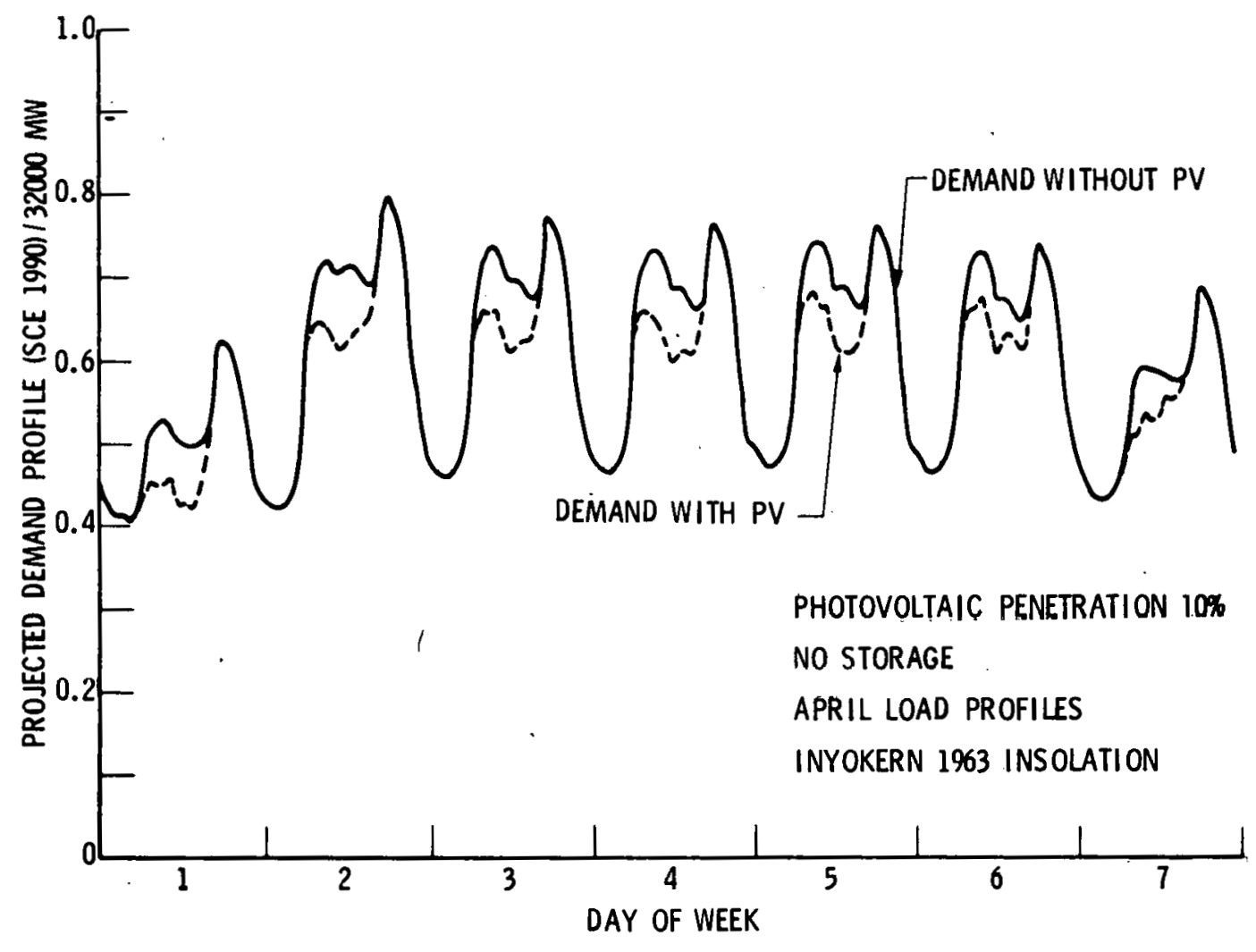

Figure 2-9. April Demand Profiles

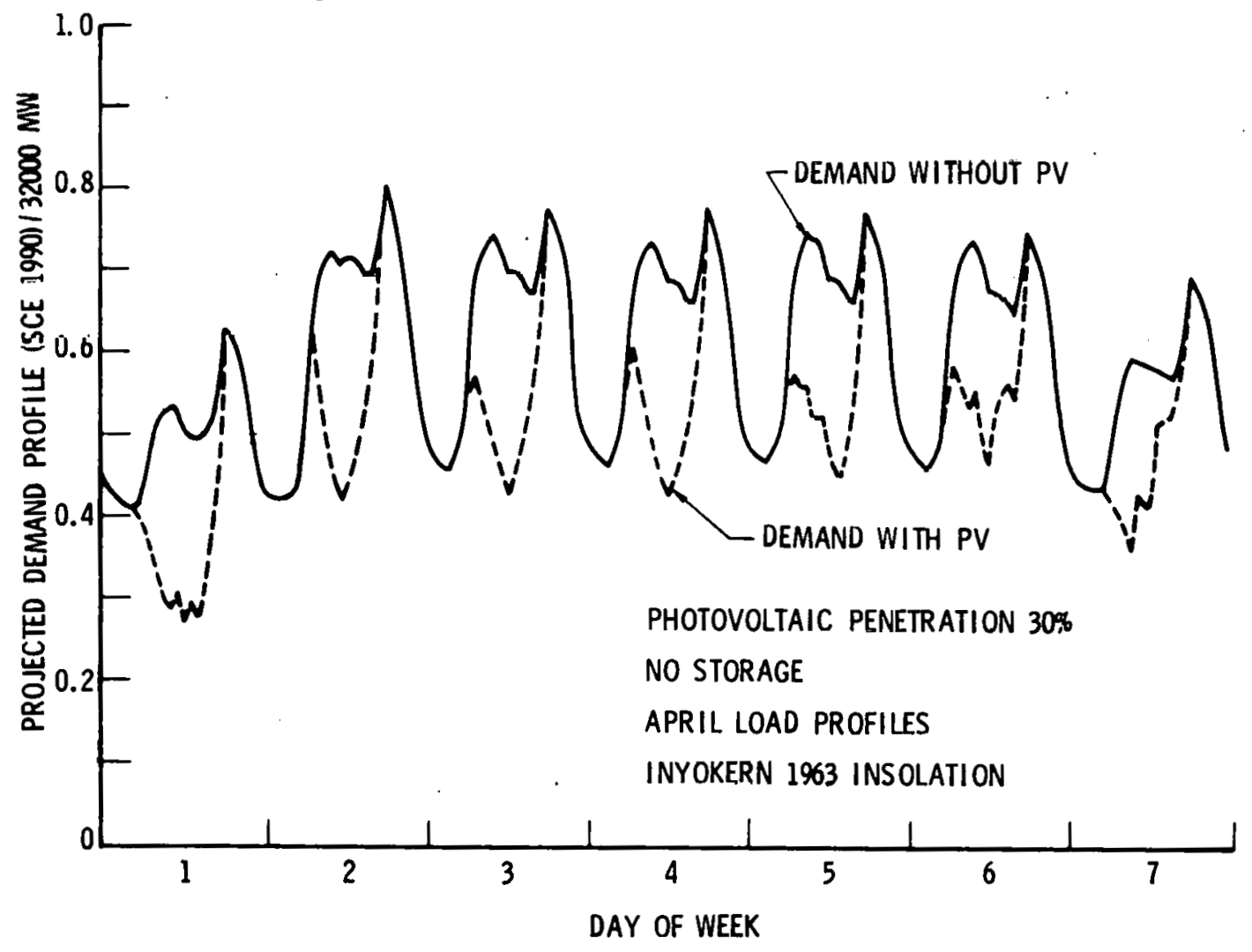

Figure 2-10. April Demand Profiles 


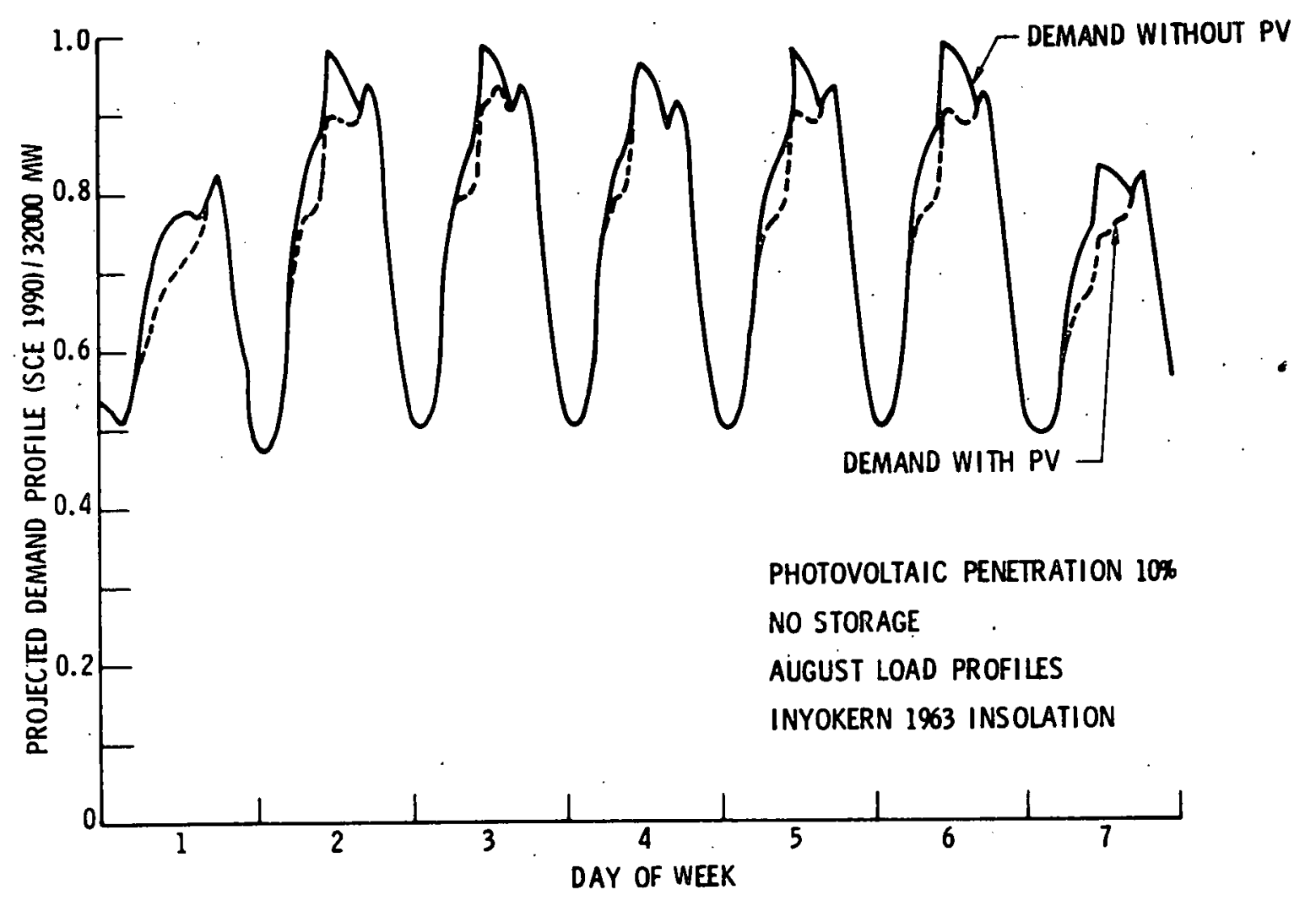

Figure 2-11. August Demand Profiles

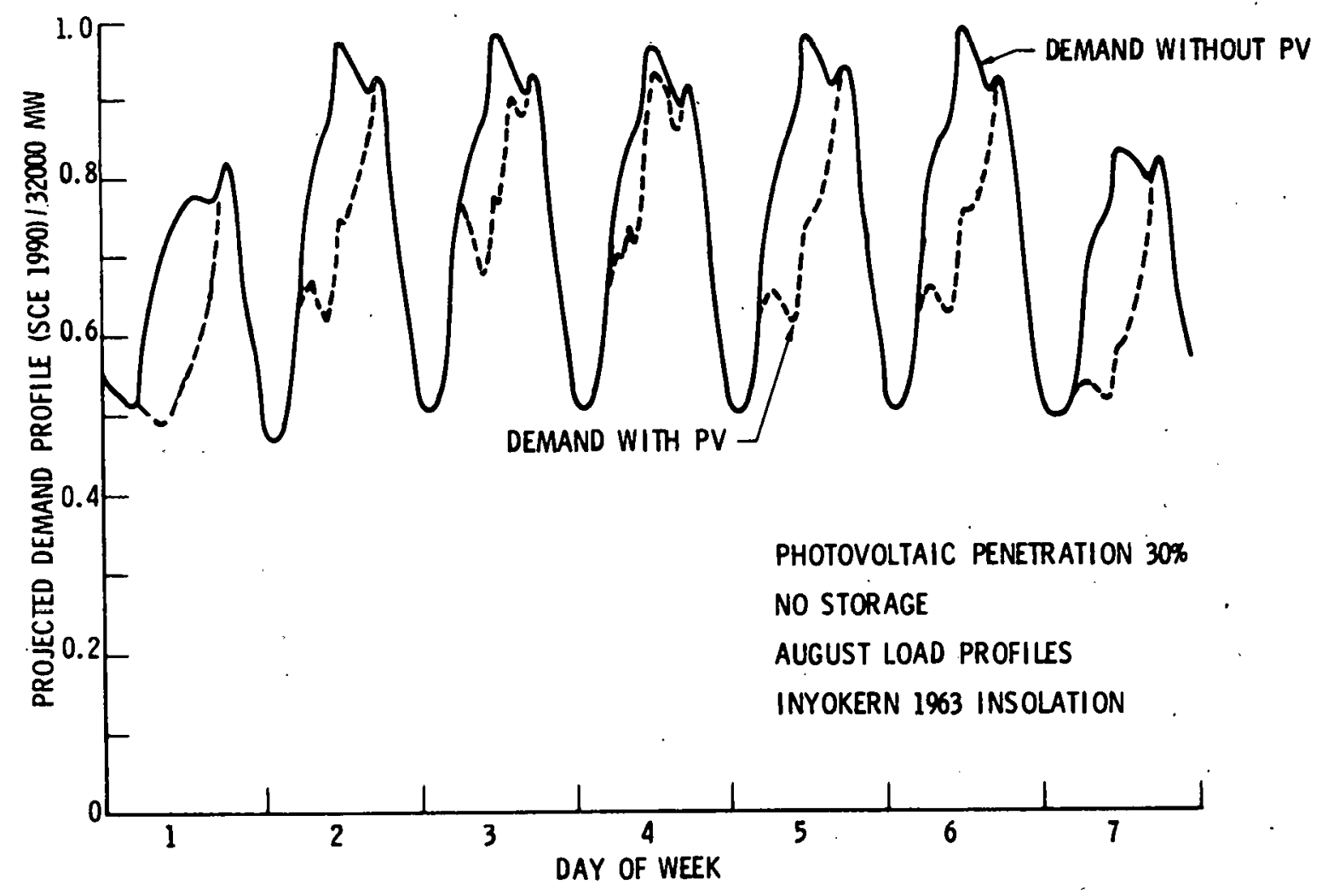

Figure 2-12. August Demand Profiles 
determined by the secondary evening peak. It appears very likely that the amount of capacity credit to be accorded solar will be utility dependent, and this issue is still very controversial.

In Figure 2-13 the effect of photovoltaic generation on the annual load duration curve is shown for six values of penetration, including zero. The effect is a more or less uniform depression of the curve along most of the capacity factor axis. It is notable that the six curves are not renormalized from curve to curve so that the peak demand is essentially unity independent of the penetration. It is clear that an increase in peaking utilization will be required to optimize the economic mix. Also worth noting is the behavior for unity capacity factor at which a fairly substantial displacement of baseload generation is evident.

Some results of the incremental cost of production optimization are presented in Figures 2-14 through 2-16. Figure 2-14 indicates the optimal capacity for the three modeled conventional plants. There are clear increases in combustion turbine utilization and decreases in baseload coal utilization as functions of increasing photovoltaic penetration. 'In Figure 2-9, results for energy production and documented. and the amount of energy produced by each conventional technology is indicated by the vertical distance between the two adjacent lines on the graph. Essentially all the energy produced by photovoltaics displaces coal use. In Figure 2-16, the energy production costs associated with each conventional plant type, including fixed, variable, and total costs, are given.

\subsection{ASSESSMENT}

Some interim observations and tentative conclusions based on the work reported here are summarized below:

\section{Incremental Cost Optimization Analysis}

- As oil prices rise oil plants, including combined cycle, become particularly inappropriate in an economically optimum system.

- Particular methodology does not permit study of the sensitivities of costs of production to oil price, since the economic optimum precludes oil from the mix altogether. 
$\stackrel{\sim}{i}$

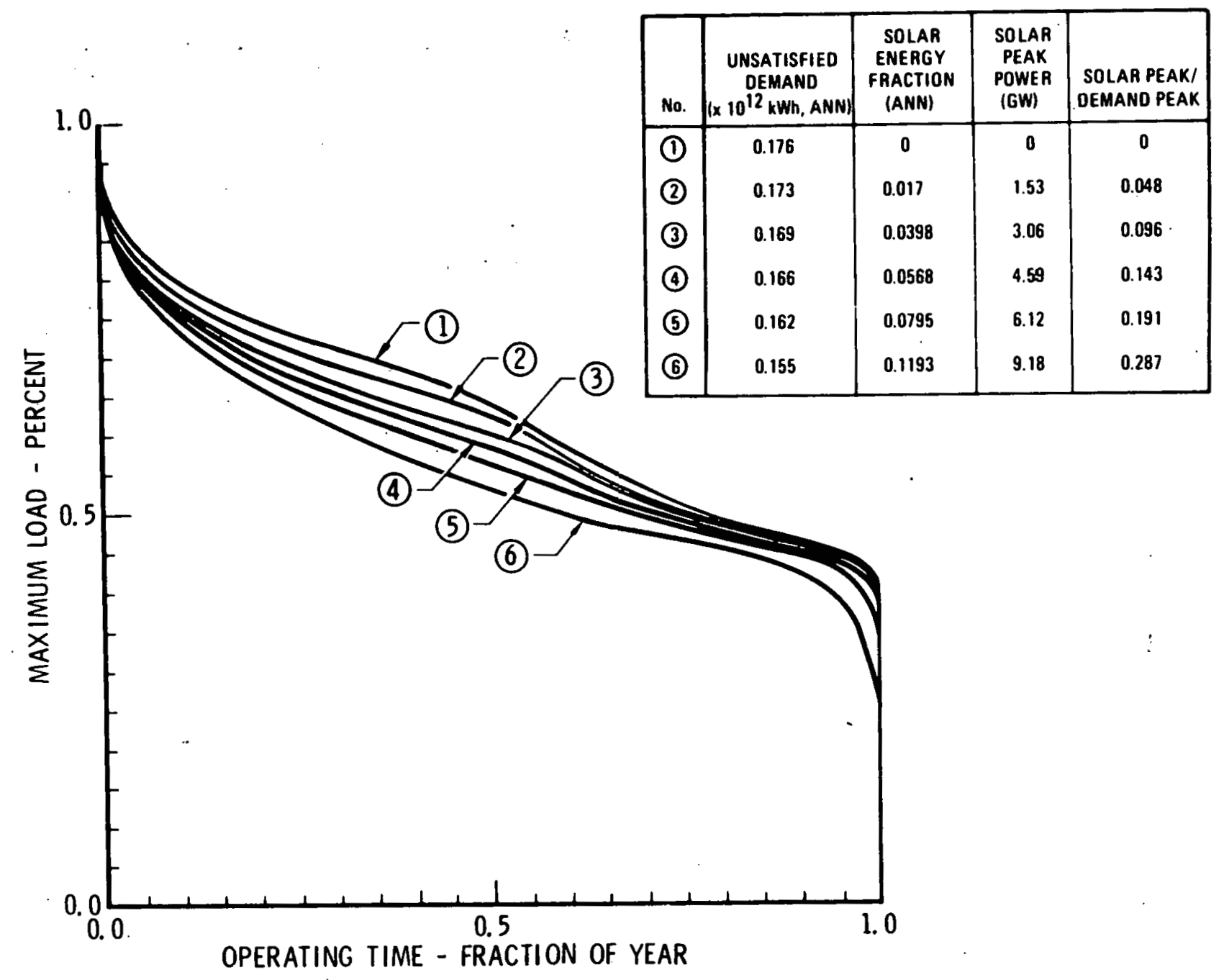

Figure 2-13. Effect of Solar Penetration on Load Duration Curve 


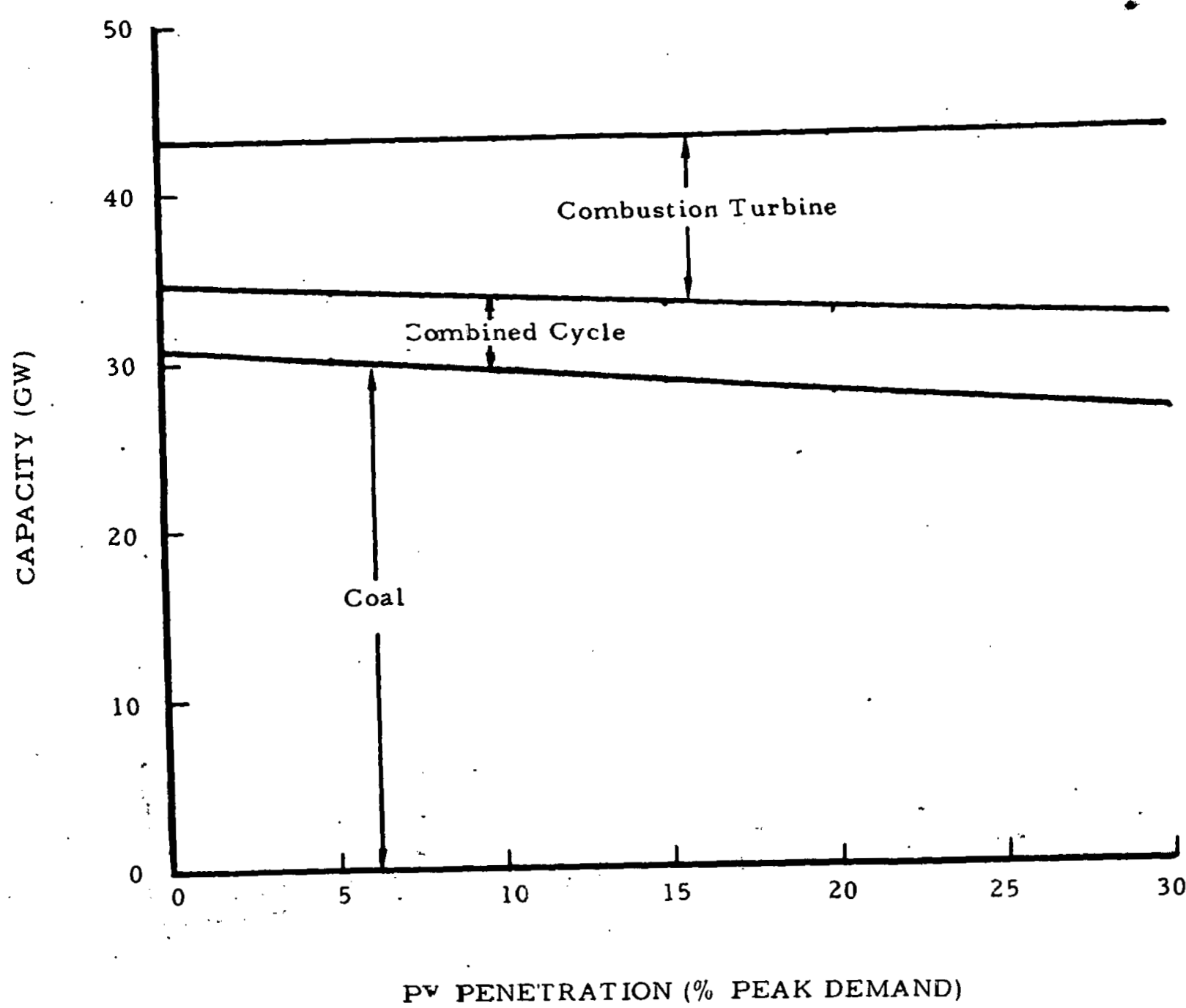

Figure 2-14, Optinal Conventional Mix vs PV Penetration 


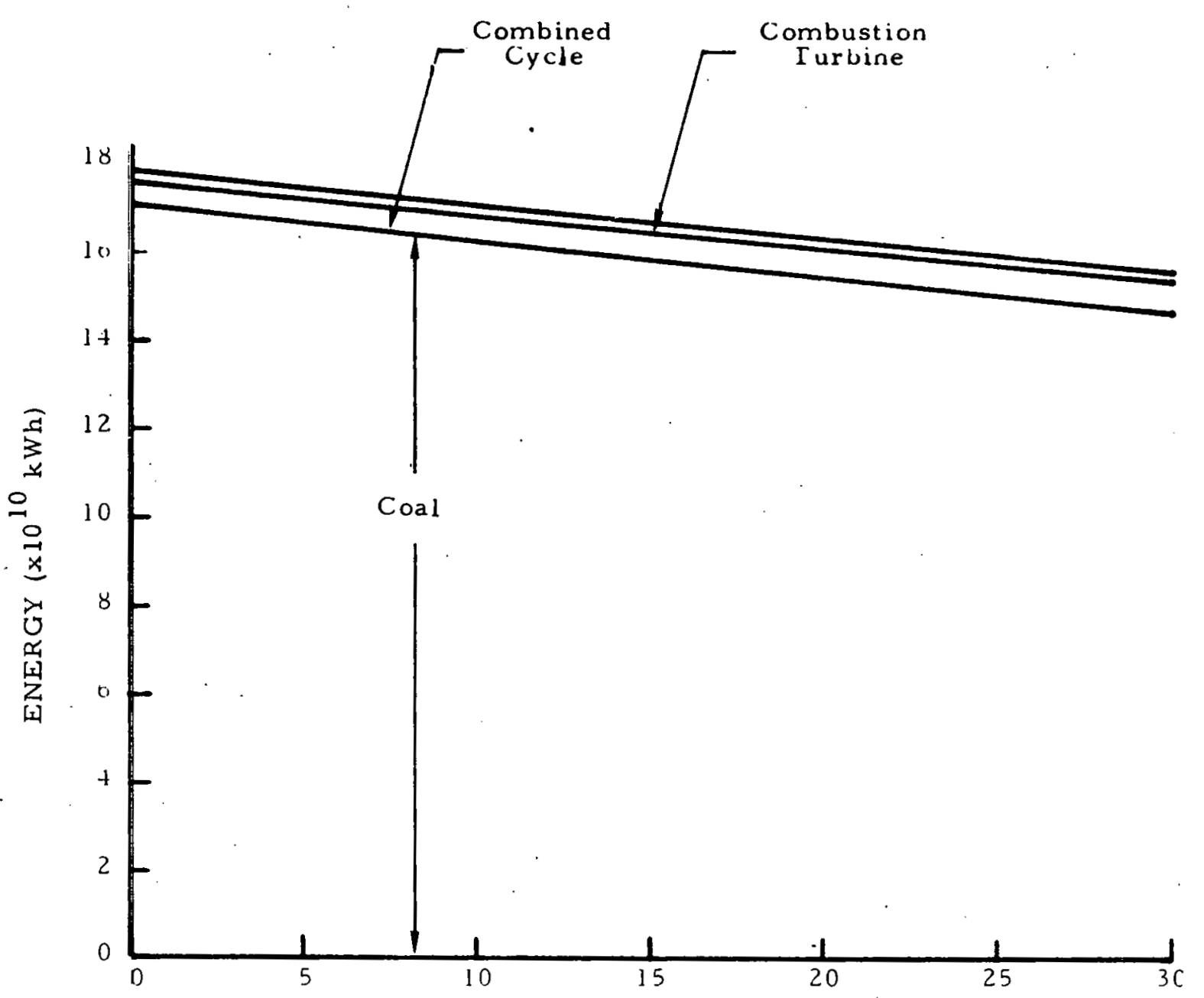

PV PENETR $\because T I O N$ (\% PEAK DEMA:VDI)

Figure 2-15. Energies Produced by Optimal Mix vs PV Penetration 
FIXED COSTS

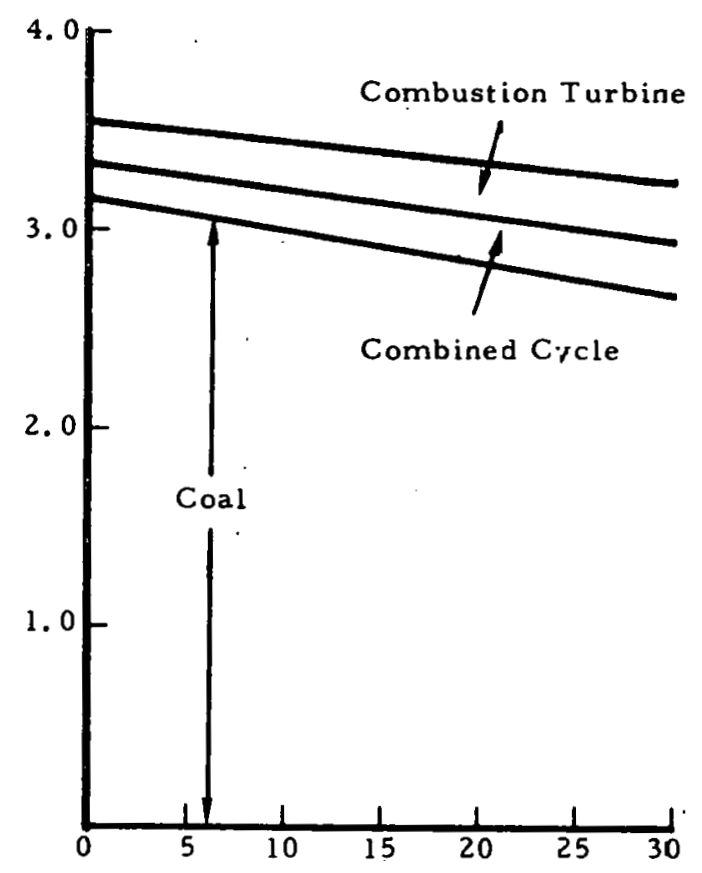

VARIABIE COSTS

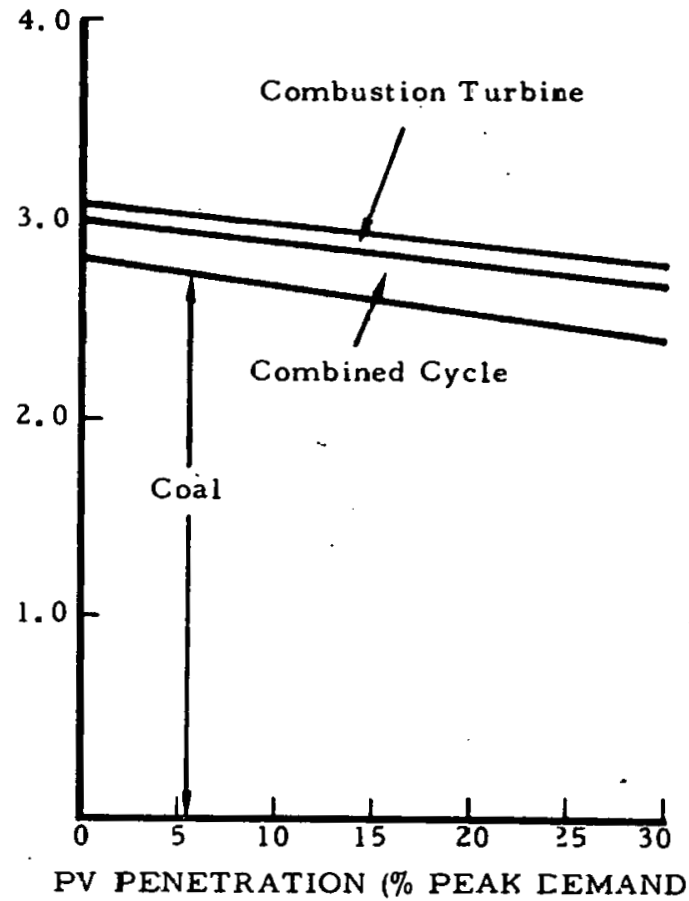

TOT AL COSTS

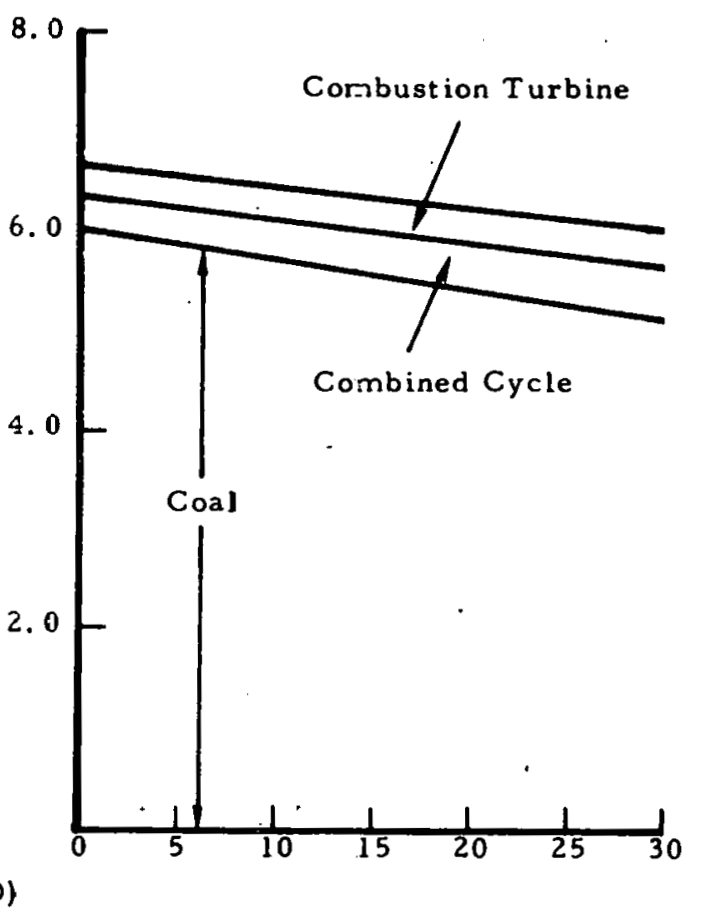

Figure 2-16. Conventional Generation Costs $\left(\begin{array}{lll}x & 10^{9} & \text { \$) }\end{array}\right.$ 


\section{Load Duration Curve Analysis}

- Shapes of weekly load duration curves are similar for different seasons and geographic regions.

- Shapes of weekly and annual load curves jiffer.

\section{$\underline{\text { PV Penetration Analysis }}$}

- Without storage or sellback large penetrations can impact baseload capacity and reduce system peaks.

- Without storage, but with perfect sellback, there is a small impact on the optimum mix of conventional plarits with a slight increase in cycling units. 
Blank

$$
2-18
$$




\subsection{IMPACTS ON PRODUCTION COS1 AND FUEL CONSUMPTION \\ FOR A FIXED UTILITY}

\subsection{INTRODUCTION AND APPROACH}

The purpose of this analysis is to investigate the impact of on-site photovoltaic (PV) units on an electric utility that has a fixed conventional generation mix. The objectives of this analysis focus on specific issues as follows:

- Quantify the impacts of grio connected residential photovoltaic units on utility fuel costs and fuel consumption.

- Evaluate the role of on-site storage and its impact on utility performance.

- Assess the impact on utility fuel consumption resulting from the sellback of excess energy to the utility.

- Explore the implications of reduced utility fuel costs that result from residential PV unit operations on residential energy price rates for backup and sellback energy.

- Investigate effects associated with variations in the size of inoividual PV units relative to individual loads.

In keeping with the guideline to focus the analysis on specific issues, several limitations were fixed early in the stucy. The first factor to be fixed was the snapshot approach taken in the analysis. That is, the analysis is performed for a single year. Another consideration is the method of characterization of the impact of the residential PV units. As noted in the first objective, two figures of merit used in this study are fuel costs and fuel consumption, especially the reduction in oil usage. It is recognized that other utility costs such as investment in capacity, transmission or distribution equipment, and operating costs such as maintenance, metering, or dispatching may also be impacted. However, the reductions in fuel costs and fuel consumption are believed to be the most significant parameters characterizing the impact of on-site PV units. 
The impact of on-site PV units is also examined in terms of the utility rate structure. As noted above, one measure of PV impact is the resulting fuel cost reduction realized by the utility. The results of the fuel cost reduction analyses are integrated into a simplified rate model to determine an appropriate rate to be paid by the homeowner-PV unit owner for backup electricity and a rate to be paid by the utility to the homeowner for PV generated energy, fed back into the utility grid.

A reference residential PV unit for use in the analysis was taken from a previous Aerospace study (Ref.3-1) of optimum residential photovoltaic electric units. A limited number of parametric changes, such as varied array size and storage capacity, are examined from the perspective of the utility. The characteristics of the reference PV unit and its associated residence are described in detail in Section 3.2. A flow chart of the plan for conducting the analysis is shown in Figure 3-1.

A definition of the reference residence is given in Section 3.2, including the house physical characteristics and demand profiles. Diversity among the PV residences is represented in the analysis by varying individual house loads. The performance of the PV unit with respect to the site meteorology is simulated using the Aerospace developed computer program PVHOUSE, discussed in Section 3.3. The PVHOUSE program generates hourly values of PV generated electrical energy consumed by the residence plus excess energy which is either stored for later use, dumped or fed back into the utility grid. The PVHOUSE output becomes the input to the utility system economic analyses.

The postulated utility is detailed in Section 3.4. The description includes characteristics such as the location, types, and sizes of plants and cost parameters. This utility description is modelled after the broadly representative synthetic utility Scenario $D$ developed by the Electric'Power Research Institute (EPRI)(Ref.3-2). The sensitivity to variations in many of the parameters used to describe the postulated utility is of definite interest to permit full understanding of the impact of on-site PV units, but those variations could not be examined within the present study. Utility production cost impacts are assessed by means of the USEM computer code; the model is described in Section 3.5. The USEM code yields annual fuel costs given the utility characteristics with and without on-site photovoltaic unit operation. The utility rate structure is also discussed in this section along with the analysis of backup and sellback rates. Conclusions and recommendations are presented in Section 3.6. 


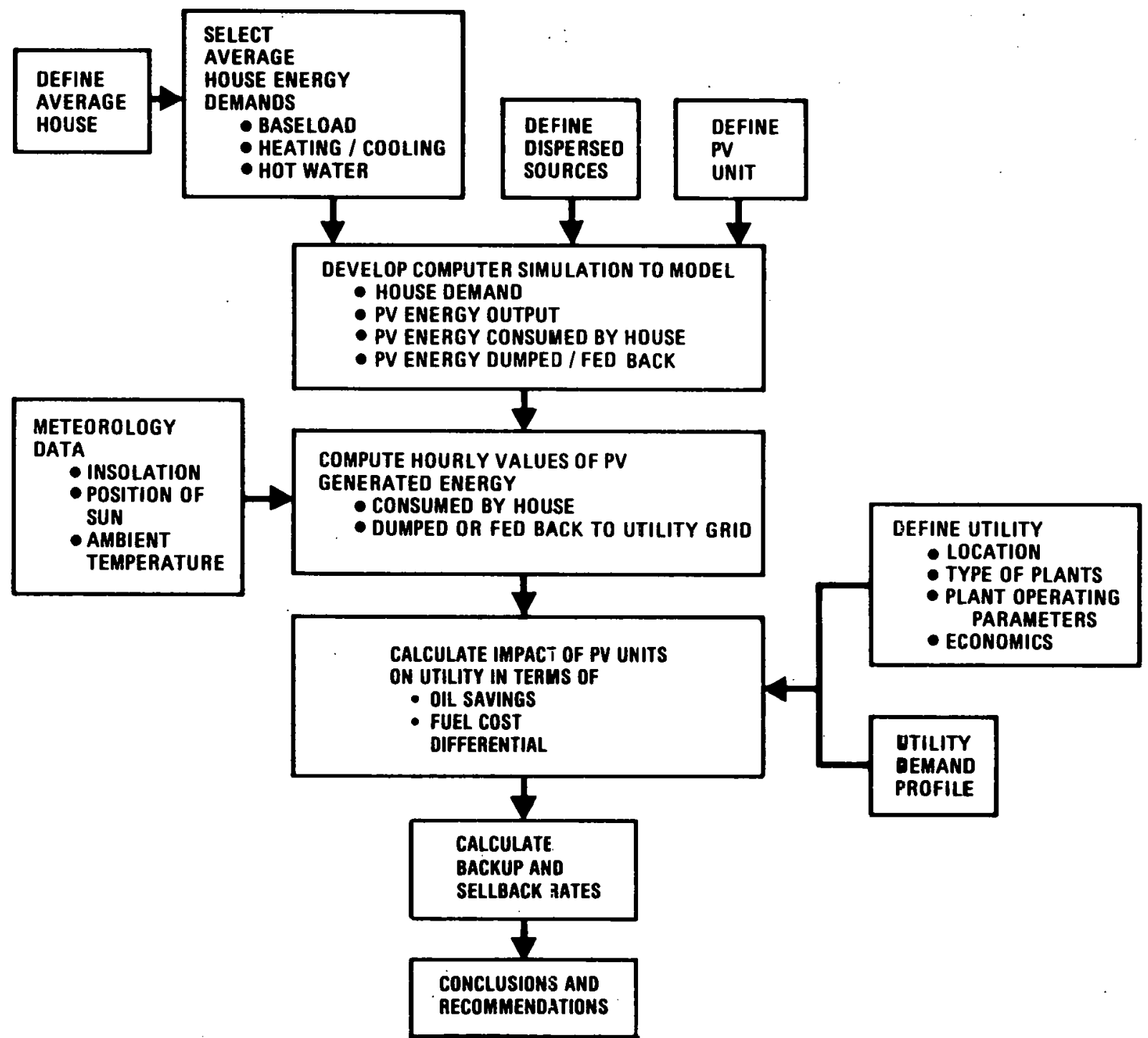

Figure 3-1. Plan for Investigating Impact of PV Units on Electrical Utilities 


\subsection{ON-SITE PHOTOVOLTAIC UNITS}

The reference residential photovoltaic unit and the model residence are described in this section. It is important to realize that the performanice of the PV unit is coupled to its associated residence. For example, the electrical output of the unit during periods of maximum insolation may far exceed the requirements of the residence although the PV energy may be a small fraction of the total load on an annual basis.

The assumed average residence and $\mathrm{PV}$ unit data are drawn from a previous Aerospace Corporation analysis of photovoltaic energy systems for single-family residential applications (Ref.3-1). In this previous study, the PV unit was optimally sized from the homeowner's perspective. The key assumptions in the optimization process were the PV unit costs, the cost of utility backup energy, exclusion of sellback to the grid, and the residence characteristics. Although some of these parameters have been changed in the present study to examine the impact on utility production costs, optimization of the PV unit from the perspective of the homeowner was not reexamined. Therefore, many of the parametric variations examined may not be optimum for the homeowner, the utility, or the aggregate of the two. Impacts and sensitivities of these parameter changes are analyzed without assertion of preferred or optimum configurations, sizes, or operations.

\subsubsection{Average Residence}

The reference average residence is described in more detail in Ref.3-1, and only the key characteristics are given here:

- Located in Phoenix, Arizona

- $1600 \mathrm{ft}^{2}$ living area

- Electrical hot water and space heating and cooling (all electric home)

- Current design standards, i.e., no special energy conservation features. 


\subsubsection{Load Profile}

The average rèsidence is characterized by load profiles comprising baseload, water heating, and space heating or cooling load components. The house load for a summer day is shown in Figure 3-2. The base load and hot water load curves vary with time of day but the associated 24 hour profiles are assumed constant' for each day of the year. Energy requirements for residential air conditioning and space heating are a function of ambient temperature as well as time of day. Details of these curves are found in Ref.3-1. The total annual load for the reference average house is approximately $28,500 \mathrm{kWh}$ with a peak demand of $11 \mathrm{~kW}$.

\subsubsection{Demand Diversity}

As previously stated, one objective of this study is to observe any effect associated with the dispersed nature of on-site PV units. Dispersion can include one or more characteristics such as the following: geographic location, meteorological (some houses shaded by a passing cloud, others in the sunshine), type of PV unit, load coincidence, relative size of PV unit to house load, etc. In this study, only demand diversity was modeled by adjusting the house load profiles. Some residences are modeled with house loads that are 10 to 30 percent greater than that of the average house, and others with house loads 10 to 30 percent lower than that of the average house. The diversity property is characterized by the house loads as shown in Table $3-1$.

Table 3-1. Definition of Load Diversity

\begin{tabular}{|c|c|}
\hline House Type & $\begin{array}{c}\text { Deviation from Average } \\
\text { House Load at Each Hour of the Year } \\
\text { (Percent) }\end{array}$ \\
\hline 1 & 30 \\
2 & 20 \\
3 & 10 \\
4 & -10 \\
5 & -20 \\
6 & -30 \\
7 & 0 \\
\hline
\end{tabular}




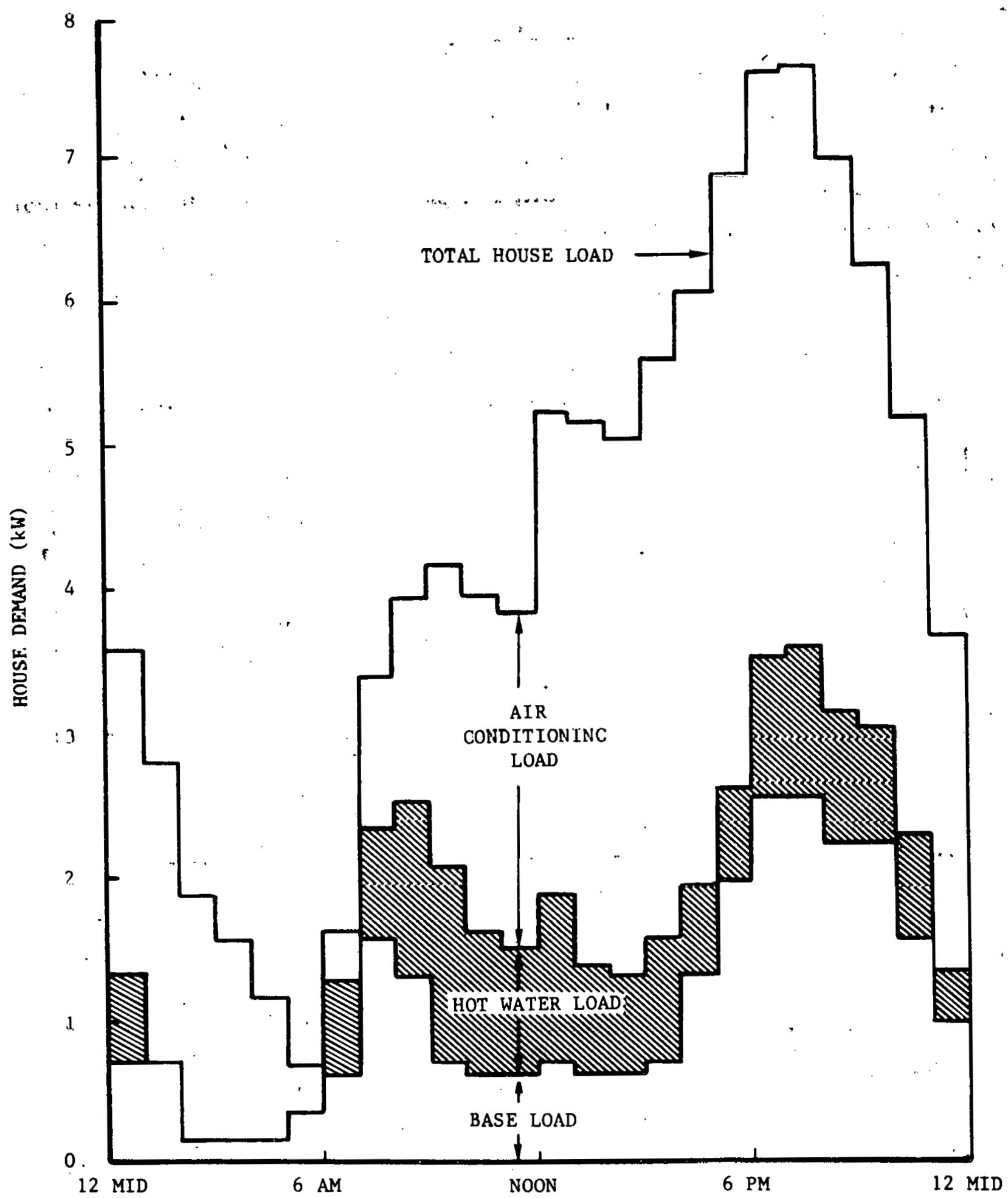

Figure 3-2. House Energy Demand 


\subsubsection{On-Site Photovoltaic Unit Configuration}

The on-site PV unit consists of the collectors or arrays, a power conditioner to convert the DC electricity generated by the arrays to AC electricity, associated support structures, and, if included, electrical storage. The PV unit configuration is basically an array of air cooled, fixed tilt, flat plate collectors mounted on the roof which is east-west oriented. The assumed PV unit parameters from Ref.3-1 are given in Table 3-2.

\section{Table 3-2. PV Unit Characteristics}

Cell Type

Cell Orientation

Cell Tilt

Cell Efficiency at $28^{\circ} \mathrm{C}$

Cell Efficiency Temperature Coefficient

Absorptivity

Cell Packing Factor

Convective Film Coefficient

Power Conditioner Efficiency

Radiative Film Coefficient

Reflectivity Efficiency
Silicon

Éast-West

$33.43^{\circ}$ (Phoenix latitude)

$12 \%$

$.005 /^{\circ} \mathrm{C}$

.77

.90

$.017\left(\mathrm{~kW} / \mathrm{M}^{2} /{ }^{\circ} \mathrm{C}\right)$

.85

$.0085\left(\mathrm{~kW} / \mathrm{M}^{2} /{ }^{\circ} \mathrm{C}\right)$

1.0

The array area is a variable; however, the maximum array area is $160 \mathrm{Mi}^{2}$ because of roof size limitations. Given these parameters, the PV unit has a rated output of $0.117 \mathrm{~kW}$ of $\mathrm{AC}$ power per $\mathrm{Mi}^{2}$ of array at standard conditions.

Another parameter in the analysis is electric storage. When storage is included in the PV unit, electric energy is stored in a battery for delivery to the house load at a later time, or dumped if the battery is fully charged and the house load is satisfied. A description of the battery storage-discharge model is given in Section 3.3.1. The battery is characterized by a roundtrip storage-discharge efficiency of 0.70 and an energy storage-discharge capacity rating in kilowatt-hours. 


\subsection{PV PERFORMANCE MODEL}

\subsubsection{PVHOUSE Model}

The hourly performance of the PV unit is modeled using The Aerospace Corporation PVHOUSE program. The function of PVHOUSE is to calculate the hourly photovoltaic-generated energy consumed and the hourly photovoltaic energy that is dumped or fed back into the utility grid by a residence, or by the aggregate of dispersed resiciences. These hourly values become the solar power input values for the utility system economic analysis aiscussed in Section 3.5. PVHOUSE, a modified version of the PVPOWER program (Ref.3-3) tailored to the specific needs of this analysis, is briefly described below.

A data tape with site meteorology (insolation, ambient temperature, etc.) is used to determine the hourly heating and cooling loads for the average residence and the hourly electric energy output from the array. The house load is compared to the output from the array with two possible outcomes. If the house load is less than the array. energy output, the photovoltaic energy consumed by the house is equal to the house load and the difference between the array output and house load is categorized as excess energy for that hour. If the PV unit does not have an electrical energy storage subsystem, the excess energy is dumped or fed back to the utility grid. If the PV unit has a storage subsystem, the excess energy is stored. When storage is filled to maximum, any excess energy delivered to storage is then dumped or fed back to the gria.

The second possible outcome occurs when there is a shortfall, that is, when the house load is greater than the energy output of the PV unit. In this situation, the PV generated energy consumed by the house for that hour is equal to the PV output. If the unit has storage, the program calculates the PV generated energy consumed by the house by adding stored energy (if available) to the array output to niake up the shortfall.

As mentioned above, PVHOUSE calculates hourly values of both photovoltaic generated energy consumed (with or without electrical storage) and excess fedback energy. The program is designed to calculate these values for both the average house and the aggregate of dispersed houses, such as those listed in Table 3-1, in a single run. 


\subsubsection{PV Analysis Considerations}

An important consideration in the analysis is the PV unit configuration that will be modeled. There is no limit to the number of array area and storage capacity combinations that can be considered. The approach taken in this analysis is to start with a PV unit configuration that is near optimal from a homeowner's viewpoint, without provision for sellback of excess, array-generated energy to the utility. Sellback is thus of little or no importance. The array area on each residence can then be ini increased for the study of its impact of this parameter on utility prociuction costs and fuel savinigs.

As discussed in Ref.3-1, the homeowner-optimal PV configuration depends on such factors as cost per peak $\mathrm{kW}$, the levelized backup power cost, and so on. Using the base case for the Phoenix study in Ref. $3-1^{*}$, an optimal PV unit has an array of 84.5 $\mathrm{Ml}^{2}$ and an electrical energy storage capacity of $32.6 \mathrm{kWh}$ when there is no sellback of excess PV-generated electricity. For this study, an array area of $80 \mathrm{M}^{2}$ is chosen as the reference case with $32.6 \mathrm{kWh}$ storage. The area is varied between $80 \mathrm{M}^{2}$ and 160 $M^{2}$ (the maximum array permitteo by physical roof area) so the effects of different collector areas can be studied. An array area of $320 \mathrm{M}^{2}$ is also employed to accurately assess impacts as array size is increased. $i$

The optimal PV unit configuration when there is no electrical storage and sellback of excess energy is not determined in Ref.3-1. However, with assumptions similar to those noted above, the optimal array area is $41.9 \mathrm{M}^{2}$ when the utility buys back excess energy at 14 percent of the cost of utility supplied energy. Since the results in Ref.3- 1 indicate that the optimal array size decreases as the sellback percentage decreases, an array area of $40 \mathrm{M}^{2}$ is chosen as the base case for an PV unit with no storage. The effect of increasing array area is studied for the no storage configuration by considering arrays as large as $320 \mathrm{M}^{2}$.

\footnotetext{
* \$0.50 per peak: watt (1975) arrays; $\$ 40 / \mathrm{kWh}$ of storage capacity; capital recovery factor of .09; levelized backup power cost of $\$ 0.07 / \mathrm{kWh}$.
} 
Load diversity is simulated by modeling seven residences with different hourly load demands as shown in Table 3-1. Calculations of PV-generated energy consumed, and dumped or fed back were made with PVHOUSE for nine house types and for 50 percent hourly load excursions from the average house load. No significant variations were found, and the load diversity factors shown in Table 3-1 are selected as being representative. These diversity factors are utilized for all PV system configurations.

\section{$3.4 \quad$ UTILITY MODEL}

\subsubsection{General Description}

The postulated summer peaking utility demand data are based on a projection of the Arizona Public Service profile typical of the Phoenix, Arizona area. The utility peak demand by month is shown in Figure 3-3. The EPRI Scenario D synthetic utility (Ref. 3-2) was used to represent the mix of generating units operated by the utility. A comparison of the postulated mix of generating units with the mix expected for Arizona Public Service in the mid-1980s is shown in Table 3-3.

Figure 3-3. Comparison of Utilities - Mix of Generating Units

\begin{tabular}{|l|c|c|}
\hline \multicolumn{1}{|c|}{ Unit Type } & Arizona Public Service* & Synthetic Utility D \\
\hline Nuclear, Steam & $36.0 \%$ & $24 \%$ \\
Coal, Fossil & $28.0 \%$ & $36 \%$ \\
Oil, Fossil & $21.0 \%$ & $-.26 \%$ \\
Combustion Turbine & $14.8 \%$ & $14 \%$ \\
Hydro & $0.2 \%$ & $0 \%$ \\
\hline
\end{tabular}

: Assuming one-third share of Palo Verde nuclear units which became operational in the mid $1980 \mathrm{~s}$. 


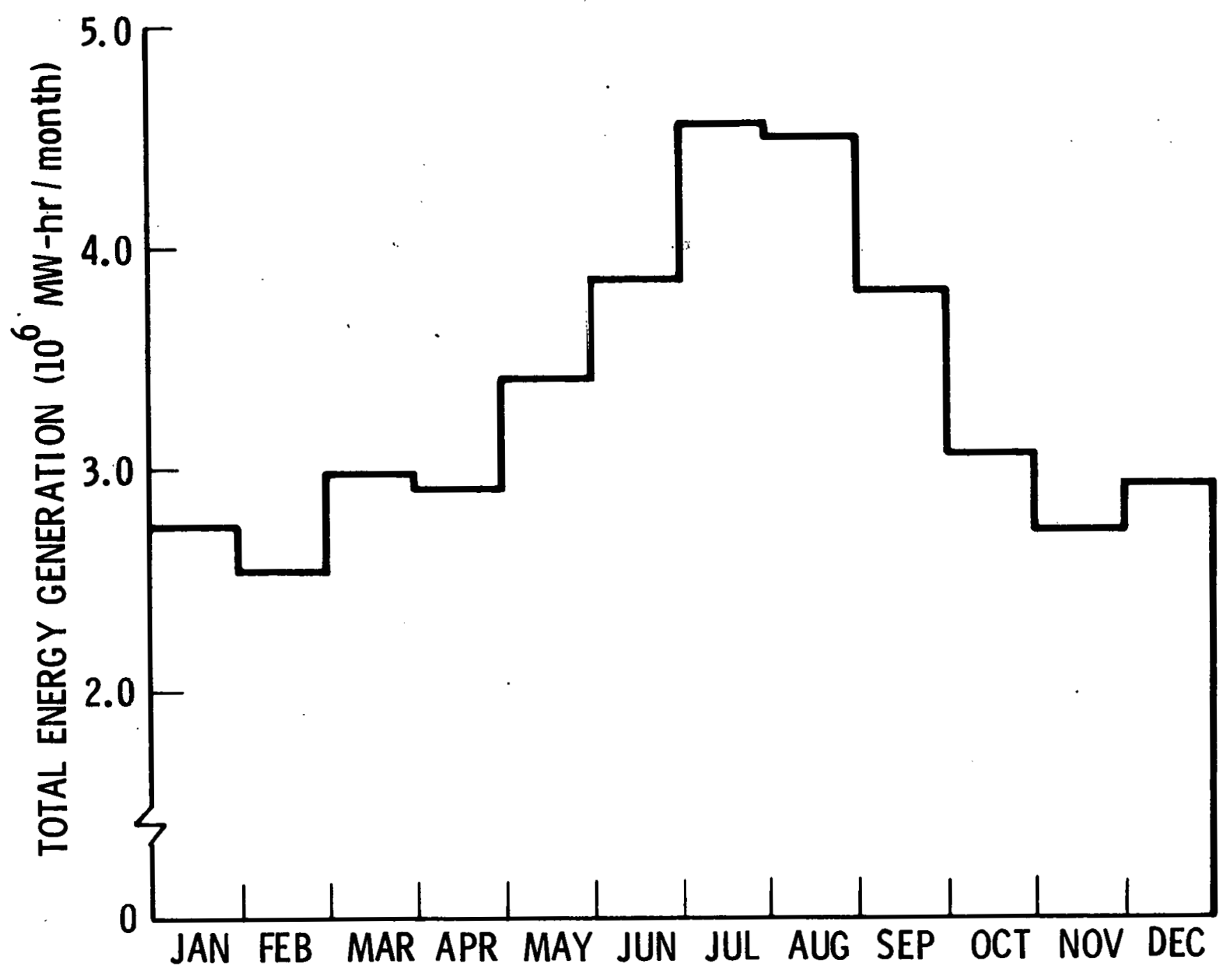

Figure 3-3. Utility Total Energy Demand by Month 
The detailed mix of plants for the postulated utility is shown in Table 3-4. The plant availabilities are taken from Ref. 3-2 and account for load reductions as well as full outages. Total installed capacity is 10,050 $\mathrm{NiW}$ with a capacity weighted average availability of 0.781 , implying an average available capacity of $7850 \mathrm{MW}$, which is also the peak, demand seen by the utility with zero penetration of PV units

Table 3-4. Mix of Plants for Utility Model:

\begin{tabular}{|l|r|r|r|r|}
\hline \multicolumn{1}{|c|}{ Plant Type } & $\begin{array}{c}\text { Size } \\
(\mathrm{MW})\end{array}$ & Number & $\begin{array}{c}\text { Capacity by Type } \\
(\mathrm{MW})\end{array}$ & Availability \\
\hline Nuclear, Steam & 1200 & 2 & 2,400 & .736 \\
Oil, Fossil & 800 & 1 & 800 & .658 \\
Coal, Fossil & 600 & 2 & 1,200 & .693 \\
Coal, Fossil & 400 & 2 & 800 & .762 \\
Oil, Fossil & 400 & 1 & 400 & .762 \\
Coal, Fossil & 200 & 8 & 1,600 & .835 \\
Oil, Fossil & 200 & 7 & 1,400 & .835 \\
Combustion Turbines & 50 & 29 & 1,450 & .900 \\
\hline Total Utility & & 52 & 10,050 & .781 \\
\hline
\end{tabular}

For each generating unit in the mix, a heat rate and fuel cost were assumed as shown in Table 3-5. These fuel costs are based on prices given in 1976 dollars in Ref. 3-4 which were escalated to 1985 prices and then expressed in 1980 dollars. The data in Tables 3-4 and 3-5 can be combined as shown in Figure 3-4 to illustrate the increase in fuel costs experienced by the utility as the demand increases. It can be seen from Figure 3-4 that the fuel costs associated with meeting the peak demand can be as much as six times greater than those for meeting baseload demand. 
Table 3-5. Fuel Cost and Efficiency Assumptions

\begin{tabular}{|c|c|c|c|c|}
\hline Type of Fuel & Size, MW & $\begin{array}{c}\text { Fuel Cost } \\
(\$ / \text { Million Btu }\end{array}$ & $\begin{array}{l}\text { Heat Rate } \\
(\mathrm{Btu} / \mathrm{kWh})\end{array}$ & $\begin{array}{l}\text { Fuel Cost } \\
(\text { Mills } / \mathrm{kWh})\end{array}$ \\
\hline Nuclear & 1200 & .885 & $1.044 \times 10^{4}$ & 9.2 \\
\hline Oil & 800 & 3.62 & $9.155 \times 10^{3}$ & 33.1 \\
\hline & 400 & 3.62 & $9.447 \times 10^{3}$ & 34.2 \\
\hline & 200 & 3.62 & $9.979 \times 10^{3}$ & 36.1 \\
\hline Coal & 600 & 1.31 & $8.989 \times 10^{3}$ & 11.8 \\
\hline & 400 & 1.31 & $9.045 \times 10^{3}$ & 11.9 \\
\hline . & 200 & 1.31 & $9.576 \times 10^{3}$ & 12.5 \\
\hline $\begin{array}{l}\text { Combustion } \\
\text { Turbine }\end{array}$ & 50 & 3.99 & $1.400 \times 10^{4}$ & 55.9 \\
\hline
\end{tabular}

The utility model also accounts for the scheduled maintenance of power plants. The generation mix is reconfigured in four week periods to reflect the mix available due to units out of service for scheculed maintenance. The maintenance interval for each type of plant is taken from Ref. 3-2, and the maintenance schedule is constructed to show the utility reserve capacity (available capacity minus the expected demand) as near a constant value as possible throughout the entire year. 


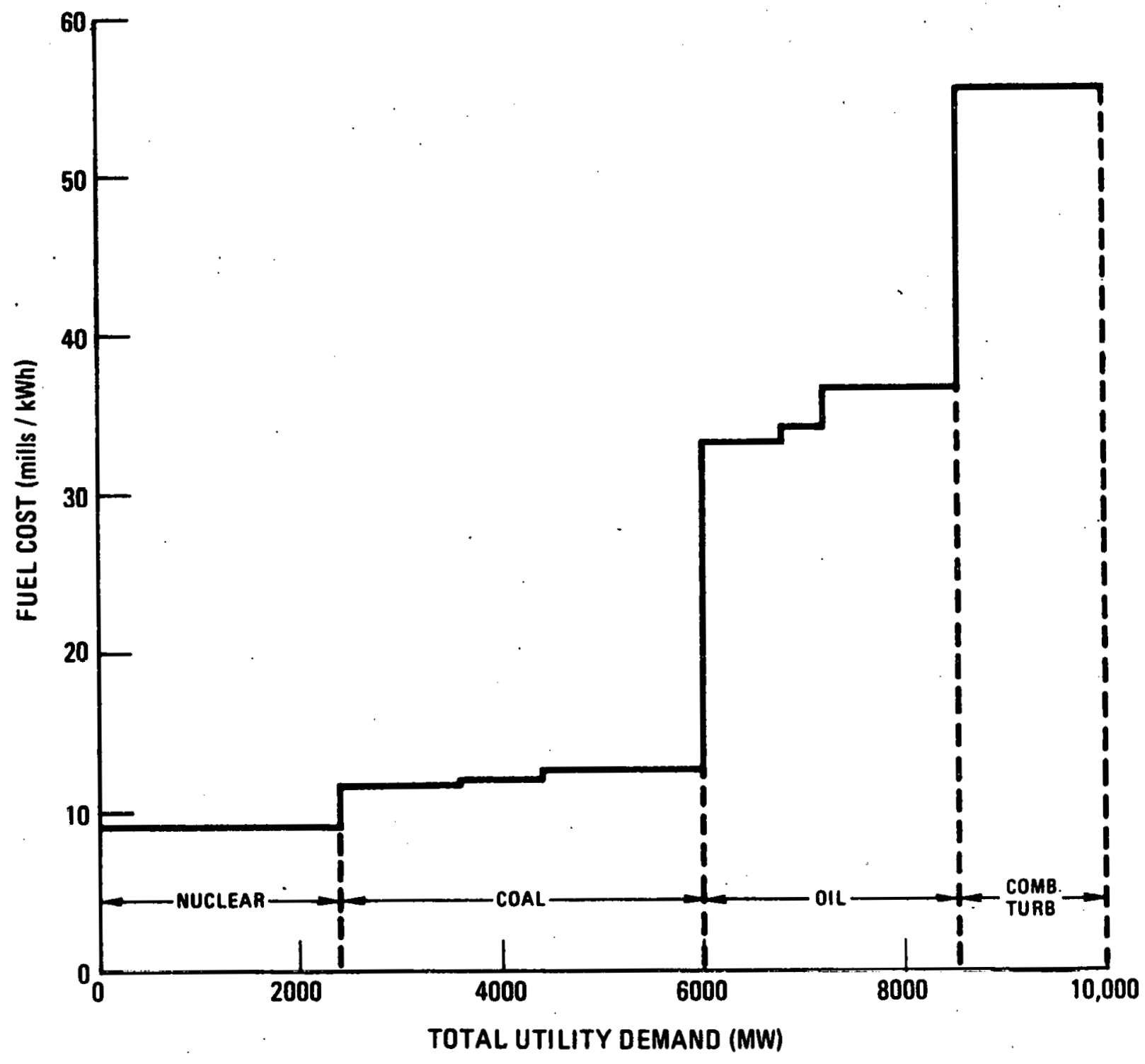

Figure 3-4. Utility Incremental Cost Curve 


\subsubsection{Utility Impact Analysis Considerations}

The impacts of on-site unit operation on the postulated electric utility are simulated by use of the USEM computer code. This program employs the incremental cost approach to cost-of-production computation based on hourly load profiles or annual load duration curves. The utility hourly load profiles are modified to account for varying levels of PV penetration by using the code PVHOUSE. The USEN program combines PVHOUSE output and hourly utility demand to construct load duration curves with and without PV penetration and compute the yearly energy output and fuel costs for each generating plant in the utility system. The program then computes the reciuced energy output and fuel costs for each individual plant and for the total utility. The USENi code is described more fully in Section 2.0.

\subsection{UTILITY INIPACT RESULTS}

\subsubsection{Preliminary Observations}

A key parameter in the study is array area per residence. Given the fixed parameters in Table 3-2, which define the PV unit characteristics, the array area dictates the amount of PV generated energy consumed by the average residence and dumped or fed back to the grid. These values, are shown in Table 3-6 for the various PV units considered in this report, where the numbers represent the fraction of total house demand $(28,525 \mathrm{kWh} / \mathrm{yr})$. For PV units either with or without storage, the backup energy required decreases and the excess $\mathrm{PV}$ energy increases as the array area increases as expected.

The array area parameter when coupled with the number of PV units defines the PV penetration. These penetrations are delineated in Table 3-7 for combinations of array area per residence and number of PV units.

An important observation is the complex interrelationship of the PV array output, house oemand, and utility load. The house demand and PV array output profiles for a week in July are shown in the bottom portion of Figure 3-5. The PV array output corresponds to that of an $80 \mathrm{Mi}^{2}$ area unit. The PV energy output below the house demand curve is consumed by the residence; the output above the house demand is 
- 100,000 UNITS $\bullet 80 \mathrm{~m}^{2}$ ARRAY AREA • NO STORAGE

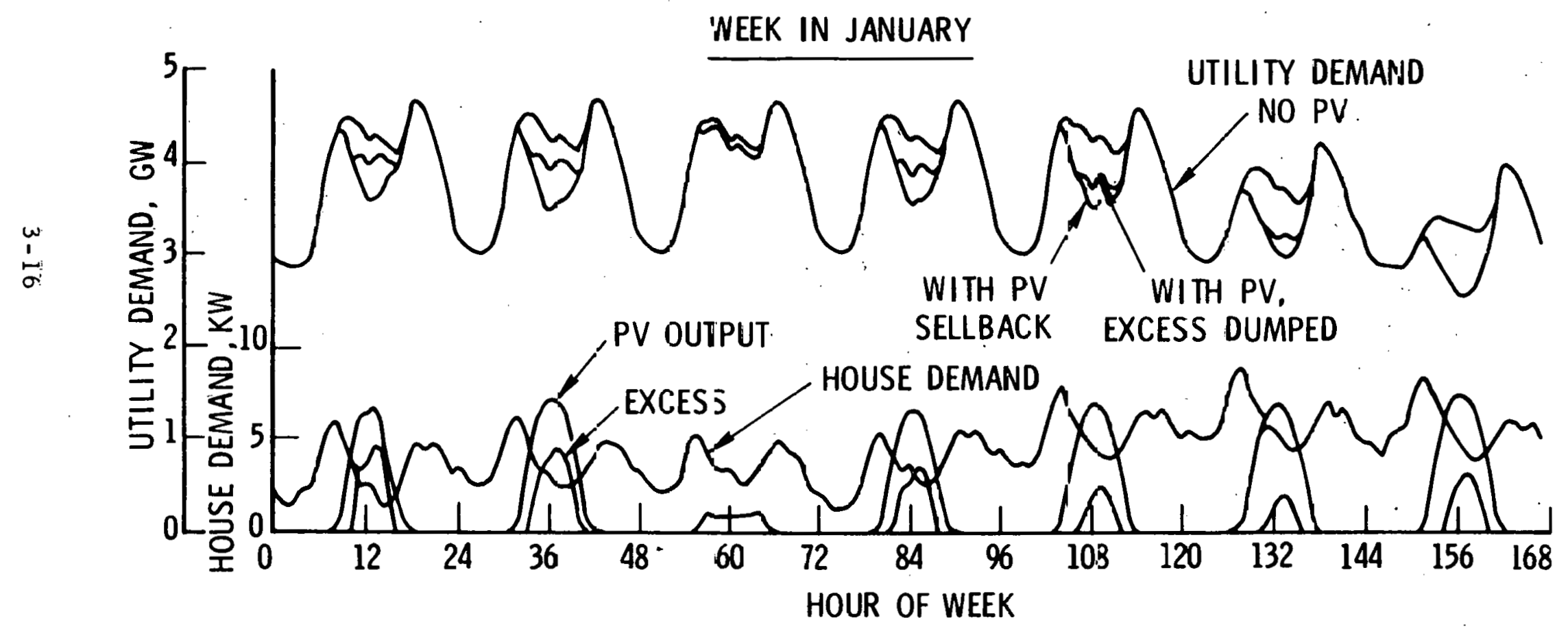

Figure 3-5. Demand and PV Output Profiles 
Table 3-6. Fractional Energy Values Due to PV Unit Operation

(House Energy Demand $=28,524 \mathrm{kWh} / \mathrm{Y} \mathrm{r}$ )

\begin{tabular}{|c|c|c|c|c|}
\hline $\begin{array}{c}\text { Array Area } \\
\left(M^{2}\right)\end{array}$ & $\begin{array}{r}\text { No } \\
\text { Backup }\end{array}$ & $\begin{array}{l}\text { age } \\
\text { Excess }\end{array}$ & $\begin{array}{l}\text { Storage } \\
\text { Backup }\end{array}$ & $\begin{array}{r}2.6 \mathrm{kWh} \\
\text { Excess }\end{array}$ \\
\hline 40 & $\cdot .72$ & .04 & .69 & 0 \\
\hline 80 & .60 & .24 & .44 & .016 \\
\hline 160 & .53 & .82 & .29 & .474 \\
\hline
\end{tabular}

Table 3-7. PV Penetration (Percent Conventional Capacity) as a Function of Array Area and Number of PV Units

\begin{tabular}{|c|c|c|c|}
\hline $\begin{array}{c}\text { Number of } \\
\text { PV Units }\end{array}$ & $40 \mathrm{M}^{2}$ & $80 \mathrm{M}^{2}$ & $160 \mathrm{M}^{2}$ \\
\cline { 2 - 4 } & 2.7 & 5.5 & 11.0 \\
100,000 & 5.6 & 11.0 & 22.0 \\
200,000 & 11.0 & 22.0 & 44.0 \\
\hline
\end{tabular}

excess PV energy which is also shown separately. The height of the PV array output curve is proportional to the array area, i.e., the height of this curve is doubled for PV units with $160 \mathrm{M}^{2}$ of collector area and halved for PV units with $40 \mathrm{Mi}^{2}$ of collector area. The excess PV energy does not have this simple relationship, with array area; the values for excess PV energy in Table 3-6 show that excess PV energy rises sharply as the array area is increased. The impact on the utility of PV equipped residences is shown on the top group of demand profiles. The upper curve represents the unmodified utility demand; note that the daily peak occurs at approximately the same time as the daily insolation peak occurs. The middle curve indicates the resulting utility demand 
when 100,000 PV units, each with $80 \mathrm{M}^{2}$ of collector area, are in operation. Note that the daily peak is reduced, which means that the most expensive energy is being displaced by operation of the PV units. The bottom curve in the upper portion of Figure 3-5 is the utility demand that results when excess PV energy is fed back into the grid. The value of the additional fuel displaced by excess energy fed back is lower (on a per kWh basis) than the fuel displaced when PV energy is directly consumed by the resicience.

A set of profiles for a seven day period in January is shown in Figure 3-6. The house demand profile is considerably different in the winter or heating season months from that shown in Figure 3-5. In the winter there is a morning peak and an evening peak with a valley centered at approximately noon in between. The utility has a similar demand profile as indicated by the upper 'curve in Figure 3-6. The PV output is seen to occur mostly during the low house demand period with some output occurring during the morning peak. The effect of $100,000 \mathrm{PV}$ units with $80 \mathrm{M}^{2}$ of collector area per unit is to shave the utility morning peak and ceepen the midday valley as indicated by the upper two curves in Figure 3-6. The impact of the excess PV energy fed back to the grid is to further deepen the utility demand valley as shown by the lowest of the upper set of demand profiles. The excess PV energy occurs during the middle of the day when the house demand is lowest and, even though there is less insolation in the winter, the excess PV energy is greater than during the summer months. Since the excess PV energy occurs during the off-peak portion of the utility demand profile, the incremental value of this energy when fed back to the grid is less than the incremental value of fuel displaced when PV energy is directly consumed by the residences.

The curves shown in Figure 3-7 demonstrate a change in impact when storage is included in the PV unit. Note that the peak is shaved in the evening as well as in the morning. This occurs because the excess PV energy which occurs during the middle of the ciay is put into storage for use later in the day when the PV array output cannot, meet the house demand or is not operational following sunset. Because of the presence of a battery, there is little or no excess PV energy generated for arrays of $80 \mathrm{M}^{2}$ area, but excess PV energy would be available to be fed back to the grid for larger 
- 100,000 UNITS $\quad$ - 80 $\mathrm{m}^{2}$ ARRAY AREA $\quad$ - $32.6 \mathrm{kWh}$ STORAGE

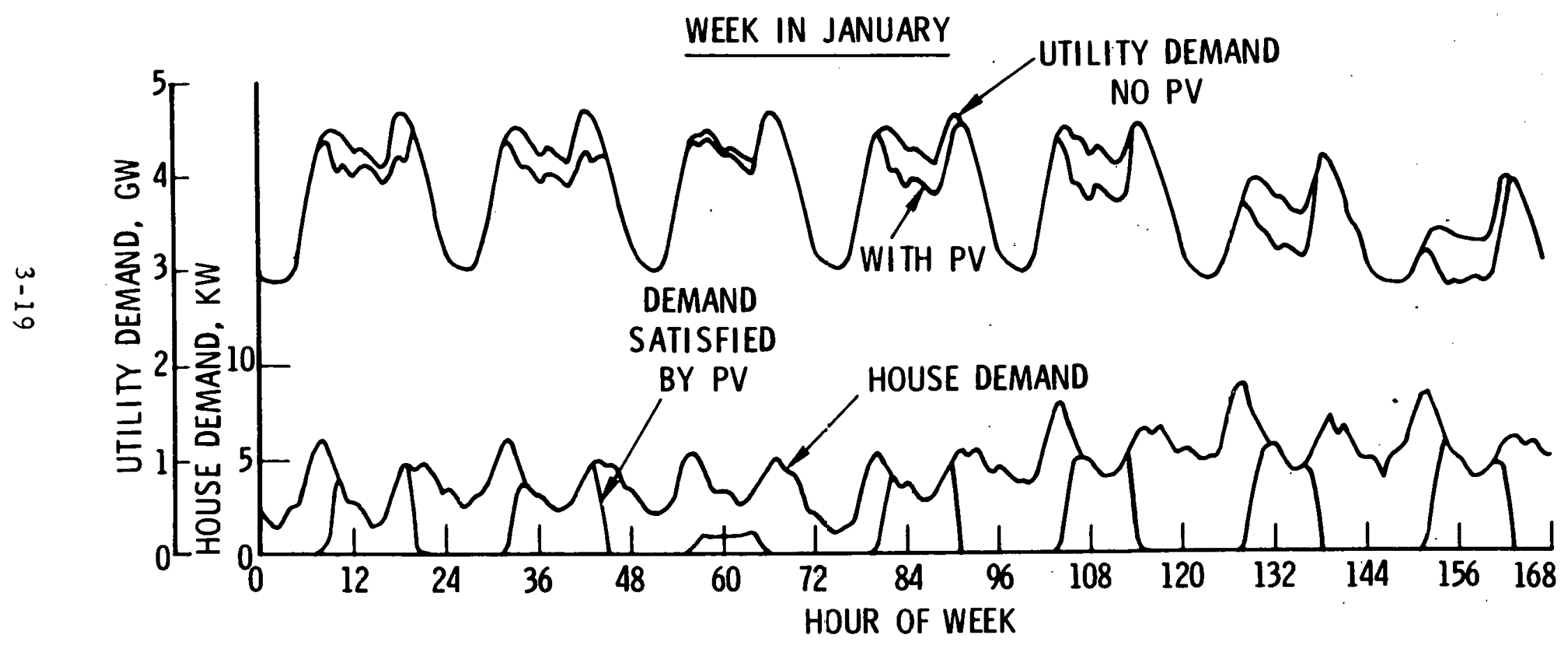

Figure 3-6. Demand and PV Output Profile 


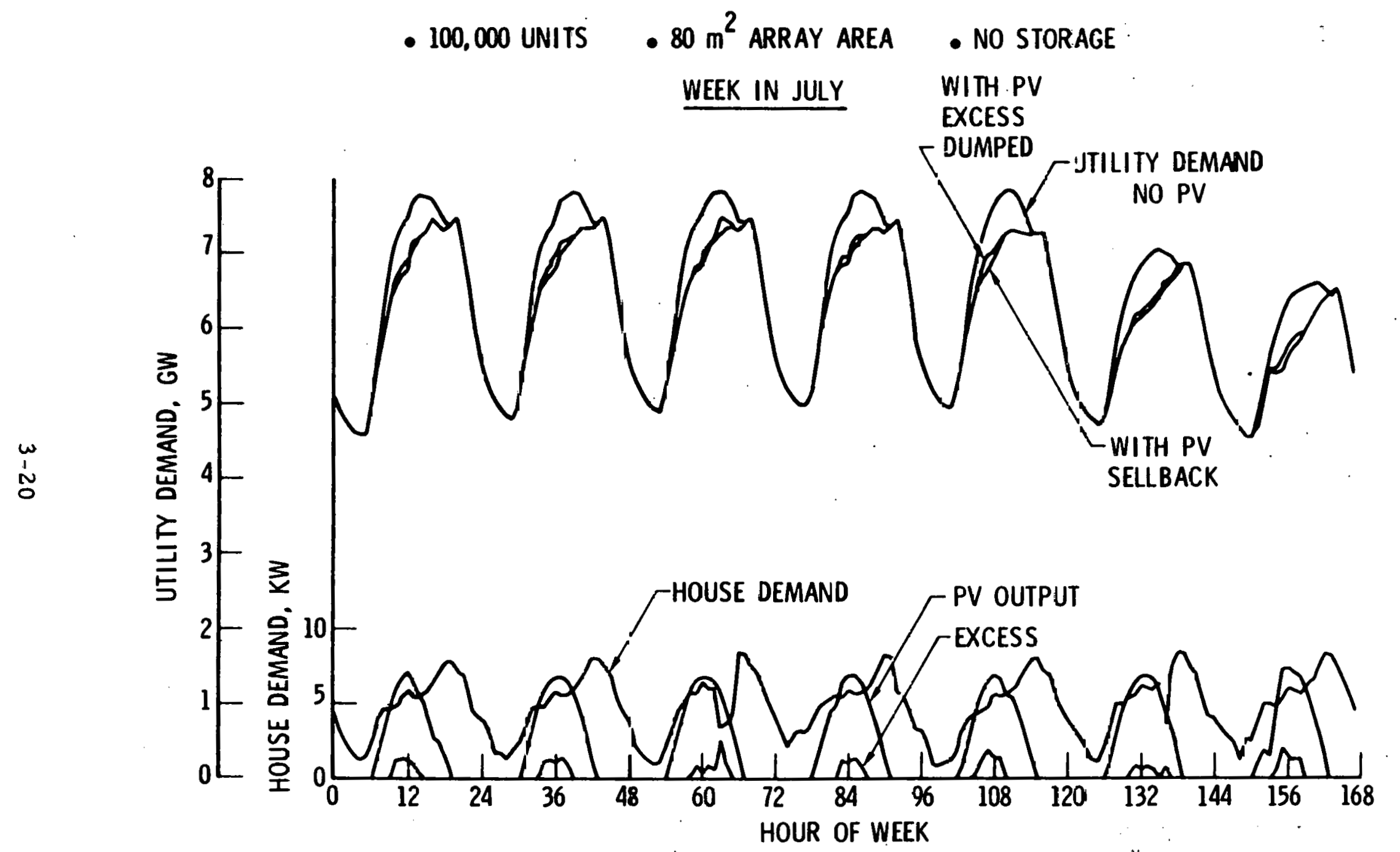

Figure 3-7. Demand and PV Output Profiles 
array areas. The PV array output, house demand and utility demand profiles are shown in Figure 3-8 for a week in July; no excess PV energy is generated during this week due to the high house demand and battery storage. The effect of the battery is to displace fuel consumed later in the day; this fuel has a lower incremental cost because utility demand is lower.

Similar curves can be constructed for various combinations of array area, storage capacity and number of PV units. However, the impacts of PV units are more precisely displayed in other ways as discussed in the following sections. The key points to be gained from the four sets of profiles are the following:

- The impact of PV arrays on the utility demand is seasonally dependent.

- Array area is an important parameter, since the amount of PV energy fed back to the grid or put in storage is proportional to collector size.

- When PV units have storage subsystems, high incremental cost energy is displaced later in the day during the winter months. During the summer months, lower incremental cost fuel is displaced later in the day.

The above considerations can be summarized on an annual basis by comparing the utility load duration curves with and without PV units in operation. In Figure 3-9 the original load duration curve is shown along with the modified curve for 100,000 PV units with $80 \mathrm{M}^{2}$ array area and no storage for the case in which excess PV energy is dumped. It is clear that the PV units displace some combustion turbine, oil, and coal generation. When excess PV energy is fed back instead of dumped, additional generation is displaced as shown in Figure 3-10. Similar load duration curves are shown in Figures 3-11 and 3-12 for 100,000 PV units having $160 \mathrm{M}^{2}$ array area and no storage. The modified curve in Figure $3-11$ is for the case when excess PV energy is dumpea and is almost identical to the modified curve in Figure 3-7. This comparison points out that the utility realizes no adcitional benefit in terms of displaced generation when the PV unit arrays are oversized with respect to the house load if excess PV 
- 100,000 UNITS $\quad 80 \mathrm{~m}^{2}$ ARRAY AREA $\quad 32.6 \mathrm{kWh}$ STORAGE WEEK IN JULY

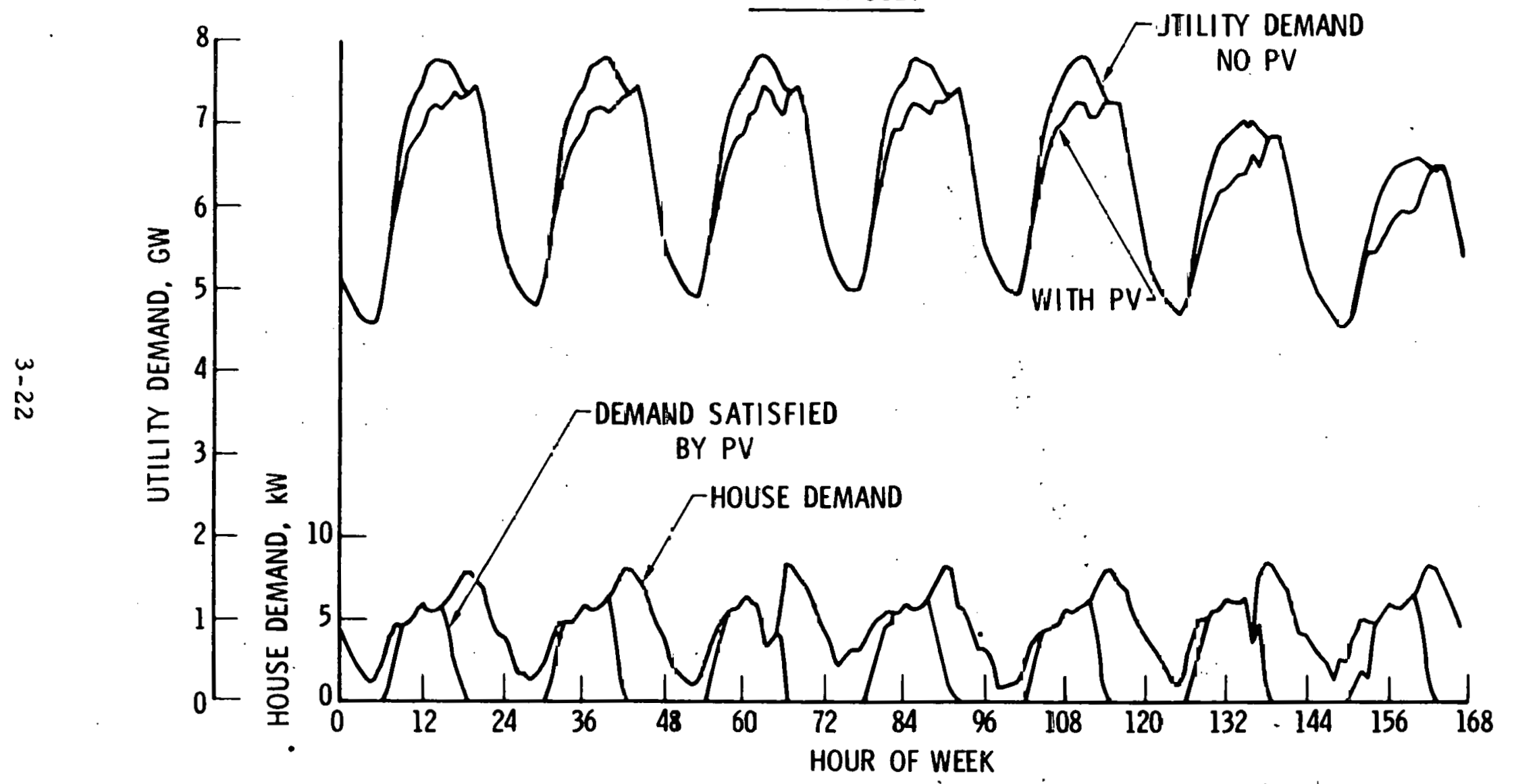

Figure 3-8. Demand and PV Output Profiles 


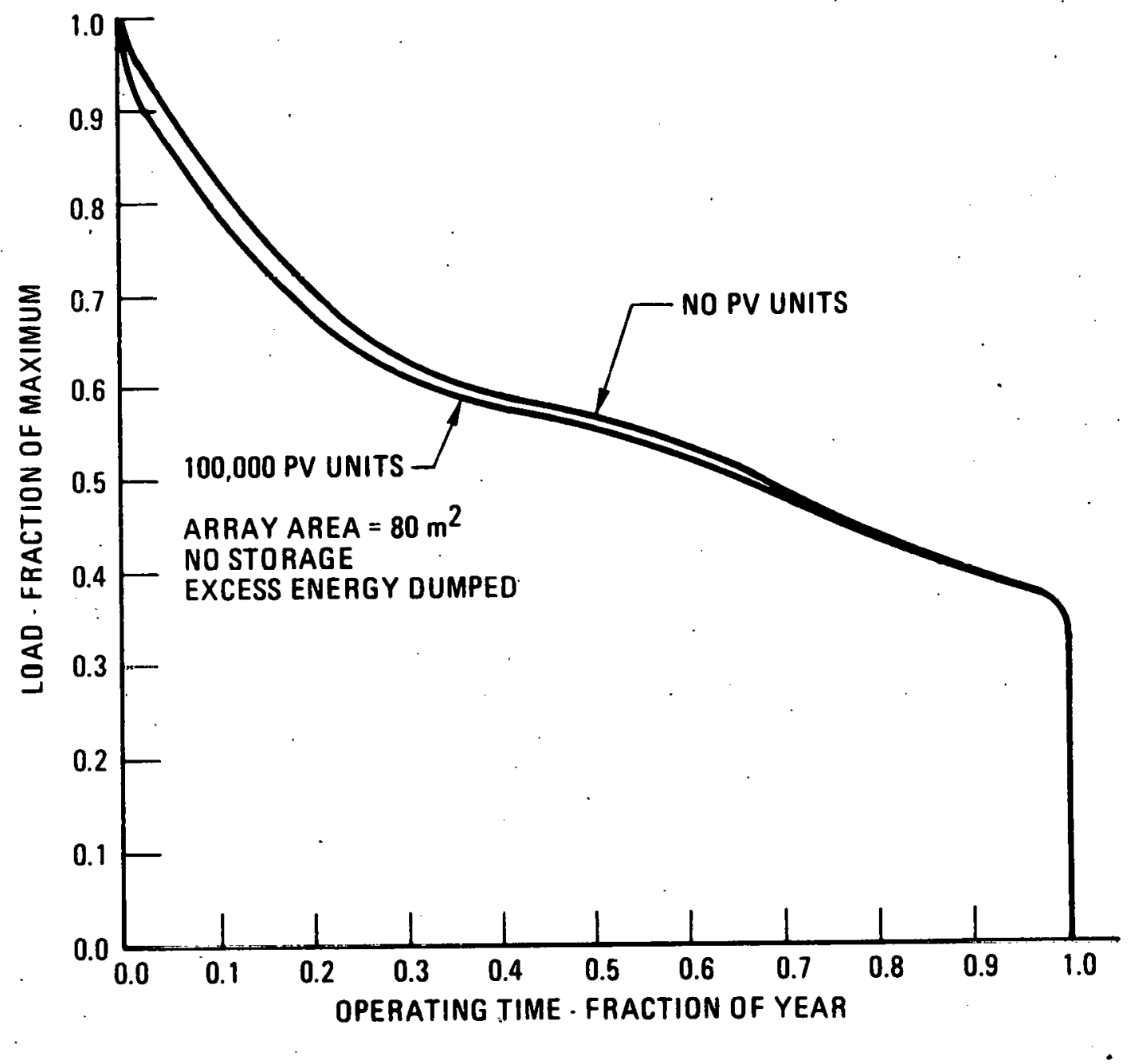

Figure 3-9. Load Duration Curve - $80 \mathrm{M}^{2}$ Array Area Excess Energy Dumped 


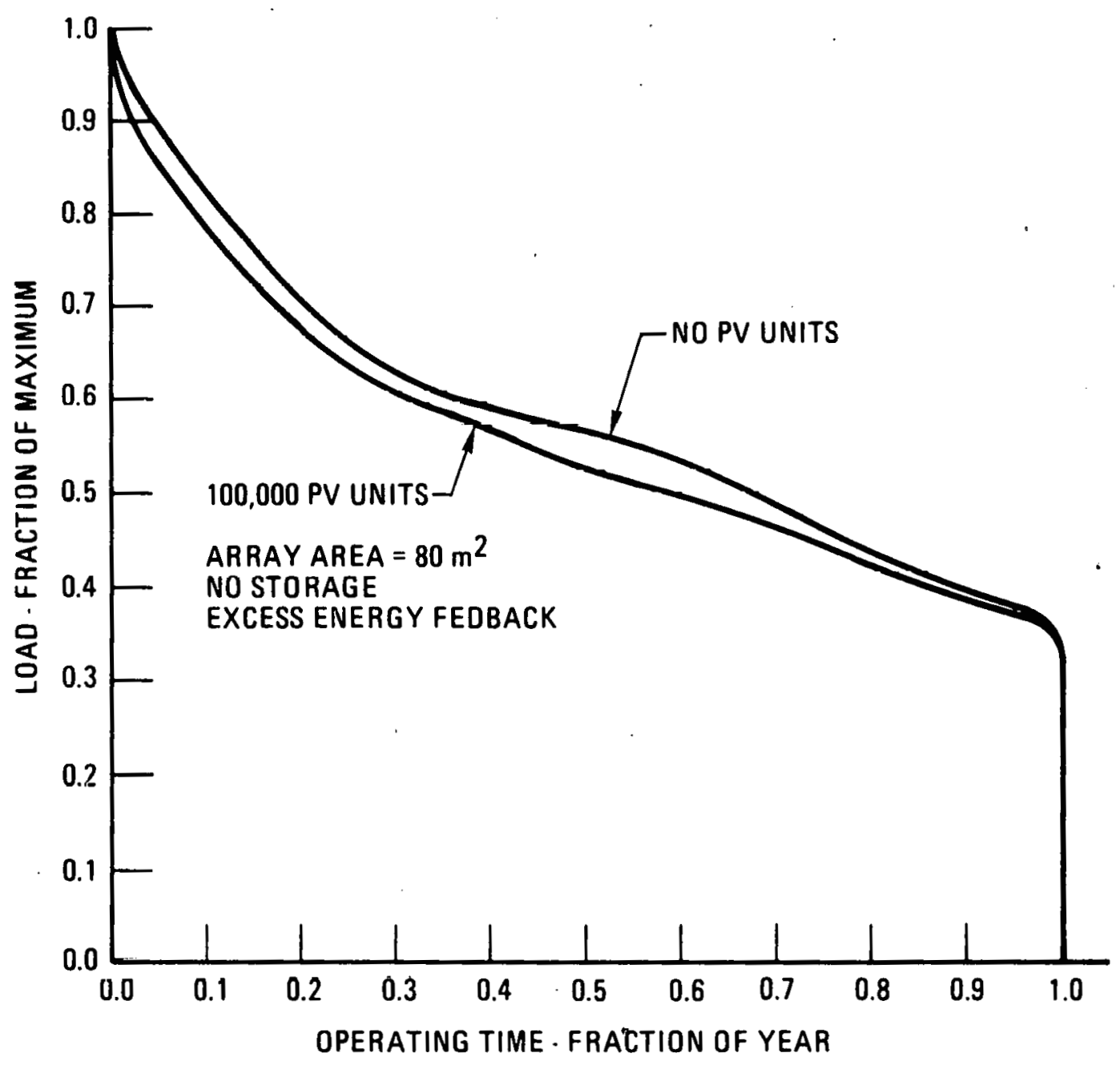

Figure 3-10. Load Duration. Curve $-80 \mathrm{M}^{2}$ Array Area Excess Energy Fedback 


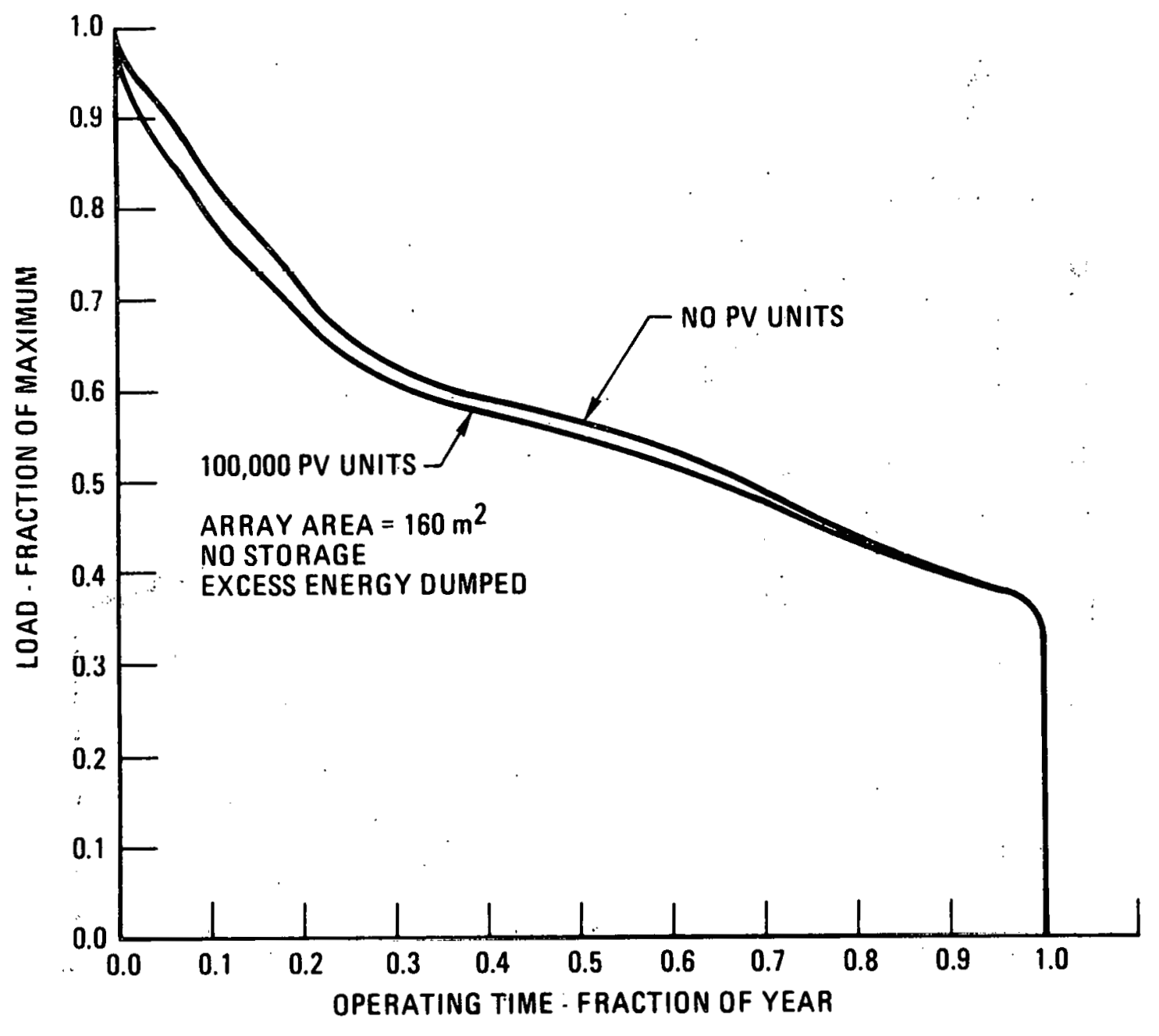

Figure 3-11. Load Duration Curve - $160 \mathrm{M}^{2}$ Array Area Excess Energy Dumped 


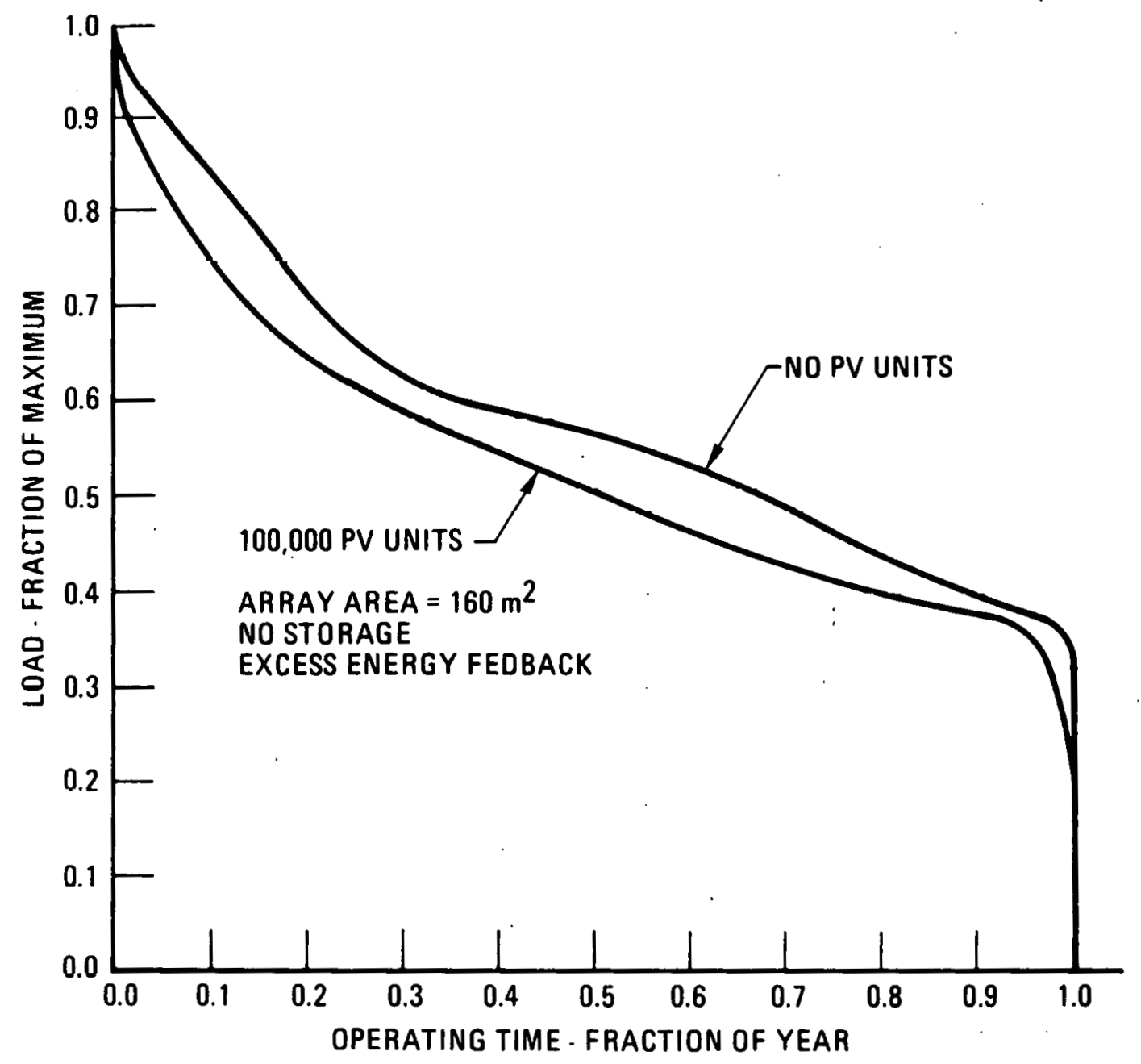

Figure 3-12. Load Duration Curve - $160 \mathrm{M}^{2}$ Array Area Excess Energy Fedback 
energy is dumped. When the excess energy is fed back to the grid, there are relatively large energy displacements as shown in Figure 3-12.

\subsubsection{Oil Conservation}

A significant impact of the introduction of on-site photovoltaic units is the reduction in conventional fuel consumption. Of particular interest is the conservation of oil. The oil savings resulting from increasing numbers of PV residences (no energy storage) is illustrated in Figure 3-13. These curves are for the case where excess energy generated by the arrays is dumped. In Figure 3-14 it is demonstrated that for a given array area, the oil savings are even greater when excess PV energy is fed back to the utility grid. Of considerable importance is the magnitude of the oil savings achievable. For the postulated utility and residential PV configuration, oil savings of approximately 4 to 20 million barrels per year are indicated for 50,000 PV residences.

Examination of Figures $3-13$ and 3-14 indicates that oil savings do not increase in proportion to the number of PV units when more than 100,000 units are considered. As more PV units are added, the energy displaced increasingly comes from the more cost efficient plants (i.e., non-oil burning units) in the utility mix. Similarly, it is noted that the oil savings increases, but in a decreasing proportion to the increase in array area per unit for a fixed number of PV units. Again, the increased array area results in adcitional energy displacement, but mostly from the more cost efficient plants.

Similar results are realized for residences with electrical energy storage subsystems. The increases in oil savings that result from an increase in the number of PV residences including storage are shown in Figure 3-15. The increase in energy savings when excess energy is ted back to the grid is shown in Figure 3-16. For residences with the "optimum" PV units (array area of $80 \mathrm{M}^{2}$; storage capacity of 32.6 kW-hour; no sellback), there is approximately a 2 percent increase in savings. This relatively small increase must be expected because the optimization of this PV configuration from the homeowner's perspective maximizes the PV energy supplied to the residence and minimizes the excess. As before, the savings decrease in proportion to the PV penetration when the number of PV units exceed 100,000 or the array area is 
0

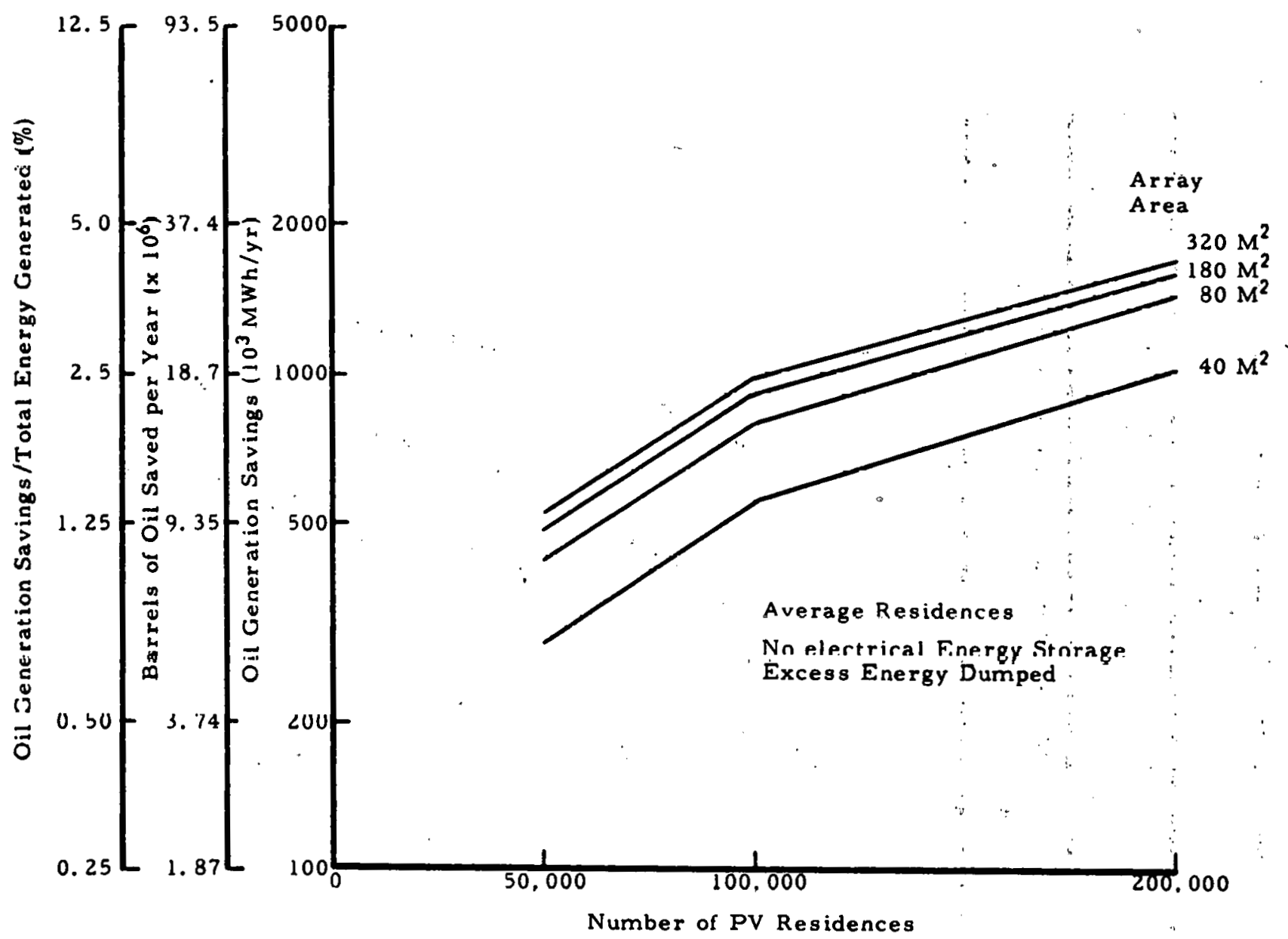

Figure $3-13$. Oil Savings vs Number of PV Residences No Storage and Excess Energy Dumped 


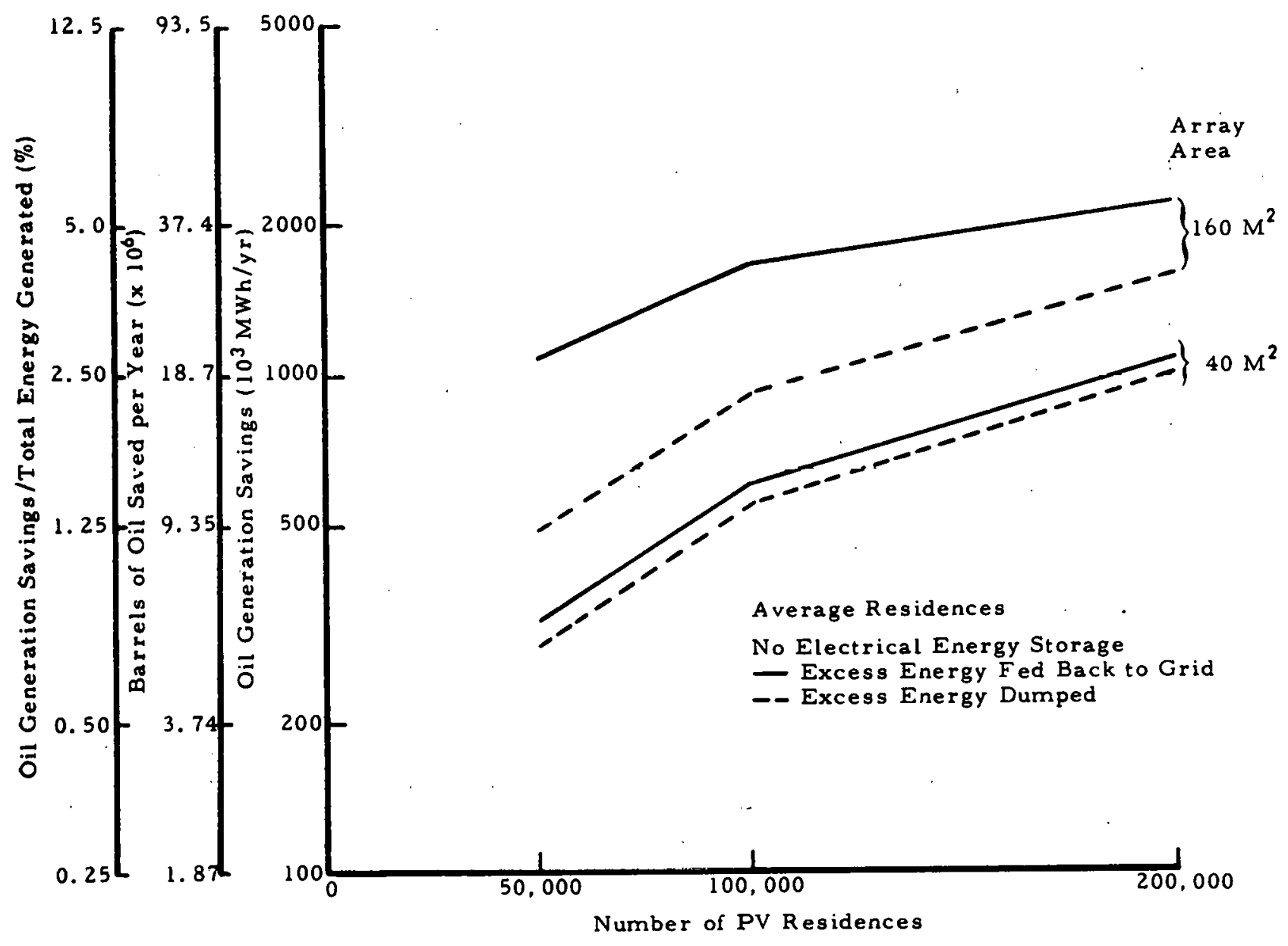

Figure 3-14. Oil Savings vs Number of PV Residences - No Storage 


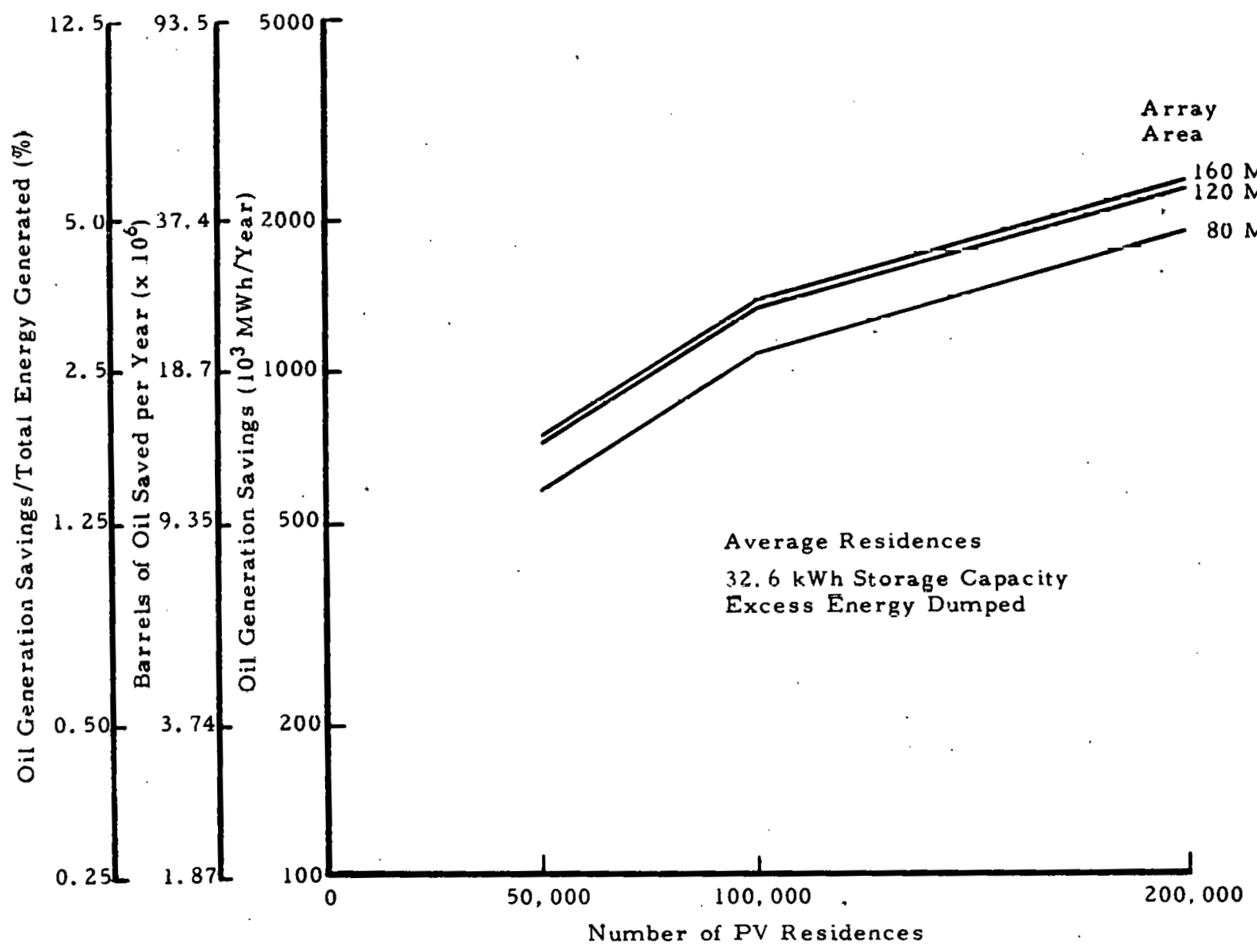

Figure 3-15. Oil Savings vs Number of PV Residences On-Site Storage and Excess Energy Dumped 


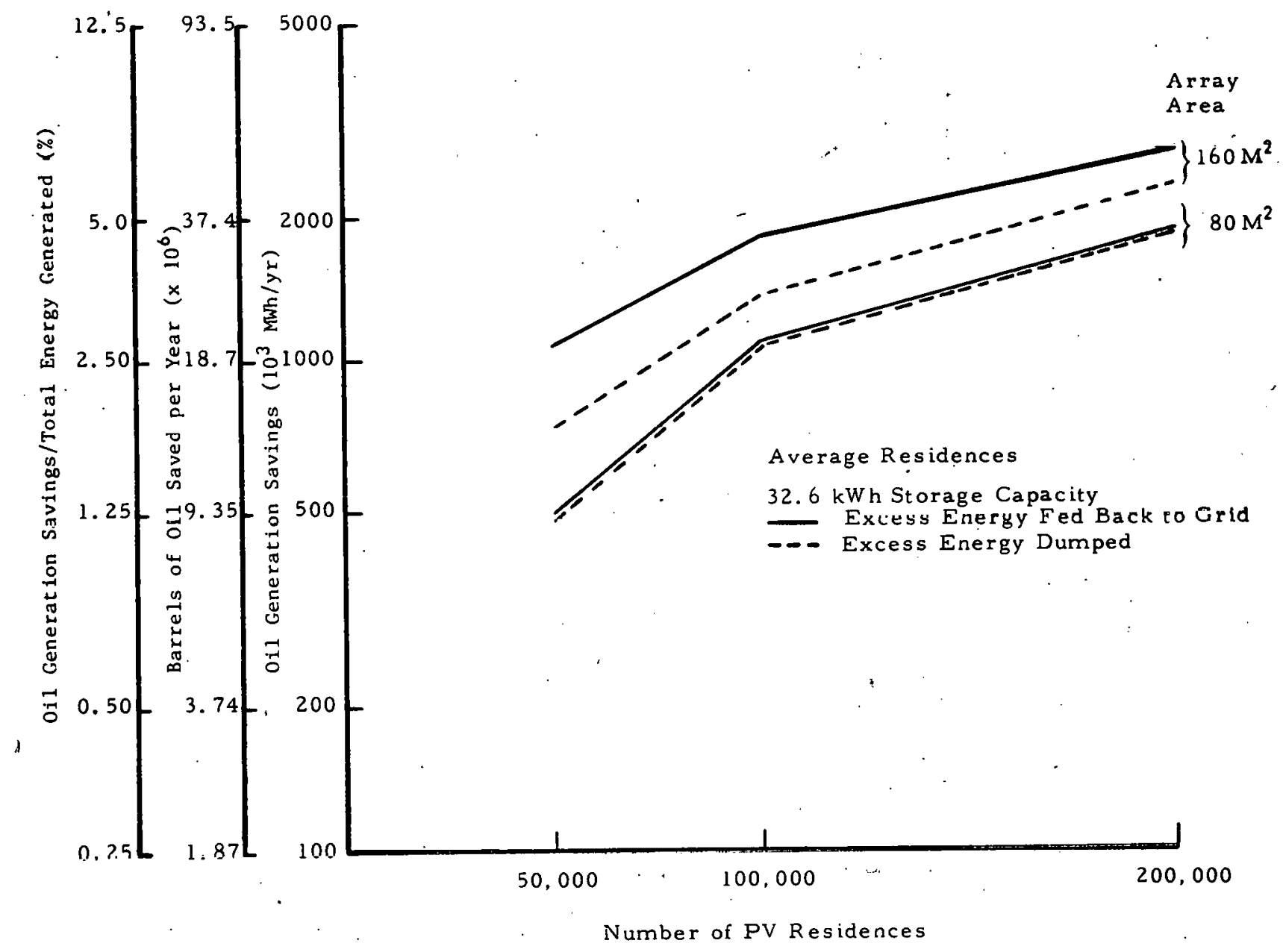

Figure 3-16. Oil Savings vs Number of PV Residences - On-Site Storage 

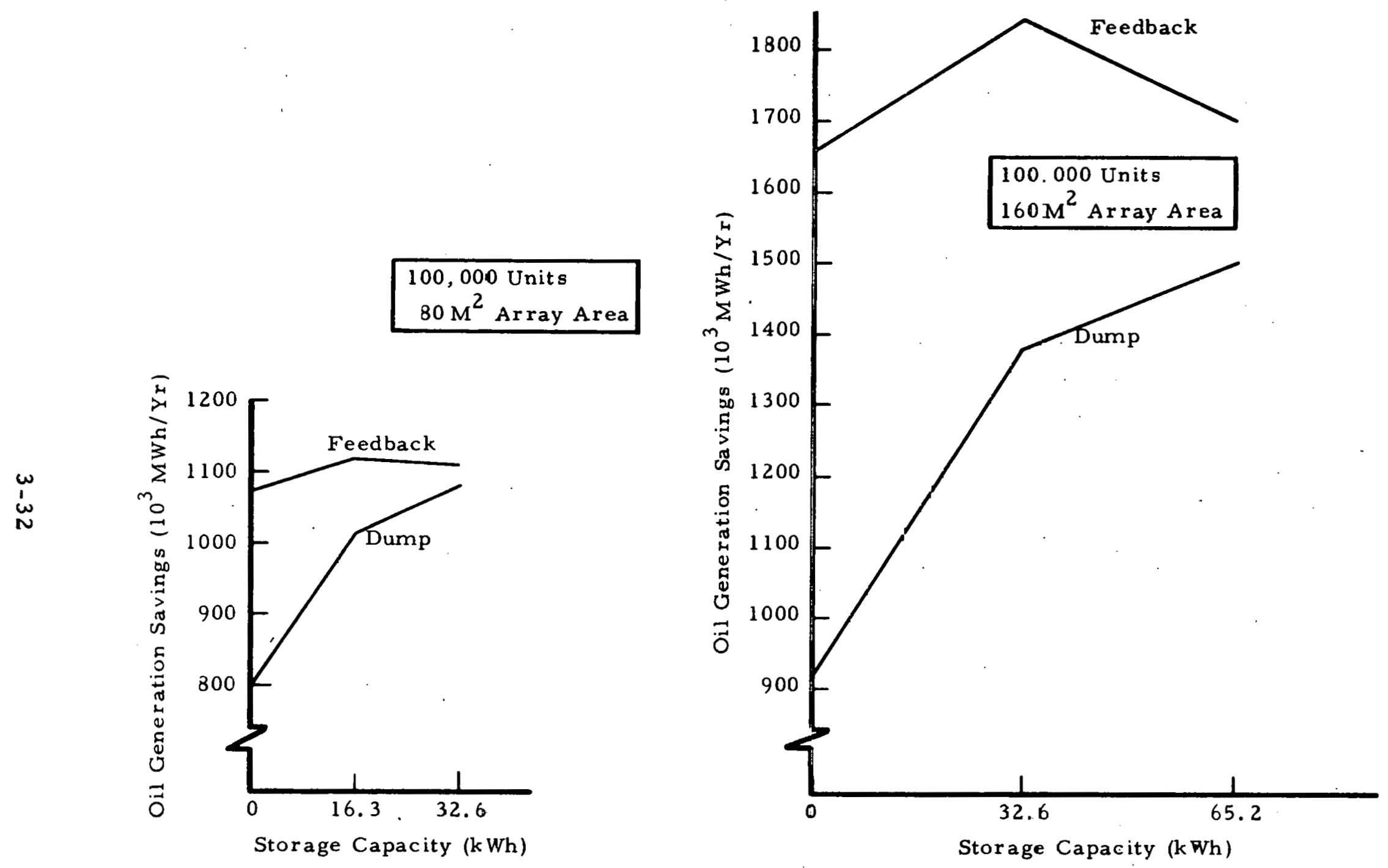

Figure 3-17. Impact of Storage and Feedback on Oil Generation Saving s 
units are put into operation. The aifference between the unmodified fuel cost and the reduceo fuel cost is the fuel cost differential. Consioering PV units without energy storage, shows utility fuel cost differentials as shown in Figure 3-18 versus the number of PV-equipped hours for four collector area cases. The results are similar to those noted for oil generation savings; the fuel cost differential does not rise as fast as the number of PV units. increases, or as the array area increases for a given number of PV units. For a given penetration (array area times the.number of PV units), the fuel cost differential increases as the number of PV units increases. The fuel cost differential is greater when excess PV generated energy is fed back to the grid, as shown in Figure 3-19. Similar results for PV units with electrical energy storage are shown in Figures 3-20 and 3-21.

The results of the fuel cost differential calculations are summarized for two cases in Figure 3-22. For both collector areas considered, the fuel cost difterential increases when storage capacity is included and excess energy is dumped. This result is expected because excess energy that is cumped can be stored in a battery for use later in the day. A different result is noted for the case in which excess PV energy is fed back to the grid. For $100,000 \mathrm{PV}$ units, each with $80 \mathrm{M}^{2}$ of collector area, the fuel cost differential decreases from $\$ 47$ million to $\$ 45.4$ million per year when a battery with $32.6 \mathrm{kWh}$ storage capacity is added. This result appears to conflict with the results shown in Figure 3-17 where the oil generation savings increase (from 1075 to $1110^{\circ}$ gigawatts) when a $32.6 \mathrm{kWh}$ battery is added to each array in the excess energy feedback case. However, the coal-generation savings (not shown in Figure 3-17) decrease for this case, and the fuel-cost value of the decreased coal-generation savings is greater than the fuel cost value of the increased oil-generation savings. Therefore, the net fuel cost differential decreases when energy storage is added to the PV units for the excess energy feedback case.

The fuel cost differential can increase when on-site storage is present and excess energy is fed back as is the case for 100,000 PV units with $160 \mathrm{M}^{2}$ array area per unit. As shown in Figure $3-22$, the differential increases from $\$ 82.5$ million to $\$ 83$ million per year when a $32.6 \mathrm{kWh}$ battery is included with each PV unit. For this case, 


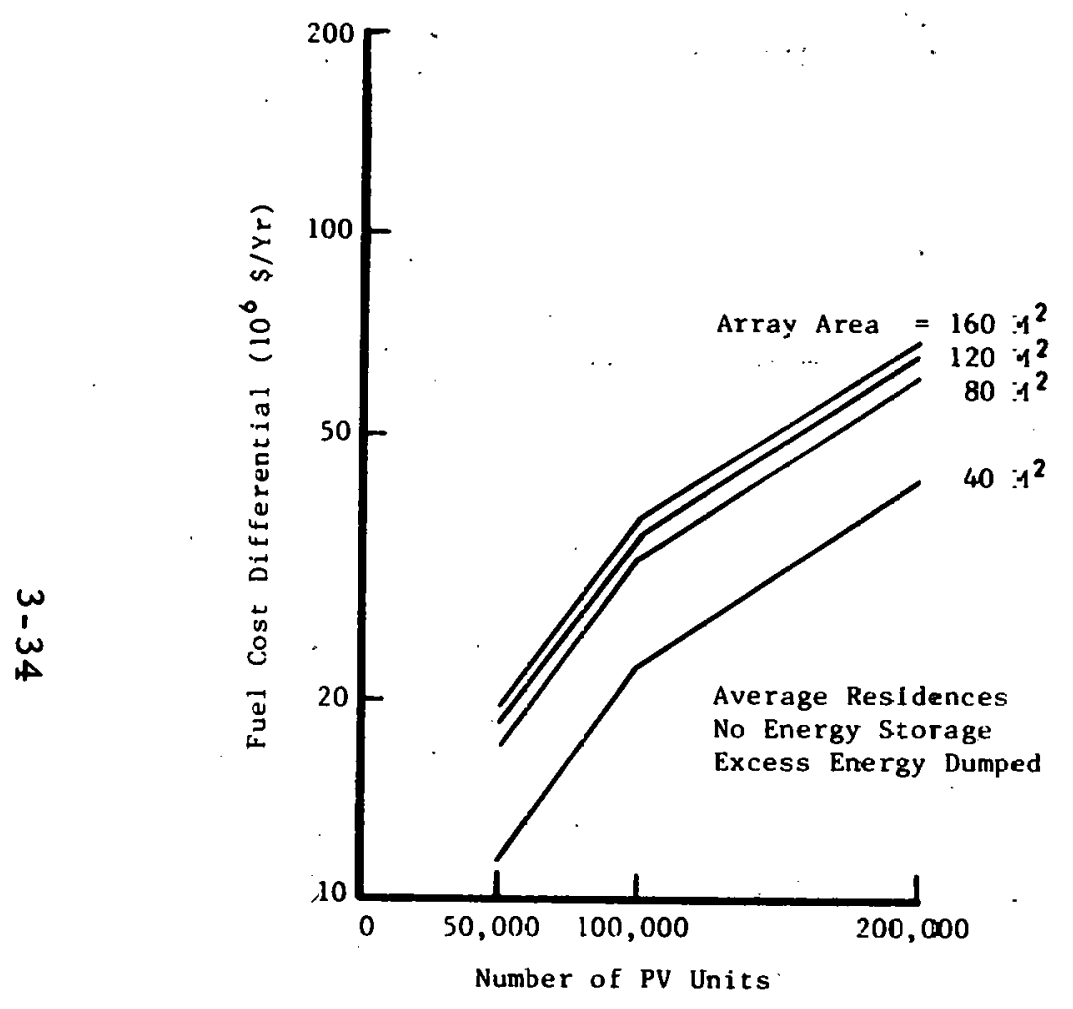

Figure 3-18. Fuel Cost Differential - No Storage and Excess Energy Dumped

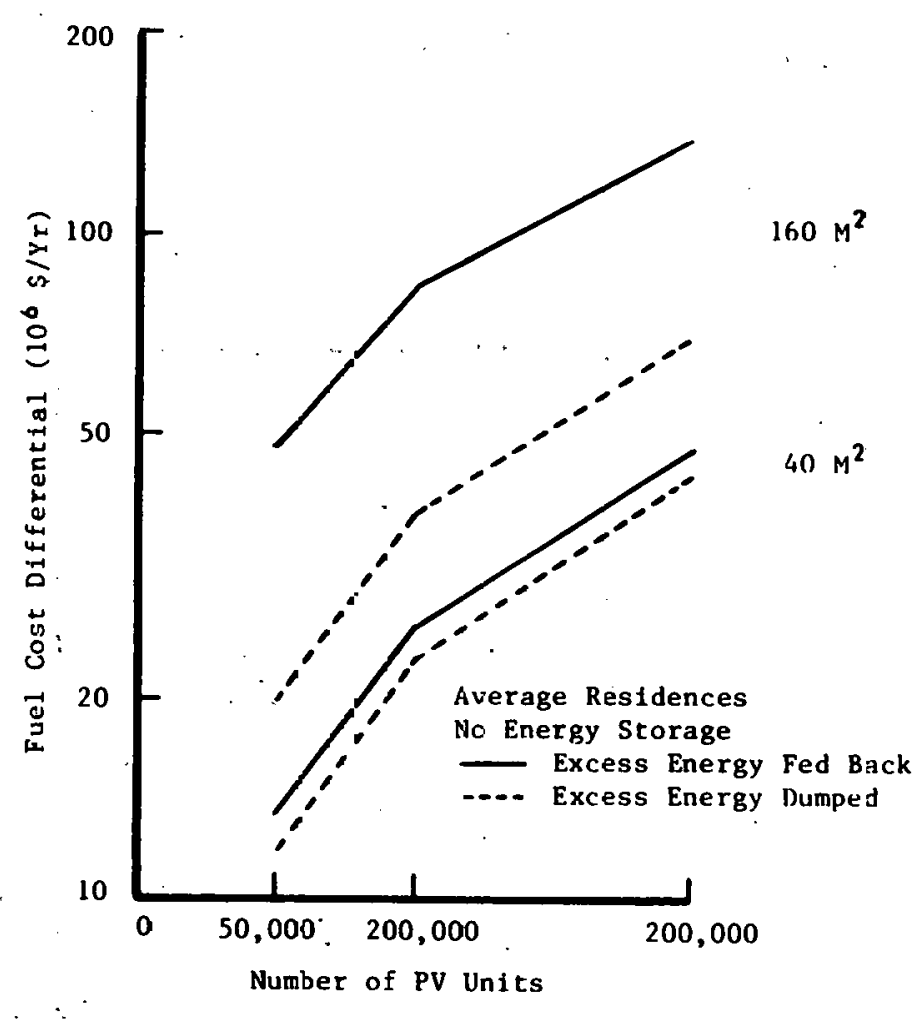

Figure 3-19. Fuel Cost Differential No Storage 


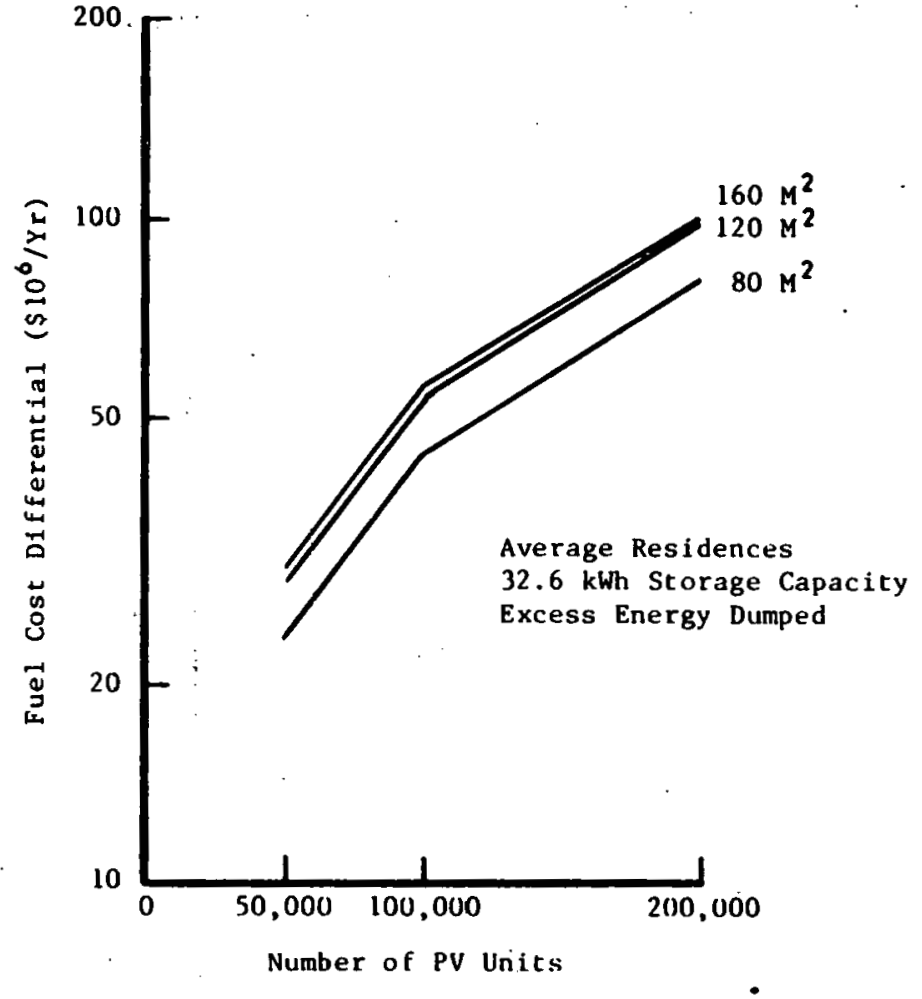

Figure 3-20. Fuel Cost Differential vs Number of PV Units - On-Site Storage and Excess Energy Dumped

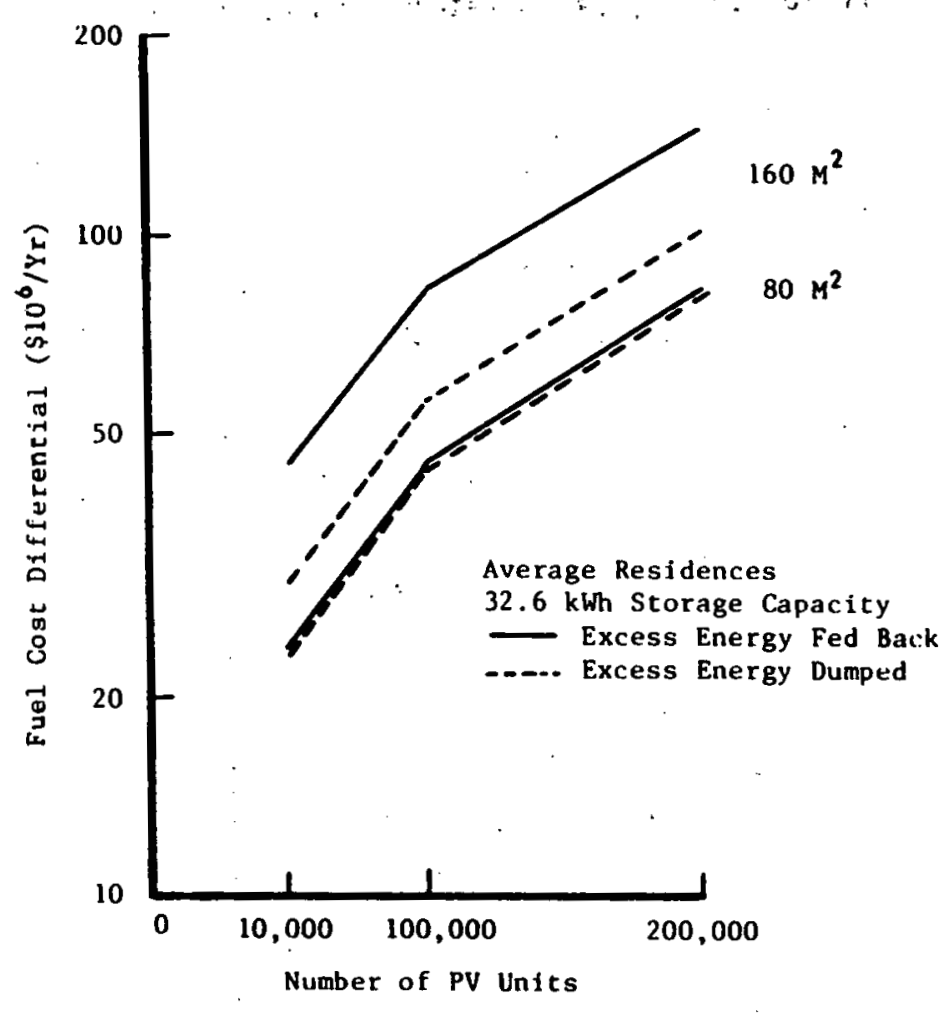

Figure 3-21. Fuel Cost Differential vs Number of PV Units - On-Site Storage 

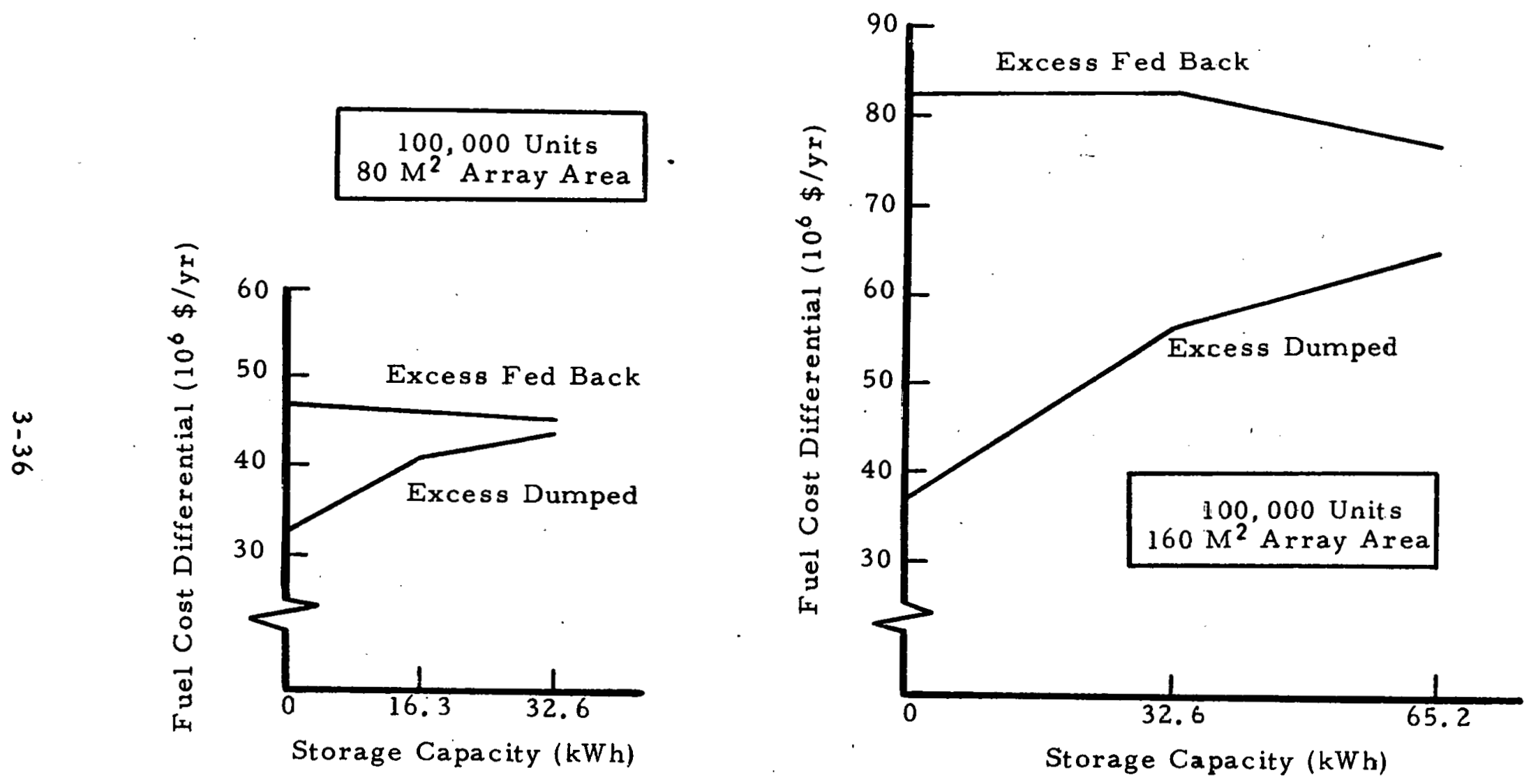

Figure 3-22. Impact of Storage and Feedback on Fuel Cost Differential 
there is an increased oil generation savings as shown in Figure 3-17, and decreased coal generation savings (not shown). The fuel cost value of the increased oil generation savings exceeds the fuel cost value of the decreased coal generation savings and thus there is a net increase in the fuel cost differential when $32.6 \mathrm{kWh}$ batteries are included. When the storage capacity is increased from 32.6 to $65.2 \mathrm{kWh}$, the situation is reversed as shown in Figure 3-22, with the fuel cost differential decreasing due to storage. The oil generation savings decrease as shown in Figure 3-17, and the coal generation savings increase. The net effect, after accounting for the value of the fuel costs involveo, is a decrease in the fuel cost differential.

The main thrust of the above discussion is to indicate that the value of the fuel cost differential is dependent on the amount and type of fuel displaced by the operation of PV units. This is especially relevant when considering the impact of excess energy fed back to the grid. The addition of storage subsystems to PV units can result in an increased or decreased fuel cost differential. depending on the number of PV units, collector area and storage capacity.

Another point to consider is the fuel cost differential realized by the utility if the utility reimburses the PV owners for the excess energy they feed back to the grid. Consider the case of 100,000 PV units, each with $80 \mathrm{M}^{2}$ of collector area and no storage. From Figure 3-22, the utility realizes an additional $\$ 14.5$ million per year ( $\$ 47$ million with feedback minus $\$ 32.5$ million with no feedback) when excess energy is fed back to the grid. If the utility fully reimburses the additional fuel cost differential to the PV owners for the energy fed back to the grid, the utility realizes a net fuel cost differential of $\$ 32.5$ million per year. It may seem logical and obvious that the utility would fully reimburse the PV owners for the additional fuel cost differential realized when energy is fed back to the grid. However, the operation of PV units plus the feedback of excess energy results in less $\mathrm{kWh}$ generation by the utility's plants and the utility must then amortize its fixed costs over fewer $k W h$. Therefore, the excess energy fed back to the grid may add some cost to the utility operation as well as reducing fuel costs. The question of payment for energy fed back to the grid is addressed in detail in the following section. 


\subsubsection{Residential Rate Implications}

The fuel cost differential realized by the utility depends on several factors including whether energy is fed back to the grid, what fraction of the fuel cost differential is reimbursed to the PV owners, the size of the PV arrays, and the amount of energy storage. Interesting and significant results of these analyses are the potential impact that the savings derived by the utility may have on residential energy rates for backup electricity and for the rate at which excess electricity is purchased by the utility. In this section, the results of the fuel cost differential analyses are integrated into a simplified rate model to determine an appropriate rate to be paid by the homeowner for backup electricity and a rate to be paid by the utility to the homeowner for sellback electricity.

The rate model of the utility is based on the following assumptions:

1. The residential rate structure is simplified and is independent of the amount of energy consumed and time of day.

2. Rates are directly related to costs incurred or avoided by the utility.

3. All houses are identical (i.e., demand and PV units).

In addition to these assumptions, the normal (i.e., non PV) residential cost of electricity is assumed as $\$ .0403$ per $\mathrm{kWh}$ which has been inferred from data in Ref. 3-5. If revenues are directly related to costs as assumed above, then any change in costs is equivalently reflecteo as a change in revenues. That is,

$$
\Delta \text { Costs }=\Delta \text { Revenues }
$$

Note that utility costs consist of fixed plus operating costs. The fixed costs are the sum of capacity and non-capacity costs; the operating costs are made up of fuel and non-fuel costs such as operators, maintenance, etc. When FV units are in operation, fuel is saved but non-fuel operating costs do not change significantly. Similarly, non-capacity costs related to fixed charges such as for transmission and distribution equipment or general plant as well as billing costs and so on do not change. Therefore,

$$
\Delta \text { Costs }=\Delta \text { Capacity Costs }+\Delta \text { Fuel Costs }
$$


Assuming zero capacity credit for the PV units, $\Delta$ Capacity is set equal to zero, and from Equations (3-1) and (3-2),

$\Delta$ Costs $=\Delta$ Fuel Costs $+\Delta$ Revenues

The $\Delta$ Fuel Costs term in the above equations is the fuel cost differential value discussed in the previous section. The $\Delta$ Revenues term in Equation 3-3 is mathematically expressed in terms of two important parameters, the backup ratio and the sellback ratio. The backup ratio, $b$, is the ratio of the rate paid by PV owners for backup energy to the normal resiciential rate. Similarly, the sellback ratio, $s$, is the ratio of the rate paid to the PV owners for excess energy fed back to the grid to the normal residential rate. The algebraic equations for $b$ and $s$ as well as the expressions for $\Delta$ Revenues and associated mathematics to solve for $b$ ano $s$ are found in Appendix C. The backup and sellback ratios for the no-storage case are shown as a function of PV penetration in Figure 3-23.

The backup ratios are found to vary slowly with increasing PV penetration and they range from approximately 1.1 to 1.3. The backup ratio increases with increasing PV penetration (i.e., either increasing array area or increasing number of PV units) because fewer $k$ Wh of energy are required from the utility's plants and the utility has to amortize its fixed costs over fewer $\mathrm{kWh}$. Note that the increase in the backup ratio is a smaller then than any increase in PV penetration. For example, when the array area is doubled from $80 \mathrm{M}^{2}$ to $160 \mathrm{M}^{2}$ for $100,000 \mathrm{PV}$ units, the backup ratio only increases from 1.20 to 1.27 , less than 6 percent increase in b. The sellback ratio also varies slowly with PV penetration; however, there is an inverse relationship between $\mathrm{s}$ and penetration. As the number of PV units or the array area is increased, the value of the auditional fuel displaced by the PV energy fed back to the grid is decreased. Therefore, the rate at which the utility reimburses the PV owners for energy fed back decreases and the sellback ratio is thus decreased.

Similar results are obtained for the on-site storage case as shown in Figure 3-24. Both the backup and sellback ratios increase slowly with increasing PV 

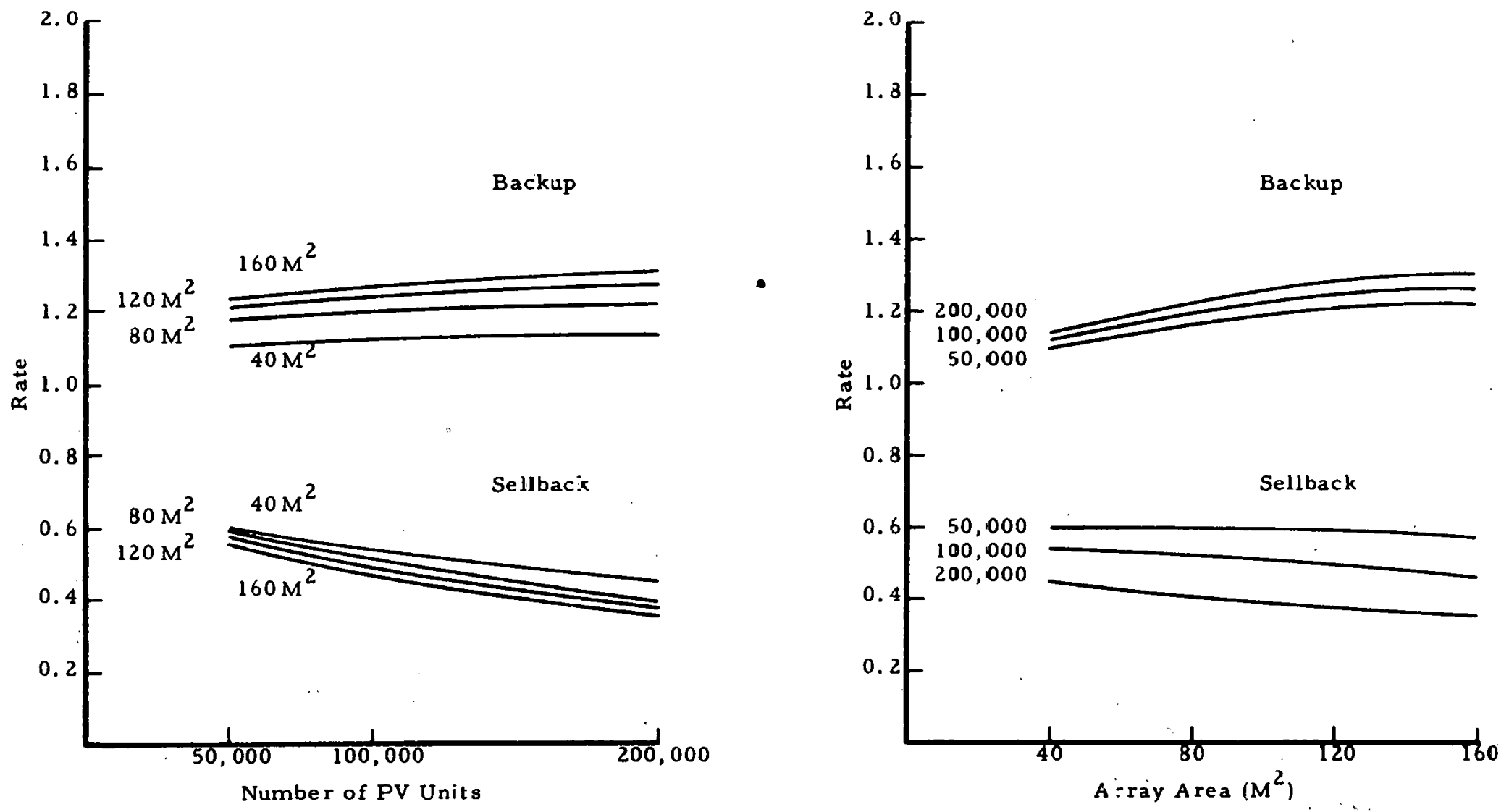

Figure 3-23. Backup and Sellback Rates vs PV Penetration - No Storage 

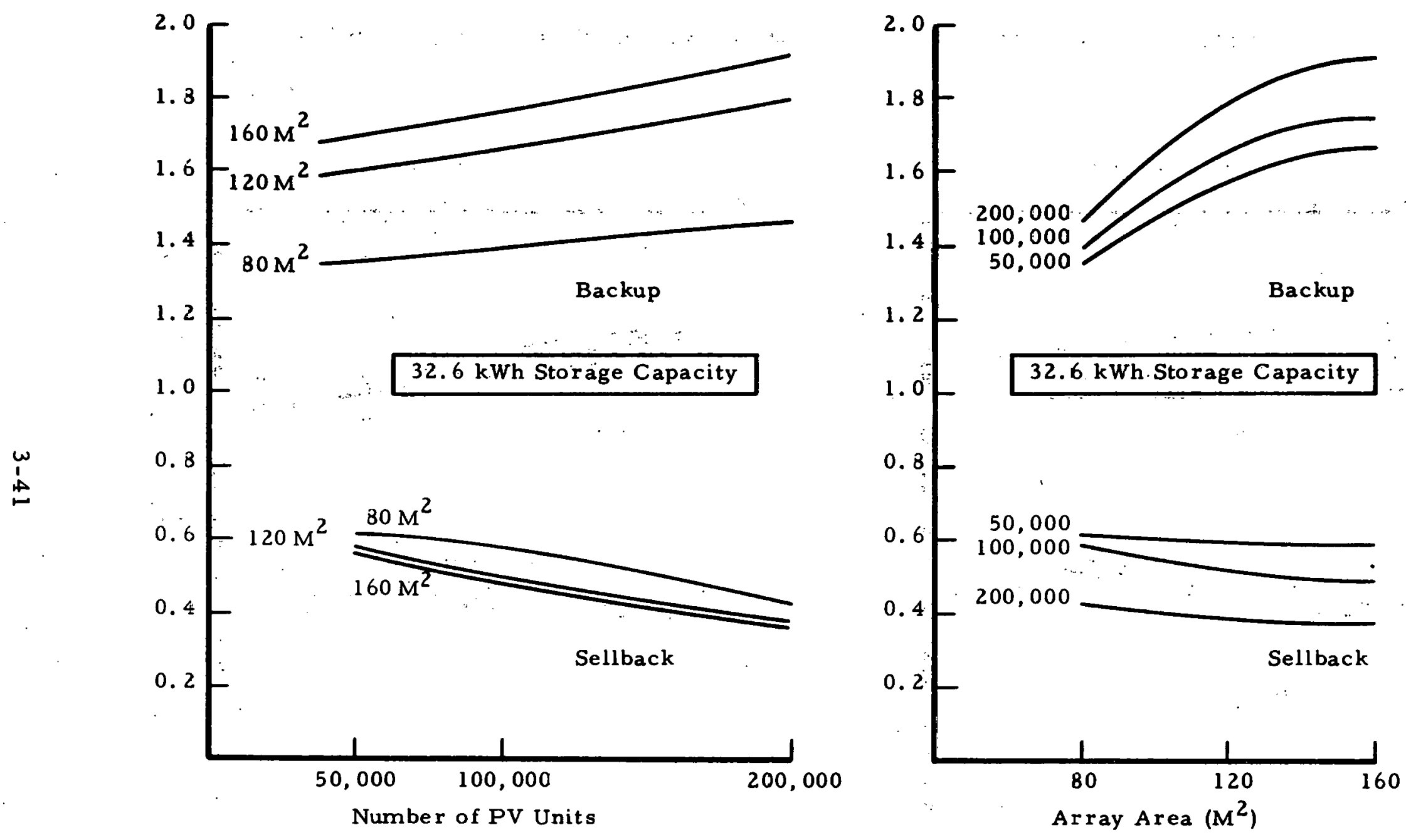

Figure 3-24. Effect of PV Penetration on Backup and Sellback Rates -

With On-Site Storage 
increased. The oil generation savings are greater for increasing PV penetration when the increase is caused by an increase in the number of PV units.

A comparison can be made for oil savings between the cases with and without on-site energy storage. The curves shown in Figure 3-17 cemonstrate that the greater oil savings are realized when on-site storage is present. For the case when excess energy is dumped (labelled as DUMP in Figure 3-17), it is obvious that the oil savings will sharply increase, because much of the energy that is cumped when no storage is present is now stored in the battery for use later in the day. The oil savings do not increase as sharply when a $32.6 \mathrm{kWh}$ storage subsystem is included and energy is fed back to the grid. As previously discussed, one impact of storage is to displace evening peak energy during the winter months; this energy normally is generated by oil fired plants. However, the 70 percent round-trip efficiency of the storage subsystem reduces the amount of oil savings. Increasing the storage capacity can result in a cecrease in oil savings when excess energy is fed back to the grid. As shown in Figure 3-17, the oil generation savings jecreases from 1840 to 1700 gigawatts when the storage capacity is doubled. Excess energy, which is displacing oil-generated energy, is put into the larger sizea battery and, given that the energy in the first $32.6 \mathrm{kWh}$ segment of the battery cisplaces a large amount of oil-generated energy later in the day, displaces mostly coal-generated energy.

Betore any attempt is máde to generallze the above results, it shuuld be liuled that: it is not clear to what extent the specific characteristics of the modeled utility are unique; the economics implications as perceived separately by the homeowner, the utility, and the aggregate of the two are not apparent; the peculiarities of the insolation and load profiles have not been explored; operating inefficiencies such as increased spinning reserve requirements have not been included; and the impact on generating capacity require ments has not been assessed.

\subsubsection{Fuel Cost Differential}

The other key figure of merit is fuel cost differential. The utility fuel cost without PV units is $\$ 520$ million per year in 1985 . The fuel cost is reduced when PV 
penetration; $b$ increases and s decreases with increasing penetration. A comparison of backup and sellback ratios for PV units with and without storage for array areas of $80 \mathrm{Mi}^{2}$ and $160 \mathrm{M}^{2}$ as given in Figure 3-25. For both collector areas, the backup ratios are greater when storage is present. This result is expected, since more utility generation is displaced with storage than without; the utility thus realizes a greater cost (i.e., amortizing fixed costs over fewer $k W h$ generated by the utility's plants), and the cost for backup energy increases. The sellback ratio is also greater when storage is included although the advantage is smaller for the larger sized arrays. As discussed previously, the net value of the fuel displaced when excess energy is fed back to the grid is greater when storage is added. However, when the storage capacity is increased, the sellback ratio can become smaller than the value for the no storage case. For a collector area of $160 \mathrm{Mi}^{2}$, and storage capacity of $65.2 \mathrm{kWh}$ per unit, $\mathrm{s}$ is smialler slightly smaller than the no storage case value for 200,000 PV units as shown in Figure 3-25. For the $65.2 \mathrm{kWh}$ storage capacity, the net value of the fuel displaced by energy fed back to the grid decreases as the number of PV units increases.

A comparison of backup and sellback ratios with respect to PV penetration is shown in Figure 3-26. The graph on the left shows that the sellback ratio is greater for all array areas at constant penetration of $16 \times 10^{6}$ (number of PV units times array. area) when storage is present. However, the sellback ratio for the storage case converges to the non-storage value of $s$ as the array area increases. The graph on the right shows that the sellback ratio is greater for lower penetrations, that is, as the penetration increases, the value of the fuel displaced by excess energy fed back to the grid decreases. The curves in both graphs show that the backup ratio is greater when the utility generates less energy, either by adding storage to the PV units or by increasing the $P V$ penetration.

\subsubsection{Dispersed Sources}

The energy load associated with a given residence significantly depends upon the life style and energy management practices of the occupants of the residence. In the present study, these variations are modeled by statistically varying the residence load profile both above and below the reference or average value as discussed in 

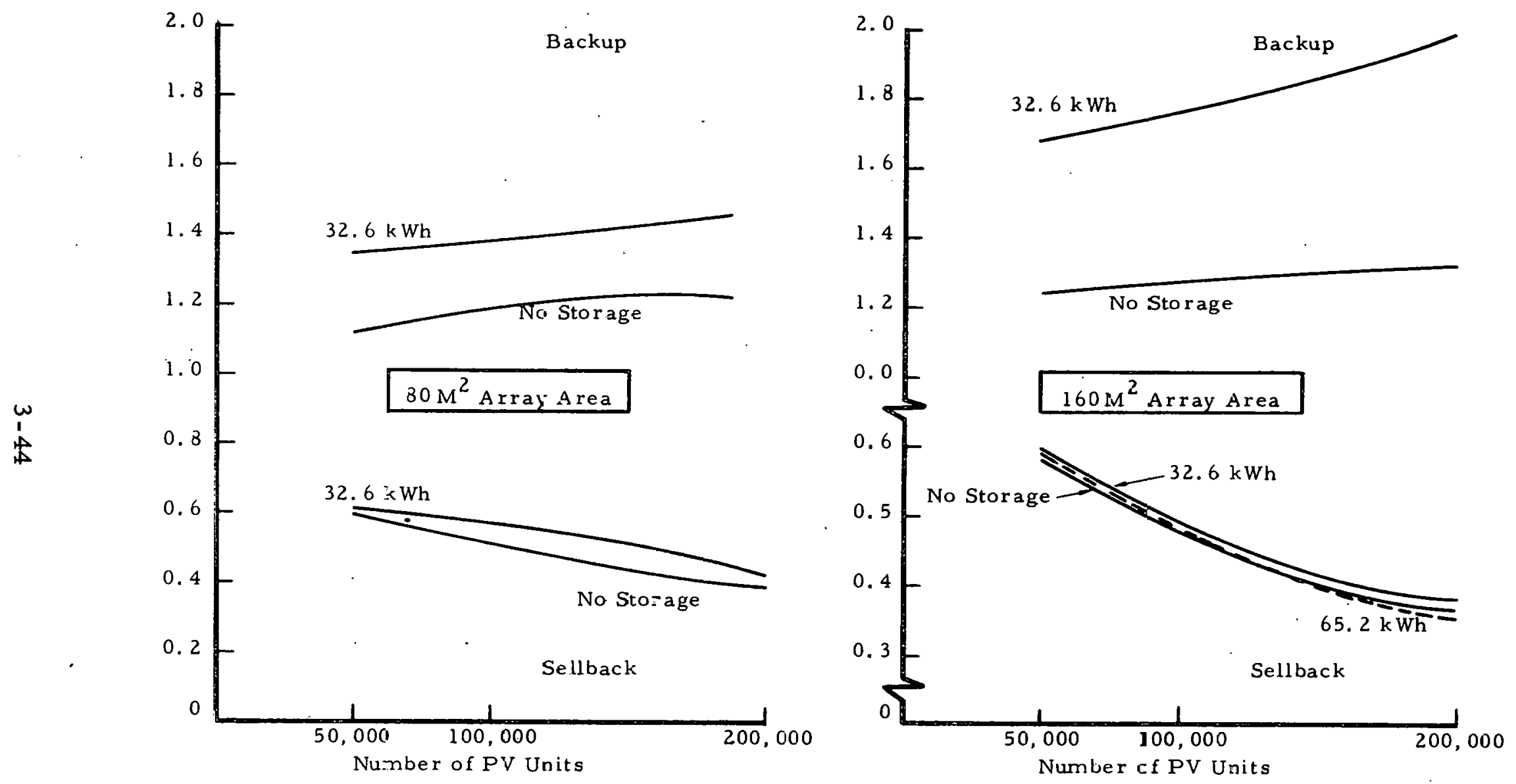

Figure 3-25. Backup and Sellback Ratios - With and Withcut Storage 

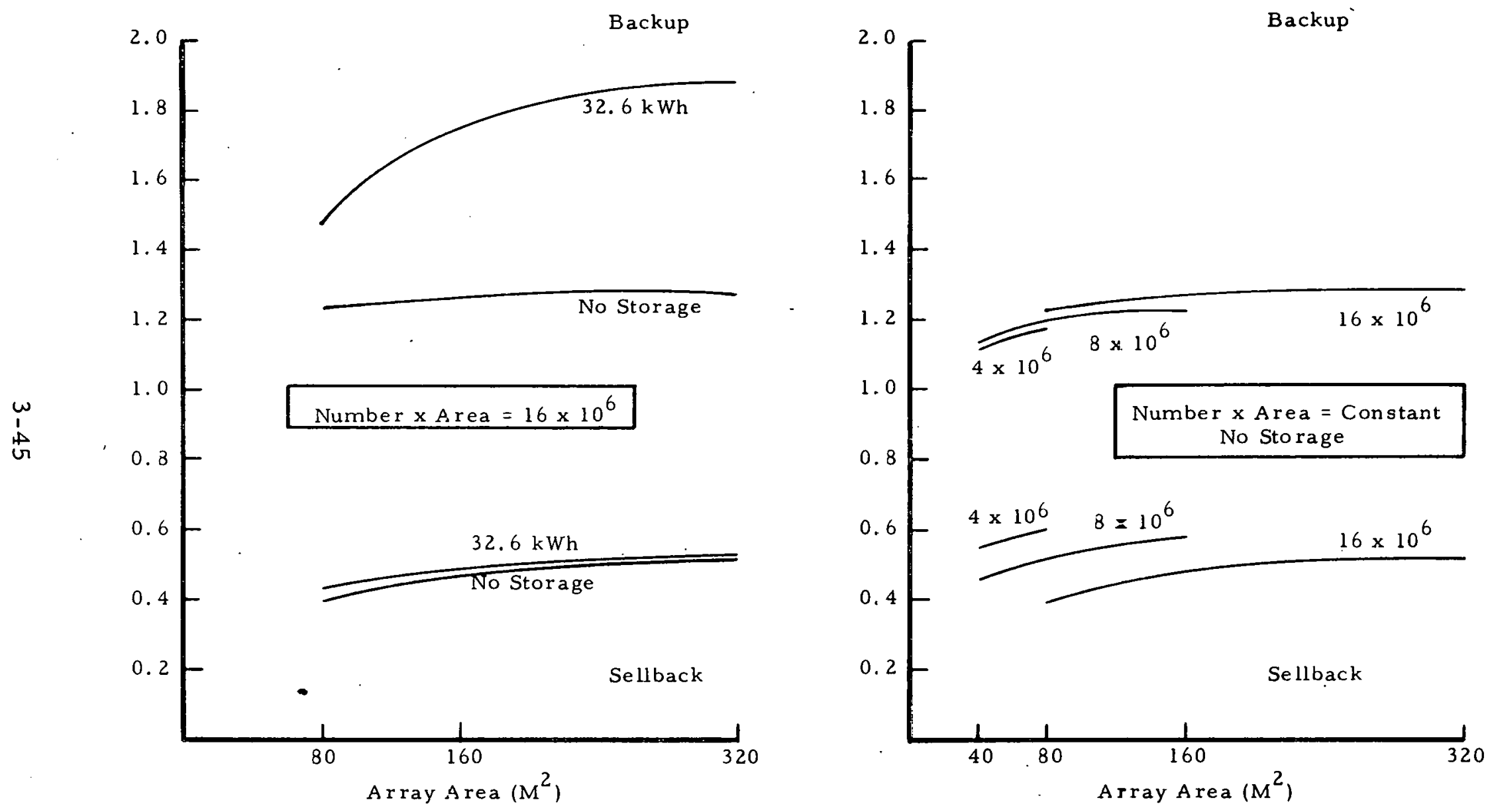

Figure 3-26. Backup and Sellback Rates as a Function of Penetration 
Section 3.2.3. In Table 3-8, savings to the utility for various numbers of $P V$ units with the same array area per house $\left(80 \mathrm{M}^{2}\right)$ are compared. The important results noted from the table are as follows:

- The fuel cost differential for a set of average houses is the same as that for a set of diverse houses when excess energy is fed back to the grid.

- When excess energy is dumped, the fuel cost differential for the diverse sources is smaller than for the average house.

- In the above case, the difference in fuel cost differential between the diverse and average houses is not significant.

The second result is caused by the residences with load profiles lower than the load profile for the average house. The PV units for these residences will generate a larger amount of excess energy, which when dumped, does not contribute to utility fuel cost savings. The third result implies that the impact of size-diverse sources as moceled in this study is essentially identical to that observed for the average house. Similar results are also obtained when examining oil savings.

Table 3-8. Comparis on of Fuel Cost Differentlal for Average and Dispersed Sources (Array Area $=80 \mathrm{M}^{2}$ and No Storage) $(106 \$ /$ Year $)$

\begin{tabular}{|c|c|c|c|c|}
\hline \multirow{2}{*}{$\begin{array}{c}\text { Number of } \\
\text { PV Units }\end{array}$} & \multicolumn{2}{|c|}{ Excess Energy Dumped } & \multicolumn{2}{c|}{ Excess Energy Fed Back } \\
\cline { 2 - 5 } & Dispersed & Average & Dispersed & Average \\
\hline 50,000 & 17.5 & 17.8 & 25.0 & 25.0 \\
100,000 & 34.3 & 34.9 & 48.0 & 48.0 \\
200,000 & 64.7 & 65.6 & 88.2 & 88.2 \\
\hline
\end{tabular}




\subsubsection{Conclusions}

The conclusions delineated below must be viewed from the proper perspective. That is, the conclusions apply specifically to the boundary concitions, assumptions and parameter values chosen here and may vary in validity for other locations, utilities, economic parameters and so on.

\section{Oil Conservation}

On-site photovoltaic units achieve oil conservation by means of a gross energy displacement effect even though much of the generating capacity was coal or nuclear. In addition there is a generation mix impact caused by the phasing between the solar insolation profile and the utility demand profile. The impact of the latter effect is highly site and season dependent.

\section{Storage and Sellback}

Oil savings are impacted by both storage and sellback. In terms of oil conservation, more barrels of oil are saved when excess PV generated energy is fed back to the grid. This impact is enhanced when on-site storage is added; however, beyond a critical value of storage capacity, the amount of oil conserved when energy is fed back decreases and approaches the amount conserved when excess PV energy is dumped. Similar trends are noted in terms of fuel cost differential. From the utility point of view, the net influence is a function of the storage inefficiencies, the prevailing rates for sellback and backup energy and the alteration in the demand profile caused by the particular storage-logic employed. Storage and sellback tend to be counteractive in that the benefit resulting from their combination is less than the sum of their individual benefits.

\section{Miodelled Sellback and Backup Rates}

The utility sellback rate decreases with increasing PV saturation and with array areas for the larger sizes, because' the incremental excess energy displaces incrementally less valuable conventional fuel. The backup rate increases with 
increasing solar penetration, both array area and saturation, because the capacity. factor of the conventional generators is thereby reduced resulting in less efficient utilization of the fixed capacity. The effect of energy storage is to further increase the backup energy rate and the sellback rate. The sellback rate decreases for very large array areas as the storage capacity increases.

\section{Coupled Analysis Needed}

The site owner and the utility company will often have opposing economic motives. Previous studies have concentrated on only one of the parties with consequent loss of economic representation for the other. System acquisition decisions must involve coupled.analyses in which the preferences, and constraints of both groups are considered.

\subsubsection{Recommendations}

The main recommendation is to develop a "coupled" analysis in which the values, preferences and constraints of both the on-site owner and the utility company are simultaneously considered. Studies to date have taken only one point of view, but the ultimate resolution of integration issues will certainly reflect both positions. 


\section{PART II. REFERENCES}

4-1. Randall, C.M., B. R. Johnson and M. E. Whitson, Jr., "Measurements of Typical Insolation Variation at Daggett, California", Aerospace Technical Report (in preparation).

4-2. Atwater, M. A., and J. T. Ball, "Numerical Solar Radiation Model Based on Standard Meteorological Observations", Solar Energy 21, 163-170, (1978).

4-3. Mahoney, P., and U. Czapski, "Mesoscale Variability of Measured Solar Radiation for Stations Across Upstate New York and Southern Canada", Research study in progress at State University of New York reported at DOE Solar Energy Research and Training Site Review, 30 October 1979, Bethesda, Maryland.

4-4. Dirmhirn, I., "Solar Energy Potential, Ultraviolet Radiation, Temperature and Wind Conditions in Mountainous Regions", Research Study in progress at Utah State University reported at DOE Division of Distributed Solar Technology Insolation Assessment Contractors' Review, 31 October - 1 November 1979, Bethesda, Maryland.

4-5. Bach, W. D., "Coastal-Inland Solar Radiation Difference Study", Research Study in progress at Research Triangle Institute, reported at DOE Division of Distributed Solar Technology Contractors' Program Review, 3-6 April 1979, Denver, Colorado.

4-6. Yinger, R. J., "Solar Energy Measurements at Selected Sites Throughout the Southwest During 1978", The West Associates Solar Resource Evaluation Project, Southern California Edison Company Project Manager, September 1979.

4-7. Randall, C. M., M. E. Whitson, Jr., and B. R. Johnson "Measurements of Insolation Variation Over a Solar Collector Field", Aerospace Technical Report ATR-79(7747)-2, 30 December 1978. 
APPENDIX C

\section{DERIVATION OF BACKUP AND SELLBACK RATES}

First, necessary parameters are defined as follows:

e $\quad=\quad$ Normal (i.e., non PV) residential rate; $\$ / \mathrm{kWh}$

$\mathrm{N}=\quad$ Number of houses with PV units

b = Ratio of rate for backup energy to normal rate; dimensionless

$\mathbf{s} \quad=\quad$ Ratio of sellback rate to normal rate; dimensionless

$\operatorname{URR}(x, y, z)=\quad$ Utility residential revenues from houses with PV units; $\$ / k W h$

$\mathrm{x} \quad=\quad$ Array area; $\mathrm{M}^{2}$

$\mathrm{y} \quad=\quad$ PV energy storage capacity; kWh

$\mathrm{z} \quad=\quad$ Flag denoting sellback; no sellback $(\mathrm{z}=1)$, sellback $(\mathrm{z}=2)$

$\mathrm{NRE}=\quad$ Normal residence energy consumption; $\mathrm{kWh} / \mathrm{year}$

$\beta=$ Fraction of house load not provided by the PV unit; dimensionless

$\delta=$ Ratio of sellback energy to house load; dimensionless

The parameters $b$ and $s$ characterize the impact of the PV units on the residential rate structure and equations in terms of $b$ and $s$ are developed below.

From Equation (3-3) and the above definitions, the reduction in utility revenue due to operation of PV units and no sellback of excess PV energy is expressed as

$$
\Delta \mathrm{URR}=\mathrm{URR}(0,0,1)-\mathrm{URR}(\mathrm{x}, \mathrm{y}, \mathrm{l})
$$

where $\quad \operatorname{URR}(0,0,1)$ is the normal utility residential revenue. That is,

$$
\operatorname{URR}(0,0,1)=(N)(e)(N R E)
$$


Also, $\quad \operatorname{URR}(x, y, 1)$ can be expressed as

$$
\operatorname{URR}(x, y, 1)=(N)(b)(e)(\beta)(N R E)
$$

Combining equations (3-4) and (3-6),

$$
\mathrm{b} \beta=-1-\frac{\Delta \mathrm{URR}}{\operatorname{URR}(0,0,1)}
$$

Similarly, the reduction in utility revenue due to operation of PV units with sellback of excess energyis given by

$$
\Delta U R R *=\operatorname{URR}(0,0,1)-\operatorname{URR}(x, y, 2)
$$

where

$$
\operatorname{URR}(x, y, 2)=(N)(b)(e)(\beta) N R E-N(s)(e)(\sigma) N R E
$$

which, after some algebra, is equivalent to

$$
\operatorname{URR}(\mathrm{x}, \mathrm{y}, 2)=\operatorname{URR}(0,0,1)[\mathrm{b} \beta-\mathrm{s} \sigma]
$$

Therefore, by substituting Equation (3-9) with (3-8),

$$
\Delta \mathrm{URR}^{*}=\operatorname{URR}(0,0,1)[1-\mathrm{b} \beta+\mathrm{s} \sigma]
$$

Further, by solving Equation (3-7) for $\triangle U R R$,

$$
\Delta \mathrm{URR}=\operatorname{URR}(0,0,1)[1-\mathrm{b} \beta]
$$

Thus, Equation (3-10) is rewritten as

$$
\Delta U R^{*} R^{*}=\Delta U R R+\operatorname{URR}(0,0,1) s \sigma
$$

and solving for $s \sigma$,

$$
s \sigma=\frac{\Delta U R R^{*}-\Delta U R R}{U R R(0,0,1)} \text {. }
$$

Values for $\triangle U R R^{*}$ and $\triangle U R R$ are taken directly from Tables 3-10 and 3-11 for a given number of PV units. The URR $(0,0,1)$ term is calculated from Equation (3-5) where $e$ is $\$ .0403 / \mathrm{kW}$-hour and NRE is $28,524 \mathrm{~kW}$-hours per year as previously noted; therefore $\operatorname{URR}(0,0,1)$ equals $\$ 1149.50$ times $N$, where $N$ is the number of houses with PV units. The backup energy and PV excess energy fractions, $\beta$ and $\sigma$ respectively, are delineated in Table 3-6 for various combinations of array area and numbers of PV units. Values of $b$ and $s$ for various PV configurations and numbers of $P V$ units have been calculated using the above equations and are shown in Table 3-12. The results are discussed below. 
FART III. CONTENTS

1.0 INTRCDUCTION ...................... 1-1

2.0 FACTORS AFFECTING RATE STRUCTURE........... 2-1

2.1 Ownership ...................... 2-1

2.2 Solar System Characteristics................. 2-1

2.3 Utility Characteristics ............... 2 - 2

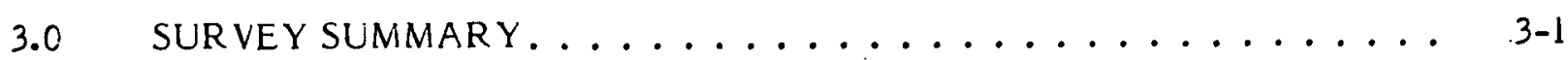

3.1 Survey Development. ........................ 3-1

3.2 Summaries of Relevant Studies ................ 3-1

4.0 EXISTING SOLAR RATE STRUCTURES . . . . . . . . . 4-1

4.1 Solar Backup Power Rates . . . . . . . . . . . . . . . . 4-1

4.2 Parallel Generation Rates for Solar . . . . . . . . . . . . . 4-2

5.0 THE FUTURE OF SOLAR RATES ............. 5 .

5.1 PURPA Requirements for Rule Making . . . . . . . . . . . 5-1

5.2 Details of the FERC Response to PURFA . . . . . . . . . 5 5-2

5.3 Areas for Further Study . . . . . . . . . . . . . $5-3$

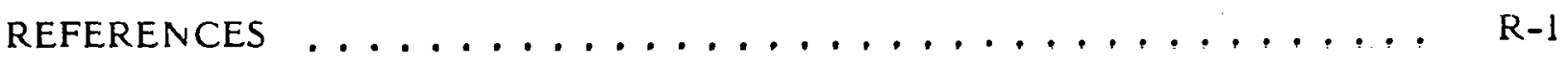

FIGURE

2-1. Simulation Results for a Fhotovoltaic Residential Installation . . . . 2-3

TABLE

4-1. Examples of Current Rates for Parallel Generation ........ 4-3 
FART III. RATE STRUCTURES FCR ON-SITE FHOTOVCLTAIC UNITS

\subsection{INTRODUCTION}

This section describes the results of a brief task whose objective was to assess current activities concerning rate structure studies, practices, rationales, and experiments as they affect the use of on-site photovoltaic power units. A telephone survey was conducted of several active researchers, utilities, and Government agencies, and the available literature was used to compile an information base on this subject.

In order to understand the rate structures which utilities would apply to solar technologies such as on-site photovoltaic power units, the basis of rate structure formulation shall first be reviewed. A good summary of this process is contained in Ref. 1 , and is quoted below:

"For the design of rate structures, electric utilities will generally undertake fully distributed cost studies that analyze past operations for a given period and allocate the revenue requirement among the various classes of service. Initially, the revenue requirement is functionalized into generation, transmission, and distribution costs. The functionalized costs are then classified into groups bearing a relationship to a cost-defining characteristic of the services rendereo. Typically, these classifications are demand, energy, and customer. Demand or capacity costs are those that vary with the $\mathrm{kW}$ of demand imposed on the system by customers. Energy costs vary with the number of $\mathrm{kWh}$ produced to serve customer usage, and include fuel, operation, and maintenance costs associated with converting fuel to electric energy, and possibly the costs to purchase power from neighboring systems. Customer costs are those related to the existence of specific customers and vary with the number of customers served.

The functionalized and classified costs are allocated to customer classes. The three primary customer classes are industrial, commercial, and residential. Energy-related costs are allocated on the basis of consumption by each class. Customer costs are allocated in accordance with the customer-related facility, metering, and billing costs associated with each class. Demand costs can be allocated in any of several methods. The peak responsibility method allocates demand costs on 
the basis of each customer class's aemand at the time of the system peak. Another method, the noncoincident peak method, allocates demand costs proportional to the peak demand of the inoividual class regardless of when that demand occurs.

If it is desired to create a rate structure based on time-ćifferentiated costs, additional steps are involved. Rating periods are selected and can be seasonal, resulting in rates differing between diurnal on- and off-peak periods. Two generally accepted principles are observed: (1) periods of greater system load have associated with them a greater portion of fixed costs per unit of demand and (2) periods of greater system load have associated with them a greater portion of variable costs per unit of consumption. Rates are generally designed with demand and energy costs higher for the seasonal and possibly daily peak period than for the corresponding off-peak period.

If rates are to be designed on the hasis of marginal cost i.c., the cost of adding an additional unit of output, a different costing approach is used by the utility. Under a marginal cost pricing scheme demand, energy and customer costs are derived and can be non-time-differentiated, time-aifferentiated by season, or time-differentiated by time of day. Economists ano some regulators contend that, ideally, consumers ought to pay a price equal to the marginal cost of the service on the basis that marginal cont pricing results in economic efficiency and optimum allocation of resources." 


\subsection{FACTORS AFFECTING RATE STRUCTURE}

\subsection{OWNERSHIP}

The rates which a utility will charge a customer, or pay a customer for electricity generated at the customer's resicience, is dependent upon ownership. If the utility owns the photovoltaic unit, the cost of power production will probably be treated as a supply of usable energy to the entire service area just as if it were produced at a central generating facility. The capital cost of the solar unit would be rolled in and treated as a rate base investment. Operating and maintenance costs would presumably be shared by all customers just as the operating and mainitenance costs of central station units are shared by all customers. Under this concept both the cost and benefits of the energy generated in the service area would be captured by all consumers. The utility might treat solar acquisition as an element in the planning of new power production and consider the overall effect of these systems on an aggregated basis. If the customer owns the solar facility, however, the rate structure must consider the impact on utility capacity, requirements, capacity utilization, system operations, the time-of-day value of sellback energy, special interconnection and metering costs, ano changes which occur as a result of increasing penetration of photovoltaics in the overall system. The utility rate base would not include the photovoltaic power production investment although the investment in distribution (excluding any interconnection equipment), transmission, capacity and general plant required to provide backup power would continue to be included in the rate base. The net of costs avoided (fuel plus capacity) and extra costs incurred would be credited to the solar unit owner presumably without an allowance for income to the utility. Customer ownership is assumed in the discussions and analysis which follow.

\subsection{SOLAR SYSTEM CHARACTERISTICS}

Since the utility generally bases its rate structure on energy use, capacity requirements, and operational efficiency*, the solar unit characteristics and output as

* Most residential rates are highly simplified ano do not explicitly identify these considerations. Operational efficiency refers to the use of a power factor-related charge. 
well as the nature of the customer demand are both important to the determination of an appropriate rate structure. The nature of the insolation on an hour-by-hour basis relative to the load is important, as well as the amount of storage present in the photovoltaic unit. This can be illustrated by referring to Figure 2-1, which shows the results of an hour-by-hour simulation of residential demand for an all-electric home in Madison, Wisconsin. For this case it was assumed that the photovoltaic unit would have no stcrage, but that parallel generation could be used. It is seen that for a photovoltaic collector area of 100 square meters, the unit has the potential of displacing 40 percent of the energy originally supplied by the utility. The dotted, shaded area of the curve represents the amount of demand satisfied directly by the solar unit. The vertical stripe portion represents a trade between the customer and the utility. This is energy which is greater than the amount needed by the home at the time it is generated and sold to the utility, and at other times is purchased from the utility to meet demands in excess of the solar unit capability (e.g., after sundown or on cloudy days). If the sale price and purchase price of this energy are the same, then the solar design assumed in Figure 2-1 (e.g., wi thout storage) may be appropriate. If, however, the utility buys back energy at a price that is much less than the price at which it sells to the customer, energy storage may be appropriate for the photovoltaic unit in order to minimize the net energy cost. Finally, in Figure $2-1$ there is a crosshatched area representing two months during which the solar output is greater than the demand which would permit a net sale to the utility. In the Niadison, Wisconsin area chosen for this example, the utility is winter-peaking and the photovoltaic surplus occurs in the summer. The price which the customer would receive might be quite different from that received in a summer-peaking area.

\subsection{UTILITY CHARACTERISTICS}

As discussed above, the summer versus winter peaking characteristics of a utility could have a profound effect on the rate structures which are appropriate for photovoltaic systems. Another characteristic is the demand profile and weather sensitivity experienced by the utility and the aggregate size of the photovoltaic 
RESIDENTIAL DEMAND/SUPPLY FOR AN ALL-ELECTRIC HOME IN MADISON, WISCONSIN

\author{
Photovoltaic Collector Area $=100$ sq. Meters \\ No Storage \\ Annual Demand $=39,910 \mathrm{kWh}$
}

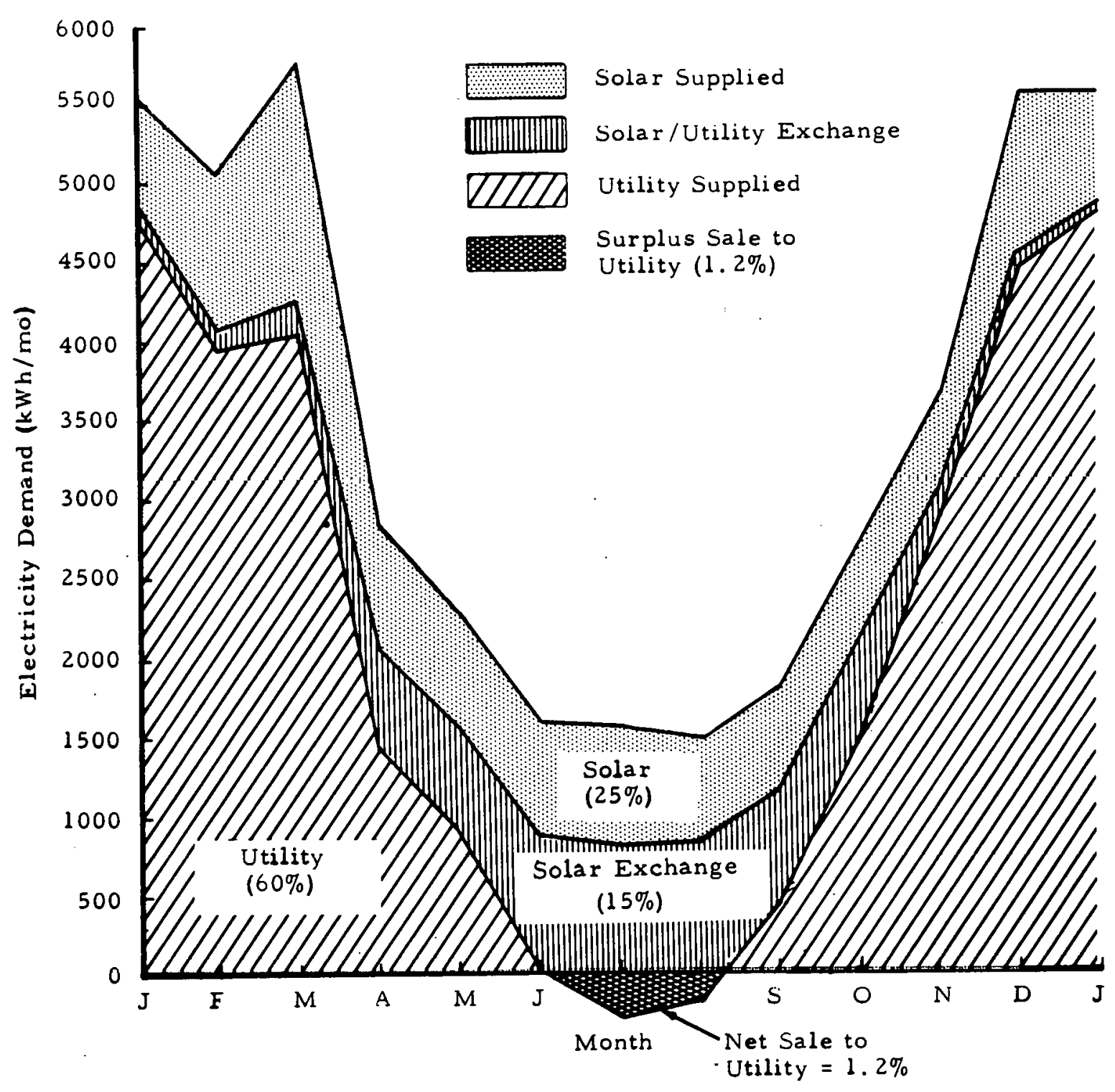

Figure 2-1. Simulation Results for a Photovoltaic Residential Installation 
demano relative to the total load. As is discussed subsequently, there is a trend toward basing utility rate structures on net avoided costs. Net avoided costs will be made up of cost reductions less cost increases. The principal cost reductions are expected to be derived from fuel savings, especially near-peak hours, and some reduction in installed capacity requirements. (Analyses indicate that there should be some capacity displacement that is less than the rated capacity on the on-site units even though periods of little sunshine are expected to occur.) Unit energy cost increases may occur from a need to use units that consume higher cost fuels per unit of energy output more frequently, to maintain larger spinning reserves, and to provide for special metering, status monitoring, maintenance, safety, or power quality provisions. 


\subsection{SURVEY SUMMARY}

\subsection{SURVEY DEVELOPMENT}

The survey began with a review of recent literature on rate structure development, especially those studies which address solar units. These included a number of time-of-day studies initiated by EPRI, and documentation of special rates developed by utilities in anticipation of solar unit employment. ERDA and DOE-funded studies were also reviewed, including those by SERI, ICF Inc., anc Clark University (Feldman and Anderson). Studies, policies, and regulations of various state and federal agencies were reviewed in depth, especially the recommendations of the Office of Technology Assessment, the requirements of Section 210 of the Public Utility Regulatory Policy Act (PURPA) of 1978, and the Federal Energy Regulatory Commission (FERC) response to that act, RM-55. Although there were a large number of literature items identified initially or during the telephone survey, a larger literature base is believed to exist that could not be identified or reviewed in the time allocated to the study.

After the initial literature review, telephone interviews were held with four researchers active in the field of utility rates, ICF, Stone \& Webster, Criterion Analysis, Dr. Richard Wieissbrod (JHU), four utilities (Los Angeles Department of Water \& Power, Southern California Edison, Wisconsin Electric Power Co., and Public Service Company of Colorado), the California PUC, and EPRI. These interviews confirmed that there were few completed studies which were applicable directly to the problem of rate making for photovoltaic systems, but revealed that some were now underway. Abstracts of several pertinent studies and their implications regarding rate structures for photovoltaic units are summarized below.

\subsection{SUMMARIES OF RELEVANT STUDIES}

EPRI Studies (Ref. 2): This is a set of electric utility rate cesign studies originally requested by the National Association of Regulatory Utility Commissioners (NARUC). The original NARUC resolution called for a stuay of the technology and cost of time-of-day metering and electronic methods of controlling peak period usage of electricity, and also a study of the feasibility and cost of shifting various types of usage from peak to off-peak periods. Although no specific study of photovoltaic units 
was conaucted, the time-of-use studies and experiments, and the development of rates using marginal costs are techniques which should prove useful in rate design for photovoltaic units.

Johns Hopkins University Study (Ref. 3): This study by Richard Weissbrod, et al., is a review of field experiments for electric rate redesign decisions in all states where these have been taking place. The general conclusion of the study is that the data generated as part of many of the rate experiments conducted in the 1975-1977 period were not of sufficient quality to be useful in assessing the impact of time-of-use rates. Since there is even less experience with on-site solar units with sellback, it can be concluded that solar rates cannot yet be based on experimental data.

Feldman-Anderson Study (Ref. 4): This study, funded by ERDA, reviews, assesses and critiques existing research and on-going activity in the interface between the public utility industry and solar energy units for buildings. Of the ten items recommended for future research, the two which would most apply to photovoltaic units are (1) "Producing a set of econometric models for market penetration accounting for marginal energy and capacity costs and prices for electric and gas utilities," and (2) "Research the effect of legislation on the solar-utility interface". The intent of this work was not to resolve specific issues but to contribute to their identification and qualitative understanding.

ICF Study (Ref.5): This on-going study contracted by the Department of Energy is a case study analysis of the regulatory and economic factors involved in designing and implementing rates for residential customers who own solar energy units. The analysis is being conducted for five utility systems where the potential for solar market penetration is significant and where some regulatory action on tariff issues has been undertaken. The principle purposes of the study are to (1) "analyze the potential impacts of alternative rate designs for auxiliary electricity on the design, operation and cost effectiveness of active solar space and water heating systems to residential customers, (2) analyze the impacts which the demands for auxiliary electricity may have on utility costs, revenues and operating characteristics, (3) study the interaction of these impacts within a regulatory environment, and (4) prepare a set of practical 
guidelines which will assist regulatory authorities and utilities in the consiaeration and possible implementaton of rates for solar auxiliary power." Other studies by ICF (Refs. 6 and 7) have addiressed the development of rates for supply.ing electricity to residential solar customers. These studies, however, do not address the question of sellback by the customer, an option which could be available to customers with photovoltaic units.

OTA Study (Ref. 8): In a study of the application of solar technology to today's energy needs, the Office of Technology Assessment recognized that Federal policies would be needed for promoting and regulating on-site solar energy. Policies which were recommended included (1) exemption of on-site equipment by regulation from Public Utility Law, (2) establishment of the rights of owners of on-site energy equipment to purchase power from existing utilities at fair rates, (3) establishment of the right of owners of on-site energy equipment to sell energy to utilities at fair rates. These recommendations were subsequently incorporated in the Public Utility Regulatory Policy Act of 1978 (Refs. 5-9). Recent rule-making by the FERC has set up specific rate-making requirements for qualifying facilities, and photovoltaic units appear to come uncier the small power production rules. The details of the PURPA and FERC rule-making are discussed in the last section of this chapter.

SERI Study (Ref. 1): This study examines the legal interactions between utilities and decentralized solar technologies. Electric utility costs and rate structures are reviewed, and the effect of rates on solar unit economics examined. The impact of solar units on electrical utilities is also ciscussed, and examples are given of existing and proposed solar and wind rates. 
Blank

$$
3-4
$$




\subsection{EXISTING SOLAR RATE STRUCTURES}

\subsection{SOLAR BACKUP POWER RATES}

Sixteen utilities in twelve states have developed electric rates which are explicitly available to residential customers who own solar space ano/or water heating units and who use electricity as a backup to these units. A listing of these rates is presented in Refs. 6 and 7. The rates incluce traditional declining block rates, energy charges varying with time of day, demand-energy rates, and controlled service tariffs. In most instances these rates are identical in structure and in level to those offered to all-electric customers. In a number of cases these rates have been incorporated to overcome exclusionary clauses. For example, some total electric schedules specify that electricity must be the primary or sole source of heating; a special rate or rider would be necessary for solar owners to be eligible for this tariff.

Many of the solar rates contain specific provisions indicating that the utility may monitor the auxiliary loads of the sclar customers. Also, many of these rates are designated as experimental to limit the number of customers served until the impact of solar customers on the utility system can be cietermined. They also emphasize that the rates are temporary and the structure of the rate may be subject to change.

The use of all electric rates as a model for experimental solar rates appears consistent with the use of only one conventional external energy source to serve the site: However, all electric rates typically inclucie lower unit energy charges due to the larger number of $k$ Wh normally supplied by the utility. The larger number of $k$ Wh provides adequate revenues to cover both fixed and variable costs even though the unit $k$ Wh rates are less than for non-all electric rates. Since on-site solar units will require backup and may involve sellback and special interconnection equipment, many of the fixed utility costs will be unchanged. The backup energy will be less than that delivered to a non-solar site. A proportional reduction in variable costs may result but the existence of unchanged fixed costs implies that the rate for backup energy should be higher than normal energy rates rather than lower as is the case for all electric rates. Fortunately PURPA has provided a philosophical basis for establishing solar 
- rates by specifying that such rates reflect cost avoidance. Although there are a large number of factors and alternative approaches to calculating costs, guidance now exists for structuring work to estimate such costs.

\subsection{PARALLEL GENERATION RATES FOR SCLAR}

Many states are now studying special rates with sellback provisions for on-site photovoltaic units and wind machines. States with such filings already adopted include California, Michigan, Miontana, and New York. Table 4-1 shows typical rate structures developed for this category. The first two, located in New York, were originally developed for windmill customers. They provide for an energy credit equal to the average cost of fuel per $k W h$, but impose a "demand" charge, either as a minimum or fixed value per kilowatt of capacity. The LADW $P$ rate schedule does not have a demand charge and provides energy credits which are different for on-peak and off-peak usage (although the values shown in the table are the same for either usage). The rates for the Southern California Edison Company are the most liberal of all, with no demand charge, and an energy credit equivalent to the energy charge except that the net energy cost cannot be negative. This rate implies a subsidy for the solar unit and does not appear to reflect the relative costs of service.

It is instructive to calculate the approximate reduction in purchased energy cost for the demand shape and assumed photovoltaic system of Figure 2-1, using, the various rate structures in Table $4-1$. If the required capacity is assumed to be $10 \mathrm{~kW}$, the following reduction results.

\section{Rate Structure}

Central Hudson Gas \& Electric Corp.

Consolidated Edison Co. of N.Y.

L.A. Department of Water \& Power

Southern California Edison Co.
$\%$ Reduction in Cost of

Furchased Energy for

the House of Figure 2-1
18

30

32

40 
Table 4-1. Examples of Current Rates for Parallel Generation

\begin{tabular}{|c|c|c|c|c|c|c|}
\hline & Utility & $\begin{array}{l}\text { Classification/ } \\
\text { Date }\end{array}$ & \multicolumn{2}{|c|}{ Filergy Claarge } & Special Charges & Energy Ciredir \\
\hline & $\begin{array}{l}\text { Central Hudson Lias \& } \\
\text { Elertric Corp }(N Y)\end{array}$ & $\begin{array}{l}\text { SC-1, Prov. 1,21 } \\
10 / 10 / 77\end{array}$ & $\begin{array}{l}\text { First } 12 \mathrm{kWh} \text { or less } \\
\text { Next } 60 \mathrm{~kW} / \mathrm{h} \\
\text { Next } 78 \mathrm{kWh} \\
\text { All over } 150 \mathrm{kWh}\end{array}$ & $\begin{array}{l}\$ 2.70 \\
\$ .0755 J / \mathrm{kWh} \\
\$ .05655 / \mathrm{kWh} \\
\$ .03894 / \mathrm{kWh}\end{array}$ & $\begin{array}{l}\text { Demand charge of } \$ 2.50 \text { per } \\
\text { kW of capacity } \\
\text { Meter charge of } \$ 1.00\end{array}$ & $\begin{array}{l}\text { Average rost of luel } \\
\text { per klih }\end{array}$ \\
\hline & $\begin{array}{l}\text { Consolidated Edison } \\
\text { Co. of New York }\end{array}$ & $\begin{array}{l}\text { Sc:-2, GS, Prov. G/ } \\
3 / 7 / 77\end{array}$ & $\begin{array}{l}\text { First } 10 \mathrm{kWh} \text { or less } \\
\text { Next } 890 \mathrm{kWh} \\
\text { All over } 900 \mathrm{kWh}\end{array}$ & $\begin{array}{l}\$ 4.96 \\
\$ .0810 / \mathrm{kWh} \\
\$ .0745 \mathrm{kJWh}\end{array}$ & $\begin{array}{l}\text { Min. charge of } \$ 6.80 \text { per } \\
\text { k } W^{\prime} \text { of capacity } \\
\text { Reverese flow meter charge } \\
\text { of } \$ 1.00\end{array}$ & $\begin{array}{l}\text { Average cost of furl } \\
\text { per } k: v h \text {. }\end{array}$ \\
\hline & $\begin{array}{l}\text { Los Angeles Dept. of } \\
\text { water and Power (CA) }\end{array}$ & $\mathrm{XD}-\mathrm{PG} / 12 / 10 / 78$ & $\begin{array}{l}\text { On peak } \\
\text { Off peak }\end{array}$ & $\begin{array}{l}(\$ .07361+E C A B F) / k W h \\
(\$ .01695+[C . A B F) / k W h\end{array}$ & Minimum charge of $\$ 6.00$ & $\begin{array}{l}\text { (In-peak } \$ .9170 / \mathrm{kWh} \\
\text { iff-peak } \$ .0170 / \mathrm{kWh}\end{array}$ \\
\hline r & $\begin{array}{l}\text { Southern California } \\
\text { Edison C:o. }\end{array}$ & $1)-P G_{j} / 1 / 1 / 79$ & $\begin{array}{l}\text { First } 100 \mathrm{kWh} \\
\text { Excess kW/ }\end{array}$ & $\begin{array}{l}\text { No additional } \\
(\$ .02423+E(A B F) / k \text { Wh }\end{array}$ & Customer charge of $\$ 6.92$ & $\begin{array}{l}\text { Same as energy charger } \\
\text { butt net energy cannot } \\
\text { be negative. }\end{array}$ \\
\hline
\end{tabular}

ECABF = Energy Cost Adjustment Billing Factor 
Note that the CHG\&E rate results in a low reduction due to the significant demarid charge, while the SCE rate shows a large reduction, since the energy credit is at the same rate as the energy charge. If a negative net energy charge were allowed, the SCE rate could result in a maximum energy bill reduction of $41.3 \%$ for the conditions illustrated in Figure 2-1. 


\subsection{THE FUTURE OF SOLAR RATES}

Most of the existing rate tariffs offered for solar are experimental in nature, and few residential customers have signed up for these rates. Utilities and regulatory agencies are moving to have the rates in place before substantial penetration of solar occurs. As the market penetration of solar with sellback potential increases, the experimental rates will be converted to more permanent rates. Since these rates can be strongly affected by Federal and state regulatory policies, it is important to examine these policies in detail in order to anticipate the new trends in rate making.

\subsection{PURFA REQUIREMENTS FOR RULE MAKING}

Public Law 95-617, the Public Utility Regulatory Folicy Act (PURPA) of 1978, (Ref. 9) was passed on November 9, 1978 as part of the Federal Energy Act. Section 210 of this Act required that the Federal Energy Regulatory Comission (FERC) prescribe rules for encouraging cogeneration and small power production. A small power production facility was defined as one which produces electric energy solely by the use of tellewable resuurces such as appllcations of solar, wind, or geothermal energy, 'and has a capacity which is not greater than $80 \mathrm{MW}$. Residential on-site photovoltaic units would qualify as a small power production facility under this definition. Within one year of enactment, the Act directed the FERC to develop rules which would require electric utilities to offer to sell and purchase electric energy from small power production facilities. It further prescribed that the rates for such sales and purchases (1) shall be just and reasonable to the electric consumers of the electric utility and in the public interest, and (2) shall not oiscriminate against qualifying cogenerators or qualifying small power producers. It also prescribed rules under which these qualifying facilities would be exempted in whole or in part from the Federal Fower Act, from the Public Utility Holding Company Act, and from certain state laws and regulations, provided the facility was smaller than $30 \mathrm{MW}$.

In response to FURPA, a set of proposed rules were issued on 18 October 1979 (Ref. 10). Comments from interested parties were due by 1 December, and a final rule-making will be promulgated soon thereafter. By 30 June 1980, cost avoidance 
data pertinent to these rules are to be proviced by the utilities, and a year from the rule-making, the Public Utilities Commissions of the various states are required to implement these rules.

\subsection{DETAILS OF THE FERC RESFONSE TO PURPA}

The initial response to the PURPA was published as a staff paper under docket number RM-79-55 on 3 July 1979, and revised rules were proposed on 18 October 1979. The latter had the benefit of responses by Public Utility Commissions and utilities to the initial staff paper. The proposed rules provide that "Electric utilities must purchase electric energy and capacity made available by qualifying cogenerators and small power producers at a rate reflecting the cost that the purchasing utility can avoid as a result of obtaining energy and capacity from these sources, rather than generating an equivalent amount of energy itself or purchasing the energy from other suppliers. To enable potential cogenerators and small power producers to be able to estimate these avoided costs, the rules require electric utilities to furnish data with regard to present and future cost of energy capacity on their system".

In regard to photovoltaic cells, the Commission made the following observation "...photovoltaic cells...have the general advantage of providing their maximum power coincident with the system peak when used on a summer peaking system. The value of such power is greater to the utility than power delivered during off-peak periods. Since the need for capacity is based on system peaks, the qualifying facility coincidence with the system peaks should be reflected in the allowance of some capacity value and an energy component that reflects the avoided energy costs at the time of the peak".

In regard to size, the rules require that each electric utility, upon request of a qualifying facility, establish a tariff or other method for setting forth standard rates for purchases from qualifying facilities with a design capacity of $10 \mathrm{k} \dot{W}$ or less. The rules further require that the electric utility offer to operate in parallel with a qualifying facility. In addition to parallel generation, the electric utilities are required to provide the following types of service: (1) supplementary power, $(\bar{z})$ backup power, (3) interruptable power, and (4) maintenance power. 
In the sale to a qualifying facility, the utility rates are required to not discriminate in comparison to rates for sales to other customers served by the electric utility. The rates for sale shall be just and reasonable ano in the public interest. Each electric utility shall provide electric energy and capacity and other services to any qualifying facility at a rate at least as favorable. as would be provided to a customer who does not have his own generation. Other sections of the FERC rules treat the problem of interconnection, and clearly assign costs of interconnection, both for purchasing and selling electricity, to the qualifying facility rather than the utility.

\subsection{AREAS FOR FURTHER STUDY}

A comparison of the current solar rates described in Section 4.0 of this chapter with the above rule-making proposed by the FERC results in some significant discrepancies, since most of the current rates do not reflect the avoided costs to the utilities in their buy-back prices. The following represent areas recommended for further study: (1) continue to monitor Fublic Utility Commissions and utilities as they respond to the FERC rule-making, (2) continue impact studies to determine the aggregate effert of solar photovoltaic units on utilities in order to develop a quantitative understanding of costs avoided and additional costs incurred as a result of on-site power units with sellback which may be' used as a basis for future rate-making, (3) explore the effects of these new rate structures and the interconnection costs on market penetration of solar photovoltaic systems as a function of different regions and utility load types. 


\section{FART III. REFERENCES}

1. Regulated Utilities and Solar Energy, Solar Energy Research Institute, Golden, Colorado, SERI/TR-62-255, June 1979

2. Electric Utility Rate Design Study, 1978 Plan of Study, Electric Power Research Institute, Palo Alto, California, December 1977

3. Field Experiments for Electric Rate Redesign Decisions: Review and Assessment, Final Report, The John Hopkins University Center for Metropolitan Flanning and Research, Baltimore, Maryland, February 1979

4. Fublic Utility and Solar Energy Interface: An Assessment of Folicy Options, Final Keport, Energy Research and Development Administration, Division of Solar Energy, December 1976

5. Case Studies on Impacts of Rate Design on Dispersed Solar Energy Systems, Task IIIB: Demand and Rates Analysis, ICF Incorporated, Washington, D.C., December 1979

6. Case Studies on Impacts of Rate Design on Dispersed Solar Energy Systems, Task 1: Literature Review and Survey of Utilities, ICF Incorporated, Washington, D.C., March 1979

7. Technical, Institutional and Economic Analysis of Alternative Electric Rate Designs and Related Regulatory Issues in Support of DOE Utility Conservation Frograms and Policy, Volume I: Domestic Rate Survey, ICF Incorporated, Washington, D.C., August 1978

8. Application of Solar Technology to Today's Energy Needs, Volume I, Office of Technology Assessment, Washington, D.C., June 1978

9. Public Law 95-617, 95th Congress, Public Utility Regulatory Policies Act of 1978 , November 1978

10. Small Power Froduction and Cogeneration Facilities - Rates and Exemptions, United States of America Federal Energy Regulatory Commissions, Docket No. RMi79-55, October 1979 